\title{
APLICAÇÕES EM FINANÇAS DA APROXIMAÇÃO DE PROCESSOS ESTOCÁSTICOS EM TEMPO CONTÍNUO POR PROCESSOS EM TEMPO DISCRETO
}

\author{
Fabio Silva Dias
}

\author{
DISSERTAÇÃO APRESENTADA AO \\ INSTITUTO DE MATEMÁTICA E ESTATÍSTICA \\ DA UNIVERSIDADE DE SÃO PAULO \\ PARA OBTENÇÃO DO GRAU DE \\ MESTRE EM ESTATÍSTICA
}

Área de Concentração: Estatística Aplicada

Orientador: Prof. Dr. Vladimir Belitsky

-- São Paulo, fevereiro de 2005 -- 


\section{APLICAÇÕES EM FINANÇAS DA APROXIMAÇÃO DE PROCESSOS ESTOCÁSTICOS EM TEMPO CONTÍNUO POR PROCESSOS EM TEMPO DISCRETO}

Este exemplar corresponde à redação final da dissertação devidamente corrigida, defendida por Fabio Silva Dias e aprovada pela comissão julgadora.

São Paulo, 11 de abril de 2005

Banca Examinadora:

- Prof. Dr. Vladimir Belitsky (orientador) - Universidade de São Paulo

- Prof. Dr. Henrique von Dreifus - Universidade de São Paulo

- Prof. ${ }^{\text {D Dr. }}$ - Chang Chung Yu Dorea - Universidade de Brasília 


\section{Agradecimentos}

Embora uma dissertação seja, pela sua finalidade acadêmica, um trabalho individual, há contribuições de natureza diversa que não podem nem devem deixar de ser realçados. Por essa razão, desejo expressar os meus sinceros agradecimentos:

- À pessoa que, antes de tudo, é minha melhor amiga e a maior colaboradora para qualquer sucesso que eu tenha alcançado ou ainda venha alcançar, minha esposa Keila;

> Ao Prof. Dr. Vladimir Belitsky, que, além de ter me fornecido uma ótima orientação, muito contribuiu para que eu desenvolvesse um espírito de pesquisa e busca pela superação de desafios; e

- Aos meus pais, cuja ajuda e persistente cobrança desde a minha infância foi fundamental para que eu encontrasse a maneira correta de iniciar toda a minha jornada. 
SUMÁRIO

1 INTRODUÇÃO

$\begin{array}{lll}1.1 & \text { Considerações iniciais } & 1\end{array}$

1.2 Um esboço do caminho a ser percorrido 4

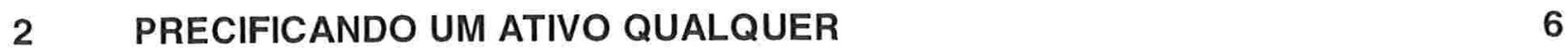

2.1 Precificando um ativo qualquer com o auxílio de cenários 6

2.2 Um paradoxo interessante 12

$\begin{array}{lll}2.3 & \text { O conceito de probabilidades neutras ao risco } & 15\end{array}$

$\begin{array}{lll}2.4 & \text { A necessidade de simplificação } & 17\end{array}$

3 SIMULANDO TRAJETÓRIAS A TEMPO DISCRETO 19

3.1 Definindo a convergência desejada $\quad 19$

3.2 A convergência em distribuição definida para passeios aleatórios 23

3.3 Algumas contribuições do Teorema de Donsker 24

4 A TEORIA DE CONVERGÊNCIA FRACA EM $\Re^{n} \quad 28$

4.1 Definições formais de convergência 28

4.2 Conceitos iniciais importantes de topologia 39

4.3 A convergência fraca em espaços métricos 43

$5 \quad$ A TEORIA DE CONVERGÊNCIA FRACA EM $C$

5.1 O espaço $C \quad 53$

5.2 Os conceitos de relativamente compacto e apertado 58

5.3 Um princípio de invariância - provando o Teorema de Donsker 69

6 USANDO A TEORIA PARA PRECIFICAR OPÇÕES EUROPÉIAS 78

6.1 A função de payoff e a adequabilidade do Teorema de Donsker 78

6.2 Modelando a dinâmica do preço do ativo base 82

6.3 Um algoritmo para precificação de opções padrão 85

$\begin{array}{lll}6.4 & \text { Estudando o algoritmo proposto } & 89\end{array}$ 
6.5 Resultados da implementação do algoritmo da Seção 6.3 101

6.6 Um algoritmo para precificação de opções exóticas 103

6.7 Implementando o algoritmo da Seção 6.6 com dados do mercado brasileiro 105

7 USANDO A TEORIA PARA PRECIFICAR OPÇÕES AMERICANAS 111

7.1 Uma equação para o preço de uma opção com exercício do tipo americano 111

7.2 Modificando o algoritmo da Seção 6.3 para o caso das opções americanas 113

7.3 Resultados da implementação do algoritmo da Seção 7.2 114

7.4 A fronteira ótima de exercício ou "curva de gatilho" 116

7.5 Modificando o algoritmo da Seção 6.6 para o caso das opções americanas 118

7.6 Implementando o algoritmo da Seção 7.5 com dados do mercado brasileiro 120

8 TÓPICOS ADICIONAIS NA TEORIA DE PRECIFICAÇÃO DE OPÇÕES 121

8.1 A questão da volatilidade $\quad 121$

8.2 O modelo GARCH para precificação de opções $\quad 124$

8.3 Implementando o modelo GARCH com dados do mercado brasileiro 129

$\begin{array}{ll}8.4 & \text { Concluindo o trabalho } \\ & 132\end{array}$

ANEXO 1 TEOREMAS IMPORTANTES PARA O CASO $S=C \quad 135$

$\begin{array}{lll}\text { A.1 O Teorema de Prohorov (Teorema 5.7) } & 135\end{array}$

$\begin{array}{lll}\text { A.2 } & \text { A Existência da Medida de Wiener } & 138\end{array}$

ANEXO 2 O USO DE MARTINGAIS NA PRECIFICAÇÃO NEUTRA AO RISCO 142

ANEXO $3 \quad$ IMPLEMENTAÇÕES EM C++ DOS ALGORITMOS PROPOSTOS 150

REFERÊNCIAS BIBLIOGRÁFICAS 162 


\section{RESUMO}

Apresentamos uma aplicação de parte da teoria estatística avançada na solução de um problema prático no mercado financeiro: a precificação de opções. Iniciaremos definindo o que são estes instrumentos financeiros conhecidos como opções e quais são os passos que devem ser seguidos para a construção de um modelo genérico para precificação destas. $O$ modelo apresentado pode ser generalizado para a precificação de um ativo financeiro qualquer.

Após esta breve introdução, veremos que este modelo exige o cálculo de uma esperança matemática para o qual nem sempre há solução analítica. Assim, partimos para resolver este problema por meio da aproximação de processos estocásticos em tempo contínuo por processos em tempo discreto. Inicialmente utilizaremos as mesmas premissas utilizadas por Black \& Scholes sobre a dinâmica do processo de preço dos ativos no mercado. Dadas estas premissas, apresentaremos os principais resultados da teoria estatística avançada que nos garante a qualidade da aproximação. Tais resultados são demonstrados de forma didática e intuitiva em três capítulos da dissertação.

Prosseguiremos apresentando sucintamente como aplicar estes resultados na precificação de opções européias e americanas, tanto as tradicionais quanto as exóticas. As aplicações sempre são efetuadas com dados reais do mercado financeiro brasileiro.

O trabalho é finalizado apresentando um modelo de precificação baseado no modelo GARCH para a volatilidade. Os resultados sugerem que este apresenta desempenho superior ao modelo tradicional de Black \& Scholes na explicação dos reais preços pelos quais certas opções foram negociadas na Bolsa de Valores de São Paulo. 


\section{ABSTRACT}

We show part of the advanced statistical theory applied to solve a practical financial problem: option pricing. We will start defining what are the financial instruments known as options and which are the steps that have to be followed to build a generic model to price them. The model shown can be generalised and be used to price any financial asset.

After this brief introduction, we will see that this model demands the evaluation of a mathematical expectation whose analytical solution does not exist in all cases. Therefore we will solve this problem approximating numerically some specific continuous time random processes by random processes defined in the discrete time space. In the beginning, we will use the same premises used by Black \& Scholes on the dynamics of the market assets price process. Given these premises, we will show several crucial results in the advanced statistical theory that guarantee the quality of the approximation obtained. Three chapters of the present work are used to demonstrate such results in a didactic and intuitive way.

We will continue presenting succinctly how to apply these results to the pricing of European and American options, dealing with the traditional and the exotic ones. All the calculations are done based in real data gathered in the Brazilian financial market.

This work is concluded introducing a pricing model based in the GARCH model for the volatility. The results obtained suggest that this alternative framework possesses an ability superior than the traditional model of Black \& Scholes to explain the real prices for the which certain options had been traded in the São Paulo Stock Market. 


\section{INTRODUÇÃO}

\subsection{Considerações iniciais}

Neste trabalho, buscaremos estudar alguns métodos atualmente utilizados para precificação de contratos de opções, focando-nos nos aspectos teóricos mas sempre dando a devida importância aos pontos práticos cruciais. Apesar do texto ser uma dissertação de mestrado, este foi composto de maneira tal que possa ser útil às pessoas de qualquer nível técnico que desejarem ter plena compreensão do método por nós analisado, exigindo assim poucos prérequisitos para a sua leitura.

Os conceitos matemáticos exigidos estão resumidos a um ano de curso elementar de Cálculo, Estatística Básica e Probabilidade. Da parte financeira não há exigências, no entanto é desejável que o leitor seja familiar com alguns conceitos básicos de juros compostos, capitalização contínua e equivalência de capitais. Estes conceitos são encontrados em qualquer livro texto de matemática financeira básica. O conhecimento prévio dos conceitos de ações, derivativos e opções padrão, americana e européia, também pode facilitar a leitura do texto. Tais conceitos podem ser adquiridos mediante leitura prévia do primeiro capítulo de Belitsky, Kimura \& Tommasini (2004). Recomenda-se aos leitores mais avançados a leitura completa de Hull (2000).

Um contrato de opções é algo semelhante a um seguro de preços, no qual o comprador deste (também conhecido como titular) adquire o direito de comprar ou de vender determinada ativo por um preço preestabelecido (preço de exercício), pagando um valor chamado prêmio. Se a opção der o direito de se comprar ela é conhecida como opção de compra, ou call, e se a mesma der o direito de se vender, ela é conhecida como opção de venda, ou put.

Se o contrato só permitir ao titular que o direito de compra ou venda seja exercido em uma única data prefixada, dizemos que este contrato possui exercício do tipo europeu, ou simplesmente é uma opção européia. Caso o contrato permita ao titular que este direito seja exercido a qualquer momento, dizemos que se trata de uma opção americana. As origens dos nomes "européia" e "americana" são desconhecidas. Tais nomes não estão relacionados a práticas comuns a alguma região geográfica particular. 
Um contrato de opções se assemelha a qualquer contrato de seguro, onde o beneficiário paga um prêmio para segurar um determinado bem. Neste caso o objetivo é segurar um preço para compra ou venda do ativo base.

Por se tratar de um contrato cujo comportamento está intimamente ligado ao de outro ativo, uma opção faz parte da classe de instrumentos financeiros conhecidos como derivativos. Existem outros derivativos, tais como os futuros e os swaps - os primeiros possuem comportamento muito parecido com o das opções, com a teoria de precificação de opções podendo ser facilmente adaptada para lidar com os futuros.

O mercado brasileiro de opções ainda é pouco desenvolvido. Em termos de negócios na Bolsa de Valores de São Paulo, as únicas opções com liquidez considerável (entenda-se por volume diário de negócios superior a meio milhão de reais, dados da BOVESPA do dia 14 de janeiro de 2005) são as opções de compra americanas sobre ações preferenciais da Telemar. Contudo, nota-se uma clara evolução neste mercado nos recentes anos. O número de ações de empresas que possuem opções vinculadas a elas vem aumentando de maneira consistente, e isto cada vez mais vem se firmando como uma tendência.

Vale lembrar que também existem outras opções além das citadas no parágrafo anterior. $O$ ativo base do contrato pode ser, a princípio, qualquer um, inclusive um outro derivativo (as conhecidas opções sobre futuro). De fato, no mercado brasileiro temos opções vinculadas aos mais variados ativos base, com a maioria não sendo negociada em bolsa de valores e não estando vinculada a ações de empresas. Portanto, torna-se muito importante aos investidores brasileiros saberem precificar adequadamente estes contratos.

Ao se precificar uma opção desejamos encontrar qual seria o preço justo que um investidor deve pagar para adquirir este direito com base no conhecimento de variáveis importantes, tais como a taxa de rentabilidade de investimentos sem risco (também conhecida como taxa de juros), as condições em que este direito pode ser exercido (tipo de exercício, preço de exercício, etc.) e outras características próprias do ativo base da opção considerada. É prática comum na engenharia financeira obter este preço utilizando-se de um dentre os três métodos mais conhecidos, a saber:

- Construir, com base na teoria de Cálculo Estocástico, um modelo de equações diferenciais parciais estocásticas, cujas soluções ditarão o preço justo exato do contrato. Um exemplo bastante conhecido é o preço justo da opção européia, que possui fórmula fechada para seu cálculo, derivada em Black \& Scholes (1973). Devido a sua complexidade e o fato de nem sempre ser possível obter uma 
solução analítica para as equações supracitadas, este método não é o preferido dos engenheiros financeiros, com estes partindo para o uso de métodos de aproximação;

- O segundo método, com certeza o mais intuitivo de todos, se baseia em construir um modelo de simulações numéricas, assumindo que o preço do ativo base segue uma determinada distribuição de probabilidade, de modo a obter trajetórias possíveis para o preço do ativo e a distribuição de probabilidade do valor da opção na data do exercício. Com base nesta distribuição de probabilidades, na taxa de juros livre de risco e no princípio de precificação por neutralidade ao risco, estima-se o valor futuro esperado do derivativo e calcula-se seu valor presente justo. Este método, apesar de intuitivo, agrega complicações ao se avaliar contratos que podem ser exercidos antes de sua data de exercício - tais como as opções americanas - visto que, dada uma trajetória para o ativo base, a data ótima de exercício de uma opção deste tipo é sabida somente se conhecida a trajetória do início ao fim, mas durante a simulação numérica de uma trajetória, o ponto final da mesma é desconhecido;

- O terceiro método lida exatamente com este inconveniente, e consiste em construir uma árvore de cenários representando todas as possíveis trajetórias do preço do ativo base - algo muito próximo do método anterior. A diferença está no fato de que o preço ótimo da opção a ser precificada é determinado por recursão reversa, percorrendo-se a árvore de cenários a partir de seus nós terminais em direção ao início, associando-se a cada nó desta árvore o preço ótimo da opção no mesmo dado o futuro esperado. A aplicação mais conhecida deste método é a árvore binomial descrita em Cox, Ross \& Rubinstein (1979). Apesar de tornar mais fácil o tratamento para as opções onde o exercício antecipado é permitido, a sua implementação é computacionalmente inviável para algumas opções exóticas, sendo assim necessário o uso do segundo método.

Podemos verificar que nos dois últimos métodos uma simplificação é feita: embora no mundo real o tempo seja contínuo, as trajetórias construídas com auxílio do computador sempre estão delineadas em um ambiente de tempo discreto. A questão inerente a este processo é se, mesmo com esta simplificação, os valores obtidos com o auxílio do computador convergem para os valores verdadeiros, pois, do contrário, as simulações efetuadas não teriam valor algum. 
Além da questão citada no parágrafo anterior, é muito provável que poucos dos que utilizem todos os dias os métodos de precificação apresentados saibam explicar alguns pontos teóricos muito importantes inerentes a estes. Por exemplo, explicar o que garante a qualidade da aproximação citada ou porque e em que condições está correto se obter o preço justo de uma opção descontando o seu valor futuro esperado pela taxa de juros livre de risco (lembremos que a opção é um ativo com risco) pode ser uma tarefa ingrata para muitos, mesmo no ramo acadêmico, apesar de, a nosso ver, o domínio destes tópicos ser um passo essencial anterior à criação e o uso de modelos mais sofisticados.

\subsection{Um esboço do caminho a ser percorrido}

O presente trabalho possui, além deste capítulo introdutório, outros sete capítulos. O principal objetivo do mesmo é apresentar, de forma intuitiva mas puramente teórica, os resultados das teorias de convergência em probabilidade e em distribuição necessários ao nosso problema, de modo a confirmar ou retirar a validade das aproximações citadas anteriormente e explicar o que garante a qualidade das mesmas. Todavia, antes de entrarmos na matemática teórica, detalharemos parte do problema prático de interesse no segundo capítulo, também apresentando o conhecido princípio de precificação por neutralidade ao risco. Ao final deste capítulo, o leitor terá o pleno entendimento de um método de precificação que, sob certas condições também detalhadas no mesmo, poderá ser utilizado para a precificação de qualquer ativo com risco - não estando restrito apenas às opções. Parte do segundo capítulo teve como base o apresentado por Chourdakis (2003).

No entanto, o leitor também saberá que este método envolve o cálculo de uma esperança de uma função, para o qual nem sempre há uma solução analítica. Assim, a partir deste ponto, deixaremos de lado temporariamente os aspectos práticos, focando-nos no objetivo principal do texto. O terceiro, o quarto e o quinto capítulo estarão destinados a cumprir este objetivo. Ao final do quinto capítulo, o leitor terá perfeito entendimento da teoria de convergência fraca, tendo inclusive provado o Teorema de Donsker, essencial para a validação dos resultados desejados. A base das explicações dadas nestes capítulos são os livros de Billingsley (1968) e Billingsley (1999), no entanto muitas outras referências também foram utilizadas, as quais serão apresentadas no decorrer dos capítulos. 
A partir do capítulo seguinte retornaremos aos aspectos práticos. Para não tornar o texto cansativo e extremamente longo, em alguns momentos a apresentação destes aspectos não terá o mesmo rigor matemático que foi aplicado nos capítulos anteriores.

No sexto capítulo toda a teoria apresentada será aplicada à precificação de contratos de opções com exercício do tipo europeu. O leitor encontrará um algoritmo para a precificação destes contratos, além de um estudo detalhado do mesmo algoritmo. Exemplos práticos de precificação destas opções a tempo discreto também serão apresentados. Iniciaremos por casos onde os modelos a tempo contínuo têm solução analítica para o problema, de modo que esta poderá ser comparada com os resultados do modelo a tempo discreto implementado, comprovando empiricamente a convergência. Concluiremos o capítulo apresentando opções exóticas para as quais, mesmo com exercício europeu, não há uma solução analítica para o problema a tempo contínuo, sendo necessário o uso do modelo a tempo discreto.

O sétimo capítulo será dedicado à aplicação de toda a teoria para os contratos de opções com exercício do tipo americano, onde a possibilidade de exercício antecipado introduz um fator de complicação na precificação, impedindo que, para a grande maioria dos tipos de opções, exista uma solução analítica para o problema considerado. Apresentaremos dois métodos que podem ser utilizados para lidar com a dificuldade adicional.

Tudo estaria concluído, se não fosse o fato de que algumas suposições efetuadas sobre a distribuição de probabilidade do preço do ativo base na prática normalmente não são válidas, sendo muito restritivas. O oitavo e último capítulo apresenta as falhas destas suposições e detalha um modelo de precificação proposto por Duan (1995) que tem a possibilidade de captar um grande número de características da distribuição de probabilidade do preço do ativo base, incorrendo em menos erros oriundos de uma excessiva simplificação.

Além dos oito capítulos, há outros três anexos onde são apresentados tópicos não menos importantes, mas para os quais julgamos dar tratamento separado para tornar o texto principal menos cansativo para o leitor. Os dois primeiros anexos se tratam de detalhamentos de resultados matemáticos utilizados no decorrer do texto. Já no último anexo são apresentados todos os algoritmos propostos nos últimos três capítulos implementados em linguagem $\mathrm{C}++$, devidamente comentados. 


\section{PRECIFICANDO UM ATIVO QUALQUER}

Durante todo o trabalho estaremos interessados em estudar modelos matemáticos para a obtenção do preço justo, ou preço de mercado, de uma opção. Assumiremos que, no nosso mercado, sempre haverá vendedores e compradores para tudo o que for negociado no mesmo. Assumiremos também que o nosso mercado possui um número infinito (ou pelo menos muito grande) de compradores e vendedores.

Definiremos o preço de mercado de alguma coisa como aquele preço tal que, sempre quando houver algum agente de mercado interessado em vender esta coisa pelo preço de mercado, haverá um outro agente de mercado interessado em comprá-la. Da mesma maneira, sempre quando houver algum agente tentando comprar a mesma coisa pelo preço de mercado dela, haverá um outro agente interessado em vendê-la.

A "coisa" a que nos referimos no parágrafo anterior doravante será chamada de ativo. $\mathrm{Na}$ área de contabilidade, um ativo é definido como tudo aquilo que pode gerar algum benefício econômico futuro ao seu possuidor. O nosso ativo não fere esta definição contábil. Como nossos ativos sempre serão negociados no mercado, qualquer possuidor de um ativo poderá vender o mesmo no mercado e, com o fluxo de caixa líquido obtido na venda, ter o benefício de consumir o que desejar.

Por enquanto, o lucro obtido entre a compra e a posterior venda do mesmo será definido como retorno deste ativo. O conceito de retorno será apresentado com maior rigor matemático posteriormente.

\subsection{Precificando um ativo qualquer com o auxílio de cenários}

Antes de entrarmos diretamente na questão de precificação de opções, vamos discutir um caso semelhante que ilustrará perfeitamente o problema envolvido. O objetivo é o mesmo: encontrar o preço justo que deve ser pago em uma determinada data para adquirir um ativo qualquer $A$, cujo retorno futuro é incerto (lembremos que uma opção, apesar de ser um derivativo, também não deixa de ser um ativo). Assumiremos que o retorno futuro deste ativo é dependente dos cenários vislumbrados para a data seguinte à da avaliação. Para um perfeito entendimento, considere a seguinte definição: 
DEFINIÇÃO 2.1. Um cenário é um conjunto de valores possíveis para todas as variáveis econômicas e não econômicas em um determinado instante de tempo.

Por exemplo, considere um mundo onde só existem dois possiveis cenários, um "bom" e outro "ruim", com as seguintes configurações:

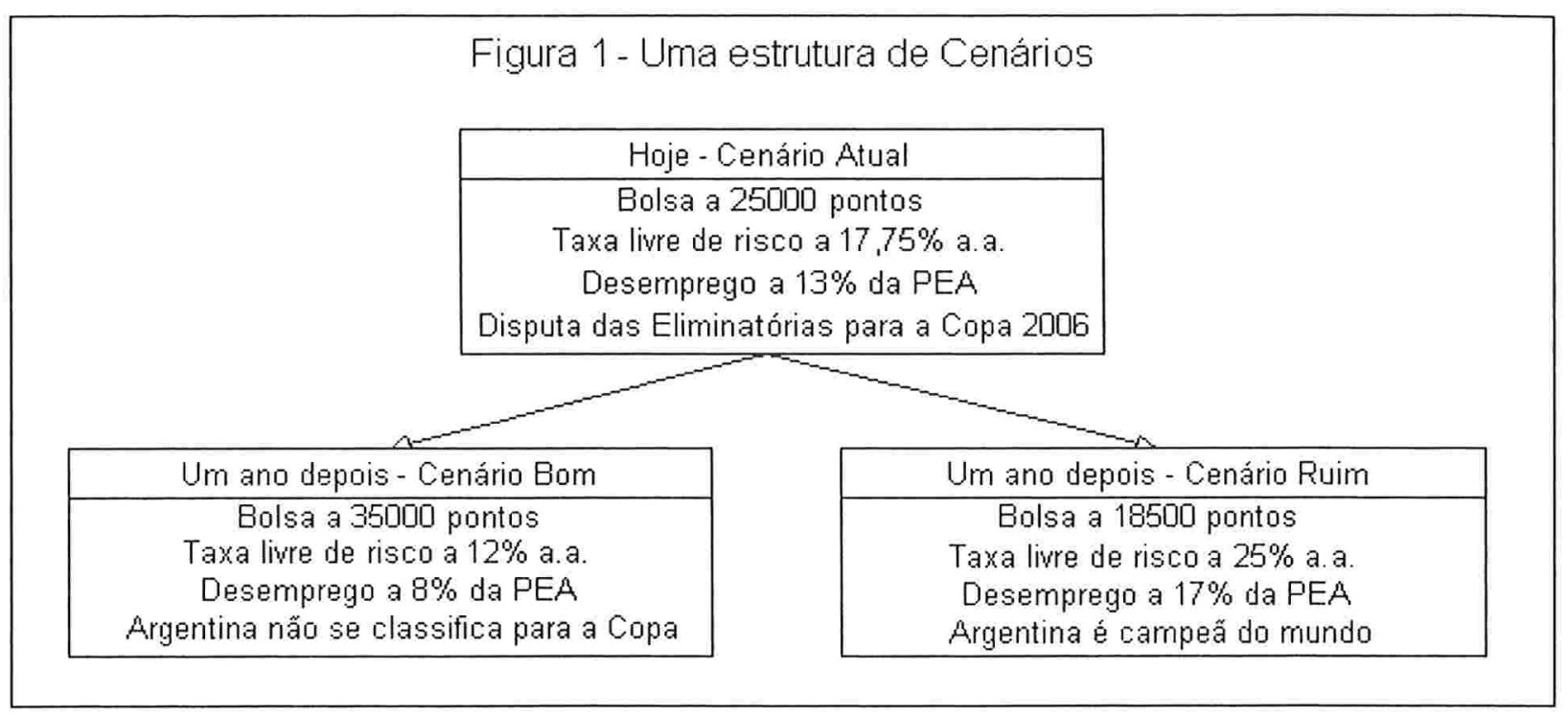

A suposição de que apenas os dois cenários acima são possíveis pode ser relaxada para uma suposição de que todos os agentes do mercado concordam que apenas os dois cenários acima são possíveis. Vamos considerar, no entanto, uma situação em que não é conhecida a probabilidade de ocorrência de cada um destes cenários, não havendo consenso no mercado sobre qual seria a real probabilidade de que um destes cenários ocorra.

Também é assumido que todos os agentes do mercado concordam que, no cenário bom, o ativo $A$ gerará um benefício futuro, ou fluxo de caixa líquido, igual a $F_{B}$ enquanto que no cenário ruim o mesmo ativo gerará um fluxo de caixa igual a $F_{R}$. Logo após a data futura, o ativo é extinto, não possuindo nenhum valor residual.

Para prosseguir com a nossa discussão, vamos apresentar uma definição econômica de um tipo de mercado. Um mercado como o definido pode ser visto como um mercado em um grau bem alto de desenvolvimento e perfeição: 


\section{8 - Precificando um Ativo Qualquer}

DEFINIÇÃO 2.2. Um mercado é completo se, para qualquer cenário possível, é possível comprar um ativo (ou uma coleção de ativos, doravante chamada de carteira) tal que ele gere um fluxo de caixa positivo e conhecido $F$ neste cenário, para qualquer valor de $F$, e gere fluxo de caixa nulo para todos os demais cenários.

Vamos exemplificar um mercado completo utilizando os cenários apresentados na Figura 1. Imagine que o mercado que visualiza os cenários apresentados nesta figura é completo e queremos fazer uma aposta com relação ao desempenho da Argentina na Copa do Mundo. No entanto, não há casas de apostas onde possamos fazer tal aposta, de forma que deveremos nos recorrer ao mercado.

A aposta que desejamos efetuar pode ser definida por dois ativos, $B$ e $R$. O ativo $B$ seria uma aposta contra a Argentina, pagando uma unidade de dinheiro caso o cenário bom se realizasse. Já a aposta a favor da Argentina seria denominada como o ativo $R$, pagando uma unidade de dinheiro caso o cenário ruim se realizasse. Em um mercado completo, estes ativos estariam disponíveis para negociação ou então, na pior das hipóteses, seria possível construir uma carteira que geraria o mesmo fluxo de caixa que estes ativos, gerando assim o mesmo efeito que a compra dos mesmos.

Note agora que, como o mercado é completo e só existem os dois cenários descritos na figura, é possível construir os ativos $B$ e $R$ tomando outros dois outros ativos, $J$ e $K$, onde o ativo $J$ possui o mesmo fluxo de caixa de um investimento na bolsa de valores, ou seja, um investimento de $\$ 25.000,00$ na data atual valeria $\$ 35.000,00$ (uma rentabilidade de $40 \%$ ) no cenário bom e \$18.500,00 (uma rentabilidade de -26\%) no cenário ruim; já o ativo $K$ é um título de renda fixa do governo federal, sendo na nossa economia hipotética isento de riscos - nada de risco de crédito, risco legal, risco cambial, risco de flutuação nas taxas de juros ou qualquer outro risco que possa espantar o investidor mais conservador de todos que irá resgatá-lo apenas no vencimento, um ano depois. A rentabilidade deste ativo até o vencimento, conforme visto na Figura 1, é de 17,75\%, e portanto um investimento de $\$ 1.000,00$ neste ativo na data atual valeria $\$ 1.775,00$ em qualquer um dos cenários. Vamos supor adicionalmente que o ativo $K$ seja negociado por preço unitário, ou seja, cada unidade comprada do ativo $K$ a um preço $P_{K}$ garantirá, em qualquer um dos cenários, um fluxo de caixa de uma unidade de dinheiro.

Assumindo ser possível a compra de frações de ativos, é fácil obter uma carteira com os ativos $J$ e $K$ que possua comportamento exatamente igual ao do ativo $B$. Para tal, seja 
$C_{B}=\left(X_{J B}, X_{K B}\right)$ um vetor cujos componentes sejam o montante que deve ser gasto na compra dos ativos $J$ e $K$ respectivamente para que o resultado global da compra seja exatamente igual ao de se comprar uma unidade do ativo $B$. Os valores de $X_{J B}$ e de $X_{K B}$ são obtidos resolvendo o seguinte sistema de equações lineares:

$$
\left\{\begin{array}{l}
X_{J B} \times 1,40+X_{K B} \times 1,1775=1 \\
X_{J B} \times 0,74+X_{K B} \times 1,1775=0
\end{array} .\right.
$$

A primeira equação dita que o fluxo de caixa do investimento deve ser igual a uma unidade de dinheiro no cenário bom e a segunda equação dita que o fluxo de caixa do investimento deve ser igual a zero no cenário ruim. Resolvendo este sistema obtemos que $X_{J_{B}}=1,5151 \mathrm{e}$ $X_{K B}=-0,9522$, ou seja, deve-se investir $\$ 1,5151$ no ativo $J$ (bolsa de valores) e posteriormente se vender $\$ 0,9522$ do ativo $K$ (ou seja, tomar dinheiro emprestado a uma taxa igual à taxa de juros sem risco).

Analogamente, é possível montar outra carteira que possua comportamento exatamente igual ao do ativo $R$. Tomando $C_{R}=\left(X_{J R}, X_{K R}\right)$ como um vetor cujos componentes sejam o montante que deve ser gasto na compra dos ativos $J$ e $K$ respectivamente para que o resultado global do compra seja exatamente igual ao de se comprar uma unidade do ativo $B$, temos que os valores de $X_{J R}$ e de $X_{K R}$ são obtidos resolvendo-se o seguinte sistema de equações lineares:

$$
\left\{\begin{array}{l}
X_{J B} \times 1,40+X_{K B} \times 1,1775=0 \\
X_{J B} \times 0,74+X_{K B} \times 1,1775=1
\end{array} .\right.
$$

E resolvendo este sistema obtemos que $X_{J B}=-1,5151$ e $X_{K B}=1,8014$, ou seja, deve-se vender $\$ 1,5151$ do ativo $J$ (o que é conhecido no mercado como venda a descoberto ou short sale - você vende o ativo $J$ sem tê-lo mas fica com a obrigação de entregá-lo em uma data futura) e posteriormente se investir $\$ 1,8014$ no ativo de renda fixa $K$. Assim, concluímos a prova de que é os ativos $B$ e $R$ existem e podem ser obtidos no mercado.

Se a única forma de se obter os ativos $B$ e $R$ fosse construindo uma carteira composta por outros ativos do mercado de comportamento futuro exatamente igual aos mesmos, é trivial que $\circ$ preço de mercado destes ativos $B$ e $R$ seria obtido calculando o preço de mercado das carteiras construídas. Assim, o preço de mercado do ativo $B$, por exemplo, que doravante chamaremos de $P_{B}$, seria igual ao preço da carteira montada anteriormente (ou 
seja, $X_{J B}+X_{K B}$ ), sendo assim igual a $\$ 0,5629$. Analogamente temos que o preço de mercado do ativo $R$, doravante denominado de $P_{R}$, seria igual a $X_{J R}+X_{K R}=\$ 0,2863$.

No entanto, se existissem outras formas de se obter os ativos $B$ e $R$ além de se montar as carteiras apresentadas anteriormente (por exemplo, se estes ativos fossem diretamente negociados no mercado ou se existissem outras carteiras de comportamento idêntico a eles), sem hipóteses adicionais haveria a possibilidade de que existisse um desbalanceamento no mercado. Por exemplo, poderíamos ter um ativo sendo negociado a um preço diferente do preço de mercado da carteira de comportamento idêntico ao do mesmo ativo.

O leitor deve se atentar ao fato de que a afirmação de que o preço de mercado de um ativo deve ser igual ao preço de uma carteira montada que possua o mesmo efeito que comprar este ativo não é válida por si só. É necessário se assumir uma nova hipótese, a de que o mercado é livre de oportunidades de arbitragem:

DEFINIÇÃO 2.3. Uma oportunidade de arbitragem é uma situação em que um agente pode, com um investimento inicial igual a zero, apresentar em todos os cenários um retorno não negativo, sendo que em pelo menos um deles este retorno é positivo.

Uma discussão mais detalhada sobre as oportunidades de arbitragem e sobre mercados livre de arbitragem é dada no Anexo 2 do presente texto. Intuitivamente, um mercado será livre de arbitragem se não existir a possibilidade de se obter um lucro esperado positivo sem que exista a possibilidade, por menor que seja, de que se ocorra uma perda. Uma oportunidade de arbitragem pode ocorrer em um mercado onde os agentes não possuam o conhecimento completo de todas as estratégias de lucro sem risco possíveis de serem montadas.

Apresentamos agora o seguinte teorema, também conhecido como a Lei de um Único Preço:

TEOREMA 2.1. Em um mercado livre de oportunidades de arbitragem, o preço de mercado de qualquer ativo $A$ deve ser igual ao preço de qualquer carteira teórica $C_{A}$ montada de forma que esta gere o mesmo fluxo de caixa gerado pela compra do ativo $A$.

Prova. Suponha que existam apenas dois cenários possiveis (a prova pode ser facilmente adaptada para o caso onde o número de cenários possíveis seja superior a dois). Seja $P_{A} \circ$ preço do ativo $A$ e $P_{C A}$ o preço da carteira $C_{A}$ que gere o mesmo fluxo de caixa gerado pela compra do ativo $A$. Temos dois casos a analisar: 
- $C_{A}=A$. Neste caso, segue trivialmente que $P_{C A}=P_{A}$;

$>C_{A} \neq A$. Neste caso, suponha que $P_{C A}>P_{A}$. Construa uma carteira obtida vendendo uma unidade de $C_{A}$ e comprando uma unidade de $A$. $O$ investimento inicial nesta carteira foi zero, já que todo o capital necessário para a compra de $A$ foi obtido com a venda de $C_{A}$. Além disso, para qualquer instante futuro, o fluxo de caixa desta carteira sempre será igual a zero, visto que $C_{A}$ e $A$ geram o mesmo fluxo de caixa. No entanto, o retorno desta carteira é, em todos os cenários, igual a $P_{C A}-P_{A}>0$ (o capital que sobrou ao comprar uma unidade de $A$ com 0 montante obtido na venda de uma unidade de $C_{A}$ ). Segue assim que este mercado não é livre de oportunidades de arbitragem, o que contradiz a nossa hipótese. Analogamente, se $P_{C A}<P_{A}$, a carteira construída vendendo uma unidade de $A$ e comprando uma unidade de $C_{A}$ oferecerá lucro sem risco, portanto concluímos que $P_{C A}=P_{A}$.

A partir deste momento, assumiremos que o nosso mercado, além de completo, é livre de oportunidades de arbitragem. A prova do Teorema 2.1 mostra que esta hipótese adicional parece ser muito razoável, visto que, se existisse alguma distorção, como o nosso mercado possui um número infinito de agentes, com certeza alguns perceberiam a oportunidade, e a demanda por lucro sem risco geraria um número muito alto de vendas do ativo que estivesse com o preço superior ao devido, puxando para baixo o preço deste até o ponto em que não existisse mais nenhuma oportunidade de arbitragem.

O Teorema 2.1 e as hipóteses assumidas implicam que com base nos preços $P_{B}$ e $P_{R}$ é possível avaliar qualquer ativo - inclusive o ativo $A$ que motivou toda a discussão efetuada sobre precificação. Isto porque sempre será possivel construir um ativo com fluxo de caixa futuro exatamente igual ao do ativo a ser avaliado, já que os ativos $B$ e $R$ existem. Note que, no caso do ativo $A$, o agente que adquirisse $F_{B}$ unidades do ativo $B$ e $F_{R}$ unidades do ativo $R$ estaria tendo, na prática, um retorno futuro exatamente igual ao do ativo $A$. Portanto, pelo Teorema 2.1, denotando como $P_{A} \circ$ preço do ativo $A$, temos que:

$$
P_{A}=P_{B} \times F_{B}+P_{R} \times F_{R}
$$

Assim, o preço do investimento $A$ pode ser facilmente derivado de (2.1.3), sendo igual a $0.5629 \times F_{B}+0,2863 \times F_{R}$. Raciocínio análogo pode ser efetuado para se obter o preço 
justo de qualquer investimento em uma condição de incerteza. Note que não foi necessário nenhum conhecimento sobre a probabilidade de ocorrência de algum cenário em particular ou nenhuma hipótese sobre o perfil de aversão a risco dos investidores.

\subsection{Um paradoxo interessante}

O leitor deve, concluída a seção anterior, estar intrigado com a informação de que a obtenção do preço de mercado de um determinado ativo não depende da probabilidade de ocorrência de um determinado cenário. Afinal, deixando o humor de lado, todo apostador esportivo sabe que, no mundo real, uma aposta de que a Argentina não irá para a Copa do Mundo é muito mais barata do que uma aposta de que ela irá para a Copa do Mundo, exatamente por ser muito mais improvável que a Argentina não vá para a Copa do Mundo!

Para esclarecer o que, em um primeiro momento, pode parecer uma incorreção, iniciaremos definindo um investidor racional.

DEFINIÇÃO 2.4. Um investidor racional é aquele que prefere, fixado um nível de risco, mais retorno a menos retorno; e fixado um nível de retorno, menos risco a mais risco.

Vamos agora verificar que fatores podem afetar o valor que um investidor racional aceitaria pagar pelos ativos $B$ e $R$ definidos na seção anterior:

> A chance de ocorrência de um determinado cenário em detrimento de outro: claramente, se o cenário $B$ parece ser mais verossímil que o cenário $R$, então o investidor racional estaria mais disposto a pagar mais por algo que terá algum valor se o cenário $B$ ocorrer do que pagar mais por algo que não terá valor nenhum se o cenário $B$ ocorrer. Note que os cenários da Figura 1 deixam implícito que pelo menos há um consenso de que o cenário $B$ é o mais provável de ocorrer, já que, se ambos os cenários tivessem a mesma probabilidade de ocorrência, 0 retorno esperado da bolsa de valores seria de $0,5 \times 40 \%+0.5 \times(-26 \%)=7 \%$ e nenhum investidor racional iria investir na bolsa de valores, um investimento de maior risco, uma vez que a taxa de juros garante sem risco um retorno de $17.75 \%$. Por isso, quando calculamos os valores de $P_{B}$ e de $P_{R}$ obtivemos que 0 investimento $B$ é mais caro que o investimento $R$. 
> O perfil de aversão a riscos do investidor: dois investidores podem ser racionais e aversos a riscos, mas ambos podem ter perfis diferentes, ou seja, um ser mais averso do que o outro. Um investidor mais idoso e já aposentado tem muito mais medo de perder capital do que um investidor mais jovem, com mais tempo para recuperá-lo. O jovem não gosta de jogar o seu dinheiro fora (atenção: estamos assumindo investidores racionais!), mas aceita correr um pouco mais de riscos se for convencido de que os retornos compensam. Portanto, para que o investidor idoso aceite adquirir um investimento mais arriscado, este tem que estar muito mais barato do deveria estar para que o jovem aceite adquiri-lo, ou seja, ele vale menos para o idoso do que para o jovem. O conceito de aversão a riscos é facilmente ilustrado com o auxílio de curvas de utilidade ${ }^{1}$, ilustradas na Figura 2 para o investidor jovem e o investidor idoso. Desta figura podemos notar duas coisas: a primeira delas é que variações negativas de mesma magnitude no consumo de ambos os investidores geram no investidor mais jovem uma variação negativa em sua utilidade de menor magnitude do que a gerada no investidor mais idoso; a segunda delas é que, para ambos os investidores, uma queda no consumo tem um efeito muito mais drástico na utilidade dos mesmos do que um aumento no consumo. Assim, se os cenários de aumento e de queda fossem igualmente prováveis, o ativo que garantisse fluxo de caixa somente no cenário de queda valeria mais do que o ativo que garantisse fluxo de caixa somente no cenário de aumento.

O leitor deve se lembrar dos cursos básicos de contabilidade e matemática financeira, nos quais ele foi ensinado que, ao se avaliar se um investimento de fluxo de caixa determinístico deve ser tomado ou não, ele deve especificar uma taxa de retorno aceitável e verificar se a taxa interna de retorno implícita no fluxo de caixa deste investimento é maior ou

\footnotetext{
${ }^{1}$ A utilidade é um conceito na teoria econômica que busca expressar o quão valioso para um investidor é um determinado nível de consumo. Acredita-se que a utilidade em função do consumo para um investidor de comportamento padrão (racional e averso a riscos) é uma curva como a descrita em Chourdakis [16] e ilustrada na Figura 2, crescente e côncava, mostrando que aumentos no consumo não têm efeito proporcional na satisfação do investidor, com a magnitude deste efeito sendo sempre menor do que a do aumento no consumo, apesar de, ao mesmo tempo, quedas no consumo gerarem um efeito negativo na satisfação de magnitude sempre superior à da queda no consumo. Isto é um pouco intuitivo. Normalmente não ficamos tão felizes quando ganhamos $\mathrm{R} \$ 1.000,00$ quanto ficariamos tristes se perdêssemos a mesma quantia.
} 
igual à taxa especificada anteriormente. De fato, ao fazer isto, o leitor está utilizando o seu perfil de aversão a riscos para determinar o que é uma taxa de retorno aceitável.

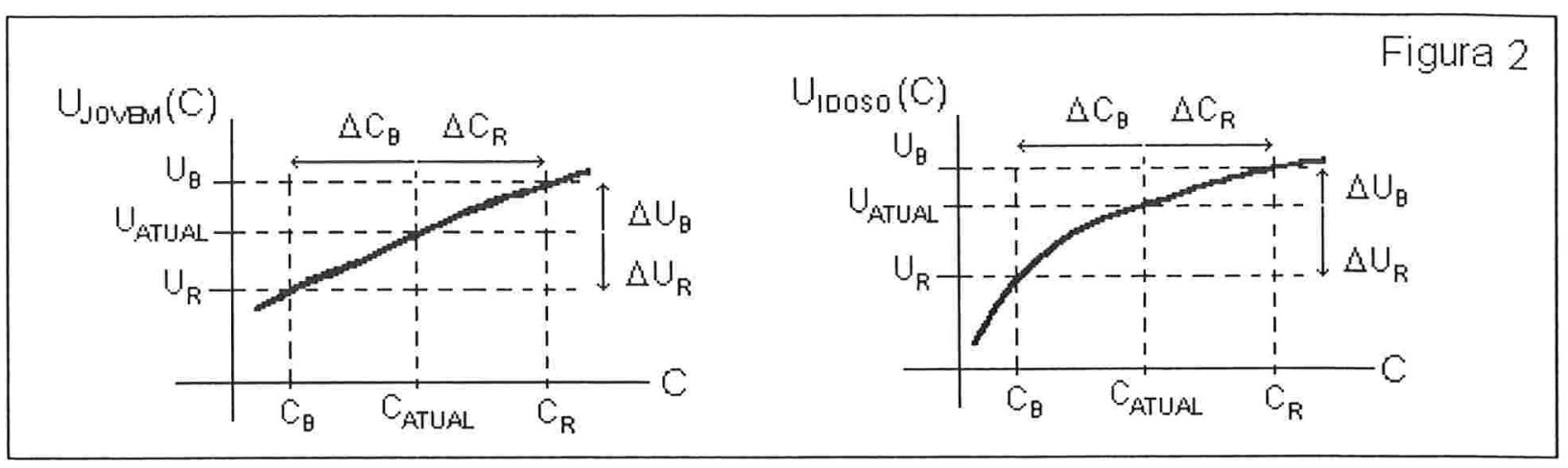

Além disso, se o leitor for confrontado com um investimento cujo fluxo de caixa não é determinístico, ele fará o possível para conhecer o seu fluxo de caixa esperado, calculando a média de algumas projeções e efetuando o cálculo da mesma maneira que para o fluxo determinístico. Nesta parte do procedimento, além de seu julgamento subjetivo sobre o que é uma taxa de retorno aceitável, ele está construindo cenários (as projeções) e utilizando as probabilidades de ocorrência destes cenários.

Portanto, é razoável imaginar que todos os agentes do mercado, ao tentarem precificar algo que está no mercado, irão, em uma primeira instância, seguir procedimentos próximos aos citados nos parágrafos anteriores. Assim, não há como negar que tanto as probabilidades reais de ocorrência dos cenários quanto o perfil de aversão a riscos de todos os agentes do mercado impactam os preços $P_{B}$ e $P_{R}$ dos ativos $B$ e $R$ definidos na seção anterior e, por conseqüência, o preço de qualquer ativo que seja negociado neste mercado.

No entanto, lembremos que, por hipótese, existem infinitos agentes no mercado e, portanto, infinitos perfis de aversão a risco. Também lembremos que, por hipótese, a verdadeira probabilidade de que um determinado cenário ocorra não é conhecida. Por fim, lembremos que, se o mercado é completo e livre de arbitragem, os preços $P_{B}$ e $P_{R}$ são únicos e bem definidos, a despeito desta infinidade de fatores conhecidos e desconhecidos que os afetam, o que soa um tanto paradoxal.

O paradoxo até agora apresentado é esclarecido ao observarmos que os preços $P_{B} \mathrm{e}$ $P_{R}$ podem ser decompostos da seguinte maneira: 


$$
\left\{\begin{array}{l}
P_{B}=\pi_{B} m_{B} \\
P_{R}=\pi_{R} m_{R}
\end{array},\right.
$$

onde $\pi_{B}$ é a verdadeira probabilidade de ocorrência do cenário $B$ e $m_{B}$ é o preço que um agente pagaria para receber, livre de riscos, uma unidade de dinheiro sabendo que na data futura o cenário que irá ocorrer é o cenário $B$ ( $\pi_{R}$ e $m_{R}$ são definidos analogamente).

É muito importante observarmos que, apesar de serem preços para se receber um retorno livre de riscos, nem $m_{B}$ e nem $m_{R}$ serão necessariamente iguais ao preço do ativo $K$ da seção anterior (o título de renda fixa do governo federal). Estes preços são determinados por cada agente e são intimamente ligados à função de utilidade do agente, sendo assim ligados ao perfil de aversão a riscos do mesmo. Isto porque, conforme apresentado anteriormente, a ocorrência de diferentes cenários tem diferentes impactos na função de utilidade de um investidor racional. Lembremos que, olhando para os cenários da Figura 1 , um investidor aceitaria pagar muito mais pelo direito de ter seu consumo assegurado na data futura sabendo que a taxa de desemprego iria subir para $17 \%-e$, portanto, a sua chance de estar desempregado nesta data e precisar deste dinheiro seria maior - do que se ele soubesse que na data futura a taxa de desemprego cairia para $8 \%$.

Desta forma, concluímos que, em um mercado completo e livre de arbitragem, onde todos os cenários futuros são conhecidos (ou pelo menos há um consenso sobre o conjunto de cenários possíveis), as reais probabilidades de ocorrência destes cenários e as preferências dos agentes de fato afetam os preços dos ativos $B$ e $R$ definidos na seção anterior. No entanto, tais fatores estão em uma condição de equilíbrio tal que o preço de mercado daqueles ativos não depende dos valores assumidos por estes fatores para um determinado agente, não sendo assim necessário conhece-los para efetuar a precificação daqueles ativos (e, portanto, para a precificação de qualquer ativo deste mercado).

\subsection{O conceito de probabilidades neutras ao risco}

Observe que, de (2.1.3) e (2.2.1), podemos afirmar que:

$$
P_{A}=\pi_{B} m_{B} \times F_{B}+\pi_{R} m_{R} \times F_{R}=E[m \times F] .
$$

Assim, como $m_{B}$ e $m_{R}$ não são necessariamente iguais ao preço de um título de renda fixa, a equação (2.3.1) deixa bem claro que o preço de mercado de um ativo não é encontrado obtendo-se o valor presente esperado do seu fluxo de caixa futuro. O preço de 
mercado de um ativo é o valor presente esperado de seu fluxo de caixa descontado por um fator que depende do perfil de aversão a riscos do agente que o estiver precificando.

Vamos lembrar que, até o momento, nada da teoria discutida pode ser aplicada no mundo real. Os ativos $B$ e $R$ definidos anteriormente não são observáveis, sendo apenas ativos imaginários. A obtenção destes ativos seria impraticável visto que, no mundo real, o número de cenários possíveis é muito grande, na verdade infinito. E mesmo que fosse possível efetuar uma lista de cenários possíveis, a tarefa de precificação continuaria um tanto complicada, pois teríamos que inferir nas probabilidades de ocorrência destes cenários e no perfil de aversão a riscos do agente precificador.

A equação (2.3.1) nos mostra como resolvermos este problema. Para isto, observe que, para $P_{K}$ igual ao preço unitário do título de renda fixa, é válido que:

$$
P_{A}=\frac{P_{k}}{P_{k}}\left(P_{B} \times F_{B}+P_{R} \times F_{R}\right)=P_{k}\left(q_{B} \times F_{B}+q_{R} \times F_{R}\right),
$$

$\operatorname{com} q_{B}=\frac{P_{B}}{P_{k}}$ e $q_{R}=\frac{P_{R}}{P_{k}}$.

Vamos agora observar alguns fatos importantes:

$>P_{B}+P_{R}=P_{k}$. Suponha que um agente decide comprar ao mesmo tempo os ativos $B$ e $R$. Como ele estará garantindo um fluxo de caixa de uma unidade de dinheiro em qualquer cenário, ele estará montando uma carteira que gera o mesmo fluxo de caixa que o ativo $K$. Portanto, como o mercado é livre de arbitragem, segue que o preço desta carteira é igual ao preço do ativo $K$;

$>q_{B}+q_{R}=1$, visto que $q_{B}+q_{R}=\frac{P_{B}}{P_{K}}+\frac{P_{R}}{P_{K}}=\frac{P_{K}}{P_{K}}=1$;

$>q_{B}>0$ e $q_{R}>0$, pois $P_{B}>0$ e $P_{R}>0$, uma vez que, por mais improvável que seja a ocorrência de um cenário qualquer, ninguém em sã consciência entregaria de graça (e muito menos pagaria para entregar) o direito de receber um fluxo de caixa de uma unidade de dinheiro se este cenário ocorrer;

r Se $r$ é a taxa de juros livre de risco expressa em termos anuais sob o conceito de capitalização contínua, temos que $P_{K}=e^{-r t}$, onde $t$ é o tempo em anos entre a data atual e a data futura. 
Com base nas três primeiras observações, concluímos que os valores $q_{b}$ e $q_{r}$ satisfazem os requisitos necessários para serem chamados de probabilidades. Agregando a quarta observação, teríamos a seguinte fórmula para o cálculo do preço justo de um investimento $A$ :

$$
P_{A}=e^{-r t} E^{Q}[F]
$$

onde $E^{Q}$ denota a esperança com base nas probabilidades $q_{b}$ e $q_{r}$ e $F$ é o fluxo de caixa futuro do ativo $A$.

Note que só está correto obter o preço de mercado do nosso ativo $A$ descontando o seu fluxo de caixa esperado pela taxa de juros livre de risco se esta esperança for calculada com base em outras probabilidades - e não as probabilidades reais, as quais assumimos serem desconhecidas. Estas novas probabilidades, além de não envolverem as probabilidades reais, não envolvem nenhum perfil de aversão à riscos dos agentes, sendo por este motivo chamadas de probabilidades neutras ao risco.

\subsection{A necessidade de simplificação}

Até o momento trabalhamos apenas com um conjunto de cenários possíveis composto por apenas dois cenários, mas o leitor pode verificar que é fácil generalizar este conceito para qualquer conjunto enumerável de cenários. Mesmo assim, no mundo real o conjunto de cenários, ainda assumindo que este é conhecido por todos, normalmente não é nem mesmo enumerável, sendo representado por uma distribuição contínua de probabilidades.

O advento das probabilidades neutras ao risco resolve de maneira eficaz este problema já que, mesmo quando os cenários são representados por uma distribuição contínua de probabilidades, é possivel encontrar uma nova distribuição que faça o papel das probabilidades neutras ao risco. É claro que esta nova distribuição tem que satisfazer alguns requisitos matemáticos para fazer este papel. Como ainda não apresentamos muitas definições matemáticas formais que farão parte deste trabalho, optamos por apresentar estes requisitos no Anexo 2.

Conhecer a distribuição das probabilidades neutras ao risco de $F$ não é suficiente para garantir que sabemos resolver o problema de precificação. O cálculo da esperança definida em (2.3.3) pode não ter uma solução analítica. Esta complicação pode surgir se descobrirmos que a distribuição cuja esperança desejamos calcular possui uma forma complicada, de difícil tratamento. 
Isto pode ocorrer mesmo se assumirmos que os retornos do ativo a ser precificado seguem uma distribuição de fácil tratamento, como a distribuição normal. Devemos observar que em todos os exemplos até o momento utilizamos um ativo com fluxo de caixa uniperiódico (ou seja, com apenas dois estados de tempo, a data atual e a data futura) e dependente apenas do cenário que se tornar real na data futura. No mundo dos derivativos, sabemos que somente algumas opções com exercício do tipo europeu possuem um fluxo de caixa desta forma.

As opções com exercício do tipo americano, por exemplo, geram um fluxo de caixa que, apesar de ser pago em apenas um instante de tempo, não pode ser modelado de forma uniperiódica porque ele pode ser gerado a qualquer momento entre a data atual e a data futura, dependendo da trajetória que o preço do ativo base seguir entre estas datas. Isto exige um modelo multiperiódico a tempo contínuo, o que é um grande fator de complicação para o cálculo da esperança definida na fórmula (2.3.3).

Uma das saídas mais utilizadas pela comunidade de engenheiros financeiros no cálculo da esperança acima para a precificação de uma opção é fazer uma simplificação do modelo real para um modelo a tempo discreto e com um conjunto discreto de cenários. Conhecida a distribuição das probabilidades neutras ao risco para a evolução do preço do ativo base, quebra-se o intervalo de tempo em um número suficientemente grande de subintervalos e simula-se um número grande de vezes as trajetórias do preço do ativo base e o fluxo de caixa gerado pela opção em cada uma destas trajetórias, obtendo-se assim uma distribuição empírica de probabilidades neutras ao risco para o fluxo de caixa futuro gerado pela opção. A esperança então é calculada em cima desta distribuição empírica obtida.

A partir do momento que deixamos o mundo real e partimos para uma aproximação, precisamos nos certificar de que esta aproximação funciona, ou seja, converge para o resultado real. Adicionalmente, precisamos conhecer plenamente os fatores que garantem a qualidade desta aproximação.

Até o momento lidamos apenas com a teoria de finanças por trás do problema prático que queremos resolver. No entanto verificamos que é necessário agora nos recorrermos à teoria matemática para resolvermos satisfatoriamente o nosso problema de finanças. Assim, prosseguiremos o nosso texto apresentando em termos matemáticos o nosso problema inicial, para posteriormente o resolvermos com todo o rigor matemático necessário. 


\section{SIMULANDO TRAJETÓRIAS A TEMPO DISCRETO}

\subsection{Definindo a convergência desejada}

Vamos começar apresentando o tipo de convergência desejada no nosso estudo. Para apresentar este resultado, consideremos distintas trajetórias, em diferentes pontos, de distintos passeios aleatórios:

$$
S_{n_{j}}^{j}=\sum_{i=1}^{n_{j}} x_{i}^{j},
$$

onde $x_{i}^{j}$ é uma variável que vale 1 com probabilidade 0,5 e -1 com probabilidade $0,5, j$ é o número da simulação e $n_{j}$ é o número de passos da simulação $j$. Para este exemplo, sem perda de generalidade, vamos tomar $j=1, \ldots, 8$. Assim, os valores de $S_{n_{j}}^{j}$ podem ser entendidos como os pontos finais de oito passeios aleatórios de mesma distribuição para um passo, mas cada um deles com um número diferente de passos.

No âmbito de finanças, também podemos interpretar $S_{n j}^{j}$ como a $j$-ésima simulação do incremento total no preço de um ativo após $n_{j}$ passos, sendo que entre cada passo o preço deste ativo pode aumentar em uma unidade de dinheiro entre um passo e outro com a mesma probabilidade de que ele pode cair uma unidade de dinheiro. Chamaremos, apenas neste capítulo, esta soma de retorno acumulado.

Cada passo pode ser entendido como um instante de tempo. Sendo assim, estaríamos obtendo, em cada simulação $j$, o retorno acumulado do ativo ao final de $n_{j}$ instantes de tempo.

Vamos agora calcular a distribuição de probabilidades das simulações definidas em (3.1.1). Para tal, consideremos:

$$
y_{i}^{j}=\frac{x_{i}^{j}+1}{2}
$$

Note que $y_{i}^{j}$ é uma variável que vale 1 com probabilidade 0,5 e 0 com probabilidade 0.5 .

É fato conhecido que: 


$$
S *_{n_{j}}^{j}=\sum_{i=1}^{n} y_{i}^{j} \approx \operatorname{Bin}\left(n_{j}, \frac{1}{2}\right) \Rightarrow E\left[S *_{n_{1}}^{j}\right]=\frac{n_{j}}{2} ; \operatorname{Var}\left[S *_{n_{1}}^{i}\right]=\frac{n_{i}}{4}
$$

e portanto

$$
\frac{S_{n_{1}}^{j}+n_{j}}{2}=\frac{\sum_{i=1}^{n_{j}}\left(x_{i}^{j}+1\right)}{2} \Rightarrow S_{n_{j}}^{j} \approx 2 \operatorname{Bin}\left(n_{j}, \frac{1}{2}\right)-n_{j} \Rightarrow E\left[S_{n_{j}}^{j}\right]=0 ; \operatorname{Var}\left[S_{n_{j}}^{j}\right]=n_{j} .
$$

Como os pontos finais dos passeios definidos anteriormente possuem todos a mesma média, podemos querer comparar estes valores e tentar chegar a alguma conclusão. No entanto, note que os oito pontos finais provavelmente estarão muito diferentes em escala porque cada trajetória tem um comprimento diferente e, conforme apresentado em (3.1.4), apesar de possuírem a mesma média, a variância do ponto final de um passeio aleatório depende do número de passos ocorridos até este ponto. A Figura 3 apresenta uma ilustração básica do que deve ter acontecido com os oito pontos definidos em (3.1.1).

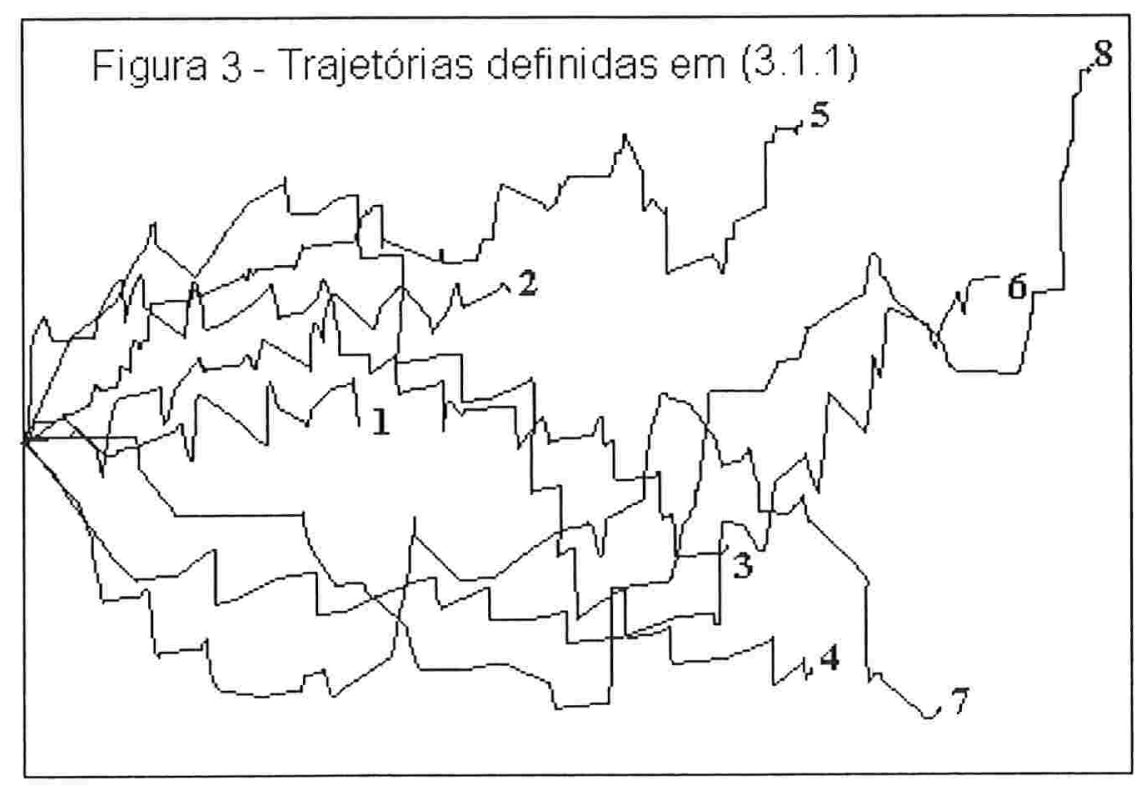

O mais correto para comparar estas as trajetórias seria consideremos cada um dos valores de:

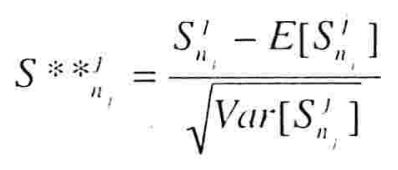


para as oito trajetórias. Isto é equivalente a pegar os oito pontos finais e normalizá-los a um número de passos comum.

A nossa intuição diz que estes valores convergem para algum ponto, já que todos estarão na mesma escala e o Teorema Central do Limite diz que a soma normalizada de variáveis aleatórias identicamente distribuídas converge sempre para alguma coisa quando tomamos um número grande de variáveis na soma. Em outras palavras, a nossa intuição diz que, para $n_{j} \rightarrow \infty$,

$$
\begin{gathered}
S * *_{n_{1}}^{1} \rightarrow a \\
S * *_{n_{2}}^{2} \rightarrow b \\
\cdots \\
S * *_{n_{\mathrm{s}}}^{3} \rightarrow h
\end{gathered}
$$

com $|a-b| \approx|a-c| \approx \ldots \approx|g-h| \approx 0$. No entanto, veremos que a nossa intuição está errada e não é isto que ocorre. Observe a Figura 4.

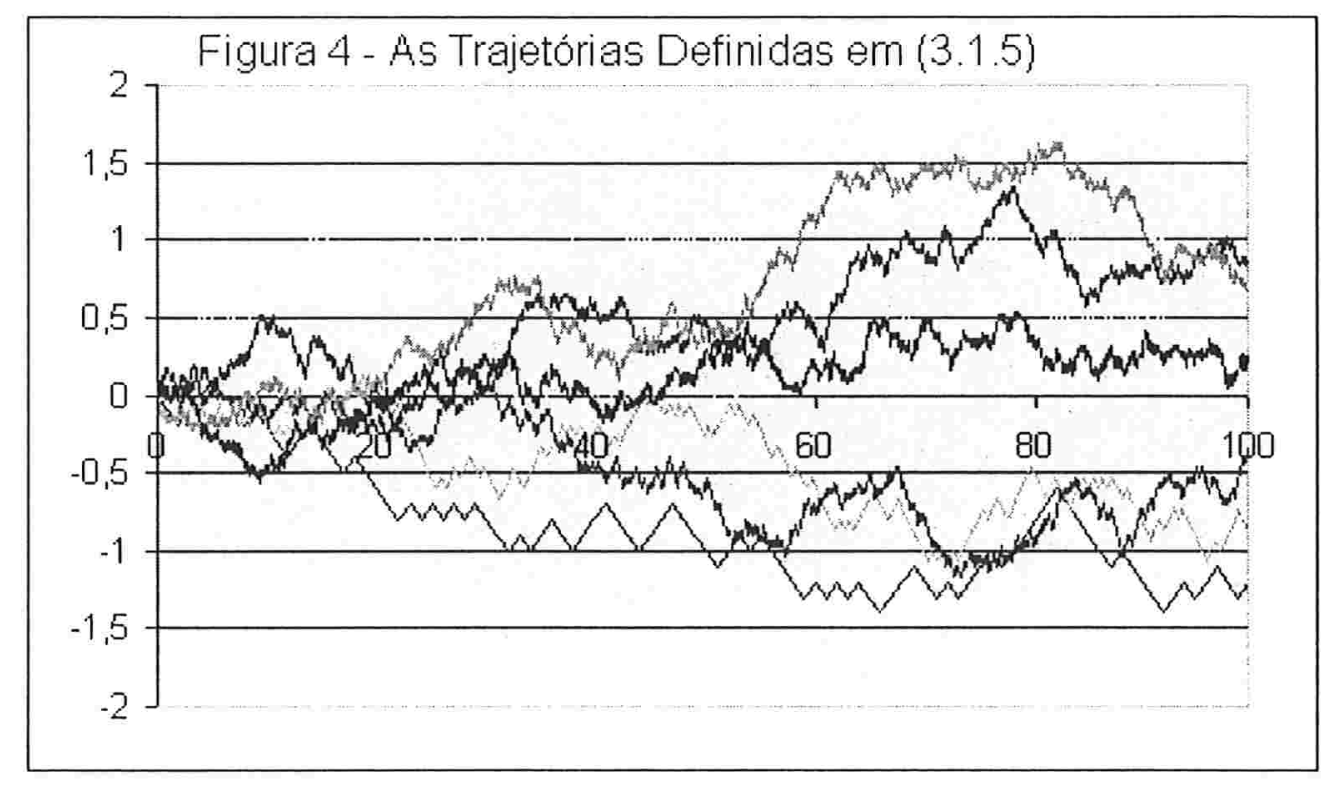

A Figura 4 ilustra os resultados obtidos em (3.1.5) para as 8 simulações, com n's crescentes e maiores que 100 (ou seja, suficientemente grandes para já ter ocorrido alguma convergência). Neste gráfico, estão as trajetórias da soma, sendo que o último valor (no ponto 100) é o valor das somas padronizadas por seus respectivos desvios padrão. 
Isto aconteceu porque, na verdade, a convergência esperada que aprendemos nos teoremas básicos é outro tipo de convergência. Não há uma convergência para um único ponto, e sim uma convergência para uma distribuição de probabilidade. Para entender melhor, considere a região hachurada do gráfico apresentado na Figura 5. A convergência que esperamos afirma que o número de passeios que terminam dentro desta região em relação ao número total de passeios efetuados converge para o número de variáveis normais padronizadas (ou seja, com esperança igual a 0 e variância igual a 1) selecionadas ao acaso que estariam dentro da mesma região em relação ao número total destas variáveis, para um número razoavelmente grande de passeios gerados. Em termos mais técnicos, a medida de probabilidade dos passeios que terminam dentro desta região converge para a medida de probabilidade das variáveis normais padronizadas dentro da mesma região.

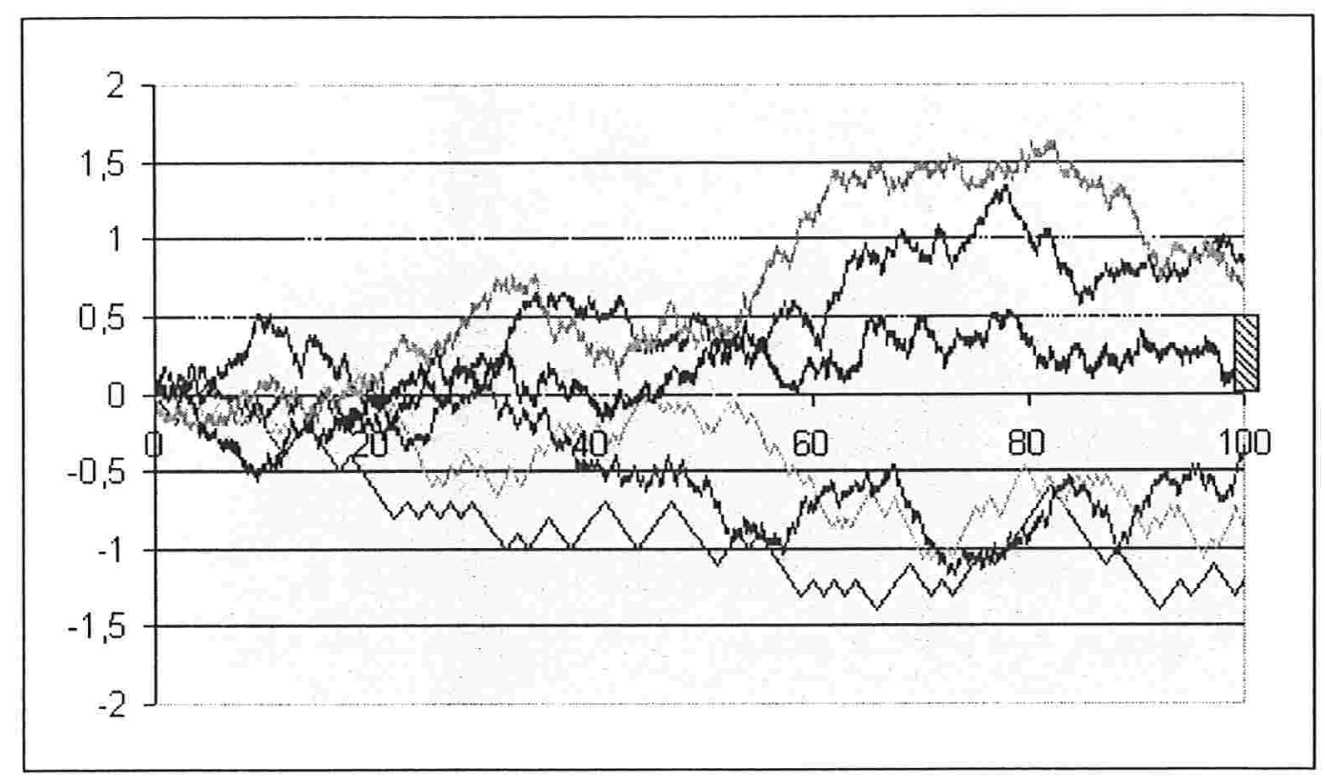

Figura 5 - Comparação entre a Normal e os passeios gerados

No nosso caso, em que temos apenas 8 passeios, era esperado que a fração de passeios que caíssem dentro desta região fosse de 0,1914 , o que implicaria 1,5317 passeios terminando dentro da região. Observa-se no gráfico dois passeios, o que é um número razoavelmente próximo do esperado. Neste caso, dizemos que houve uma convergência em distribuição de probabilidades, ou simplesmente convergência em distribuição. 


\subsection{A convergência em distribuição definida para passeios aleatórios}

Até o momento trabalhou-se apenas com o ponto final da trajetória, e concluiu-se que o mesmo convergia em distribuição para uma variável aleatória normal. Vamos agora dar um passo adiante, trabalhando com a trajetória inteira, ou seja, com toda a seqüência de variáveis $x_{i}^{j}$ que definem (3.1.1) e não apenas com a sua síntese.

Para os leitores com pouca familiaridade na nomenclatura, esta seqüência pode ser chamada de processo estocástico. De fato, qualquer coleção de variáveis aleatórias indexadas recebe o mesmo nome. Um processo estocástico envolve um elemento aleatório e um elemento temporal. No caso anterior, o tempo é definido pelo índice $i$, sendo uma variável inteira não negativa (tempo discreto). Não há problemas em definir o elemento temporal como uma variável real não negativa, e no caso teríamos um modelo de tempo contínuo.

Há um teorema que afirma que a seqüência de processos estocásticos definida anteriormente também converge para um processo em comum, conhecido como processo de Wiener ou movimento browniano. O movimento browniano também é conhecido na física como o movimento aleatório de partículas microscópicas suspensas em um fluido. A definição matemática de um movimento browniano $W(t)$ é dada por:

DEFINIÇÃO 3.1. - Se $W(t)$ é um movimento browniano, então:

$>W(0)=0$, com probabilidade 1 ;

> $W(t)$ é uma função contínua de $t$;

> $W(t+h)-W(t) \sim N(0, h), \forall t \geq 0, h>0$; e

- Para $0 \leq t_{1} \leq t_{2} \leq \ldots \leq t_{m}, W\left(t_{2}\right)-W\left(t_{1}\right), W\left(t_{3}\right)-W\left(t_{2}\right), \ldots, W\left(t_{m}\right)-W\left(t_{m-1}\right)$ são independentes.

A convergência desejada é regida pelo teorema a seguir, ainda apresentado com um menor rigor técnico, e cuja formulação foi atribuída a Donsker: 
TEOREMA 3.1. Seja $S_{n_{j}}^{j}=\sum_{i=1}^{n_{j}} x_{i}^{j}$, onde $x_{i}^{j}$ é tal como definido em (3.1.1) e seja $W\left(n_{j}\right)$ um movimento browniano conforme a definição 3.1. Se $n_{j} \rightarrow \infty$, então $S_{n}^{j}$, converge em distribuição para $W\left(n_{i}\right)$.

A interpretação qualitativa do teorema acima é a seguinte: Suponha que $\xi(t)$ é o retorno acumulado de um ativo no tempo $t$ (ou para os físicos, a posição de uma partícula no tempo $t$ ). Se este retorno acumulado for sujeito a deslocamentos aleatórios e independentes em sucessivas vezes $t_{1}, t_{2}, \ldots$ e os intervalos $t_{1}, t_{2}-t_{1}, t_{3}-t_{2}, \ldots$ forem razoavelmente pequenos, os retornos acumulados resultantes $\xi\left(t_{1}\right), \xi\left(t_{2}\right), \ldots$ irão desempenhar aproximadamente um movimento browniano.

\subsection{Algumas contribuições do Teorema de Donsker}

No capítulo introdutório citamos três métodos amplamente utilizados pelos engenheiros financeiros para o cálculo do preço de mercado de uma opção. Voltando a estes métodos, lembremos que Black \& Scholes (1973) encontraram o preço justo exato de uma opção européia assumindo que o logaritmo da taxa de variação acumulada do preço do ativo base seguia um movimento browniano. No entanto, mesmo com esta hipótese, o cálculo se torna bastante complicado quando envolve outros fatores, como por exemplo a possibilidade de exercício antecipado. A primeira contribuição do Teorema 3.1 está em garantir que, se a taxa de variação do preço do ativo base realmente seguir um movimento browniano, a aproximação da trajetória do ativo base em uma árvore de cenários em tempo contínuo (como a feita por Cox, Ross \& Rubinstein (1979)), se construída com um número razoavelmente grande de passos e com aberturas de mesma média e variância que as assumidas na construção do modelo de tempo contínuo, irá convergir para um movimento browniano, validando assim o método. Em outras palavras, os cálculos efetuados na árvore a tempo discreto convergem para o valor exato que seria obtido com um modelo de Cálculo Estocástico a tempo contínuo. Isto facilita a precificação de opções envolvendo exercício antecipado, já que este fator pode ser lidado de forma razoavelmente simples em um modelo de árvores, como veremos no decorrer deste trabalho. 
A segunda contribuição do Teorema 3.1, também muito útil para os agentes do mercado, está em garantir que, se as variações percentuais que ocorrem nos preços de mercado de um determinado ativo durante os diversos instantes de tempo realmente forem independentes e identicamente distribuídos, não está se errando muito ao se assumir que o logaritmo da taxa de variação acumulada do preço deste mesmo ativo siga um movimento browniano, principalmente se o nosso objetivo for inferir apenas nesta variação acumulada decorrido um número razoável de instantes de tempo (e não em todo o processo estocástico que define a variação acumulada). Um exemplo de situação onde só estamos interessados no ponto final da trajetória é a precificação de uma opção européia padrão, já que o único fator que afeta seu preço na data do exercício é o preço final do ativo base.

Esta segunda contribuição é importante visto que a premissa de que um movimento browniano rege a taxa de variação acumulada do preço de um ativo não é utilizada apenas na derivação do modelo de Black \& Scholes (1973). Ela também ainda vem sendo também utilizada por muitas tesourarias, cujo pessoal normalmente não possui conhecimento da teoria estatística necessária para o uso de modelos mais sofisticados, ou então simplesmente não dispõe do tempo necessário para se dedicar à construção destes modelos. Um exemplo de uso desta premissa é o cálculo do conhecido Value at Risk (V@R) paramétrico, o qual indica, com um determinado nível de confiança, qual o pior resultado que um montante aplicado em ativos com risco pode obter em um intervalo de tempo. O leitor que desejar conhecer esta aplicação é encorajado a consultar Jorion (1997).

Uma outra aplicação desta segunda contribuição do Teorema de Donsker está na definição de mercado eficiente, que será passada ao leitor nas próprias palavras de um distinto estudioso da teoria de eficiência de mercados (Fama (1964)), que em seu trabalho afirma:

DEFINIÇÃO 3.2. "Um mercado 'eficiente' é definido com um mercado onde há um numero suficientemente grande de investidores racionais e buscadores de lucro, competindo ativamente, cada um tentando prever futuros valores de mercado de ativos individuais, sendo que as informações atuais importantes estão livremente disponíveis a todos os participantes. Neste mercado, a competição entre os muitos participantes inteligentes levará a uma situação onde, a qualquer ponto no tempo, os preços atuais dos ativos refletirão todos os efeitos de informações baseadas em eventos que já aconteceram ou em eventos que, no momento da avaliação, o mercado espera que ocorra no futuro. Em outras palavras, em um 
mercado eficiente a qualquer ponto no tempo o preço de mercado de um ativo será uma boa estimativa de seu valor intrínseco."

Lembremos que, em qualquer mercado, são as informações disponíveis sobre um ativo com risco que guiam os preços de mercado deste, pois são com base naquelas que os agentes projetam seus cenários futuros para o fluxo de caixa do mesmo. Por exemplo, a chegada da informação de que houve uma descoberta de um novo poço de petróleo no Rio de Janeiro irá instantaneamente deslocar o preço da ação da Petrobrás para cima, visto que os agentes irão projetar maiores lucros para esta empresa, o que a fará um ativo de maior valor.

No entanto, em um mercado eficiente, apenas novas informações irão guiar os preços dos ativos negociados neste mercado, já que, a qualquer momento, todas as informações disponíveis neste momento estão refletidas nestes preços do momento. Portanto, se a chegada de novas informações for algo realmente aleatório, então os preços dos ativos também sofrerão deslocamentos aleatórios.

Da mesma forma, com base no Teorema de Donsker, poderemos afirmar que, se as novas informações, além de se tornarem disponíveis de maneira aleatória, forem independentes entre si e identicamente distribuídas ${ }^{2}$, os preços dos ativos em um mercado eficiente convergirão para um movimento browniano.

O debate sobre mercados eficientes resultou em centenas ou até milhares de estudos empíricos com a intenção de determinar se os mercados de fato são eficientes. Muitos investidores de pouca experiência no mercado são surpreendidos ao aprender que há uma quantidade alarmante de evidências suportando estas hipóteses.

\footnotetext{
2 O termo "informações identicamente distribuídas" pode ser interpretado como informações que possuem a mesma distribuição de probabilidade para o impacto que elas gerarão no preço dos ativos no mercado em geral. Por exemplo, se as novas informações forem sempre de mesma relevância para o mercado, ou de graus de relevância parecidos, elas satisfarão a definição de informações "identicamente distribuídas". No entanto, se o processo da chegada de novas informações for constituído por informações de pequeno grau de relevância para o mercado (por exemplo, informações que afetam apenas algumas empresas e/ou setores individualmente) misturadas com uma quantidade esporádica de outras informações mais fortes como, por exemplo, a ocorrência de um ataque terrorista em uma grande economia (ou seja, algo de forte impacto no mercado como um todo), não será possivel afirmar que estas informações foram "identicamente distribuídas".
} 
Os fatos expostos nesta seção nos levam a estudar mais a fundo a convergência verificada no Teorema de Donsker, cuja prova envolverá conceitos avançados de topologia e teoria da medida, sendo o objetivo dos nossos próximos dois capítulos. Acreditamos que o pleno entendimento destes dois capítulos permitirá ao leitor não apenas conhecer as situações onde este teorema é válido, podendo aplicá-lo de forma proficiente em seus problemas financeiros, como também entender outras definições matemáticas muito importantes, as quais também são utilizadas em uma gama de aplicações práticas que vai muito além da teoria de precificação de opções. 


\section{A TEORIA DE CONVERGÊNCIA FRACA EM $\mathfrak{R}^{n}$}

Uma definição matemática mas ainda não muito formal para a convergência em distribuição de uma seqüência de variáveis aleatórias se baseia em dizer que, se $X_{i}, i=1,2,3 \ldots$ são variáveis aleatórias com valores reais e respectivas funções de distribuição de probabilidade $F_{i}, i=1,2,3 \ldots$ e $X_{i}$ converge em distribuição para $X$ conforme $i \rightarrow \infty$, temos que $F_{i}(x) \rightarrow F(x)$ conforme $i \rightarrow \infty$, para todos os valores de $x$ onde $F$ é contínua.

Tal convergência, como implícito no nome, envolve apenas as distribuições das variáveis aleatórias. Isto significa que uma variável pode convergir em distribuição para outra que não precisa nem mesmo estar no mesmo espaço de probabilidade, ou seja, ser definida pelo mesmo experimento aleatório. Isto difere um pouco de outros modelos de convergência conhecidos.

Outra maneira, mais formal, de definir o mesmo tipo de convergência, reside em defini-la a partir de medidas de probabilidade. Antes de efetuar tal definição, é necessário apresentar alguns conceitos teóricos.

Os termos "medida", "mensurável", etc. possuem definições precisas e extremamente técnicas na teoria da medida, envolvendo anéis e outros conceitos mais complexos como $\sigma$ álgebras. Por estar fora do escopo deste trabalho estudar a teoria da medida, em alguns momentos trabalharemos com estes conceitos de maneira mais informal, deixando para o leitor que busca maior formalidade o livro de Rao (1987) como referência bibliográfica. Adicionalmente, caso o leitor deseje conhecer de uma maneira mais profunda outros conceitos básicos, sugerimos que o mesmo consulte Mood, Graybill \& Boes (1974) e Munkres (2000).

\subsection{Definições formais de convergência}

Um modelo matemático para um fenômeno de realização aleatória deve refletir as concepções intuitivas atribuídas à probabilidade de ocorrência deste fenômeno e outros conceitos ligados a ela. Uma das concepções intuitivas com a qual trabalhamos desde o ensino fundamental diz que a probabilidade deve ser aditiva: se não é possível que dois eventos $A$ e $B$ aconteçam ao mesmo tempo, ou seja, se eles não possuem interseção, então 
a probabilidade de que se aconteça o evento $A$ ou o evento $B$ deve ser igual à soma das probabilidades de ocorrência de $A$ e de $B$.

Outra concepção intuitiva diz que a probabilidade de que nada aconteça tem que ser igual a zero; ao mesmo tempo, a probabilidade de que aconteça qualquer coisa tem que ser igual a um. Por fim, uma outra concepção intuitiva diz que a probabilidade de que o evento $A$ não aconteça é igual à probabilidade de que qualquer coisa aconteça com exceção de $A$, ou seja, um menos a probabilidade de ocorrer o evento $A$.

Estas três concepções implicam toda a definição de um modelo matemático de probabilidades de ocorrência de fenômenos aleatórios para uma coleção de subconjuntos de um conjunto completo (correspondente ao evento "acontecer qualquer coisa") se este for fechado em relação às operações de união, interseção e complemento e contiver os conjuntos vazio (o evento "nada acontecer") e também o próprio conjunto completo.

Para tornar a discussão um pouco mais precisa, apresentamos uma definição matemática para o significado do conjunto completo a que nos referimos, o qual doravante será denominado de espaço amostral:

DEFINIÇÃO 4.1. - O conjunto $\Omega$ é chamado de espaço amostral se este possui todos os possíveis resultados para um possível experimento aleatório. Por exemplo, o experimento de se lançar um dado possui como seu espaço amostral o conjunto $\Omega=\{1,2,3,4,5,6\}$. conjunto total de cenários possíveis apresentado no segundo capítulo também é um exemplo de espaço amostral.

Também é importante definirmos o significado do conceito de fechado em relação a operações com conjuntos. Para isso, definimos de forma mais precisa a coleção de subconjuntos do espaço amostral que estamos interessados em estudar.

DEFINIÇÃO 4.2. - Seja $\Omega$ um conjunto e $\Sigma$ uma coleção de subconjuntos de $\Omega$. Chamamos $\Sigma$ de $\sigma$-álgebra sobre $\Omega$ se $\Sigma$ possui as seguintes propriedades:

- O espaço amostral $(\Omega)$ pertence a $\Sigma$;

- Se o conjunto $E$ pertence a $\Sigma$; então o complemento de $E$ também pertence a $\Sigma$;

- Se $E_{l}, E_{2}, \ldots$ é uma seqüência em $\Sigma$ então sua união enumerável também está em $\Sigma$. 
A exigência de que a coleção de subconjuntos do espaço amostral seja fechada com relação à união enumerável é feita para atender a necessidade prática de estudar a probabilidade de limites de eventos. No caso do nosso estudo, essa necessidade surge no objetivo de aproximar a probabilidade de um certo evento envolvendo um processo em tempo contínuo por probabilidades de eventos envolvendo processos em tempo discreto. É claro que para poder formalizar qualquer afirmação que envolve, por exemplo, o conceito de limite, precisamos que a probabilidade possa ser atribuída não somente a cada conjunto da seqüência como também ao conjunto limite desta seqüência.

As considerações apresentadas no parágrafo anterior fazem com que o modelo matemático com o qual iremos trabalhar envolva a coleção de subconjuntos que forme uma $\sigma$-álgebra sobre o espaço amostral. Além disso, permite que uma probabilidade esteja definida para todos os conjuntos de tal coleção.

Durante o nosso trabalho não estaremos trabalhando com espaços amostrais de estruturas completamente genéricas. O espaço amostral com que trabalharemos tem uma propriedade especial, a qual nos permite definir uma nova estrutura matemática, conhecida pelo nome de espaço métrico. A definição formal de espaço métrico é dada a seguir:

DEFINIÇÃO 4.3. - Seja $\Omega$ um conjunto e $d$ uma função tal que, para quaisquer elementos $x, y \in \Omega$ temos que $d(x, y) \in \mathfrak{R}_{+}$. Chamamos o espaço $S=(\Omega, d)$ de espaço métrico e a função $d$ de métrica.

A idéia desta definição é simples: se para o conjunto $\Omega$ é possível medir a distância entre dois elementos quaisquer do mesmo, o par composto pelo conjunto e pela função em questão é chamado de espaço métrico. A métrica acima apresentada, apesar de parecer um tanto artificial e desnecessária, será importante para a definição do conceito de continuidade de uma função, o qual será muito utilizado no próximo capítulo. Além disso, nos espaços métricos de interesse estaremos focados em estudar uma $\sigma$-álgebra sobre o mesmo que é construída de maneira especial. A métrica, apesar de não ser essencialmente necessária para a construção desta $\sigma$-álgebra, nos auxiliará nesta tarefa. Para tal, considere a seguinte definição de conjunto aberto: 
DEFINIÇÃO 4.4. - Seja $\varsigma$ um subconjunto de um espaço métrico. Dizemos que $\varsigma$ é aberto se para cada ponto $x$ de $\varsigma$ é possível definir uma vizinhança de $x$ (ou seja, um conjunto de pontos $y$ tais que $d(x, y)<\varepsilon$ para algum $\varepsilon$ ) cujos pontos da mesma também estejam em $\varsigma$ (a vizinhança definida neste parágrafo também é conhecida como bola aberta de raio $\varepsilon$ ).

A $\sigma$-álgebra de nosso interesse é definida com base nos conjuntos abertos, conforme definido a seguir:

DEFINIÇÃO 4.5. - Seja $(\Omega, d)$ um espaço métrico. Considere a menor $\sigma$-álgebra que contenha todas as bolas abertas de $\Omega$. Denominamos esta por $\sigma$-álgebra de Borel sobre $\Omega$.

O conceito de "menor $\sigma$-álgebra" está relacionado ao sentido de inclusão. O leitor deve observar que, para uma dada coleção de subconjuntos de $\Omega$, existem diversas $\sigma$ álgebras que contenham esta coleção. Assim, a menor $\sigma$-álgebra que contenha a coleção de interesse é definida como a coleção de subconjuntos $A$ de $\Omega$ tais que $A$ pertence a cada uma das diversas $\sigma$-álgebras que contenham a coleção em questão. Em outras palavras, a menor $\sigma$-álgebra que contenha uma dada coleção é obtida pela interseção de todas as $\sigma$-álgebras que contenham tal coleção.

Até o momento citamos várias vezes que iremos atribuir probabilidades a eventos, mas sem dar a definição formal de probabilidade para o nosso modelo matemático. Com base nas primeiras definições deste capítulo, podemos agora definir uma medida de probabilidade como segue:

DEFINIÇÃO 4.6. - Suponha que temos um experimento aleatório, com espaço amostral $\Omega$. Uma medida de probabilidade $P$ é uma função de valores reais definida em uma $\sigma$-álgebra $\Sigma$ que satisfaz os seguintes axiomas:

- $P(A)$ é não negativa para qualquer evento $A \in \Sigma$;

r Se $A_{i}, i=1,2, \ldots$ é uma coleção enumerável de elementos disjuntos dois a dois, então:

$$
P\left(\bigcup_{i=1.2 \ldots} A_{i}\right)=\sum_{i=1.2 \ldots} P\left(A_{i}\right)
$$


> $P(\Omega)=1$ (e portanto, do axioma anterior, temos que $P(\varnothing)=0$ ).

Se a função $P$ não satisfizer apenas a exigência de que $P(\Omega)=1$, ainda poderemos dizer que esta função é uma medida. Neste caso, $P(\Omega)$ poderá assumir qualquer valor, inclusive $+\infty$, como na medida de Lebesgue para o conjunto dos números reais.

Após definirmos todos os elementos básicos do nosso modelo matemático, precisamos definir as ferramentas a serem utilizadas nos cálculos envolvidos neste modelo. O conceito de integral de Riemann é bastante utilizado em cálculo e estatística básica. Como ilustrado na Figura 6, ao calcular a integral de Riemann de uma função em um intervalo, estamos particionando o mesmo em diversos sub-intervalos de comprimento infinitesimal $d x$ e somando as diversas áreas abaixo da curva da função, obtidas pelo produto do valor da função pelo comprimento do intervalo, ou seja, $f(x) d x$. O particionamento é feito no domínio da função.

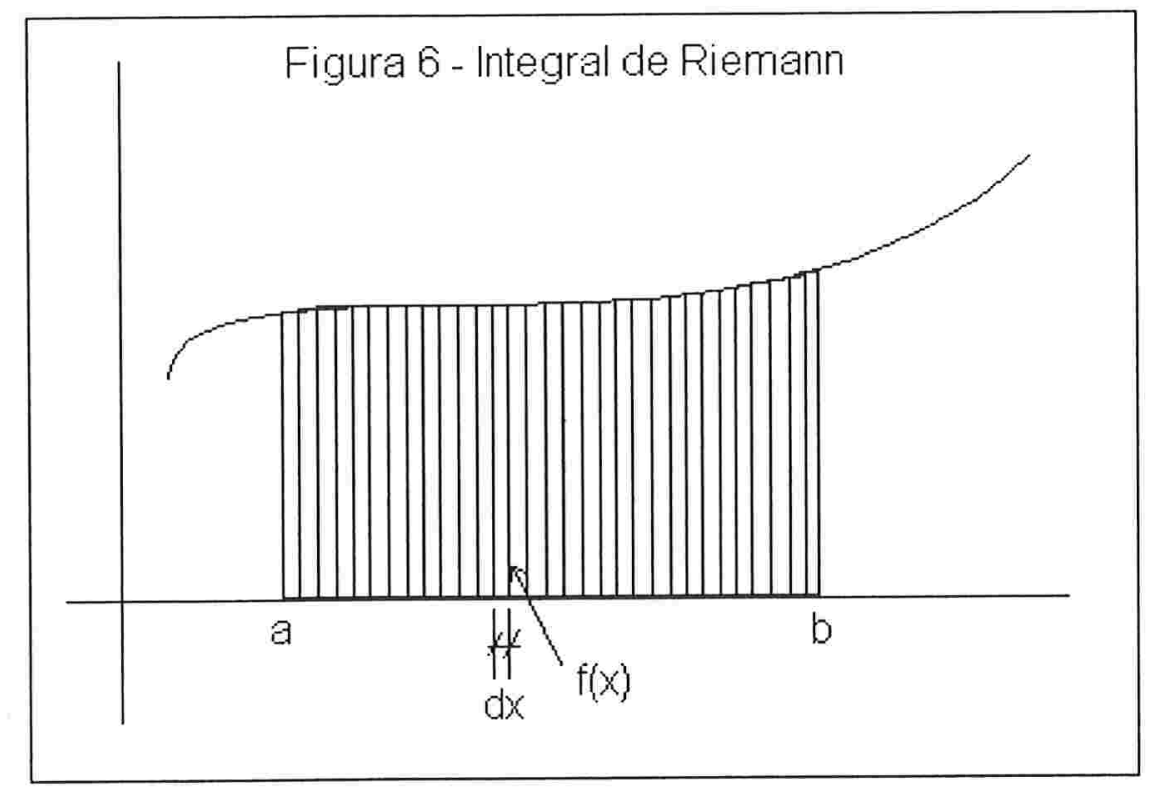

Todavia o comportamento da integral de Riemann quando se deseja trabalhar com teoremas limite ou com determinadas funções é difícil de analisar, sendo em alguns casos nem mesmo definido. Este tipo de análise é de vital importância quando trabalhamos com séries de Fourier, transformadas ou mesmo em outros casos de estatística avançada. 
Destarte, a integral de Lebesgue foi definida de modo um pouco diferente, mais fácil de calcular, para viabilizar estas situações.

Conforme ilustrado na Figura 7, ao calcular uma integral de Lebesgue de uma função sobre um intervalo, estamos particionando a imagem da função neste intervalo em diversas partes de comprimento infinitesimal onde, para cada parte, a função tem aproximadamente o mesmo valor. Para cada uma destas partes da imagem encontramos o sub-intervalo correspondente do domínio da função e calculamos o seu comprimento. O valor da integral será a soma das diversas áreas obtidas com o produto do comprimento do intervalo pelo valor da função neste intervalo.

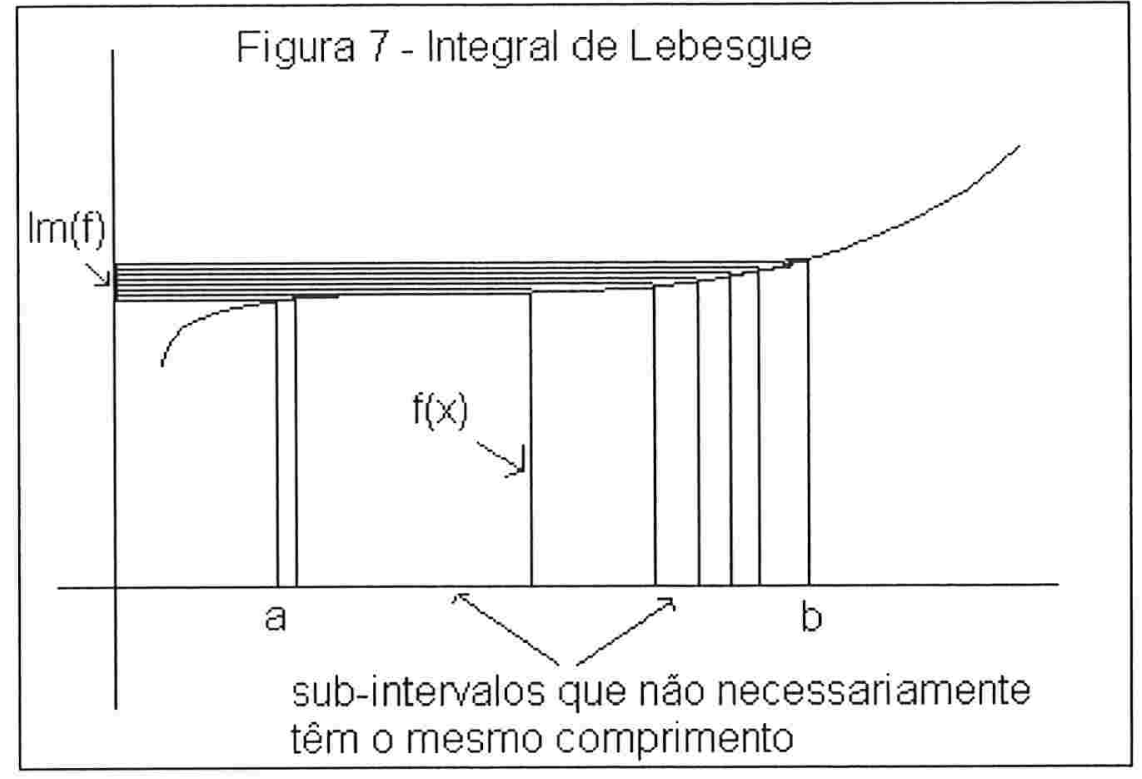

A integral de Lebesgue pode ter o seu conceito generalizado, podendo ser calculada sobre não só um intervalo como também sobre mas com qualquer subconjunto do domínio da função - na verdade sobre qualquer espaço. Além disso, não é necessário usarmos sempre o comprimento do intervalo para o cálculo da integral. De fato, qualquer medida pode ser utilizada para o cálculo da integral de Lebesgue.

A notação utilizada para uma integral de Lebesgue de uma função $f$, sobre um espaço $\Omega$ utilizando uma medida $P$ é:

$$
\int_{\Omega} f d P
$$


Pelas figuras anteriores fica evidente que, se o espaço for um intervalo nos reais e a medida for o comprimento, as integrais de Riemann e de Lebesgue coincidem. No entanto, isto só é válido para funções contínuas. No caso de outras funções, nem sempre isto é válido, como veremos no exemplo a seguir.

Considere $f *(x)$, para $x$ real, definida como:

$$
f *(x)=\left\{\begin{array}{llc}
1 & \text { se } & x \in \text { irracionais } \\
0 & \text { se } & x \in \text { racionais }
\end{array}\right.
$$

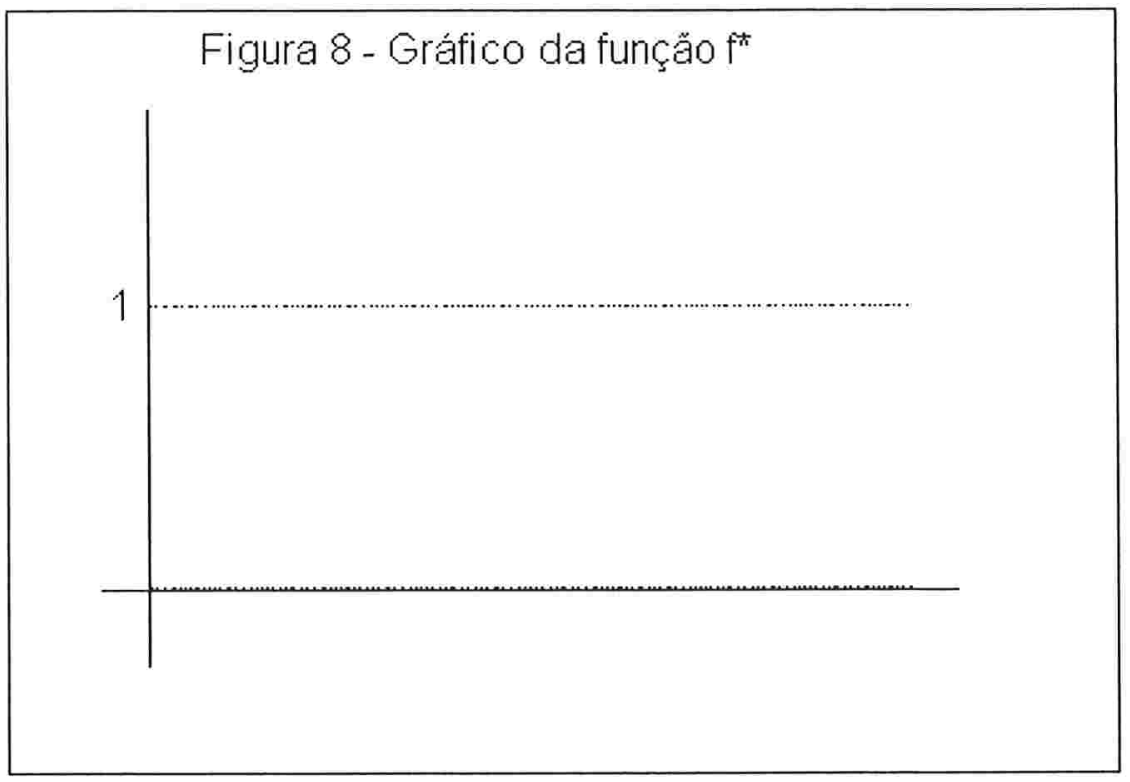

Para esta função,

$$
\int_{0}^{1} f^{*}(x) d x \text { não é definido }
$$

Mas, tomando $\Omega=[0,1]$ e $P$ o comprimento do intervalo, temos que:

$$
\int_{\Omega} f * d P=1
$$

Esta diferença se deve ao fato de a definição formal da integral de Riemann rezar que, particionando o intervalo de integração em diversos intervalos $\left[x_{i}, x_{i+1}\right)$ de comprimento infinitesimal como apresentado na Figura 9, temos que

$$
\sum_{i=1}^{n} f *\left(\alpha_{i}\right)\left|x_{i+1}-x_{i}\right| \rightarrow \int_{x_{1}}^{x_{n}} f *(x) d x
$$

para qualquer $\alpha_{i} \in\left[x_{i}, x_{i-1}\right)$, independente da escolha dos $\alpha_{i}$ 's. 


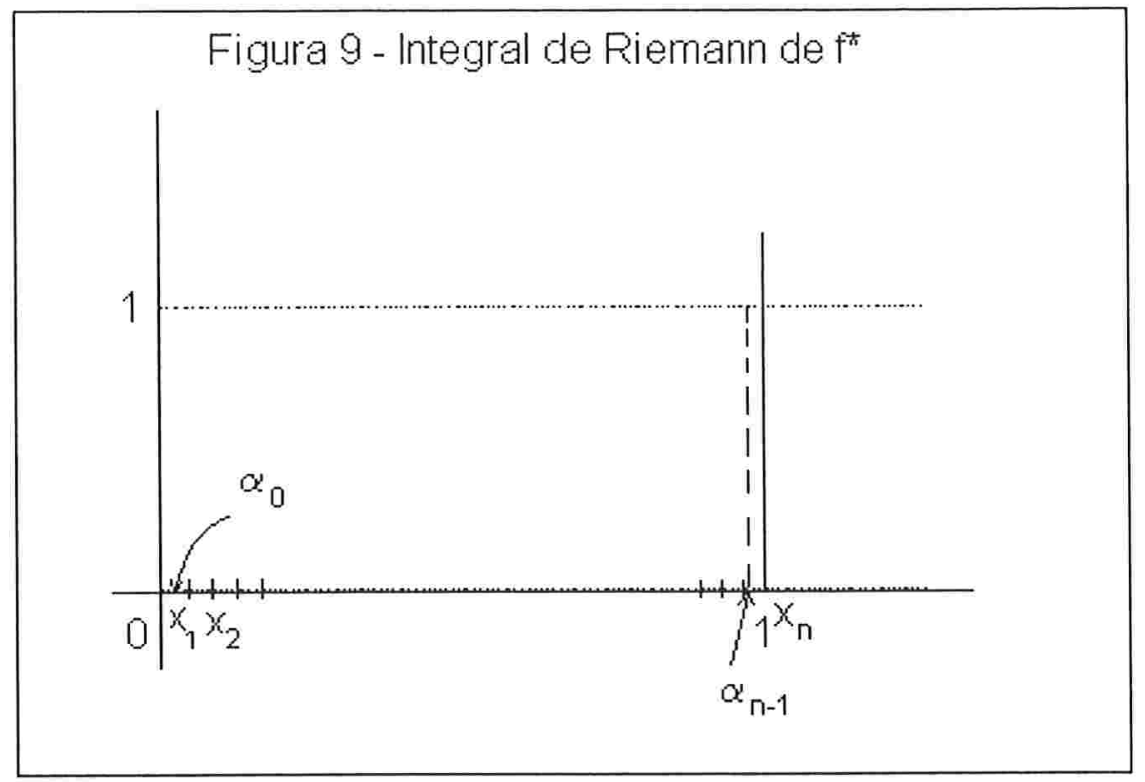

No entanto, neste caso se escolhermos todos os $\alpha_{i}$ 's irracionais, a soma definida em (4.1.2) converge para 1, e se escolhermos todos os $\alpha_{i}$ 's racionais, a soma converge para 0. Desta forma, não há convergência independente da escolha e portanto a integral de Riemann não é definida.

Para o cálculo da integral de Lebesgue, particionamos a imagem da função, que no caso é o conjunto formado pelos pontos $\{0,1\}$. O valor da integral será

$$
\begin{aligned}
& \int_{\Omega} f * d P=0 \cdot P\left[\omega: f^{*}(\omega)=0\right]+1 \cdot P\left[\omega: f^{*}(\omega)=1\right]= \\
& =1 \cdot P[\text { todos os pontos irracionais do intervalo }[0 ; 1)]=1
\end{aligned}
$$

A integral de Lebesgue será útil para definirmos a convergência que desejamos estudar no nosso modelo matemático, conforme apresentado a seguir:

DEFINIÇÃO 4.7. - Seja $S=(\Omega, d)$ um espaço métrico e $P$ é uma medida de probabilidade definida em $(\Omega, \Sigma)$, onde $\Sigma$ é a $\sigma$-álgebra de Borel sobre $\Omega$ (tomando a métrica $d$ para a obtenção das bolas abertas). Dizemos que uma seqüência de medidas de probabilidade $P_{n}$ converge fracamente para $P$ se: 


$$
\int_{S} f d P_{n} \rightarrow \int_{S} f d P
$$

para toda função $f$ limitada, contínua e real em $S$. Também podemos denotar que $P_{n} \Rightarrow P$.

A notação $\int_{S} f d P$ na verdade significa $\int_{\Omega} f d P$, lembrando que a métrica $d$ determina $\Sigma$, na qual, por sua vez esta definida a medida $P$. No entanto, a partir deste ponto utilizaremos para esta integral a notação $\int_{S} f d P$ apenas para mantê-la uniforme com a encontrada na literatura, em particular com os livros de Billingsley (1968) e Billingsley (1999).

Vamos agora definir todo o "ambiente de trabalho" do modelo matemático. Este ambiente também é conhecido como espaço de probabilidade e utiliza todas as definições dadas anteriormente:

DEFINIÇÃO 4.8. - Um espaço de probabilidade é uma tripla $(\Omega, \Sigma, P)$ onde $\Omega$ é um conjunto, $\Sigma$ é uma $\sigma$-álgebra sobre $\Omega$ e $P$ uma medida de probabilidade sobre $\Sigma$.

Este conceito pode ser visualizado melhor considerando o espaço de probabilidade associado ao lançamento de uma moeda justa. Neste caso, temos que:

$>\Omega=\{H, T\}$;

$>=\{\phi,\{H\},\{T\},\{H, T\}\} ; \mathrm{e}$

$>P$ é uma função tal que $P[\phi]=0, P[\{H\}]=P[\{T\}]=1 / 2, P[\{H, T\}]=1$.

Os conceitos de variável aleatória e distribuição de probabilidades estudados nos cursos de estatística básica também devem ser redefinidos para a nossa linguagem formal. Apresentamos nas próximas definições estes conceitos.

DEFINIÇÃO 4.9. - Seja $X$ um mapeamento de um espaço de probabilidade $\left(\Omega^{\star}, \Sigma^{*}, Q\right)$ em um espaço métrico $S=(\Omega, d)$. Se este mapeamento é mensurável, ou seja, $X^{-1}(A) \in \Sigma^{*}$ para todo $A \in S$ (e portanto $Q\left[X^{-1}(A)\right]$ é definido), então $X$ é um elemento aleatório. Além disso, tomando $d$ como a distância euclidiana, se $S=\mathfrak{R}^{1}$, diz-se que $X$ é uma variável aleatória e para $S=\mathfrak{R}^{k}$ diz-se que $X$ é um vetor aleatório. 
Voltemos ao exemplo do espaço de probabilidade associado ao lançamento de uma moeda justa. Se definirmos o mapeamento $X$ deste espaço aos reais correspondente a

$$
X=\left\{\begin{array}{lll}
1 & \text { se } & \text { cara }-H \\
0 & \text { se } & \text { coroa }-T
\end{array}\right.
$$

temos que $X$ definido em (4.1.3) é uma variável aleatória.

DEFINIÇÃO 4.10. - Seja $S=(\Omega, d)$ um espaço métrico, $\Sigma$ a $\sigma$-álgebra de Borel sobre $\Omega$ e $X$ um elemento aleatório definido pelo mapeamento do espaço de probabilidade $\left(\Omega^{*}, \Sigma^{*}, Q\right)$ no espaço métrico $S$. A distribuição de $X$ é a medida $P$ definida em $(S, \Sigma)$ tal que, para todo $A \in \Sigma, P[A]=Q\left[X^{-1}(A)\right]$.

Em nosso exemplo do lançamento de uma moeda justa, a distribuição de $X$ é a medida $P$ tal que $P(\omega: X(\omega)=0)=P[\{H\}]=1 / 2$ e $P(\omega: X(\omega)=1)=P[\{T\}]=1 / 2$.

Após as diversas definições dadas anteriormente, estamos aptos para definir a convergência em distribuição de variáveis aleatórias a partir de medidas de probabilidade.

DEFINIÇÃO 4.11. - Uma seqüência de elementos aleatórios $\left\{X_{n}\right\}$ converge em distribuição para o elemento aleatório $X$ se as distribuições $\left\{P_{n}\right\}$ de $\left\{X_{n}\right\}$ convergem fracamente para a distribuição $P$ de $X$. Denotamos esta convergência por $X_{n} \stackrel{D}{\longrightarrow} X$.

O leitor pode notar que a convergência em distribuição é um caso particular de convergência fraca. Um exemplo intuitivo da definição de convergência em distribuição dada acima é o mesmo que o dado ao final da Seção 3.1. Além deste tipo de convergência, durante o decorrer do capítulo utilizaremos outro conceito, definido a seguir.

DEFINIÇÃO 4.12. - Para um elemento aleatório a de um espaço métrico $S=(\Omega, d)$, se

$$
P\left[d\left(X_{n}, a\right) \geq \varepsilon\right] \stackrel{n \rightarrow \infty}{\longrightarrow} 0
$$

para todo $\varepsilon$ positivo, temos que $X_{n}$ converge em probabilidade para a, escrevendo:

$$
X_{n} \stackrel{P}{\longrightarrow} a
$$


A idéia central da convergência em probabilidade é que, para qualquer $\varepsilon$ positivo, é possivel achar um certo valor de $n$ tal que, a partir deste valor, a probabilidade de termos um valor de $X_{n}$ superior a $a+\varepsilon$ ou inferior a $a+\varepsilon$ tende a zero.

Podemos visualizar facilmente esta definição tomando $X_{n}$ como a seguinte seqüência de variáveis aleatórias:

$$
X_{n} \sim N\left(0, \frac{9}{n^{2}}\right)
$$

Conforme $n$ aumenta, a variância de $X_{n}$ é reduzida, apesar da média continuar a mesma. Para esta seqüência, $X_{I}$ é uma variável normal de média igual a zero e desvio padrão igual a três, $X_{2}$ é uma variável normal de mesma média, mas com desvio padrão igual a um e meio e assim por diante. Assim, quanto maior o valor de $n$, mais centrada em torno de sua média é a distribuição de $X_{n}$.

Tomemos $a$ igual a zero e $\varepsilon$ igual a 0,9 . Para $n$ igual a dois, temos que:

$$
P\left[d\left(X_{n}, a\right) \geq \varepsilon\right]=P\left[\left|X_{2}-0\right| \geq 0,9\right]=0,55
$$

Já para $n$ igual a oito, temos que:

$$
P\left[d\left(X_{n}, a\right) \geq \varepsilon\right]=P\left[\left|X_{8}-0\right| \geq 0,9\right]=0,016
$$

Enquanto que para $n$ igual quinze, verificamos que:

$$
P\left[d\left(X_{n}, a\right) \geq \varepsilon\right]=P\left[\left|X_{15}-0\right| \geq 0,9\right] \leq 10^{-5}
$$

A Figura 10 ilustra este conceito. Nesta figura, temos um gráfico de cinco realizações aleatórias de $X_{n}$, para $n$ variando de 1 a 8 . As realizações obtidas são plotadas em função de $n$. O intervalo da linha pontilhada é $[-0,9 ; 0,9]$.

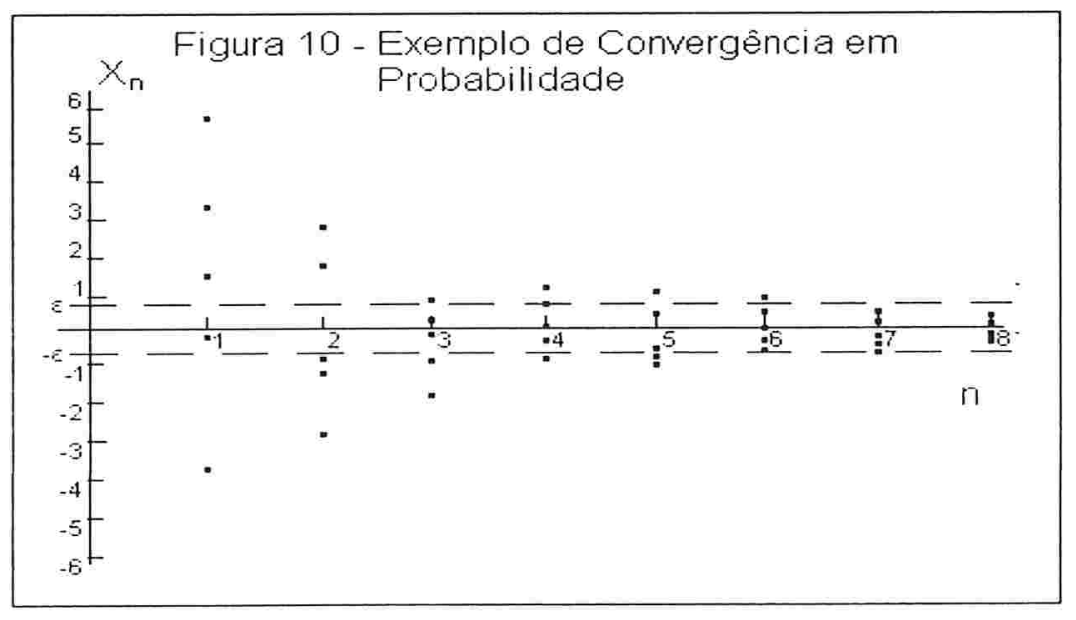




\subsection{Conceitos iniciais importantes de topologia}

As demonstrações dos teoremas das próximas seções exige um conhecimento prévio de topologia comum a quase todas as hipóteses assumidas. Definições específicas a um teorema em particular não serão apresentadas nesta seção, sendo apresentadas apenas quando forem necessárias. Estas definições também podem ser encontradas nos trabalhos de Munkres (2000), Billingsley (1968) e Billingsley (1999). Visto que o escopo deste trabalho está limitado a espaços métricos, as definições serão focadas a este tipo de estrutura, embora na matemática teórica formal estas definições sejam mais abrangentes.

DEFINIÇÃO 4.13. - Seja $Y$ um subconjunto de $S$. Uma coleção $C=\left\{C_{i}\right\}_{i=1,2 \ldots . . .}$ de subconjuntos de $S$ é uma cobertura de $Y$ se $Y \subset \bigcup_{i=1.2, \ldots} C_{i}$. Se todos os subconjuntos desta coleção são abertos, então dizemos que esta coleção é uma cobertura aberta de $Y$. Uma subcobertura da cobertura $C$ é uma coleção de subconjuntos de $C$ que também é cobertura de $Y$.

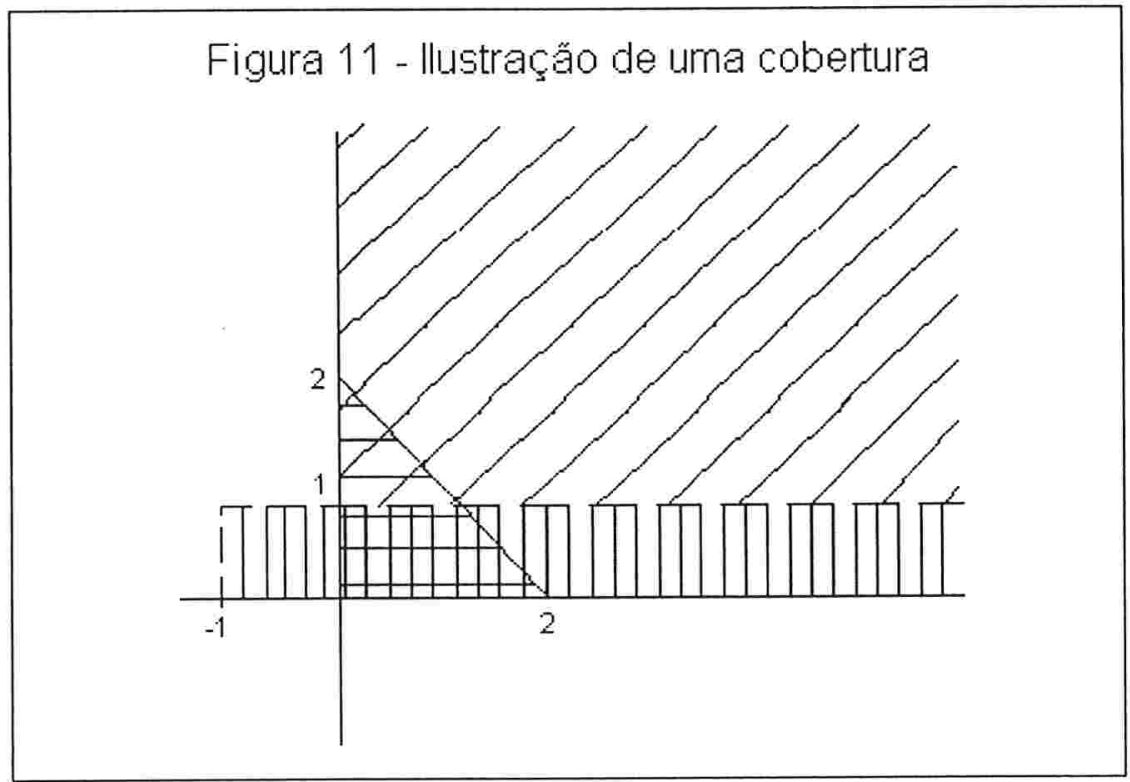


Um exemplo de cobertura é dado na Figura 11. Tomando ${ }^{3} S=\mathfrak{R}^{2}$ e $Y$ igual ao primeiro quadrante, temos que os conjuntos $C_{1}=\left\{(x, y) \in \mathfrak{R}^{2}: x \geq-1,0 \leq y \leq 1\right\}, C_{2}=$ $\left\{(x, y) \in \mathfrak{R}^{2}: x \geq 0, y \geq 1\right\}$ e $C_{3}=\left\{(x, y) \in \mathfrak{R}^{2}: x+y \geq 2, x \geq 0, y \geq 0\right\}$ formam uma cobertura de $Y$. A área em azul na figura corresponde ao conjunto $Y$. A área com listras verticais engloba o conjunto $C_{1}$, a área com listras transversais engloba o conjunto $C_{2}$ e a área com listras horizontais engloba o conjunto $C_{3}$. Note que a área da união destes três conjuntos "cobre" a área do conjunto $Y$.

Além disso, é possível verificar que $C_{1}, C_{2}$ e $C_{3}$ "cobrem" $Y$ com folga. Mesmo que retirarmos o conjunto $C_{3}$ da cobertura ainda poderemos com os conjuntos $C_{1}$ e $C_{2}$ "cobrir" a área de $Y$ e, desta forma, temos que $C_{1}$ e $C_{2}$ formam uma subcobertura de $C_{1}, C_{2}$ e $C_{3}$.

Outras definições de propriedades de conjuntos importantes para o nosso modelo matemático são dadas a seguir:

DEFINIÇÃO 4.14. - Um subconjunto $A$ de um espaço $S$ é denso se o único subconjunto fechado de $S$ contendo $A$ é o próprio $S$. Isto também significa que o fecho de $A$ é $S$.

Em outras palavras $A$ é denso em $S$ se qualquer ponto de $S$ pode ser aproximado por um ponto de $A$ com qualquer nível de precisão. Um exemplo clássico de um subconjunto denso é o conjunto dos números racionais, que é denso nos reais.

DEFINIÇÃO 4.15. - Um espaço S é dito separável se ele contém um subconjunto denso e enumerável.

Informalmente, podemos dizer que um espaço é separável se for possível construir uma lista de elementos deste espaço suficiente para aproximar qualquer elemento do

${ }^{3}$ Como já apresentado, para que um espaço métrico seja bem definido, além do conjunto devemos citar a métrica entre estes elementos. No caso de $\mathfrak{R}^{n}$, habitualmente omite-se a referência à métrica, deixando implícito que a função em questão é $d=|x-y|=\sqrt{\sum_{i=1}^{k}\left(x_{i}-y_{i}\right)^{2}}$. Doravante, ao se omitir a métrica e os conjuntos em questão forem os reais e/ou os racionais, deve-se entender que a métrica em questão é a padrão supracitada, ou seja, a igualdade $S=\Re^{2}$ deve ser entendida como $S=\left(\Re^{2} \cdot d\right)$ Novamente, esta simplificação na notação tem o objetivo de torná-la mais uniforme com a apresentada nos livros de Billingsley (1968) e Billingsley (1999). 
mesmo com a precisão que for desejada. Esta definição não é muito restritiva; de fato, a maioria dos espaços que conhecemos são separáveis. $\mathfrak{R}^{n}$ é separável, visto que possui um subconjunto denso e enumerável - os racionais.

DEFINIÇÃO 4.16. - Uma seqüência $\left\{x_{n}\right\}$ é dita fundamental ou de Cauchy se

$$
\sup _{i . j \geq n} d\left(x_{i}, x_{j}\right) \rightarrow_{n} 0 \text {. }
$$

Conforme ilustrado na Figura 12, uma seqüência com esta propriedade é uma seqüência que converge para algum ponto. No caso da ilustração, a seqüência converge para o ponto $\boldsymbol{x}^{*}$. Esta tipo de seqüência já é bastante comum ao leitor de maior familiaridade com cálculo.

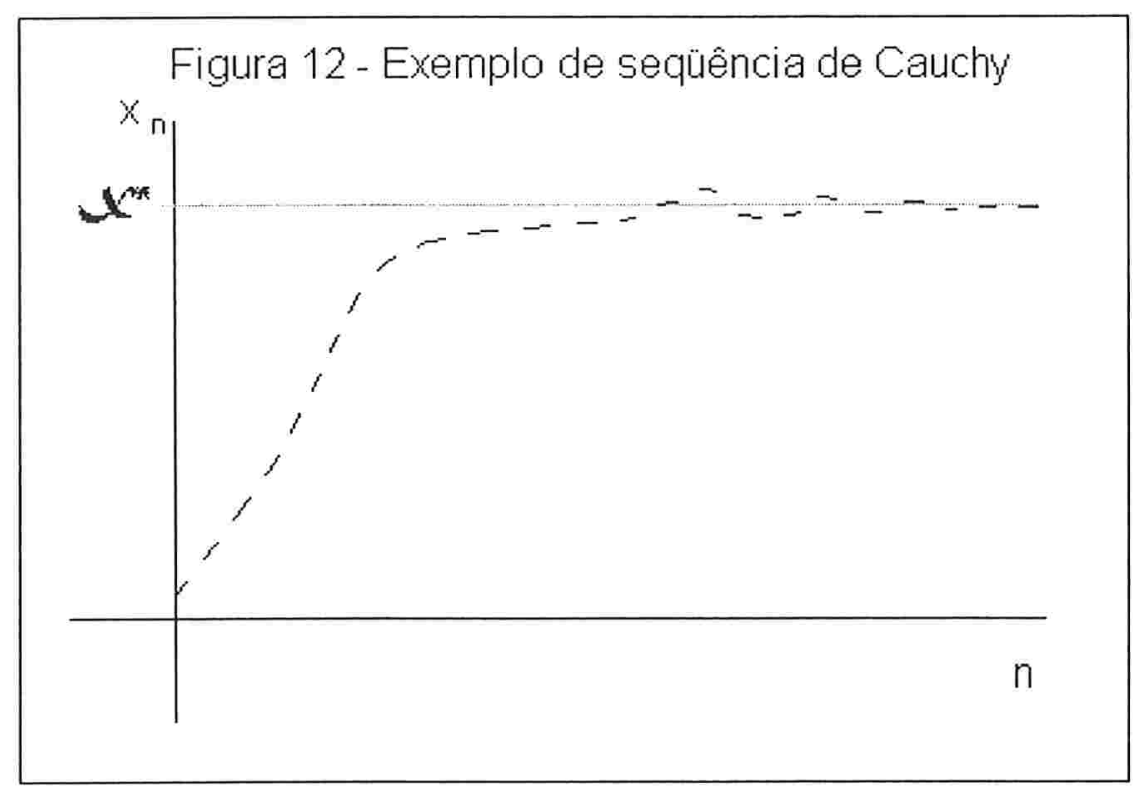

DEFINIÇÃO 4.17. - Um espaço $S$ é dito completo se qualquer seqüência de Cauchy em $S$ tem seu limite em $S$, ou seja, converge para um ponto de $S$.

Os racionais são um exemplo de um espaço que não é completo. Para verificar isto, tomemos como exemplo a conhecida série de Gregory e Leibniz: 


$$
x_{n}=4 \sum_{k=1}^{n} \frac{(-1)^{k+1}}{2 k-1}=\frac{4}{1}-\frac{4}{3}+\frac{4}{5}-\frac{4}{7}+\frac{4}{11}-\ldots
$$

Apesar da série definida em (4.2.2) apenas assumir valores racionais, é fato conhecido que esta série converge para $\pi$, que não é racional. Portanto, temos que os racionais não são um conjunto completo.

Intuitivamente podemos interpretar um espaço completo como um espaço tal que se andarmos por pontos deste conjunto nunca poderemos convergir a um "buraco", mas sim a um elemento do próprio conjunto. Entre dois números racionais sempre existirá um "buraco", correspondente a um número irracional. Por esta razão eles não são um conjunto completo. Como exemplo de conjunto completo temos os reais.

Todavia é importante salientar que a definição dada anteriormente depende fortemente da métrica definida para o espaço. Assim, um espaço métrico pode ser completo para uma métrica e não o ser para outra. Por exemplo, o espaço $S=\Re$ é completo para a métrica padrão, enquanto que para a métrica:

$$
d(x, y)=\left|\frac{1}{x}-\frac{1}{y}\right|
$$

este espaço não é mais completo. Para ver isso, basta tomar a seqüência:

$$
x_{n}=n^{2}
$$

para a qual, é fácil verificar que, quando $n$ tende ao infinito, a condição dada em (4.2.1) passa a ser válida, ou seja, a distância definida em (4.2.3) calculada entre dois pontos "próximos" tende a zero. No entanto, também é fácil verificar que esta seqüência não tem limite em $S$. Mais precisamente, esta seqüência não possui limite.

Uma propriedade semelhante é definida a seguir. Tal propriedade não depende mais da métrica, apesar de ser mais restritiva.

DEFINIÇÃO 4.18. - Um espaço S é dito compacto se toda cobertura aberta de $S$ possui uma subcobertura finita.

Em outras palavras, um espaço é compacto se ele for "pequeno" em um certo sentido e se ele contiver todos os seus pontos limites. As propriedades de compacto e completo são relacionáveis. Isto porque se $S$ é completo e existe um conjunto finito de pontos $P_{k}=\left\{x_{k}\right\}$ tal que para todo $\varepsilon$ positivo e para todo $x$ em $S$ sempre há um elemento de $P_{k}$ com $d\left(x, x_{k}\right)<\varepsilon$ 
então pelo menos o fecho de $S$ é compacto (Hofmann (2004)). Por isto que em $\mathfrak{R}^{n}$ um subespaço é compacto se o mesmo for fechado e limitado, como a Figura 13 ilustra para $\Re^{2}$ com a métrica padrão. O fato deste conjunto ser fechado garante que ele continua completo e o fato dele ser limitado garante que ele é equivalente à união de um número finito de bolas abertas de centros $\left\{x_{k}\right\}$ e raio $\varepsilon$, já que $\mathfrak{R}^{n}$ é separável. Esta união faria o papel da subcobertura da definição.

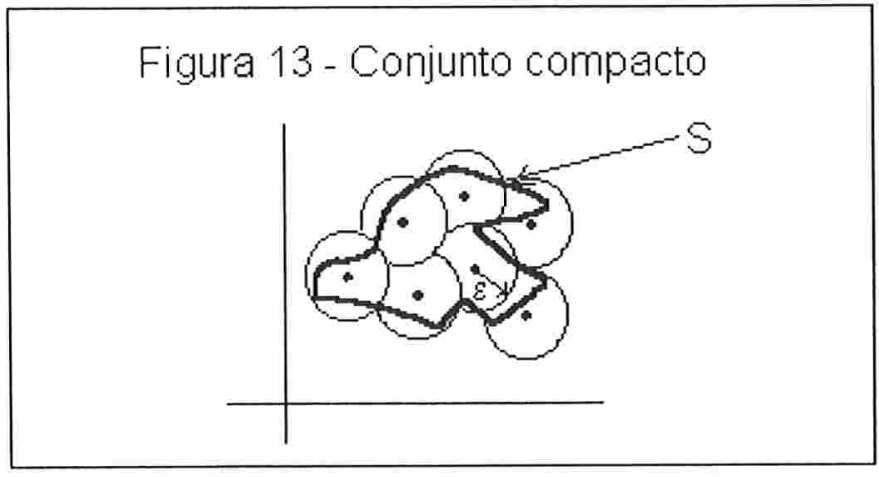

\subsection{A convergência fraca em espaços métricos}

Nosso objetivo nesta seção é estudar detalhadamente o conceito de convergência fraca, para no capítulo posterior demonstrarmos o Teorema 3.1. Para tanto, durante o resto do presente capítulo vamos utilizar a seguinte notação:

> $S=(\Omega, d)$ é um espaço métrico, e $d$ é sempre uma distância (ou métrica);

- $\Sigma$ é a $\sigma$-álgebra de Borel em S; e

> $(\Omega, \Sigma, P)$ é um espaço de probabilidade, onde $\Omega$ é o espaço amostral, $\Sigma$ é uma $\sigma$-álgebra sobre $\Omega$ e $P$ uma medida de probabilidade sobre $\Sigma$.

Também no decorrer deste capítulo, iremos sempre assumir que $S$ é separável e completo, embora parte dos teoremas a serem demonstrados valha mesmo que a hipótese assumida sobre $S$ não seja válida. Quando for necessária alguma propriedade mais restritiva, esta será apresentada no enunciado do teorema a ser demonstrado.

Teorema 4.1. Para todo $A \in \sum$ e $\varepsilon>0$ existe um conjunto fechado $F$ e um conjunto aberto $G$ tal que $F \subset A \subset G$ e $P(G-F)<\varepsilon$, onde $P$ é uma medida de probabilidade em $(S, \Sigma)$. 
Prova. Vamos primeiro considerar o caso em que $A$ é fechado. Seja $x$ um elemento de $S$ e $d(x, A)$ a distância entre $x$ e $A$. Agora tome $F=A$ e $G=[x: d(x, A)<\delta]$. Neste caso, temos que $G$ tende a $F$ quando $\delta$ tende a zero, ou seja, $G-F \downarrow \varnothing$ conforme $\delta \downarrow 0$. Assim, da definição de probabilidade (Definição 4.6), temos que $P(G-F) \downarrow 0$ conforme $\delta \downarrow 0$. Em outras palavras, para qualquer valor de $\varepsilon$ será possível encontrar um $\delta$ tal que $P(G-F)<\varepsilon$.

Considere agora a classe $\Gamma$ dos conjuntos $A$ tais que sempre exista um conjunto fechado $F$ e um conjunto aberto $G$ tal que $F \subset A \subset G$ e $P(G-F)<\varepsilon$ (ou seja, a classe dos conjuntos onde a propriedade deste teorema é satisfeita). Note que:

1) A união finita de elementos de $\Gamma$ está em $\Gamma$. Para verificar este fato, tome os conjuntos $A_{n} \in \Gamma, F_{n}$ fechados e $G_{n}$ abertos tais que $F_{n} \subset A_{n} \subset G_{n}$ e $P\left(G_{n}-F_{n}\right)<\varepsilon / 2^{n+1}$, e seja $F=\bigcup_{n \leq n_{n}} F_{n}$, com $n_{0}$ tal que $P\left(\bigcup_{n} F_{n}-F\right)<\varepsilon / 2$. Para $G=\bigcup_{n} G_{n}$, temos que $F \subset \bigcup_{n} A_{n} \subset G$. Além disso,

$$
\begin{gathered}
P(G-F)=P\left(\bigcup_{n} G_{n}-\bigcup_{n} F_{n}+\bigcup_{n} F_{n}-F\right)< \\
<P\left(\bigcup_{n} G_{n}-\bigcup_{n} F_{n}\right)+\varepsilon / 2 \leq P\left(\bigcup_{n}\left[G_{n}-F_{n}\right]\right)+\varepsilon / 2 \leq \\
\leq \sum_{n} P\left(G_{n}-F_{n}\right)+\varepsilon / 2=\sum_{n} \varepsilon / 2^{n+1}+\varepsilon / 2=\varepsilon / 2+\varepsilon / 4+\varepsilon / 8+\ldots+\varepsilon /(n+1)<\varepsilon .
\end{gathered}
$$

2) Se $A \in \Gamma$ então também $A^{C} \in \Gamma$. Isto é trivial, pois se existe um conjunto fechado $F$ e um conjunto aberto $G$ tal que $F \subset A \subset G$ e $P(G-F)<\varepsilon$, então $G^{C} \subset A^{C} \subset F^{C}$ e $P\left(F^{C}-G^{C}\right)<\varepsilon$, sendo que $G^{C}$ é um conjunto fechado e $F^{C}$ é um conjunto aberto.

Portanto, concluímos que a classe $\Gamma$ é uma $\sigma$-álgebra. Mas o leitor deve lembrar que a propriedade deste teorema é satisfeita por qualquer conjunto fechado $A \in \Sigma$. Portanto, a classe $\Gamma$ contém todos os conjuntos fechados $A \in \Sigma$.

Considere um conjunto fechado $F$ e tome o conjunto aberto $G_{n}=[x: d(x, F)<1 / n]$. Se $G_{n} \in \Sigma$, então $\bigcup_{n=1}^{\infty} G_{n}=F \in \Sigma$. Note que $\Sigma$ é a menor $\sigma$-álgebra gerada pelos subconjuntos abertos de $\Omega$ (Definição 4.5), e assim podemos concluir que todos os subconjuntos fechados de $\Omega$ também estão em $\Sigma$. Analogamente podemos concluir que todos os subconjuntos abertos de $\Omega$ também estão na menor $\sigma$-álgebra gerada pelos subconjuntos fechados (basta 
observar que qualquer conjunto aberto $G=\bigcup_{n=1}^{\infty} F_{n}$, com $\left.F_{n}=\left\lfloor x: d\left(x, G^{c}\right) \leq 1 / n\right\rfloor\right)$. Assim, concluímos que $\Sigma$ também é a menor $\sigma$-álgebra gerada pelos subconjuntos fechados de $\Omega$.

Como a classe $\Gamma$ contém todos os conjuntos fechados $A \in \Sigma$, concluímos que esta classe também contém a menor $\sigma$-álgebra gerada por estes. Mas do parágrafo anterior temos que esta $\sigma$-álgebra é $\Sigma$, e assim concluímos que $\Gamma$ contém $\Sigma$, ou seja, todo $A \in \Sigma$ satisfaz a propriedade do teorema.

O teorema anteriormente demonstrado também pode ser interpretado como segue: para qualquer conjunto $A$, é possível aproximar o valor de $P(A)$ por um valor de $P(F)$ com $F$ fechado, com o nível de precisão que for desejado.

Apresentamos no próximo teorema condições úteis equivalentes à convergência fraca; qualquer uma destas condições é equivalente à definição. O teorema também é conhecido como Teorema de Portmanteau.

Teorema 4.2. Sejam $P_{n}, P$ medidas de probabilidade em $(S, \Sigma)$. As seguintes afirmações são equivalentes:

(i) $\quad P_{n} \Rightarrow P$;

(ii) $\quad \lim _{n} \int_{S} f d P_{n}=\int_{S} f d P$ para toda função real $f$ limitada e uniformemente contínua em $S$;

(iii) $\quad \limsup _{n} P_{n}(F) \leq P(F)$ para todo conjunto fechado $F$;

(iv) $\quad \liminf _{n} P_{n}(G) \geq P(G)$ para todo conjunto aberto $G$;

(v) $\quad \lim _{n} P_{n}(A)=P(A)$ para todo conjunto $A$ tal que os pontos de sua fronteira tenham probabilidade zero (tais conjuntos também são conhecidos como conjuntos de $P$ continuidade.

Para entender estas condições, considere a medida de probabilidade $P$ definida em $\Re^{2}$ como:

$$
P(x)=\left\{\begin{array}{ccc}
1 & \text { se } & x=(1 ; 1) \\
0 & \text { demais } & \text { casos }
\end{array}\right.
$$


Ao mesmo tempo, seja $P_{n}$ a medida de probabilidade definida em $\Re^{2}$ como:

$$
P_{n}(x)=\left\{\begin{array}{ccc}
1 & \text { se } & x=(1+1 / n ; 1-1 / n) \\
0 & \text { demais } & \text { casos }
\end{array}\right.
$$

E seja $P^{*}{ }_{n}$ a medida de probabilidade definida em $\mathfrak{R}^{2}$ como:

$$
P^{*}(x)=\left\{\begin{array}{ccc}
1 & \text { se } & x=(3 / 4 ; 1-1 / n) \\
0 & \text { demais } & \text { casos }
\end{array}\right.
$$

É fácil verificar que $P_{n}$ converge fracamente para $P$. Para tal, verifique na Figura 14 os pontos que formam uma reta pontilhada transversal (pontos em azul na versão colorida do presente texto), correspondentes à seqüência de pontos $x_{n}$ tais que $P_{n}$ vale um. Neste caso, os pontos em que a medida $P_{n}$ dá peso unitário se aproximam do ponto $x=(1 ; 1)$, que é o ponto para o qual $P$ dá peso unitário. Assim, para qualquer função real contínua, $\int_{S} f d P_{n}=1 \times f\left(x_{n}\right) \rightarrow 1 \times f(x)=\int_{S} f d P$, portanto a condição (ii) vale.

Considere agora os pontos que formam uma reta vertical (em vermelho na versão colorida), correspondentes à seqüência de pontos $x^{*}{ }_{n}$ tais que $P{ }^{*}$ vale um, e a função $f\left(x^{1} ; x^{2}\right)=\operatorname{sen}\left(x^{1}+x^{2}\right)$, limitada e uniformemente contínua em $\mathfrak{R}^{2}$. Neste caso,

$$
\int_{S} f d P *_{n}=1 \times f\left(x *_{n}\right) \rightarrow \operatorname{sen}(7 / 4) \neq \operatorname{sen}(2)=1 \times f(x)=\int_{S} f d P
$$

Assim, como não vale a condição (ii), temos que $P^{*}{ }_{n}$ não converge fracamente para $P$. De fato, neste caso $\lim _{n} \int_{S} f d P^{*}{ }_{n}=\int_{S} f d P$ somente para as funções $f$ tais que $f(1 ; 1)=f(3 / 4 ; 1)$. Como existem infinitas funções limitadas e uniformemente contínua em $\Re^{2}$ tais que isto não é válido, a condição (ii) não é válida e portanto não há a convergência. 


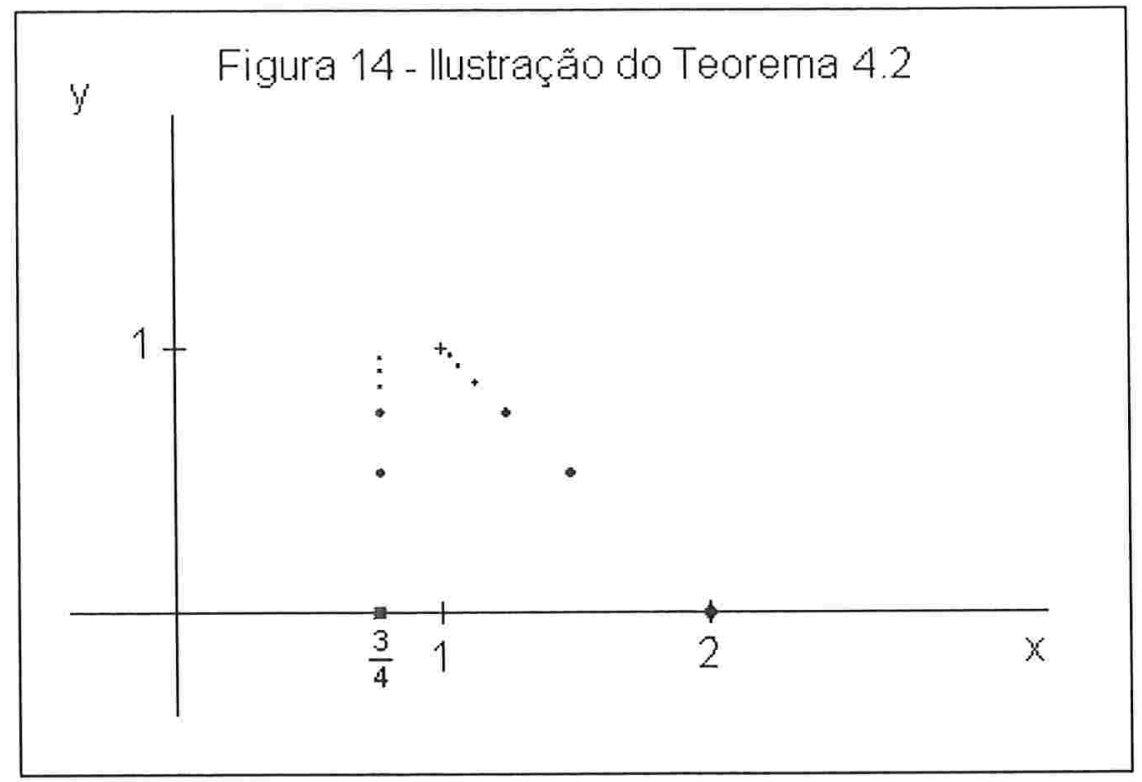

Prova do Teorema 4.2. A implicação (i) $\rightarrow$ (ii) é trivial, já que toda função limitada e uniformemente contínua também é contínua, e portanto esta implicação segue da definição de convergência fraca.

Para provar a implicação (ii) $\rightarrow$ (iii), tome qualquer $\varepsilon$ positivo e a função:

$$
g(x)=\max \{0 ; 1-d(x, F) / \varepsilon\}
$$

É fácil verificar que $\limsup _{n} P_{n}(F) \leq \limsup \int_{S} g d P_{n}$. Seja $F^{\varepsilon}=\{x: d(x, F)<\varepsilon\}$. Neste caso, $\int_{S} g d P \leq P\left(F^{\varepsilon}\right)$. Mas a condição (ii) implica que $\lim _{n} \int_{S} f d P_{n}=\int_{S} f d P$ para toda função $f$ limitada e uniformemente contínua, portanto $\limsup _{n} P_{n}(F) \leq \limsup \int_{S} g d P_{n}=$ $=\int_{S} g d P \leq P\left(F^{\varepsilon}\right)$. Se $F$ é fechado, então para $\varepsilon \downarrow 0$ temos a desigualdade dada em (iii). Já a equivalência entre (iii) e (iv) segue facilmente tomando o complemento.

Além disso (iii) \& (iv) $\rightarrow$ (v). Sejam respectivamente $A^{\circ}$ e $A^{\circ}$ o interior e o fecho de $A$. As condições (iii) e (iv) juntas implicam que:

$$
P\left(A^{-}\right) \geq \limsup { }_{n} P_{n}\left(A^{-}\right) \geq \limsup { }_{n} P_{n}(A) \geq \liminf _{n} P_{n}(A) \geq \liminf _{n} P_{n}\left(A^{o}\right) \geq P\left(A^{o}\right)
$$

Se $A$ é um conjunto de $P$-continuidade então $P\left(A^{-}\right)=P\left(A^{\circ}\right)=P(A)$ e portanto a implicação (v) é válida. 
Por fim, (v) $\rightarrow$ (i). Sem perda de generalidade, assuma que $0<f<1$. Então $\int_{S} f d P=\int_{0}^{\infty} P[f>t] d t=\int_{0}^{1} P[f>t] d t$, e similarmente o mesmo é válido para $\int_{S} f d P_{n}$. Se $f$ é contínua, então a fronteira do conjunto $[f>t]$ está contida no conjunto $[f=t]$ e portanto $[f>t]$ é um conjunto de $P$-continuidade exceto para um conjunto enumerável de $t$ 's. Assim, pela condição (v) e pelo Teorema da Convergência Limitada (Wheeden \& Zygmund (1977)), temos que:

$$
\int_{S} f d P_{n}=\int_{0}^{1} P_{n}[f>t] d t \rightarrow \int_{0}^{1} P[f>t] d t=\int_{S} f d P
$$

O Teorema 4.2 possui uma versão correspondente utilizando conceitos de elementos aleatórios, definidos anteriormente. Esta versão afirma que as seguintes afirmações são equivalentes:

(i) $\quad X_{n} \stackrel{D}{\longrightarrow} X$;

(ii) $\left.\lim _{n} E\left\{f\left(X_{n}\right)\right]\right\}=E\left\{\left[f\left(X_{n}\right)\right]\right\}$ para toda função real $f$ limitada e uniformemente contínua em $S$;

(iii) $\limsup _{n} P\left\{X_{n} \in F\right\} \leq P\{X \in F\}$ para todo conjunto fechado $F$;

(iv) $\quad \liminf _{n} P\left\{X_{n} \in G\right\} \geq P\{X \in G\}$ para todo conjunto aberto $G$;

(v) $\lim _{n} P\left\{X_{n} \in A\right\}=P\left\{X_{n} \in A\right\}$ para todo conjunto $A$ tal que a probabilidade de que $X$ pertença à fronteira de $A$ seja igual a zero (tais conjuntos também são conhecidos como conjuntos de $X$-continuidade.

Esta versão do Teorema 4.2 nos permite formular outro teorema, útil para a demonstração de convergência fraca para elementos aleatórios. No teorema a seguir, além da hipótese comum de que $S$ é separável, assumimos que, para cada $n, X_{n}$ e $Y_{n}$ são definidos no mesmo espaço amostral. Desta forma, é possível definir a distância $d\left(X_{n}, Y_{n}\right)$ - a função com valor $d\left(X_{n}(\omega), Y_{n}(\omega)\right)$ para um dado $\omega$.

Teorema 4.3. Se $X_{n} \stackrel{D}{\longrightarrow} X$ e $d\left(X_{n}, Y_{n}\right) \stackrel{P}{\longrightarrow} 0$ então $Y_{n} \stackrel{D}{\longrightarrow} X$.

Prova. Seja $F_{\varepsilon}=\{x: d(x, F) \leq \varepsilon\}$. Temos que $P\left\{Y_{n} \in F\right\} \leq P\left\{d\left(X_{n}, Y_{n}\right) \geq \varepsilon\right\}+P\left\{X_{n} \in F_{\varepsilon}\right\}$ e que, como $F_{\varepsilon}$ é fechado, pelo Teorema 4.2, $P\left\{X_{n} \in F_{\varepsilon}\right\} \geq \lim \sup _{n} P\left\{X_{n} \in F_{\varepsilon}\right\}$. Além disso, 
como $P\left\{Z \in F_{\varepsilon}\right\} \geq P\{Z \in F\}, \forall Z \quad$ e $d\left(X_{n}, Y_{n}\right) \stackrel{P}{\longrightarrow} 0$, também é válido afirmar que $\limsup \sup _{n} P\left\{X_{n} \in F_{\varepsilon}\right\} \geq \lim \sup _{n} P\left\{Y_{n} \in F\right\}$. Sem perda de generalidade, para $F$ fechado, então tomando $\varepsilon \downarrow 0$ temos que $F_{\varepsilon} \downarrow F$ e o resultado segue novamente pelo Teorema 4.2.

Tomando $X_{n} \equiv X$ obtemos o seguinte corolário:

Corolário 4.1. Para $X$ e $Y_{n}$ elementos aleatórios de $S$, se $d\left(X, Y_{n}\right) \stackrel{P}{\longrightarrow} 0$ então $Y_{n} \stackrel{D}{\longrightarrow} X$.

Prosseguindo com a apresentação dos teoremas básicos para a construção da nossa teoria, demonstramos o teorema a seguir:

Teorema 4.4. Seja $u$ uma subclasse de $\Sigma$. Se as três hipóteses abaixo são válidas:

(i) U é fechada sob a formação de interseções finitas;

(ii) cada conjunto aberto em $\Omega$ é uma união enumerável de elementos de $\mathscr{U}$; e

(iii) $\quad P_{n}(A) \stackrel{n \rightarrow \infty}{\longrightarrow} P(A)$ para todo $A$ em $u$.

Então $P_{n} \Rightarrow P$.

Prova. Considere os elementos $A_{l}, A_{2}, \ldots, A_{m}$ pertencentes à subclasse $u$. Pela fórmula de inclusão-exclusão,

$$
P_{n}\left(\bigcup_{i=1}^{m} A_{i}\right)=\sum_{i} P_{n}\left(A_{i}\right)-\sum_{i j} P_{n}\left(A_{i} A_{j}\right)+\sum_{i j k} P_{n}\left(A_{i} A_{i} A_{k}\right)-\ldots
$$

Mas, por (i), todas as interseções entre os elementos $A_{i}$ estão em $u$ e assim, por (iii), temos que (4.3.5) converge para $\sum_{i} P\left(A_{i}\right)-\sum_{i j} P\left(A_{i} A_{i}\right)+\sum_{i j k} P\left(A_{i} A_{j} A_{k}\right)-\ldots$ e portanto

$$
P_{n}\left(\bigcup_{i=1}^{m} A_{i}\right) \stackrel{n \rightarrow \infty}{\longrightarrow} P\left(\bigcup_{i=1}^{m} A_{i}\right) .
$$

Agora, considere um conjunto aberto $G$. Por (ii), $G=\bigcup_{i} A_{i}$ para alguma seqüência $\left\{A_{i}\right\}$ de elementos de $\mathcal{U}$. Conforme ilustrado na Figura 15 , para um dado $\varepsilon$ podemos obter um novo conjunto $G^{*}$ composto por quase todos os elementos da seqüência supracitada tal que sua medida de probabilidade só difira da medida de $G$ em uma quantia menor que $\varepsilon$, ou seja, 
$G^{*}=\bigcup_{i=1}^{m} A_{i}: P\left(G^{*}\right)>P(G)-\varepsilon . \quad$ Assim, aplicando (4.3.6), temos que $P(G)-\varepsilon<P\left(G^{*}\right)=\lim _{n \rightarrow \infty} P_{n}\left(G^{*}\right) \leq \liminf _{n} P_{n}(G)$. Como $\varepsilon$ foi escolhido arbitrariamente, podemos tomá-lo tendendo a zero, o que torna válida a condição (iv) do Teorema 4.2. $\square$

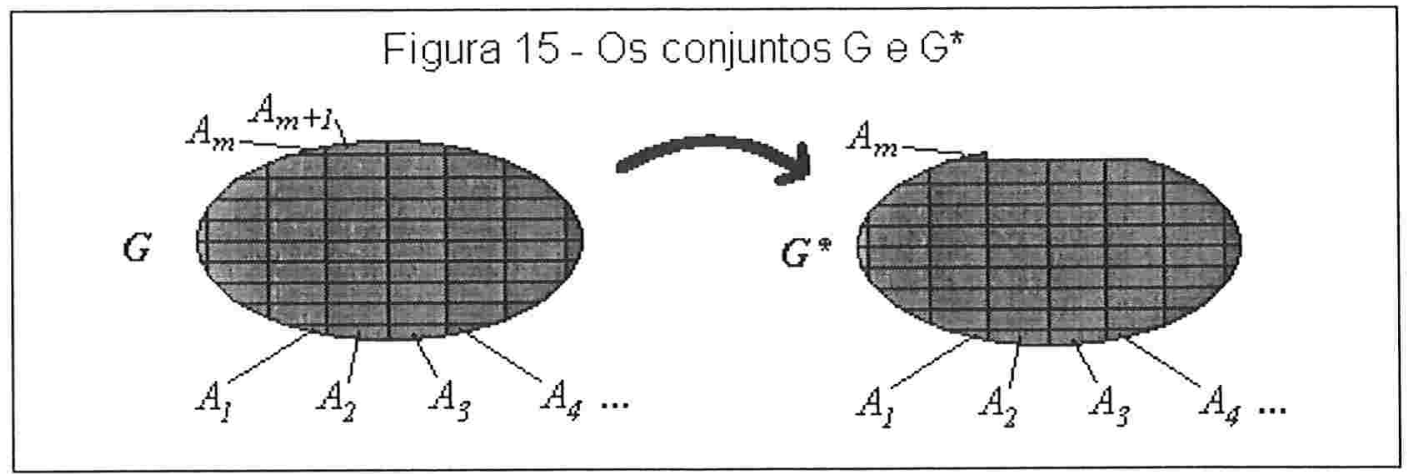

Uma aplicação prática do Teorema 4.4 está no espaço $\Re^{\infty}$, o espaço gerado pelas seqüências infinitas $x=\left(x_{1}, x_{2}, \ldots\right)$ de números reais (ou seja, cada ponto $x$ é uma seqüência). A vizinhança de um ponto em $\Re^{\infty}$ é definida pelos conjuntos da forma:

$$
N_{k, e}(x)=\left\{y:\left|x_{i}-y_{i}\right|<\varepsilon, \quad i=1, \ldots, k\right\} .
$$

DEFINIÇÃO 4.19. - Em $\Re^{\infty}$, chamamos de um conjunto de dimensões finitas um conjunto da forma $\pi_{k}^{-1} H$, onde $\pi_{k}$ é projeção natural de $\mathfrak{R}^{\infty}$ a $\mathfrak{R}^{k}$, definida por $\pi_{k}(x)=\left(x_{1}, \ldots, x_{k}\right)$, e $H \in \Re^{k}$.

Em outras palavras, $\pi_{k}^{-1} H$ é o conjunto das seqüências infinitas de números reais tais que o vetor $\left(x_{1}, \ldots, x_{k}\right)$ está em $H$. Tomando, por exemplo, $H \in \mathfrak{R}^{2}=[0 ; 1] \times[-1 ; 1]$, temos que $\pi_{k}^{-1} H$ é o conjunto das seqüências infinitas de números reais tais que $x_{l}$ está no intervalo $[0 ; 1]$ e $x_{2}$ está no intervalo $[-1 ; 1]$.

DEFINIÇÃO 4.20. - Dadas as medidas de probabilidade $P_{n}$ e $P$, dizemos que há convergência das distribuições de dimensões finitas de $P_{n}$ para as de $P$ se $P_{n}(A) \stackrel{n \rightarrow \infty}{\longrightarrow} P(A)$ para todos os conjuntos de dimensões finitas $A$. 
No espaço $\mathfrak{R}^{\infty}$, se houver convergência das distribuições de dimensões finitas de $P_{n}$ para as de uma determinada medida de probabilidade $P$, então $P_{n} \Rightarrow P$. Para verificar a validade desta afirmação, denote como 7 a classe dos conjuntos de dimensões finitas e $\mathbb{R}^{\infty}$ a menor $\sigma$-álgebra gerada por todos os conjuntos abertos de $\Re^{\infty}$. Para qualquer $H$ igual a um subconjunto aberto do $\mathfrak{R}^{k}$, é válido afirmar que $\pi_{k}^{-1} H=H \times \mathfrak{R}^{1} \times \mathfrak{R}^{1} \times \ldots \subset \mathfrak{R}^{\infty}$, ou seja $\pi_{k}^{-1} H$ é resultante do produto entre o conjunto $H$ e uma "cauda" qualquer, sendo que este produto está contido em $\mathfrak{R}^{\infty}$. Ou seja, $\pi_{k}^{-1} H \in \mathbb{R}^{\infty}$ e portanto $\exists$ é uma subclasse de $\mathbb{R}^{\infty}$.

Como $R^{\infty}$ é separável, para cada conjunto aberto $G$ de $R^{\infty}$ há em 7 uma seqüência finita ou infinita de conjuntos $\left\{A_{i}\right\}$, onde cada $A_{i}$ é subconjunto de $G$, tal que $G$ está contido no interior da união destes conjuntos, o que implica que $G$ é igual a união destes conjuntos. Ou seja, como cada conjunto da forma (4.3.7) está em $\exists$ e $R^{\infty}$ é separável, 7 gera $R^{\infty}$ e assim 7 satisfaz as condições necessárias para ser tomada como a classe $u$ do Teorema 4.4 .

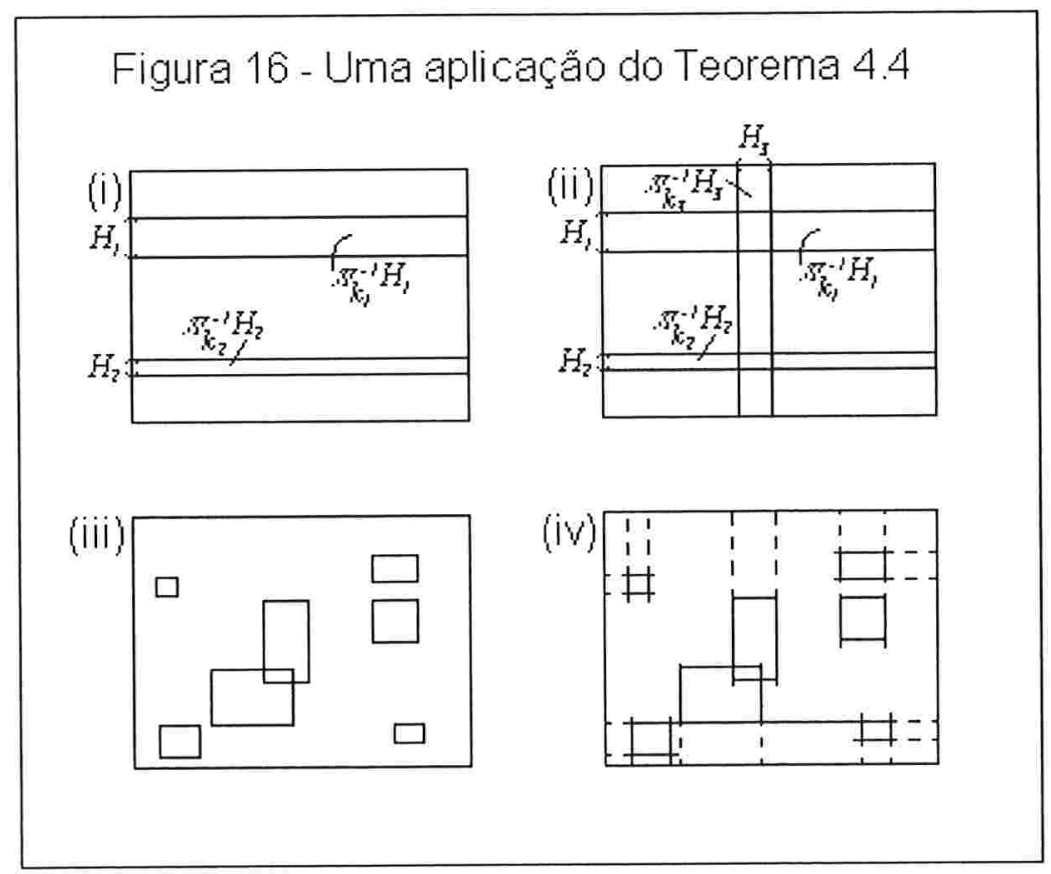

Para visualizar o que foi delineado no parágrafo anterior, considere o que é ilustrado na Figura 16. Nesta figura, o espaço $\mathfrak{R}^{\infty}$ é denotado por um quadrado. Nas bordas do 
quadrado teríamos os espaços $\mathfrak{R}^{k}$. Em (i), podemos ver os conjuntos $H_{1}$ e $H_{2}$, que seriam intervalos na borda do quadrado. Neste caso, a projeção $\pi$ (um dos conjuntos de dimensões finitas) seria a faixa horizontal gerada pelo conjunto da borda. Este conceito pode ser generalizado para todas as bordas, assim teríamos em (ii) o conjunto 7 , contendo todas as faixas - verticais e horizontais.

Em (iii) são ilustrados os conjuntos abertos do espaço, com a topologia retangular como dada em (4.3.7). No entanto, como pode ser visto em (iv), qualquer um destes conjuntos pode ser gerado por uma quantidade enumerável de interseções das faixas. O mesmo continuaria válido ainda que os conjuntos fossem circulares, visto que um círculo é uma união enumerável de retângulos. 


\section{A TEORIA DE CONVERGÊNCIA FRACA EM $C$}

\subsection{O espaço $C$}

Como já previamente dito, estamos interessados em estudar convergências de funções de trajetórias. Para tanto, vamos definir um novo espaço métrico onde seus elementos não são números nem vetores, e sim funções contínuas.

Seja $C=C[0,1]$ o espaço gerado por todas as funções contínuas $x(t)$ com domínio no intervalo [0;1]. Para um elemento $x^{+}$deste espaço, definindo a norma do mesmo como $\|x\|=\sup _{t}|x(t)|$ e para elementos $x$ e $y$, a distância entre estes dois elementos é definida como:

$$
d(x, y)=\|x-y\|=\sup _{t}|x(t)-y(t)| .
$$

As trajetórias apresentadas no terceiro capítulo introdutório (e ilustradas na Figura 4) são exemplos de funções pertencentes ao espaço $C$ se ajustadas para possuir domínio entre zero e um - na figura elas foram ajustadas para que seus respectivos domínios estivessem entre zero e cem. A convergência fraca entre estas trajetórias é o alvo do Teorema de Donsker, que será provado no final do presente capítulo.

Assim como os números reais, o espaço $C$ é separável. Para verificar isto, particione o intervalo $[0 ; 1]$ em $k$ subintervalos $I_{k i}=[(i-1) / k ; i / k]$. Seja $P_{k}$ o conjunto de funções $f$ tais que $f(i / k)$ é um número racional e que os demais pontos sejam interpolações lineares dos extremos de cada subintervalo. A Figura 17 ilustra dois elementos de $P_{k}$ para $k=8$. É fácil verificar que $\bigcup_{k} P_{k}$ é um conjunto enumerável, visto que os racionais são um conjunto enumerável. Além disso, seja $x$ um elemento qualquer de $C$ - ilustrado na Figura 18 como a linha preta. Como o intervalo [0,1] é compacto, qualquer função com domínio neste intervalo e que seja contínua também é uniformemente contínua, ou seja, sempre é possível, para qualquer valor de $\varepsilon$, escolher um valor de $k$ tal que $|x(t)-x(i / k)|<\varepsilon$, com $t \in I_{k i}, 1 \leq i \leq k$.

\footnotetext{
${ }^{4}$ Apenas para não tornar a notação extremamente carregada, em alguns momentos uma função $x(t)$ pertencente ao espaço $C$ pode ser referida apenas como $x$.
} 


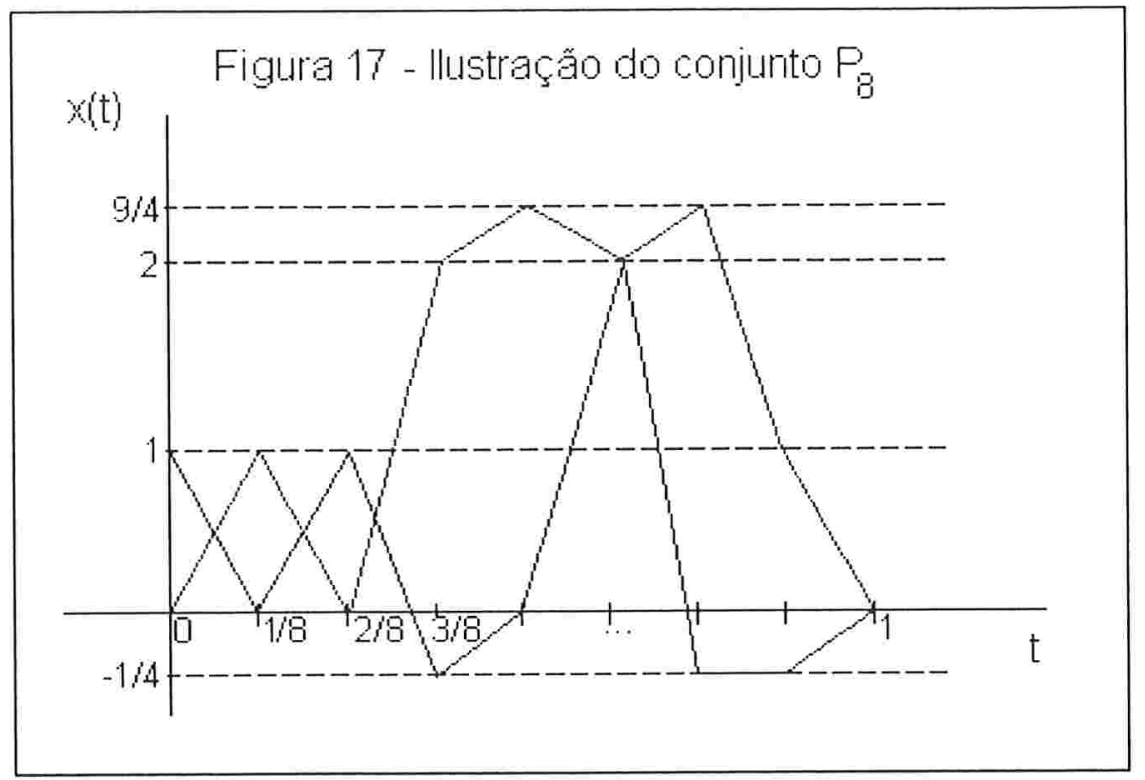

Assim, escolhendo $k$ da maneira citada no parágrafo anterior, é possível escolher $y \in P_{k}$ tal que $|y(i / k)-x(i / k)|<\varepsilon$ para cada $i$ - ilustrado na Figura 18 como a linha azul. Como também pode ser visto na mesma figura, $y(i / k)$ está a um raio de $2 \varepsilon$ de $x(t)$ para $t \in I_{k i}$, sendo o mesmo válido para $y((i-1) / k)$. Como $y(t)$ é uma combinação convexa de $y((i-1) / k)$ e $y(i / k)$, ele também está a um raio de $2 \varepsilon$ de $x(t)$, de modo que $d(x, y)=\sup _{t}|x(t)-y(t)| \leq 2 \varepsilon$, o que prova que $\bigcup_{k} P_{k}$ é denso em $C$ e portanto $C$ é separável.

O espaço $C$ também é completo: se $x_{n}$ é fundamental, o que ocorre se $\varepsilon_{n}=\sup _{m>n} d\left(x_{n}, x_{m}\right) \longrightarrow 0$, então, para cada $t,\left\{x_{n}(t)\right\}$ é fundamental na reta real, tendo portanto um limite $x(t)$. Assim, $\left|x_{n}(t)-x_{m}(t)\right| \longrightarrow m \rightarrow \infty\left|x_{n}(t)-x(t)\right| \leq \varepsilon_{n}$, portanto $x_{n}(t)$ converge uniformemente para $x(t)$, que está em $C$ pois $x$ é contínua, com $d\left(x_{n}, x\right) \rightarrow 0$.

Em $C$ os conjuntos de dimensões finitas são definidos de forma muito parecida com a dada na seção anterior para $\mathbb{R}^{\infty}$. Para defini-los, considere o conjunto $T=\left\{t_{1}, t_{2}, \ldots, t_{k}\right\}$ de pontos ordenados no intervalo $[0 ; 1]$ e seja $\pi_{T}$ o mapeamento que leva o ponto $x$ de $C$ ao ponto $\left(x\left(t_{l}\right), \ldots \ldots r\left(t_{k}\right)\right)$ de $\mathfrak{R}^{k}$. Os conjuntos de dimensões finitas são definidos como os conjuntos da forma $\pi_{T}^{-1} H$, com $H \in \Re^{k}$. 


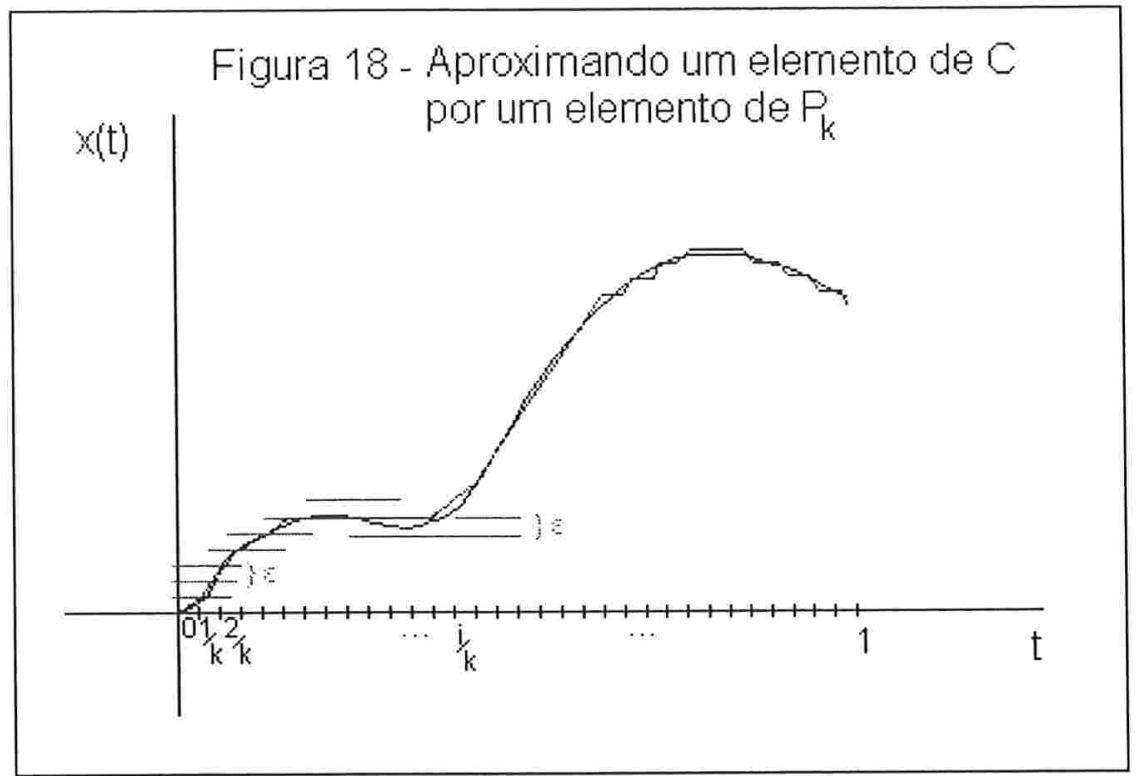

Isto significa que $\pi_{T}^{-1} H$ é o conjunto das funções contínuas $x(t)$ com domínio no intervalo $[0 ; 1]$ tais que o vetor $\left(x\left(t_{l}\right), \ldots, x\left(t_{k}\right)\right)$ está em $H$. Tomando, por exemplo, $H \in \mathfrak{R}^{2}=[0 ; 1] \times[-1 ; 1]$, temos que $\pi_{T}^{-1} H$ é o conjunto das funções contínuas com domínio no intervalo [0;1] que "passam por dentro" do intervalo [0;1] quando $t=t_{l}$ e que ao mesmo tempo "passam por dentro" do intervalo $[-1 ; 1]$ quando $t=t_{2}$.

No espaço $\mathfrak{R}^{\infty}$, vimos que se houver convergência das distribuições de dimensões finitas das medidas de probabilidade $P_{n}$ para as de uma determinada medida de probabilidade $P$, então $P_{n} \Rightarrow P$. O mesmo não é válido para o espaço $C$. Para verificar isto, considere a função:

$$
x_{n}(t)=n t I_{[0: 1 / n]}(t)+(2-n t) I_{(1 / n ; 2 / n]}(t),
$$

a qual está ilustrada na Figura 19. Note que, para qualquer $t$ no intervalo $[0 ; 1], x_{n}(t)$ converge para zero, o que significa que $x_{n}(t)$ converge para a função constante 0 pontualmente. No entanto, para todo $n, d\left(x_{n}, \mathbf{0}\right)=1$ pois para qualquer valor de $n$ existirá um valor de $t$ tal que $x_{n}(t)=1$.

Considere agora as medidas de probabilidade $P_{n}=\left\{1\right.$ para $x_{n}, 0$ para as demais $\}$ e $P=$ \{1 para a função constante 0, 0 para as demais\}. É fácil verificar que as distribuições de dimensões finitas de $P_{n}$ convergem para as de $P$, pois para qualquer seleção de intervalos $\left[a_{i}: b_{t}\right]$, a partir de um certo $n$ tendendo ao infinito, a função $x_{n}$ "passará por dentro" ou deixará de "passar por dentro" do intervalo $\left[a_{t} ; b_{i}\right]$ no instante $t$ somente se a função constante $\mathbf{0}$ 
também o fizer. Portanto, para qualquer seleção de intervalos $\left[a_{t} ; b_{t}\right]$, o valor da medida $P_{n}$ para o conjunto das funções que "passam por dentro" destes intervalos converge para o valor de $P$ para este mesmo conjunto.

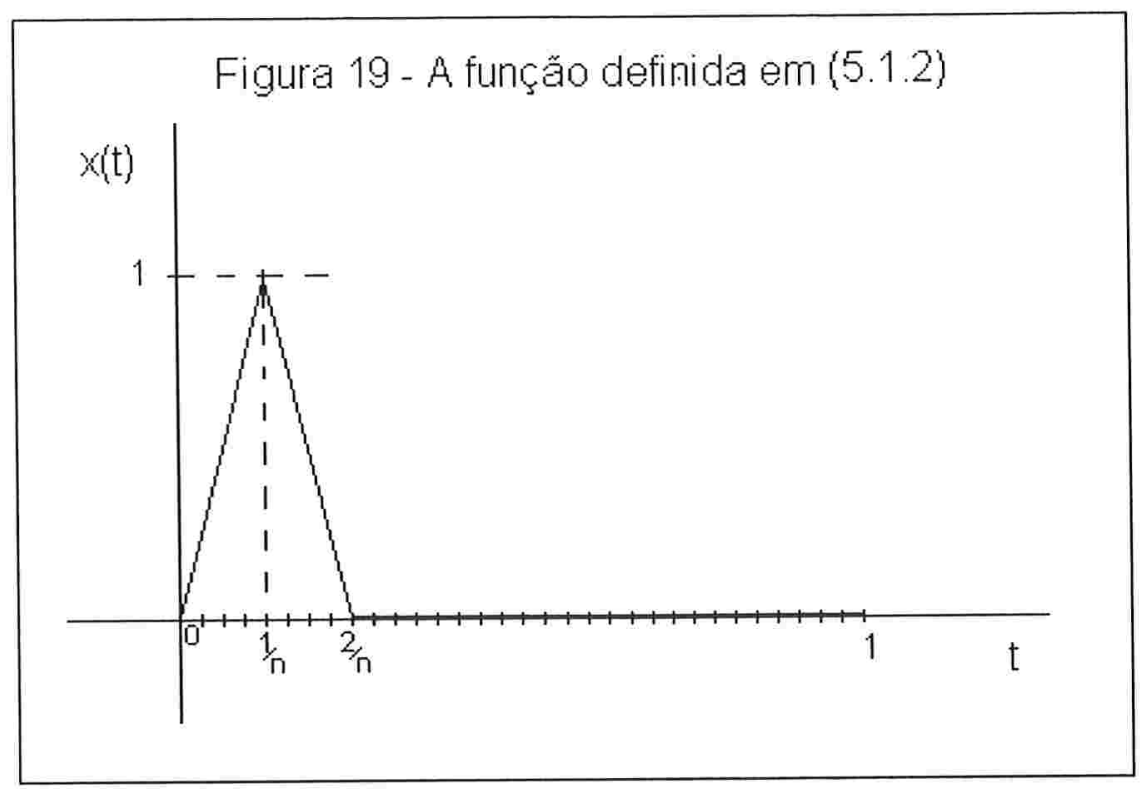

Isto está ilustrado na Figura 20, onde temos três intervalos selecionados arbitrariamente. Seja $A=\left\{x \in C: x\left(t_{1}\right) \in\left[a_{1} ; b_{1}\right], x\left(t_{2}\right) \in\left[a_{2} ; b_{2}\right], x\left(t_{3}\right) \in\left[a_{3} ; b_{3}\right]\right\}$. Em (i) é possível ver que a função $x_{8}$ "passa por dentro" dos três intervalos, pertencendo portanto ao conjunto $A$, o que implica $P_{S}(A)=1$. Mas a função constante 0 não "passa" pelo primeiro intervalo, o que implica $P(A)=0$. No entanto, (ii) mostra que a função $x_{16}$ já não "passa" mais pelo primeiro intervalo, o que implica $P_{20}(A)=P(A)=0$. Além disso, qualquer função $x_{n} \operatorname{com} n$ superior a 16 possui o mesmo comportamento, não "passando" pelo primeiro intervalo e "passando" pelos demais. Disto também fica claro que, mesmo trazendo o primeiro intervalo para qualquer lugar próximo do zero, é possível encontrar uma função $x_{n}$ que não "passará por dentro" dele. 


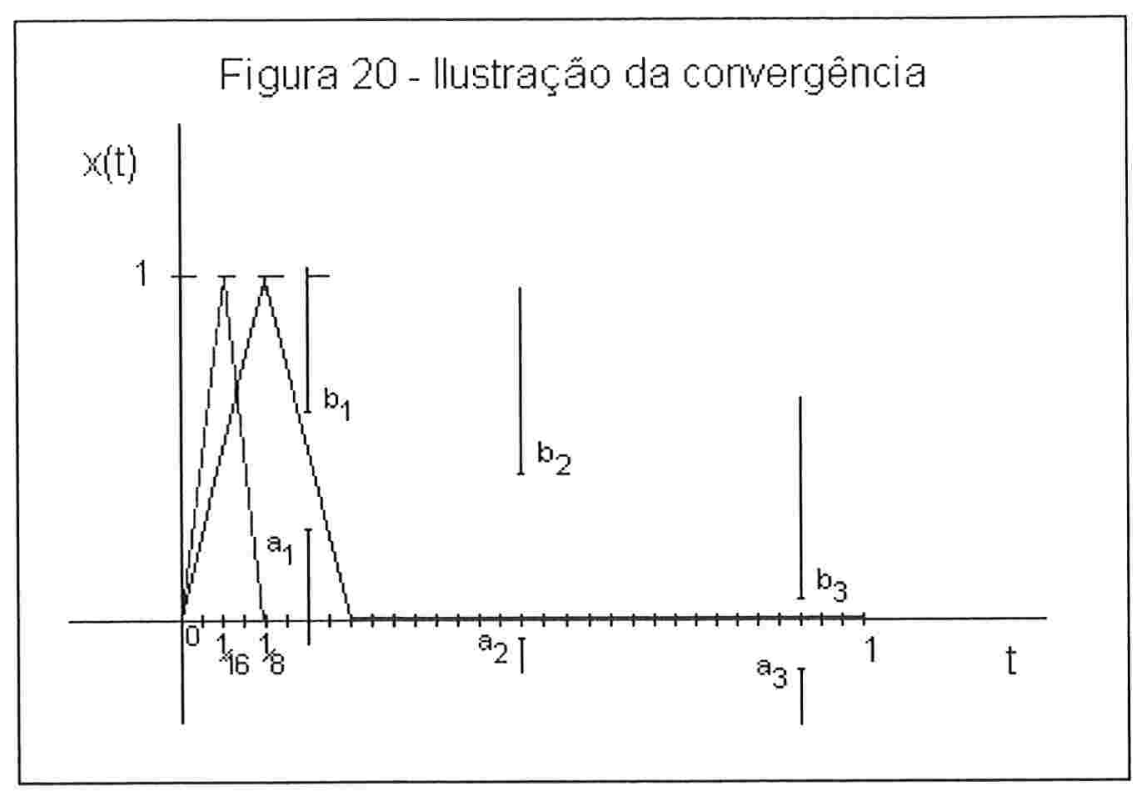

No entanto, apesar de haver a convergência entre as distribuições de dimensões finitas, não é verdade que haja a convergência fraca de $P_{n}$ para $P$. Para ver isto, considere a função $f^{*}: C \rightarrow \mathfrak{R}$ definida por $f^{*}(x)=1-d(x, \mathbf{0})$. Se houvesse a convergência fraca, então teríamos que:

$$
\int_{C} f d P_{n} \rightarrow \int_{C} f d P
$$

para toda função $f$ limitada, contínua e real em $C$. Mas, neste caso,

$$
\left.\int_{C} f * d P_{n}=f *\left(x_{n}\right) \cdot P_{n}\left(x_{n}\right)+f *(\text { demais funções }) \cdot P_{n} \text { (demais funções }\right)=1-d\left(x_{n}, \mathbf{0}\right)=0
$$

enquanto que

$$
\begin{aligned}
& \int_{C} f * d P=f *(\mathbf{0}) \cdot P(\mathbf{0})+f *(\text { demais funções }) \cdot P(\text { demais funções })=1-d(\mathbf{0 , 0})=1 . \\
& \text { Como } \int_{C} f * d P_{n} \neq \int_{C} f * d P, P_{n} \text { não converge fracamente para } P .
\end{aligned}
$$

Ao passarmos do espaço $\mathfrak{R}^{\infty}$ para o espaço $C$ (ou seja, ao passarmos de seqüências para funções reais), perdemos a garantia de convergência fraca com a convergência das distribuições de dimensões finitas. Intuitivamente, a causa desta perda está no fato de que uma seqüência é algo enumerável, não havendo nada entre o k-ésimo e o $(k+1)$-ésimo elementos de uma seqüência. Nas funções reais, mesmo que o conjunto dos números reais seja um conjunto separável, podendo assim ser aproximado por um conjunto 
enumerável, sempre haverá ao menos um ponto entre o k-ésimo e o $(k+1)$-ésimo pontos da aproximação, e neste ponto pode acontecer um "escape de massa", como no exemplo anterior. Desta forma, para que a convergência das distribuições de dimensões finitas determine uma convergência fraca em $C$, é necessário obtermos uma condição adicional garantindo que o "escape" citado também não esteja ocorrendo. Qual seria esta condição?

\subsection{Os conceitos de relativamente compacto e apertado}

É evidente que a condição que buscamos está relacionada às medidas de probabilidade para as quais desejamos provar a convergência. Se as medidas $P_{n}$ não atribuíssem massa às funções que geram este escape de massa (por exemplo, se estivéssemos estudando $P_{n}=\left\{1\right.$ para $x_{n}^{*}(t)=x_{n}(t) / n, 0$ para as demais $\left.\}\right)$ a convergência das distribuições de dimensões finitas teria sido condição suficiente para haver convergência fraca. A busca pela condição inicia-se na seguinte definição:

DEFINIÇÃO 5.1. - Seja П uma família de medias de probabilidade em $(S, \Sigma)$. Para uma dada medida de probabilidade $Q$, se toda seqüência $\left\{P_{n}\right\}$ em $\Pi$ contém uma subseqüência $\left\{P_{n(i)}\right\}$ tal que $P_{n(i)} \Rightarrow_{i \rightarrow \infty} Q$ dizemos que $\Pi$ é relativamente compacta.

Para entendermos no que esta condição pode nos ajudar, é necessário recorrermos a alguns conceitos de Teoria da Medida. Tais conceitos estão resumidos no teorema abaixo:

TEOREMA 5.1. Seja $\mathcal{C}$ uma coleção de subconjuntos do espaço amostral $\Omega$. Se $\mathcal{C}$ é fechado sob interseções finitas, dizemos que $C$ é um $\pi$-sistema. Já se $\Omega \in \mathcal{C}$, $C$ é fechado sob diferenças de dois elementos se um deles está contido no outro e $\ell$ é fechado sob uniões enumeráveis monotonamente crescentes, dizemos que $\ell$ é um $\lambda$-sistema. Dadas estas definições, as seguintes afirmações são válidas:

(i) Se $\ell$ é ao mesmo tempo um $\pi$-sistema e um $\lambda$-sistema, então $C$ é uma $\sigma$ álgebra.

(ii) Se $C_{1}$ é um $\pi$-sistema e $\varrho_{2}$ é um $\lambda$-sistema tal que $C_{1}$ está contido em $\varrho_{2}$, então a $\sigma$-álgebra gerada por $\mathcal{C}_{1}$ também está contida em $\ell_{2}$. 
(iii) Se duas medidas de probabilidade $P$ e $Q$ definidas em $(\Omega, \Sigma)$ coincidem em todos os elementos de $\mathcal{C}$, onde $\varrho$ é um $\pi$-sistema e $\Sigma$ é a menor $\sigma$-álgebra gerada por $\mathcal{C}$, então $P$ e $Q$ são iguais.

Prova de (i). Como $C$ é um $\lambda$-sistema, o espaço amostral pertence a $C$. Além disso, se o conjunto $E$ pertence a $\varrho$, então o complemento de $E$ também pertence a $\varrho$ visto que $E$ está contido no espaço amostral; portanto a diferença entre o espaço amostral e o conjunto $E$ (que é o complemento de $E$ ) também pertence a $C$ (pela segunda propriedade de um $\lambda$ sistema). Logo, resta apenas provar que se $E_{l}, E_{2}, \ldots$ é uma seqüência em $C$ então sua união enumerável também está em $e$.

Para tanto, considere os conjuntos $A_{n}=\bigcup_{i=1}^{n} E_{i}=\left(\bigcap_{i=1}^{n} E_{i}^{C}\right)^{C}$ (onde $c$ é o operador complemento). Tais conjuntos pertencem a $\mathcal{C}$, já que este é fechado sob interseções finitas (por ser um $\pi$-sistema) e também é fechado sob complementação, como já provado. Mas, $\left\{A_{n}\right\}$ é uma seqüência monotonamente crescente (visto que $A_{n-1}=\bigcup_{i=1}^{n-1} E_{i} \subset \bigcup_{i=1}^{n} E_{i}=A_{n}$ ) e portanto $\bigcup_{i=1}^{\infty} A_{i} \in e$. Como $\bigcup_{i=1}^{\infty} A_{i}=\bigcup_{i=1}^{\infty} \bigcup_{j=1}^{i} E_{i}==\bigcup_{i=1}^{\infty} E_{i}$, temos que a união enumerável dos conjuntos $E_{1}, E_{2}, \ldots$ também está em $\mathcal{C}$, o que completa a prova.

Prova de (ii). Seja $G$ o menor $\lambda$-sistema que contém $\ell_{1}$. Como toda $\sigma$-álgebra também é um $\lambda$-sistema, segue trivialmente que $G$ está contido na $\sigma$-álgebra gerada por $\ell_{1}$. Agora considere o conjunto:

$$
C_{1 \mathrm{~A}}=\left\{B \in G: B \cap A \in G \text {, para todo } A \in C_{1}\right\}
$$

Como $C_{1}$ é fechado sob interseções finitas, para todo $B$ que está em $\mathcal{C}_{1}$ sua interseção com $A$ também está em $\varrho_{1}$, estando também em $G$ visto que $G$ contém $\varrho_{1}$. Portanto $\varrho_{1 A}$ contém $C_{1}$. Além disso, $\varrho_{1 \mathrm{~A}}$ também é um $\lambda$-sistema pois:

- $\Omega \in \mathcal{C}_{1 \mathrm{~A}}$ uma vez que $\Omega \in G$ e quando $A \in \mathcal{C}_{1}, \Omega \cap A=A$ também pertence a $G$, já que $G$ contém $C_{1}$;

r para $B_{1}$ e $B_{2}$ em $C_{1 \mathrm{~A}}$ tais que $B_{1} \subset B_{2},\left(B_{2}-B_{1}\right) \cap A=\left(B_{2} \cap A\right)-\left(B_{1} \cap A\right)$, que está em $G$ (e, portanto, também em $C_{1 \mathrm{~A}}$ ) uma vez que $G$ é um $\lambda$-sistema e $\left(B_{1} \cap A\right) \subset\left(B_{2} \cap A\right) ; \mathrm{e}$ 
se $\left\{B_{n}\right\}$ é uma seqüência monotonamente crescente de conjuntos em $C_{1 \mathrm{~A}}$, então $\bigcup_{i=1}^{\infty}\left(B_{i} \cap A\right)=\left(\bigcup_{i=1}^{\infty} B_{i}\right) \cap A=B \cap A, \operatorname{com} B=\bigcup_{i=1}^{\infty} B_{i}=\lim _{n \rightarrow \infty} B_{n}$, e portanto sua união enumerável está em $\ell_{1 A}$.

Pela definição de $G$ como o menor $\lambda$-sistema que contém $\ell_{1}$, temos que $G$ está contido em $C_{1 A}$, o que implica que $B \cap A \in G$ para quaisquer $A \in C_{1}$ e $B \in G$. Agora considere o conjunto:

$$
C_{2 \mathrm{~A}}=\{B \in G: B \cap A \in G \text {, para todo } A \in G\}
$$

Como todo $A$ que está em $G$ também está em $\ell_{1}$ e, como provado no parágrafo anterior, para qualquer $A \in \mathcal{C}_{1}, B \cap A \in G$ quando $B \in G$, temos que $\varrho_{2 A}$ contém $C_{1 A}$. Mas, como já provado, $e_{1 \mathrm{~A}}$ contém $\ell_{1}$, o que implica que $\varrho_{1} \subset \varrho_{2 A}$. Além disso, seguindo um procedimento análogo ao efetuado para $C_{1 A}$, prova-se também que $C_{2 A}$ é um $\lambda$-sistema, o qual contém $G$ pela definição deste como o menor $\lambda$-sistema que contém $\mathcal{C}_{1}$, fato que implica que $B \cap A \in G$ para quaisquer $A$ e $B \in G$. Portanto, $G$ além de $\lambda$-sistema também é um $\pi$ sistema, o que implica que $G$ é uma $\sigma$-álgebra. Por conter toda a classe $C_{1}, G$ também contém a $\sigma$-álgebra gerada por $e_{1}$. Portanto $G$ é a $\sigma$-álgebra gerada por $e_{1}$.

Finalmente, por hipótese $\ell_{2}$ é um $\lambda$-sistema que contém $C_{1}$. Assim, pela definição de $G$, claramente $G \subset \ell_{2}$, o que completa a prova.

Prova de (iii). Seja $G$ o conjunto:

$$
G=\{A \in \Sigma: P(A)=Q(A)\}
$$

Como, por hipótese, $P$ e $Q$ coincidem em todos os elementos de $C$, $C$ está contido em $G$. Mas $G$ é um $\lambda$-sistema pois:

- $\Omega \in G$ uma vez que $P(\Omega)=Q(\Omega)=1$;

r para $B_{1}$ e $B_{2}$ em $G$ tais que $B_{1} \subset B_{2}, \quad P\left(B_{2}-B_{1}\right)=P\left(B_{2}\right)-P\left(B_{2} \cap B_{1}\right)=$ $=P\left(B_{2}\right)-P\left(B_{1}\right)=Q\left(B_{2}\right)-Q\left(B_{1}\right)=Q\left(B_{2}-B_{1}\right)$, portanto $B_{2}-B_{1}$ está em $G$; e

r se $\left\{B_{n}\right\}$ é uma seqüência monotonamente crescente de conjuntos em $G$, então $P\left(\bigcup_{i=1}^{\infty} B_{i}\right)=P(B)=Q(B)=Q\left(\bigcup_{i=1}^{\infty} B_{i}\right)$, com $B=\bigcup_{i=1}^{\infty} B_{i}=\lim _{n \rightarrow \infty} B_{n}$, e portanto sua união enumerável está em $G$. 
Como $G$ é um $\lambda$-sistema contendo $\mathcal{C}$, por (ii) $G$ também contém a menor $\sigma$-álgebra gerada por $\mathcal{C}$. Portanto, $P$ e $Q$ coincidem em $\Sigma$. $\square$

Com base nos conceitos apresentados e discutidos no teorema anterior, é possível demonstrar o seguinte teorema:

TEOREMA 5.2. Se $P(A)$ coincide com $Q(A)$ em todos os conjuntos de dimensões finitas $A$ de $C$ (ou seja, se as distribuições de dimensões finitas de $P$ e $Q$ são iguais) então $P$ e $Q$ são iguais.

Prova. Considere os conjuntos de dimensões finitas $A=\bigcap_{t}\{y:|x(t)-y(t)| \leq \varepsilon\}$, com $t$ variando em todos os racionais do intervalo [0;1] (ou seja, o conjunto das funções que, quando $t$ é racional, "passam por dentro" do intervalo $\left.\left[x_{i}(t)-\varepsilon ; x_{i}(t)+\varepsilon\right]\right)$ e com $x \in C$ escolhido arbitrariamente. O fecho de cada um destes conjuntos é igual a $B(x ; \varepsilon)$ - a bola fechada de raio $\varepsilon$ em torno de $x$. Desta forma, a $\sigma$-álgebra gerada pelos conjuntos $A$ contém todas as bolas fechadas $B(x ; \varepsilon)$, contendo também todas as bolas abertas de mesmo raio em torno do mesmo ponto $x$. Como $C$ é separável, cada conjunto aberto em $C$ é uma união enumerável destas bolas abertas, de modo que a $\sigma$-álgebra em questão também conterá todos os conjuntos abertos de $C$.

Além disso, como $\pi_{T}$ é um mapeamento contínuo então ele também é mensurável (Billingsley, 1968), e assim a $\sigma$-álgebra gerada pelos conjuntos da forma $\pi_{T}^{-1} H$ (ou seja, os conjuntos de dimensões finitas) está contida na $\sigma$-álgebra gerada por todos os conjuntos abertos em $C$. Conclui-se, portanto, que a $\sigma$-álgebra gerada pelos conjuntos de dimensões finitas é igual à $\sigma$-álgebra gerada pelos conjuntos abertos de $C$.

Por fim, dados os conjuntos $T=\left\{t_{1}, t_{2}, \ldots, t_{k}\right\}$ e $S=\left\{t_{1}, t_{2}, \ldots, t_{k}, s\right\}$ de pontos ordenados no intervalo $\left[0 ; 1\right.$ é sempre possível definir uma projeção $\phi$ de $\Re^{k+1}$ para $\Re^{k}$ tal que $\pi_{T}=\phi \pi_{S}$ e portanto $\pi_{T}^{-1} H=\phi \pi_{S}^{-1} H \quad$ (o que, intuitivamente, significa dizer que o conjunto de pontos definindo um conjunto de dimensões finitas em $C$ pode sempre ser aumentado, de modo que dois conjuntos $A$ e $A *$ podem ser representados como $A=\pi_{T}^{-1} H$ e $A^{*}=\pi_{T}^{-1} H^{*}$ para 0 mesmo conjunto de pontos $T)$. Como $A \cap A^{*}=\pi_{T}^{-1}\left(H \cap H^{*}\right)$ temos que os conjuntos de dimensões finitas são um $\pi$-sistema. Como as medidas $P$ e $Q$ coincidem em todos os 
elementos de um $\pi$-sistema e a $\sigma$-álgebra na qual elas estão definidas é a mesma que a $\sigma$ álgebra gerada pelo $\pi$-sistema, segue pelo ítem (iii) do Teorema 5.1 que $P$ e $Q$ são iguais.

Após tantas definições e teoremas (cujas provas provavelmente tomaram tempo considerável do leitor menos familiarizado com a Teoria da Medida), vamos voltar à pergunta formulada na seção anterior e cuja busca pela resposta levará toda a atual seção do presente texto: qual condição adicional deve ser obedecida para que a convergência das distribuições de dimensões finitas implique convergência fraca?

A resposta a esta pergunta surge como aplicação direta da Definição 5.1 e do Teorema 5.2. Pois suponha que $P_{n}$ e $P$ sejam medidas de probabilidade tais que as distribuições de dimensões finitas de $P_{n}$ convergem para as de $P$ e que, além disso, a família de $\left\{P_{n}\right\}$ é relativamente compacta (note que agora estamos lidando com uma família de seqüências - o que, pela Definição 5.1, significa que toda subseqüência $\left\{P_{n(i)}\right\}$ contém uma outra subseqüência $\left\{P_{n(i(m))\}}\right\}$ tal que $P_{n(i(m))} \Rightarrow_{m \rightarrow \infty} Q$, onde $Q$ é alguma medida de probabilidade). Neste caso, teremos que $P_{n} \Rightarrow P$.

A demonstração deste fato depende de dois teoremas adicionais. No primeiro, seja $P$ uma medida de probabilidade em $(S, \Sigma)$ e $h$ um mapeamento mensurável do espaço métrico $S$ para outro espaço métrico $S^{\prime}$. Temos que:

TEOREMA 5.3. Se $h$ é contínuo, então $P_{n} \Rightarrow P$ implica que $P_{n} h^{-1} \Rightarrow P h^{-1}$.

Prova. Como $P_{n} \Rightarrow P$ implica $\int_{S} f(h(x)) P_{n}(d x) \rightarrow \int_{S} f(h(x)) P(d x)$ e, se $h$ é contínuo, então $f(h(x))$ é limitado e contínuo em $S$ sempre que $f(y)$ for limitado e contínuo em $S$; por transformação de variáveis nas integrais, temos que $\int_{S^{\prime}} f(y) P_{n} h^{-1}(d y) \rightarrow \int_{S^{\prime}} f(y) P h^{-1}(d y)$, ou seja, $P_{n} h^{-1} \Rightarrow P h^{-1}$

A contribuição do Teorema 5.3 ao nosso caso original está no fato de que, como $P_{n(i(m))} \Rightarrow_{m \rightarrow \infty} Q$, então $P_{n(i, m)} \pi_{T}^{-1} \Rightarrow_{m \rightarrow \infty} Q \pi_{T}^{-1}$, pois os conjuntos de dimensões finitas são 
definidos por um mapeamento contínuo ${ }^{5}$. Mas, como sabemos de antemão que $P_{n} \pi_{T}^{-1} \Rightarrow_{n \rightarrow \infty} P \pi_{T}^{-1}$, então $Q \pi_{T}^{-1}=P \pi_{T}^{-1}$, ou seja, as distribuições de dimensões finitas de $P$ e de $Q$ são iguais. Mas o Teorema 5.2 garante que, neste caso, $P$ e $Q$ são iguais. Isto significa que toda subseqüência $\left\{P_{n(i)}\right\}$ contém uma outra subseqüência $\left\{P_{n(i(i m))}\right\}$ convergindo fracamente para $P$ - e não para um limite qualquer $Q$.

Mas isto também implica que a seqüência inteira $\left\{P_{n(i)}\right\}$ converge fracamente para $P$, como iremos provar no teorema a seguir:

TEOREMA 5.4. Para uma dada medida de probabilidade $P$ e uma seqüência de medidas de probabilidade $\left\{P_{n}\right\}$ definidas em $(S, \Sigma)$, se toda subseqüência $\left\{P_{n(i)}\right\}$ contém uma outra subseqüência $\left\{P_{n(i(m))\}}\right\}$ tal que $P_{n(i(m))} \Rightarrow_{m \rightarrow \infty} P$ então $P_{n} \Rightarrow_{n \rightarrow \infty} P$.

Prova. Suponha que $P_{n}$ não converge fracamente para $P$. Isto significa que, para alguma função $f$ limitada, contínua e real em $S, \quad \lim _{n \rightarrow \infty} \int_{S} f d P_{n} \neq \int_{S} f d P$. Logo existirá uma subseqüência $\left\{P_{n(i)}\right\}$ tal que, para algum $\varepsilon$ positivo, $\left|\int_{S} f d P_{n(i)}-\int_{S} f d P\right|>\varepsilon$, não contendo, portanto, nenhuma outra subseqüência que esteja convergindo fracamente para $P$, o que nos leva a uma contradição. $\square$

A Figura 21 apresenta duas seqüências onde apenas uma delas é convergente, ilustrando claramente a prova do teorema anterior. Note que na seqüência não convergente

${ }^{5}$ É possível enfraquecer a hipótese de continuidade. Para isto, tome por $D_{h}$ o conjunto dos pontos de descontinuidade de $h$. O seguinte teorema é válido:

TEOREMA 5.5. Se $P\left(D_{h}\right)=0$, então $P_{n} \Rightarrow P$ implica $P_{n} h^{-1} \Rightarrow P h^{-1}$.

Prova. Seja $F$ um subconjunto fechado de $S^{\prime}$ e $\left(h^{-l} F\right)$ o fecho de $h^{-l} F$. Neste caso, temos que

$$
\lim \sup _{n} P_{n}\left(h^{-1} F\right) \leq \limsup _{n} P_{n}\left(\left(h^{-1} F\right)^{-}\right)
$$

pois $h^{-1} F \subset\left(h^{-1} F\right)^{-}$. Além disso, como $P_{n} \Rightarrow P$, pelo Teorema 4.2 temos que

$$
\limsup P_{n}\left(\left(h^{-1} F\right)^{-}\right) \leq P\left(\left(h^{-1} F\right)^{-}\right) .
$$

Por fim, como $P\left(D_{h}\right)=0$ e $\left(h^{-1} F\right)^{-} \subset D_{h} \cup\left(h^{-1} F\right)$, temos que $P\left(\left(h^{-1} F\right)^{-}\right)=P\left(h^{-1} F\right)$, e portanto, de (5.2.1) e de (5.2.2) concluímos que $\limsup P_{n} h^{-1}(F) \leq P h^{-1}(F)$, o que, aplicando novamente o Teorema 4.2, implica que $P_{n} h^{-1} \Rightarrow P h^{-1}$. 
$\left\{P_{n}^{2}\right\}$ não existe um momento em que, a partir dele, os valores da integral calculado em $\left\{P_{n}^{2}\right\}$ - as cruzes azuis na figura - fiquem próximos do valor da integral calculado em $P$, distanciando-se deste em no máximo $\varepsilon$, para qualquer $\varepsilon$. Assim, basta tomar como $\left\{P_{n(i)}^{2}\right\}$ a seqüência composta pelos pontos em que o valor da integral em $\left\{P_{n}^{2}\right\}$ se distancia por mais de $\varepsilon$ do valor da integral em $P$ - na figura são as cruzes dentro da elipse. Claramente, é impossível que $\left\{P_{n(i)}^{2}\right\}$ contenha alguma subseqüência se aproximando do valor da integral em $P$, já que os valores da integral em $\left\{P_{n(i)}^{2}\right\}$ estão sempre distantes dos valores em $P$ por mais de $\varepsilon$.

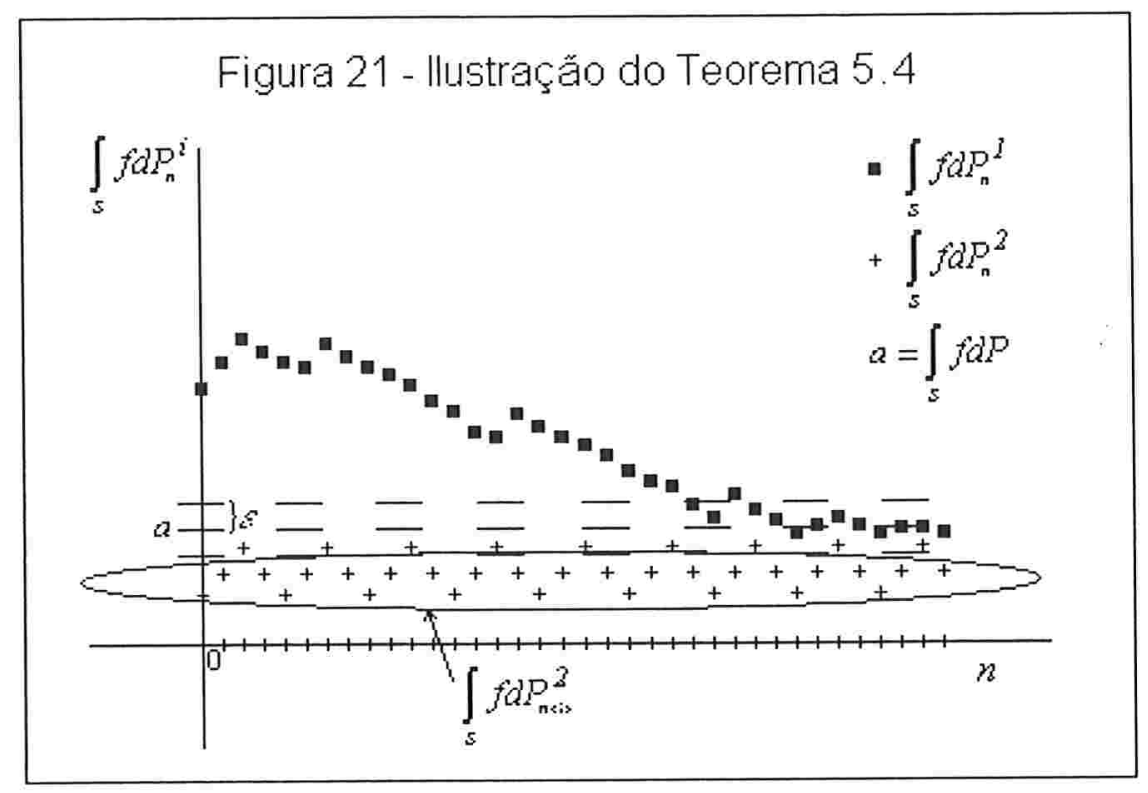

Portanto, resumindo todas as informações obtidas até o presente momento, podemos enunciar o seguinte teorema:

TEOREMA 5.6. Se $P_{n}$ e $P$ são medidas de probabilidade em $(S, \Sigma)$ tais que as distribuições de dimensões finitas de $P_{n}$ convergem para as de $P$ e que, além disso, a família de $\left\{P_{n}\right\}$ é relativamente compacta, então $P_{n} \Rightarrow P$.

A condição estabelecida no parágrafo anterior, apesar de efetiva, ainda não ajuda muito, já que em alguns casos pode ser muito complicado provar que toda subseqüência 
possui uma outra subseqüência convergente. Por enquanto não encontramos nenhuma condição fácil de ser aplicada na prática garantindo que a convergência das distribuições de dimensões finitas implique convergência fraca. O conceito dado abaixo irá nos ajudar nesta árdua missão:

DEFINIÇÃO 5.2. - Uma família $\Pi$ de medias de probabilidade em $(S, \Sigma)$ é dita apertada se para todo $\varepsilon$ existe um conjunto compacto $K$ tal que $P(K)>1-\varepsilon$ para todo $P$ em $\Pi$.

O teorema abaixo, provado por Prohorov, garante uma maneira efetiva de se provar que uma família é relativamente compacta:

TEOREMA 5.7. Se П é apertada, então ela também é relativamente compacta.

Como o principal objetivo do presente trabalho é mostrar de forma didática e ilustrada a teoria de convergência fraca, apresentaremos e ilustraremos a prova deste teorema apenas para o caso em que o espaço métrico $S$ é o conjunto dos números reais. A prova para o caso geral seguirá procedimento análogo, reduzindo todos os casos mais complexos ao caso dos conjunto dos números reais. Caso o leitor deseje conhecer a prova formal deste teorema, a mesma está transcrita no Anexo 1 deste trabalho.

Iniciamos a demonstração apresentando o que é conhecido como Teorema de Seleção de Helly:

TEOREMA 5.8. Qualquer seqüência $\left\{F_{n}\right\}$ de funções de distribuição em $\mathfrak{R}$ contém uma subseqüência $\left\{F_{n(k)}\right\}$ tal que $F_{n(k)}(x) \rightarrow F(x)$ conforme $k \rightarrow \infty$, para todos os valores de $x$ onde $F$ é contínua, sendo que $F$ é uma função qualquer contínua à direita e não decrescente.

Lembrando que as funções de distribuição possuem direta relação com as medidas de probabilidade definidas, o teorema acima nos auxilia a redefinir o conceito de relativa compactação apresentado anteriormente para o caso dos números reais: haverá relativa compactação se a função qualquer $F$ do Teorema 5.8 também for uma função de distribuição. Ou seja, neste caso teremos que a seqüência das medidas de probabilidade 
$\left\{P_{n}\right\}$ associadas às funções de distribuição $\left\{F_{n}\right\}$ é relativamente compacta (a medida $Q$ da Definição 5.1 será a medida de probabilidade associada à função $F$, a qual existirá somente se a função $F$ for uma função de distribuição).

Prova do Teorema 5.8. Construa uma tabela como a apresentada na Figura 22, onde $a_{1}, a_{2}$, $a_{3}, \ldots$ é uma enumeração qualquer dos números racionais. Como $F_{n}\left(a_{i}\right)$ está no intervalo [0;1] para qualquer $n$ e qualquer $i$, então sempre será possível definir uma subseqüência convergente $F_{n(k)}\left(a_{i}\right)$, cujo limite também sempre estará no intervalo supracitado. Portanto, defina a função $F^{*}\left(a_{i}\right)=\lim _{k} F_{n(k)}\left(a_{i}\right) . \quad F^{*}$ é não decrescente pois para $a_{k}>a_{j}$ a subseqüência $\left\{F_{n(k)}\left(a_{k}\right)\right\}$ dominará a subseqüência $\left\{F_{n(k)}\left(a_{j}\right)\right\}$, já que cada $F_{n}$ é não decrescente. Agora defina a função $F(x)=\inf \left\{F^{*}\left(a_{j}\right): a_{j}>x, x \in \mathfrak{R}\right\}$ (ou seja, para cada $x$ irracional defina $F(x)$ como o valor de $F^{*}$ no primeiro racional maior que $x$ e para cada $x$ racional defina $F(x)$ como o valor de $F^{*}$ no próximo racional da lista se a mesma estivesse em ordem crescente). Esta função é contínua à direita por definição e em todos os pontos $x$ racionais ou irracionais tais que ela é contínua ela também é o limite de $F_{n(k)}(x)$.

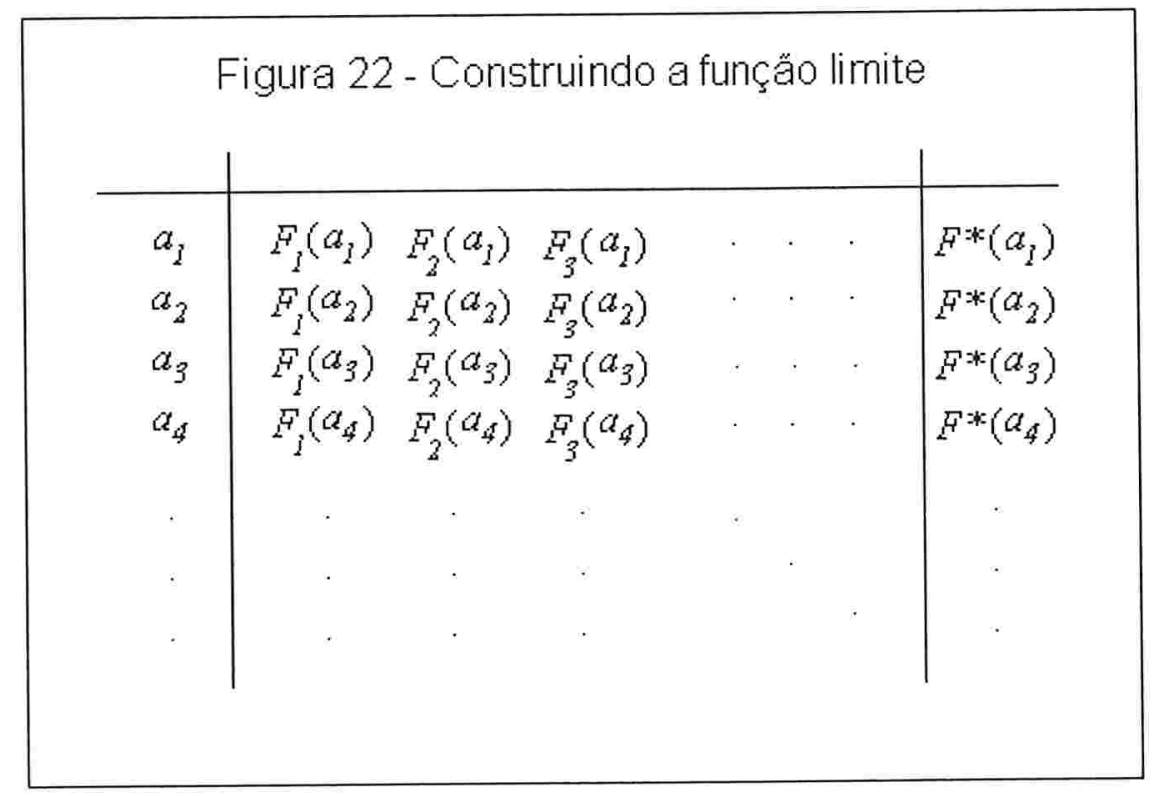

Prova do Teorema 5.7 para $S=\mathfrak{R}$. Em $\mathfrak{R}$, se a seqüência das medidas de probabilidade $\left\{P_{n}\right\}$ é apertada, então para todo $\varepsilon$ existe um intervalo $[-a ; a]$ tal que $P_{n}([-a ; a])>1-\varepsilon$ para todo $n$. Escolha $a$ tal que $P_{n}(-a)=P_{n}(a)=0$. Então para as funções de distribuição $\left\{F_{n}\right\}$ 
associadas temos que $F_{n}(-a) \leq \varepsilon, F_{n}(a) \geq 1-\varepsilon$ para todo $n$. Portanto, para todo $n$, segue que $\lim _{x \rightarrow-\infty} F_{n}(x)=0$ e $\lim _{x \rightarrow \infty} F_{n}(x)=1$, de modo que qualquer que seja a subseqüência escolhida para a construção da $F^{*}$ do Teorema $5.8, \lim _{x \rightarrow-\infty} F^{*}(x)=0$ e $\lim _{x \rightarrow \infty} F^{*}(x)=1$ e assim segue que $F^{*}$ é uma função de distribuição.

Agora resta definir como verificar no espaço $C$ se uma família é apertada ou não. Conforme apresentado no exemplo do final da seção anterior, intuitivamente a diferença entre o espaço das seqüências e o espaço das funções reais estava no fato de que sempre haveria ao menos um ponto entre o k-ésimo e o $(k+1)$-ésimo pontos de uma aproximação, de forma que neste ponto poderia acontecer um "escape de massa". De fato, ao se considerar o espaço $C$, para que uma família de medidas de probabilidade possa ser tida como apertada é exigido que esta atribua medidas cada vez menores (assintoticamente iguais a zero) para as funções que não sejam uniformemente limitadas e uniformemente equicontínuas.

Para entender melhor as exigências delineadas no parágrafo anterior, vamos definir algo que nos ajude a medir "o quão equicontínua" uma função é.

DEFINIÇÃO 5.3. - Seja $x$ um elemento de C. O módulo de continuidade de $x$ é dado por:

$$
w_{x}(\delta)=\sup _{|s-t|<\delta}|x(s)-x(t)|, \operatorname{com} 0<\delta<1
$$

Em outras palavras, o módulo de continuidade de uma função para um dado valor de $\delta$ é o valor do maior "salto" que esta função possa dar dentro de um intervalo de comprimento $\delta$.

Definido o módulo de continuidade de uma função, o teorema a seguir apresenta qual condição uma família de medidas de probabilidade deve obedecer para que esta seja considerada apertada. Neste teorema, $e$ é a $\sigma$-álgebra de Borel gerada pelos conjuntos abertos de $C$.

TEOREMA 5.9. A seqüência $\left\{P_{n}\right\}$ de medidas de probabilidade em $(C, \varrho)$ é apertada se as seguintes condições são válidas:

$$
\begin{gathered}
\lim _{i \rightarrow \infty} \sup _{n}\left\{P_{n}(x:|x(0)|>\lambda)\right\}=0 \\
\lim _{\delta \rightarrow 0} \sup _{n}\left\{P_{n}\left(x: w_{i}(\delta)>\varepsilon\right)\right\}=0, \forall \varepsilon>0
\end{gathered}
$$


Prova. Suponha que (5.2.4) e (5.2.5) são válidas. Para um dado $\varepsilon$, construa o conjunto $B_{0}=\{x:|x(0)| \leq \lambda\}$ escolhendo $\lambda$ tal que $\sup _{n} P_{n}(x:|x(0)|>\lambda) \leq \varepsilon / 2$ e para cada $k$ natural diferente de zero construa o conjunto $B_{k}=\left\{x: w_{x}\left(\delta_{k}\right) \leq k^{-1}\right\}$ escolhendo $\delta_{k}$ tal que $\sup _{n} P_{n}\left(x: w_{x}\left(\delta_{k}\right)>k^{-1}\right) \leq \varepsilon / 2^{k+1}$. Para $\quad$ conjunto $K=\bigcap_{k \in N} B_{k}$, temos que $P_{n}\left(K^{c}\right) \leq \sum_{k \in N} P_{n}\left(B_{k}\right)=\sum_{k \in N} \varepsilon / 2^{k+1}=\varepsilon$, portanto $P_{n}(K)>1-\varepsilon$. Resta provar que $K$ é compacto.

Note que, para $k^{*}$ arbitrário e para qualquer elemento $x$ de $\mathrm{C}$,

$$
|x(t)| \leq|x(0)|+\sum_{i=1}^{k^{*}}\left|x\left(t \frac{i}{k^{*}}\right)-x\left(t \frac{i-1}{k^{*}}\right) \leq\right| x(0) \mid+w_{x}\left(t / k^{*}\right) k^{*}
$$

ou seja, o valor absoluto de uma função no instante $t$ é no máximo o seu valor absoluto no instante 0 somado com o valor absoluto de todos os "saltos" dados pela mesma entre o início e o final dos $k^{*}$ intervalos precedentes de tamanho $t / k^{*}$.

Da construção de $K$, temos que $\lfloor x(0) \mid$ irá valer no máximo $\lambda$. Mas também da construção de $K$, para qualquer valor de $k$ natural diferente de zero existe um $\delta_{k}$ tal que $w_{x}\left(\delta_{k}\right) \leq k^{-1}$ em todos os elementos $x$ de $K$, isto é, para quaisquer $t$ e $\varepsilon$ positivos é possível achar um valor de $k^{*}$ tal que $w_{r}\left(t / k^{*}\right) \leq \varepsilon$. Portanto, de (5.2.6) temos que

$$
|x(t)| \leq \lambda+\varepsilon k^{*}, \forall x \in K \Rightarrow \sup _{t} \sup _{x \in K}|x(t)|<\infty
$$

O resto da prova é semelhante ao efetuado para provar que o espaço $C$ é separável. Iremos encontrar um conjunto finito de elementos de $C P_{k}=\left\{x_{k}\right\}$ tal que para todo $\varepsilon$ positivo $\mathrm{e}$ para todo $x$ em $K$ sempre há um elemento de $P_{k} \operatorname{com} d\left(x, x_{k}\right)<\varepsilon$, o que garantirá que pelo menos o fecho de $K$ é compacto.

Seja $\alpha=\sup _{t} \sup _{r \in K}|x(t)|, v$ um inteiro tal que $\alpha / v<\varepsilon / 2$ e $H$ o conjunto finito de pontos da forma $\alpha u / v$, com $u=-v, \ldots,-1,0,1, \ldots, v$. Agora, ache 0 valor de $k^{*}$ tal que $w_{x}\left(1 / k^{*}\right) \leq \varepsilon / 2$ em todos os elementos $x$ de $K$ e tome como $P_{k}$ O conjunto composto pelos elementos de $C$ que são lineares em cada subintervalo $\left[(i-1) / k^{*}: i / k^{*}\right], i=1, \ldots, k^{*}$, e assumem valores em $H$ nos pontos $i / k * i=0,1 \ldots, k^{*}$. Claramente $H$ possui um número finito de pontos (a saber, $\left.(2 v+1)^{k+1}\right)$. 
Para todo elemento $x$ de $K,\left|x\left(i / k^{*}\right)\right| \leq \alpha$, o que implica que existe um ponto $y$ em $P_{k}$ tal que:

$$
\mid x\left(\frac{i}{k^{*}}\right)-y\left(\frac{i}{k^{*}}\right)<\varepsilon / 2, \quad i=0,1, \ldots, k^{*} .
$$

Uma vez que $w_{x}\left(1 / k^{*}\right) \leq \varepsilon / 2$ e y é linear em cada subintervalo $\left[(i-1) / k^{*} ; i / k^{*}\right]$, de (5.2.8) segue que $d(x, y)=\sup _{t}|x(t)-y(t)|<\varepsilon$, ou seja, é possível aproximar qualquer elemento de $K$ por um elemento de $P_{k}$ de maneira análoga à ilustrada na Figura 18 , com o nível de precisão que for desejado. Fazendo uma analogia ao espaço $\mathfrak{R}^{2}$, ilustrado na Figura 13 , os elementos de $P_{k}$ são os centros das bolas de raio $\varepsilon$ que formam a subcobertura finita de $K$.

Como os conjuntos $B_{k}$ são fechados, a interseção dos mesmos também o é. Desta forma, $K$ é igual ao seu fecho (que é compacto), sendo assim compacto.

\subsection{Um princípio de invariância - provando o Teorema de Donsker}

A busca pela prova de que podemos utilizar um processo estocástico a tempo discreto para aproximar corretamente um processo estocástico a tempo contínuo direcionou o capítulo anterior e o capítulo presente. Após tantas definições e teoremas, finalmente podemos provar o teorema de interesse destes dois capítulos. Para tal, vamos definir uma nova medida de probabilidade:

DEFINIÇÃO 5.4. - Seja $W$ uma medida de probabilidade definida em $(C, \varrho)$, onde $C$ é a $\sigma$ álgebra de Borel gerada pelos conjuntos abertos de $C$. W é uma medida de Wiener se, para $x$ um elemento de $C$, temos que:

(i) Sob $W$, para cada $t$, a variável aleatória $x(t)$ segue distribuição Normal com média zero e variância $t$, ou seja,

$$
W\{x(t) \leq \alpha\}=\frac{1}{\sqrt{2 \pi t}} \int_{-\infty}^{\alpha} e^{-u^{2} / 2 t} d u
$$

(ii) Sob $W$, o processo estocástico $\{x(t): 0 \leq t \leq 1\}$ possui incrementos independentes, ou seja, para $0 \leq t_{0} \leq t_{1} \leq \ldots \leq t_{k} \leq 1$, as variáveis aleatórias $x\left(t_{1}\right)-x\left(t_{0}\right), x\left(t_{2}\right)-x\left(t_{1}\right), \ldots, x\left(t_{k}\right)-x\left(t_{k-1}\right)$ são independentes. 
Note que, sob $W$, os incrementos são, além de independentes, estacionários, visto que, para $s<t$, a distribuição de $x(t)-x(s)$ depende apenas da diferença $t-s$, sendo normal de variância $t-s$.

Como exemplo de um uso prático da medida de Wiener, o leitor pode tomar $x(t)$ como o preço (ou então o logaritmo do preço) de um ativo na bolsa de valores no instante de tempo $t$. A função $x$ pode ser vista como o histórico da trajetória deste preço entre os instantes de tempo $t=0$ e $t=1$. A medida de Wiener associa a esta trajetória $x$ uma distribuição apropriada para a descrição de um movimento browniano.

De fato, a Definição 5.4 apenas cria a medida de Wiener, sem efetivamente provar se é possível construí-la apenas com base nas especificações arbitrariamente dadas para suas distribuições de dimensões finitas. Isto nem sempre é possível fazer, por exemplo, não existe uma medida de probabilidade $P$ tal que sob a mesma $x(t)$ seja uma variável aleatória degenerada constante e igual a zero para $t<1 / 2$ e igual a um para $t \geq 1 / 2$.

Felizmente existe a medida de Wiener, o que nos possibilita continuar. Uma prova da existência desta medida e sua construção detalhada se baseiam intuitivamente em encontrar uma seqüência de medidas $P_{n}$ em $(C, e)$ que aproxima a suposta medida $W$. Como trabalho semelhante já será efetuado durante a prova do Teorema de Donsker, para não tornar repetitivo o texto do presente capítulo optamos por deixar a construção da medida $W$ fora do mesmo, estando a mesma detalhada no Anexo 1 deste trabalho.

Durante o resto do capítulo, trabalharemos com uma seqüência infinita de variáveis aleatórias i.i.d. $\xi_{1}, \xi_{2}, \ldots$ de média zero e variância $\sigma^{2}$ finita definidas em um espaço de probabilidade $(\Omega, \Sigma, P)$. Para cada natural $k$, defina

$$
S_{k}=\sum_{i=1}^{k} \xi_{i} \text { para } k>0 \text { e } S_{\mathrm{k}}=0 \text { para } k=0 \text {. }
$$

Agora para cada natural $n$ e $0 \leq t \leq 1$ defina o seguinte elemento aleatório:

$$
x_{n}(t)=\frac{1}{\sigma \sqrt{n}}\left(S_{\lfloor n t\rfloor}+(n t-\lfloor n t\rfloor) \xi_{\lfloor n t\rfloor+1}\right),
$$

onde $\lfloor x\rfloor$ denota o maior inteiro menor ou igual a $x$.

Note que $x_{n}(t)$ é o elemento de $C$ obtido particionando o intervalo [0:1] em $n$ subintervalos $I_{n}=[(i-1) / n ; i / n]$ e tomando a função $x$ tal que $x(i / k)=S_{i} / \sigma \sqrt{n}$ e que os demais 
pontos sejam interpolações lineares dos extremos de cada subintervalo. Como para cada $t$, $x_{n}(t)$ é uma variável aleatória, diz-se que $x$ é uma função aleatória.

Vale lembrar que as trajetórias apresentadas no capítulo introdutório (e ilustradas na Figura 2), se ajustadas para possuir domínio entre zero e um - na figura elas foram ajustadas para que seus respectivos domínios estivessem entre zero e cem, são valores que $x_{n}$ pode assumir. Se cada $\xi_{i}$ assume os valores 1 e $-1 \mathrm{com}$ probabilidade $1 / 2$ cada um, então $\sigma^{2}=1$ e $x_{n}$ é a trajetória de um passeio aleatório simétrico.

O seguinte teorema nos auxiliará a compreender o comportamento de $x_{n}(t)$ :

TEOREMA 5.10. Seja $0=t_{0}<t_{1}<\ldots<t_{k}$. O vetor de dimensão $k$ e componentes $x_{\mathrm{n}}\left(t_{j}\right)-x_{\mathrm{n}}\left(t_{j-1}\right)$, com $j=1, \ldots, k$ converge em distribuição, conforme $n$ tende ao infinito, para um vetor aleatório com componentes independentes $z_{j}$, onde cada $z_{j}$ segue distribuição Normal de média zero e variância $t_{j}-t_{j-1}$.

Prova. Para $t$ fixo, temos que $\lim _{n \rightarrow \infty}\lfloor n t\rfloor=n t$. Desta forma, para todo $\varepsilon$ positivo, $P\left[d\left((n t-\lfloor n t\rfloor) \xi_{] n ![+1}, 0\right) \geq \varepsilon\right]=P\left[(n t-\lfloor n t\rfloor) \xi_{\lfloor n\rfloor+1} \mid \geq \varepsilon\right] \stackrel{n \rightarrow \infty}{\longrightarrow} 0 \Rightarrow d\left(x_{n}(t), S_{\lfloor n t\rfloor} / \sigma \sqrt{n}\right) \stackrel{P}{\longrightarrow} 0$, ou seja, o termo em $\xi_{\lfloor n\rfloor+1}$ converge em probabilidade para zero. Mas pelo Teorema Central do Limite, $S_{\lfloor n t\rfloor} / \sigma \sqrt{n} \stackrel{D}{\longrightarrow} N\left(0,{ }^{\lfloor n t} /_{n}\right) \stackrel{D}{\longrightarrow} N(0, t)$. Assim, do Teorema 4.3 segue que $x_{n}(t) \stackrel{D}{\longrightarrow} N(0, t)$. Além disso, nos valores de $t$ tais que $n t$ é inteiro, $S_{n t}$ e $S_{n t+1}-S_{n t}=\xi_{n t+1}$ são independentes (pois as variáveis $\xi_{\mathrm{i}}$ são independentes). Novamente, como o termo em $\xi_{\lfloor n t+1}$ converge em probabilidade para zero, assintoticamente ele pode ser ignorado, portanto temos que os incrementos da função aleatória $x_{n}(t)$ são assintoticamente independentes, ou seja $x_{n}\left(t_{j}\right)-x_{n}\left(t_{j-1}\right)$ é assintoticamente independente de $x_{n}\left(t_{j-1}\right)-x_{n}\left(t_{j-2}\right)$ para $t_{j-}$ ${ }_{2}<t_{j-1}<t_{j}$ e portanto $x_{\mathrm{n}}\left(t_{j}\right)-x_{\mathrm{n}}\left(t_{j-1}\right)$ converge em distribuição para uma Normal de média zero e variância $t_{j}-t_{j-1}$. $\square$

O Teorema 5.10 afirma que $x_{n}(t)$ converge pontualmente para um movimento browniano. Desta forma, o mesmo pode ser rescrito como: "As distribuições de dimensões finitas das medidas de probabilidade $P_{n}$ em $(C, \varrho)$ associadas às funções aleatórias $x_{n}(t)$ convergem para as de $W$, onde $W$ é a medida de Wiener". Para comprovar que estas 
medidas convergem fracamente para $W$ - o principal objetivo dos últimos dois capítulos, resta provar que as mesmas são apertadas.

Em outras palavras, devemos provar que assintoticamente $P_{n}$ atribui medida zero a todos os elementos de C cuja trajetória apresente um ou mais "saltos" drásticos. Isto também significa que, observando $x_{n}(t)$ como um processo estocástico, a probabilidade de que este processo oscile muito dentro de um determinado intervalo de tempo vai se tornando cada vez menor quanto menor é o intervalo de tempo considerado.

O lema a seguir nos ajudará a entender e provar a validade da condição necessária para que as medidas de probabilidade associadas $x_{n}(t)$ sejam apertadas:

LEMA 5.1. Considere $S_{k}, k \geq 0$, definido conforme (5.3.2). Sejam $\alpha, \beta$ e $\gamma$ números reais com $\alpha \geq \beta \geq \sigma \sqrt{2(n-1)}$ e sejam $n$ e $N$ números naturais com $n \geq 1$ e $N \geq n$. As seguintes desigualdades são válidas:

$$
\begin{gathered}
P\left(\max _{j \leq n}\left|S_{j}\right|>\alpha\right) \leq 2 P\left(\left|S_{n}\right|>\alpha-\beta\right) \\
P\left(\max _{\substack{1 \leq j \leq n \\
0 \leq k \leq N}}\left|S_{j+k}-S_{k}\right|>\gamma\right) \leq\left(\frac{N}{n}+3\right) P\left(\max _{j \leq n}\left|S_{j}\right|>\gamma / 3\right) .
\end{gathered}
$$

A Figura 23 nos ajudará a compreender a importância do lema proposto. Nesta figura é apresentada uma trajetória possível da soma definida em (5.3.2) para $0 \leq k \leq N+n$. Intuitivamente, a desigualdade (5.3.5) trata com a probabilidade de que, dentro de qualquer "subintervalo de comprimento $n$ " (em aspas porque a soma só está definida para valores naturais de $k$ ) esta trajetória dê um "salto" de magnitude superior a $\gamma$, limitando-a a uma constante multiplicada pela probabilidade de que esta trajetória dê um salto de magnitude superior a $/ 13$ dentro do primeiro subintervalo de mesmo comprimento. Note que a desigualdade (5.3.5) trata com um conceito próximo ao de módulo de continuidade para a soma.

Fica evidente que no nosso caso estaremos interessados em trabalhar com valores de $n$ e $N$ tais que $n / N \rightarrow 0$ já que um dos nossos interesses é verificar se a soma possui trajetórias uniformemente equicontínuas. Assim, a desigualdade (5.3.5) por si só não é muito útil, visto que a constante multiplicativa no limite superior dado tenderá $a+\infty$. A 
desigualdade (5.3.4) servirá para mostrar que a probabilidade que está sendo multiplicada pela constante em (5.3.5) irá para zero mais rapidamente do que a constante para $+\infty$.

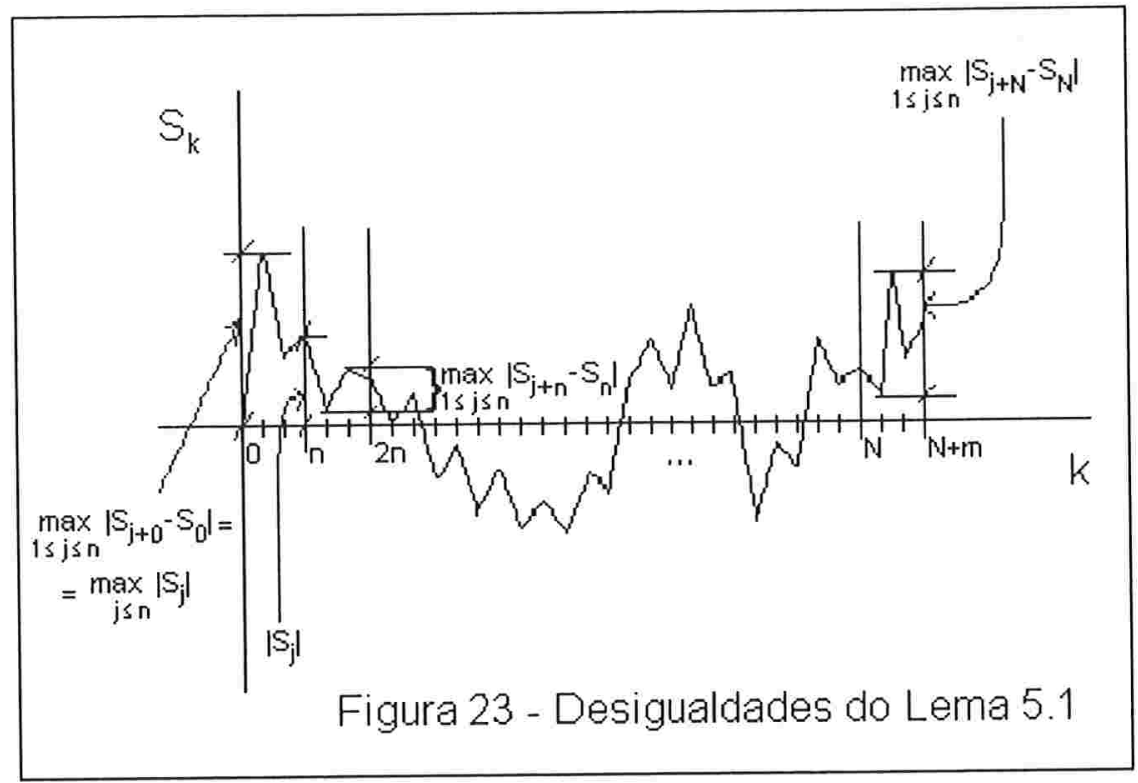

Prova do Lema 5.1. Seja $\tau=\min \left\{j:\left|S_{j}\right|>\alpha\right) \quad\left(t\right.$ denota a primeira vez que $S_{k}$ ultrapassa $\alpha$ em módulo). Então:

$$
P\left(\max _{j \leq n}\left|S_{j}\right|>\alpha\right)=P(\tau \leq n)=P\left(\tau \leq n,\left|S_{n}\right|>\alpha-\beta\right)+P\left(\tau \leq n,\left|S_{n}\right| \leq \alpha-\beta\right)
$$

Sendo que $P\left(\tau \leq n,\left|S_{n}\right| \leq \alpha-\beta\right)=P\left(\bigcup_{j=1}^{n}\left(\tau=j,\left|S_{n}\right| \leq \alpha-\beta\right)\right)$. Como $\tau=n \Rightarrow\left|S_{n}\right|>\alpha$ e $(\tau=i) \cap(\tau=j)=\varnothing$ para $i \neq j$, então

$$
P\left(\tau \leq n,\left|S_{n}\right| \leq \alpha-\beta\right)=\sum_{i=1}^{n-1} P\left(\tau=j,\left|S_{n}\right| \leq \alpha-\beta\right) .
$$

Uma vez que se $\left|S_{n}\right| \leq \alpha-\beta$ então com certeza $\left|S_{n}-S_{\tau}\right| \geq \beta$, temos que

$$
P\left(\tau=j,\left|S_{n}\right| \leq \alpha-\beta\right) \leq P\left(\tau=j,\left|S_{n}-S_{j}\right|>\beta\right)=P(\tau=j) P\left(\left|S_{n}-S_{j}\right|>\beta\right),
$$

visto que $S_{n}-S_{j}$ e $S_{j}$ são independentes.

Pela hipótese de que $\beta \geq \sigma \sqrt{2(n-1)}$, segue da desigualdade de Chebyshev que

$$
P\left(\left|S_{n}-S_{i}\right|>\beta\right) \leq \frac{\operatorname{Var}\left(S_{n}-S_{i}\right)}{\beta^{2}}=\frac{\sigma^{2}(n-j)}{\beta^{2}} \leq \frac{\sigma^{2}(n-1)}{\beta^{2}} \leq \frac{\sigma^{2}(n-1)}{2 \sigma^{2}(n-1)}=\frac{1}{2} .
$$

Juntando (5.3.7), (5.3.8) e (5.3.9) obtemos que 


$$
P\left(\tau \leq n,\left|S_{n}\right| \leq \alpha-\beta\right) \leq \sum_{j=1}^{n-1} \frac{1}{2} P(\tau=j)=\frac{P(\tau \leq n-1)}{2}
$$

e assim, lembrando que $P\left(\tau \leq n,\left|S_{n}\right|>\alpha-\beta\right) \leq P\left(\left|S_{n}\right|>\alpha-\beta\right)$, de (5.3.6) temos que

$$
P(\tau \leq n) \leq P\left(\left|S_{n}\right|>\alpha-\beta\right)+\frac{P(\tau \leq n)}{2},
$$

o que pode ser rescrito como a desigualdade em (5.3.4).

Agora tome $m=\left\lfloor\frac{N}{n}\right\rfloor$ e considere os "subintervalos de comprimento $n$ " $\{n p, n p+1, \ldots, n(p+1)-1\}$, com $p=0, \ldots, m$. Note que o inteiro $N$ está no último subintervalo. Considere o evento $\max _{\substack{1 \leq j \leq n \\ 0 \leq k \leq N}}\left|S_{j+k}-S_{k}\right|>\gamma$ e sejam $j$ e $k$ os inteiros onde esta condição é válida e $p^{*}$ o inteiro tal que $n p^{*} \leq k \leq n\left(p^{*}+1\right.$ ) - 1 (ou seja, o valor de $p$ tal que $k$ esteja no subintervalo $\left.\left\{n p^{*}, n p^{*}+1, \ldots, n\left(p^{*}+1\right)-1\right\}\right)$. Assim, temos dois casos possíveis para $j+k$ :

(i) $\quad n p^{*} \leq j+k \leq n\left(p^{*}+1\right)-1$ (Ilustrado na Figura 24):

Com certeza teremos que $\left|S_{n p^{*}}-S_{k}\right|>\gamma / 3$ (Figura 24a) ou $\left|S_{n p^{*}}-S_{k+j}\right|>\gamma / 3$ (Figura 24b) - note que é possível até mesmo termos as duas condições válidas ao mesmo tempo - e portanto sempre haverá um $0 \leq p^{*} \leq m$ tal que $\max _{j \leq n}\left|S_{n p^{*}}-S_{j}\right|>\gamma / 3$.

(ii) $\quad n\left(p^{*}+1\right) \leq j+k \leq n\left(p^{*}+2\right)-1$ (Ilustrado na Figura 25):

Com certeza teremos que $\left|S_{n p}-S_{k}\right|>\gamma / 3$ (Figura 25a) ou $\left|S_{n p^{*}}-S_{n\left(p^{*}+1\right)}\right|>\gamma / 3$ (Figura 25b) ou $\left|S_{n\left(p^{*}+1\right)}-S_{k+j}\right|>\gamma / 3$ (Figura 25c), também sendo possível termos mais de uma condição válida ao mesmo tempo, e portanto sempre haverá um $0 \leq p^{*} \leq m+1$ tal que $\max _{j \leq n}\left|S_{n p^{*}}-S_{j}\right|>\gamma / 3$.

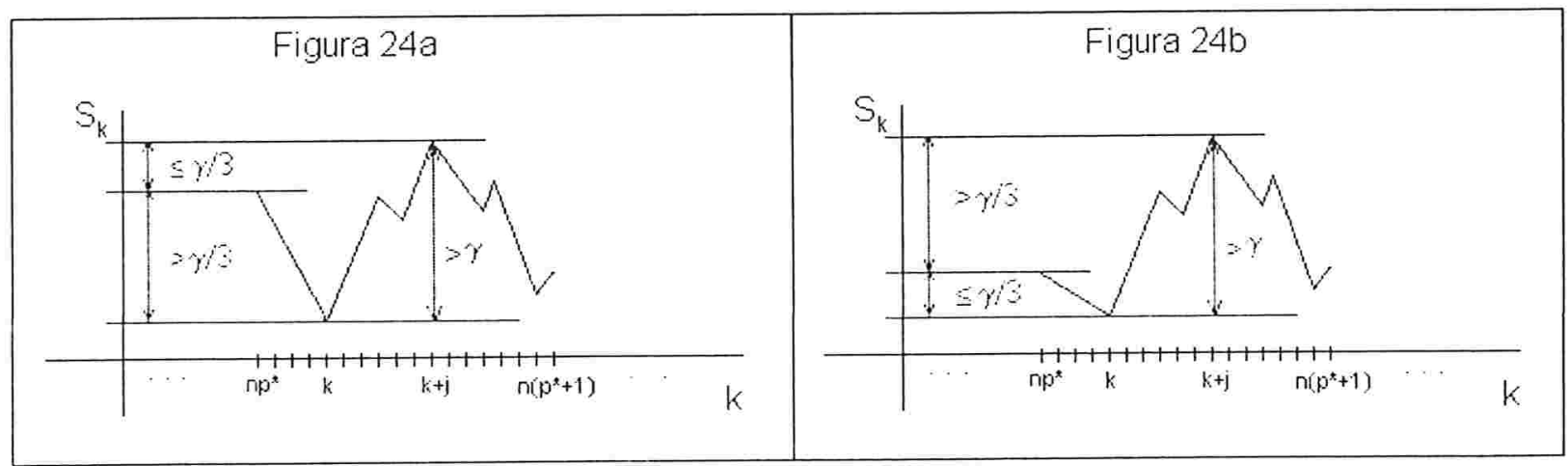




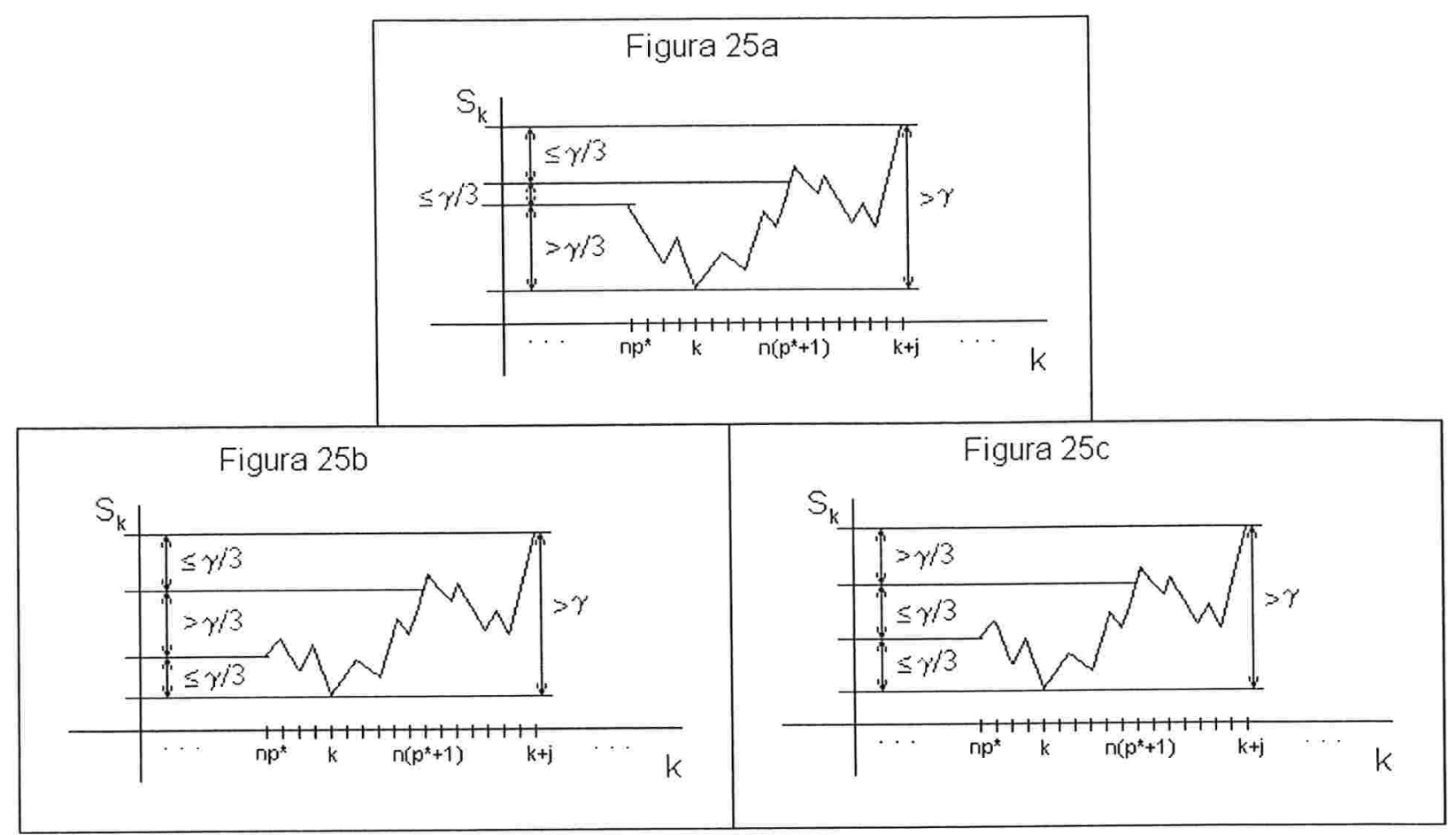

Portanto, concluímos que o evento $\max _{\substack{1 \leq j \leq n \\ 0 \leq k \leq N}}\left|S_{j+k}-S_{k}\right|>\gamma$ está contido no evento $\bigcup_{0 \leq p \leq m+1}\left\{\max _{j \leq n}\left|S_{n p}-S_{n p+j}\right|>\gamma / 3\right\}$, ou seja, se em algum momento a soma, definida em $\{0,1, \ldots, N+n\}$, der um "salto" de magnitude superior a $\gamma$ levando no máximo $n$ passos para tal, com certeza ela terá dado um "salto" de magnitude superior a $\gamma / 3$ em algum dos "subintervalos de comprimento $n$ " $\{n p, n p+1, \ldots, n(p+1)-1\}$, com $p=0, \ldots, m$. Note que

$$
P\left(\bigcup_{0 \leq p \leq m+1}\left\{\max _{j \leq n}\left|S_{n p}-S_{n p+j}\right|>\gamma / 3\right\} \leq \sum_{p=0}^{m+1} P\left(\max _{j \leq n}\left|S_{n p}-S_{n p+j}\right|>\gamma / 3\right) .\right.
$$

Como as variáveis que definem a soma são iid, temos que todas as probabilidades da soma em (5.3.12) são iguais, e portanto podemos considerar apenas a probabilidade de ocorrência do evento para $p=0$, de forma que

$$
\sum_{p=0}^{m+1} P\left(\max _{j \leq n}\left|S_{n p}-S_{n p+j}\right|>\gamma / 3\right)=(m+2) P\left(\max _{j \leq n}\left|S_{j}\right|>\gamma / 3\right) .
$$

Como $m=\left\lfloor\frac{N}{n}\right\rfloor \leq \frac{v}{n}+1$, de (5.3.12) e (5.3.13) temos que

$$
P\left(\max _{\substack{1 \leq j \leq n \\ 0 \leq k \leq N}}\left|S_{j+k}-S_{k}\right|>\gamma\right) \leq\left(\frac{N}{n}+3\right) P\left(\max _{i \leq n}\left|S_{j}\right|>\gamma / 3\right) .
$$


Com base no Lema 5.1, podemos provar o seguinte teorema:

TEOREMA 5.11. As medidas de probabilidade $P_{n}$ em $(C, \mathcal{C})$ associadas às funções aleatórias $x_{n}(t)$ definidas em (5.3.3) são apertadas.

Prova. Como $P_{n}(x:|x(0)| \neq 0)=0$, pelo Teorema 5.9 resta-nos apenas provar que $\lim _{\delta \rightarrow 0} \sup _{n}\left\{P_{n}\left(x: w_{x}(\delta)>\varepsilon\right)\right\}=0, \forall \varepsilon>0 . \quad$ Mas $w_{x}(\delta)>\varepsilon \Leftrightarrow \max _{|s-r| \leq \delta}\left|x_{n}(t)-x_{n}(s)\right|>\varepsilon$. Além disso, como $x_{n}$ é linear por partes entre os pontos $x_{n}(t)$ tais que $t / \delta$ é natural, o máximo somente é atingido nestes pontos, de modo que só é necessário os mesmos. Todavia, nestes pontos temos que $x_{n}(t)$ é da forma $S_{k} / \sigma \sqrt{n}$, com $0 \leq k \leq n$. Da desigualdade (5.3.5) do Lema 5.1 e do fato de que $(\lfloor n \delta\rfloor+1) / n>\delta$, temos que

$$
\begin{gathered}
P\left(\max _{|s-1| \leq \delta}\left|x_{n}(t)-x_{n}(s)\right|>\varepsilon\right) \leq P\left(\max _{\substack{0 \leq j \leq\lfloor n \delta\rfloor+1 \\
0 \leq k \leq n}}\left|S_{j+k}-S_{k}\right|>\varepsilon \sigma \sqrt{n}\right) \leq \\
\leq\left(\frac{n}{\lfloor n \delta\rfloor+1}+3\right) P\left(\max _{j \leq\lfloor n \delta+1 \mid}\left|S_{j}\right|>\varepsilon \sigma \sqrt{n} / 3\right)
\end{gathered}
$$

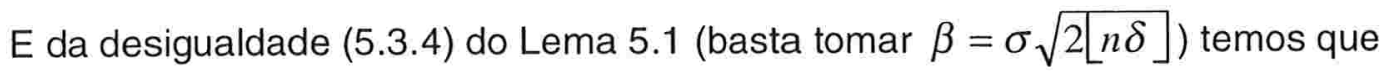

$$
P\left(\max _{j \leq\lfloor n \delta\rfloor+1 \mid}\left|S_{j}\right|>\varepsilon \sigma \sqrt{n} / 3\right) \leq 2 P\left(\left|S_{\lfloor n \delta\rfloor+1}\right|>\varepsilon \sigma \sqrt{n} / 3-\sigma \sqrt{2\lfloor n \delta\rfloor)}\right.
$$

Como pelo Teorema Central do Limite, $S_{\lfloor n \delta+1} / \sigma \sqrt{[n \delta]} \stackrel{D}{\longrightarrow} N(0,1)$, e pela desigualdade de Markov $P(|Z|>\lambda)=P\left(Z^{4}>\lambda^{4}\right) \leq \frac{E\left(Z^{4}\right)}{\lambda^{4}}, Z \sim N(0,1)$, temos que

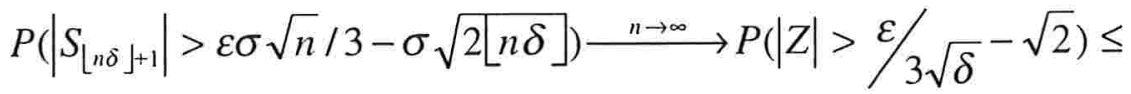

$$
\begin{aligned}
& \leq \frac{3 \delta^{2}}{(\varepsilon / 3-\sqrt{2 \delta})^{4}}
\end{aligned}
$$

Desta forma,

$$
\begin{aligned}
& \lim _{\delta \rightarrow 0} \sup _{n}\left\{P_{n}\left(x: w_{x}(\delta)>\varepsilon\right)\right\}=
\end{aligned}
$$

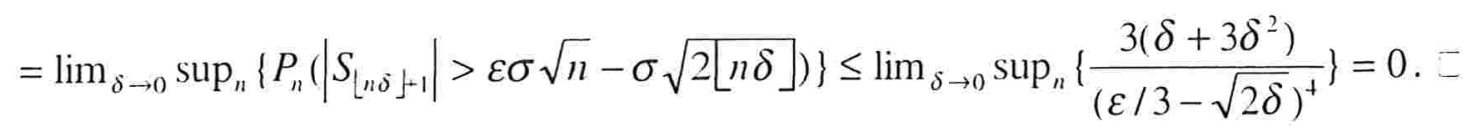


Portanto, como uma simples conseqüência dos Teoremas 5.6, 5.7, 5.10 e 5.11, finalizamos este capítulo enunciando novamente o Teorema de Donsker (que foi enunciado como o Teorema 3.1, mas sem utilizar os conceitos de convergência fraca e se preocupando apenas com a somatória):

TEOREMA 5.12. As medidas de probabilidade $P_{n}$ em $(C, C)$ associadas às funções aleatórias $x_{n}(t)$ definidas em (5.3.3) convergem fracamente para a medida de Wiener, ou seja,

$$
\int_{C} f d P_{n} \rightarrow \int_{C} f d W
$$

para toda função $f$ limitada, contínua e real em $C$. 


\section{USANDO A TEORIA PARA PRECIFICAR OPÇÕES EUROPÉIAS}

Como visto no segundo capítulo, precificar uma opção envolvia o cálculo da esperança matemática de uma função das trajetórias do preço do ativo base até a data do exercício. Vimos também que mesmo assumindo uma distribuição relativamente simples para os retornos do ativo base (um movimento browniano), em muitas situações o cálculo exato desta esperança é um tanto complicado, não possuindo solução analítica. Assim, nos três capítulos seguintes estudamos uma teoria que nos permitisse aproximar numericamente o valor de tal esperança matemática, apresentando no final do quinto capítulo o Teorema de Donsker, que será a base teórica das aproximações que faremos.

O Teorema de Donsker, em outras palavras, nos garante que a esperança de qualquer função real, contínua e limitada das trajetórias de um movimento browniano pode ser aproximada pela esperança da mesma função calculada nas trajetórias de um processo estocástico mais simples, definido em (5.3.3). O objetivo do presente capítulo é exibir os detalhes da construção do processo supracitado. Inicialmente trabalharemos apenas com as opções de exercício europeu por estas possuírem fluxo de caixa mais simples, sendo assim ideais para que se ilustre apenas a contribuição do Teorema de Donsker nas aproximações feitas. Para efeito de simplicidade, estaremos sempre trabalhando com ativos base que não gerem fluxos de caixa intermediários (por exemplo, ações que não pagam dividendos).

\subsection{A função de payoff e a adequabilidade do Teorema de Donsker}

A função para a qual se deseja calcular a esperança é de fácil obtenção no caso das opções de exercício europeu, visto que estas só permitem exercício na data final, e portanto só gerarão fluxo de caixa nesta única data. Esta função, ilustrada na Figura 26, também é conhecida como função de payoff, sendo definida da seguinte maneira para as opções de compra:

$$
f(S)=\max (0 ; g(S)-h(S))
$$

onde $S$ é a trajetória do preço do ativo base entre a data do início da opção (que pode, sem perda de generalidade, ser assumida como a data de cálculo) e a data do exercício, sendo assim um elemento de $C$. A função $h(S)$ também é conhecida como preço de exercício ou 
strike da opção. Ela representa o quanto o titular da opção tem o direito de pagar pelo ativo base para adquiri-lo na data do exercício. Exceto para algumas opções exóticas, esta função é uma constante, e neste caso dizemos que a opção possui strike fixo. Já $g(S)$ é uma função que representa o preço do ativo base na data do exercício. Sendo assim, como ninguém irá exercer um direito se este der prejuízo, o fluxo de caixa gerado pela opção é dado pela expressão (6.1.1).

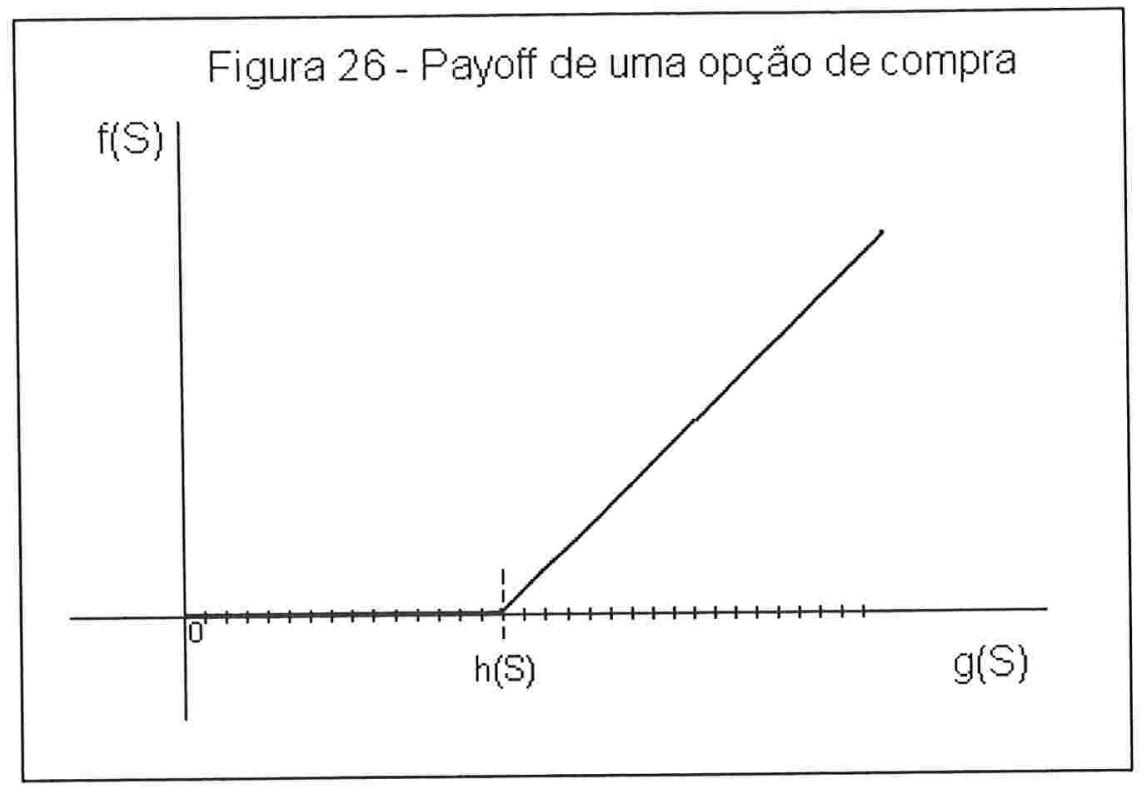

Foi afirmado que $g(S)$ apenas representa o preço do ativo base porque nem sempre a opção apenas dá ao seu titular o direito de comprar o ativo base na data do exercício pagando $h(S)$, único caso em que $g(S)$ de fato seria o preço do ativo base na data de exercício. Existem vários tipos de opções exóticas que dão ao titular o direito de, na data de exercício, comprar o ativo base por $h(S)$ e a obrigação de, uma vez exercido o direito de compra, imediatamente vender o ativo base por $g(S)$, com $g(S)$ não sendo necessariamente o valor do mesmo na data de exercício.

É claro que a compra e venda do parágrafo anterior não ocorrem (seria um tanto ineficiente em termos de custos de transação). No ato do exercício, ocorre apenas a liquidação financeira da opção, com o titular recebendo $g(S)-h(S)$.

Um tipo de opção bastante negociado no mercado financeiro é a conhecida opção padrão, ou plain vanilla. Uma opção padrão possui strike fixo igual a $K$ e não gera nenhuma 
obrigação adicional ao titular. Sem dúvida, um dos fatores que ajuda este tipo de opção a se manter como o mais popular é sua simplicidade.

Podemos definir analogamente a função de payoff para uma opção de venda. Neste caso, teríamos:

$$
f(S)=\max (0 ; h(S)-g(S))
$$

com $S$ sendo um elemento de $C$ correspondente à trajetória do preço do ativo base entre a data início da opção e a data de exercício, $h(S)$ representando o quanto o titular da opção tem o direito de receber pelo ativo base para vendê-lo na data de exercício e $g(S)$ representando o preço do ativo base na data do exercício. Esta função é ilustrada na Figura 27.

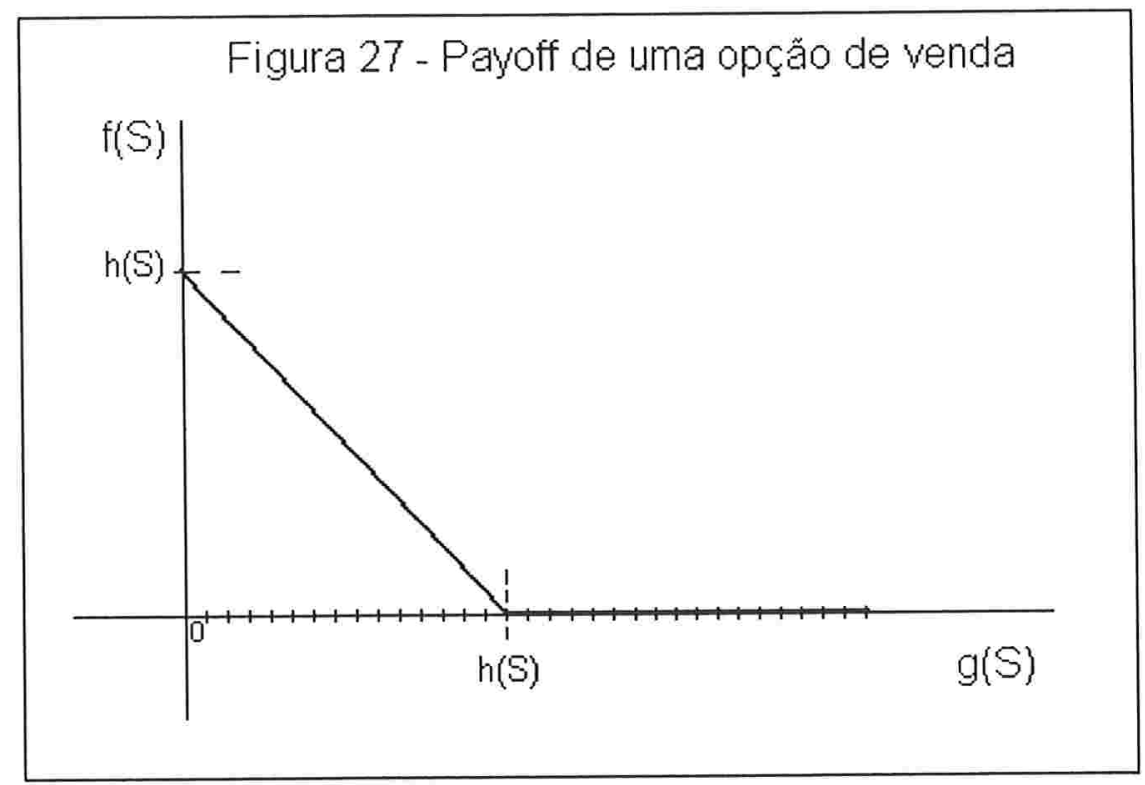

A complexidade que a função de payoff pode assumir, descrita nos parágrafos anteriores, deixa claro o porquê de para muitas opções exóticas não se existir uma solução analítica para o cálculo da esperança desta função, mesmo para as opções de exercício europeu, que são mais simples pois só possuem uma data de exercício, e com simplificações no modelo estatístico, assumindo-se um movimento browniano para os retornos do ativo base.

No entanto, a descrição dada anteriormente gera uma dúvida adicional sobre a adequabilidade do Teorema de Donsker para o nosso caso, visto que tal teorema só garante que a esperança de uma função calculada a tempo discreto irá convergir para o valor 
verdadeiro a tempo contínuo nos casos em que a função é limitada. Mas as Figuras 26 e 27 deixam claro que, no caso das opções de compra e das opções de venda onde o strike não é fixo, a função de payoff não é limitada.

Felizmente, isto não chega a ser um inconveniente, o que justifica o fato de muitos cientistas do ramo financeiro nem mesmo atentarem para este fato. Embora a função de payoff não seja limitada, é possível truncá-la, criando uma nova função de payoff limitada e de comportamento quase igual ao da função original. Para confirmar esta observação, tome um número real $k$ e considere a seguinte função:

$$
f_{k}(S)=\min (k ; f(S)),
$$

ilustrada na Figura 28. Como esta função é limitada, teremos que $\int_{C} f_{k} d P_{n} \stackrel{n \rightarrow \infty}{\longrightarrow} \int_{C} f_{k} d W$, onde $P_{n}$ são as medidas de probabilidade do processo a tempo discreto e $W$ é a medida de Wiener. Além disso, Egloff \& Min-Oo (2002) mostram que o erro de se aproximar a real função de payoff pela função truncada tende a zero conforme $k$ tende ao infinito, isto é, para quaisquer valores de $n$ e de $\varepsilon>0$, existe um valor de $k$ suficientemente grande tal que:

$$
\int_{C}\left|f_{k}-f\right| d P_{n}<\varepsilon
$$

Portanto, $\quad \int_{C}\left|f_{k}-f\right| d W<\varepsilon \Rightarrow \int_{C} f_{k} d P_{n} \stackrel{n \rightarrow \infty}{\longrightarrow} \int_{C} f d W$, ou seja, a esperança a tempo discreto da função de payoff truncada converge para o valor real da esperança da função de payoff. Em termos mais simples e menos precisos, isto ocorre porque a função de payoff de uma opção cresce de forma linear, conforme ilustrado nas Figuras 26 e 27, apresentando assim uma velocidade razoavelmente lenta de crescimento. Vale salientar que não é possível efetuar o truncamento de $f$ por $f_{k}$ em todas as condições; a aplicação desta técnica em aproximação numérica de processos deve ser considerada caso a caso.

É interessante notar que, ao implementar um algoritmo para precificação de opções, não há a preocupação de se criar uma função de payoff truncada e de se trabalhar com ela. No entanto, este procedimento já está implícito ao passarmos do mundo teórico para as implementações em programas de computador, visto que ao construirmos estes programas estamos utilizando estruturas de dados de precisão limitada. Por exemplo, ao armazenar a função de payoff em uma variável do tipo float na linguagem $\mathrm{C}_{++}$, estamos, sem perceber, truncando a função, tomando $k=3,402823466 \times 10^{38}$ (Stroustrup, 2000). 
Definida a função de payoff, vamos apresentar agora um modelo matemático para a dinâmica do preço do ativo e de seu retorno. Com base no modelo a ser apresentado e na função de payoff de uma opção, poderemos ir um passo adiante e construir um algoritmo para precificação da opção em questão.

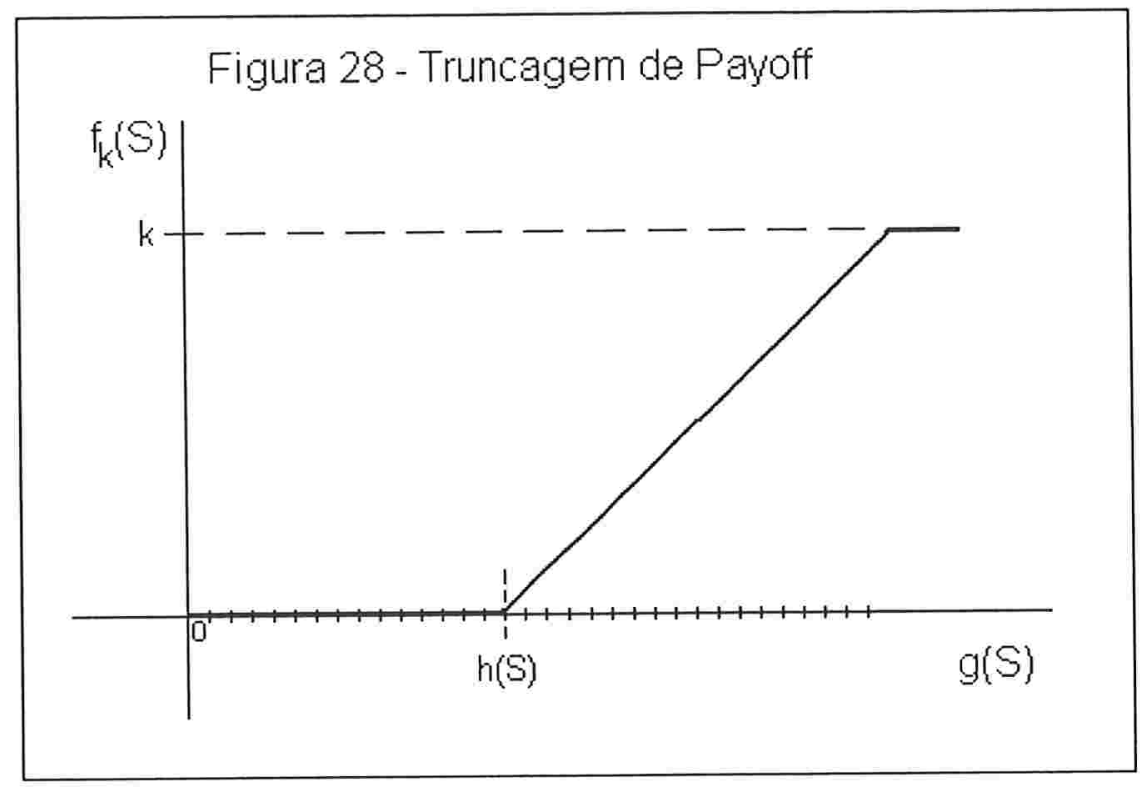

\subsection{Modelando a dinâmica do preço do ativo base}

Durante o restante do texto, designaremos o tempo por $t$, assumindo que o eixo de tempo está padronizado no intervalo [0;1]. Desta forma, o ponto zero seria a data para a qual se deseja calcular o preço da opção (a data de cálculo) e o ponto um representaria a data do exercício da opção. Portanto, se ndu é o número de dias úteis entre a data de cálculo e a data do exercício da opção, um intervalo de comprimento igual a ano no tempo real terá comprimento de $252 /$ ndu no nosso eixo de tempo padronizado (para um ano brasileiro padrão de 252 dias úteis).

Utilizaremos $S$ para a trajetória do preço do ativo base, e sendo assim, $S(t)$ denotará o preço do ativo no tempo $t$. Outro processo a ser considerado será dado por $R(t)=\ln (S(t) / S(0))$, o qual denominaremos retorno acumulado do ativo base até o tempo $t$. O leitor deve notar que tanto $S(t)$ quanto $R(t)$ são funções contínuas, sendo elementos de $C$. 
Postulamos que a dinâmica do processo de retorno do preço do ativo, isto é, do processo $R(t)$ segue um movimento browniano $B(t)$ com parâmetro de deslocamento $\mu \mathrm{e}$ parâmetro de volatilidade $\sigma^{*}$. Tal movimento browniano é semelhante ao da Definição 3.1, sendo um processo com trajetórias contínuas e incrementos independentes. A diferença está no fato de que $B(t+h)-B(t) \sim N\left(\mu h, \sigma^{* 2} h\right), \forall t \geq 0, h>0$. Lembramos ainda que $B(t)$ pode ser escrito como

$$
B(t)=\mu t+\sigma * W(t), t \geq 0,
$$

onde $W(t)$ é o movimento browniano padrão da definição 1.1 .

Da definição de $R(t)$, segue o modelo matemático para a dinâmica do preço do ativo, dado por:

$$
S(t)=S(0) \times \exp \{B(t)\}, t \geq 0 .
$$

Alternativamente, pode-se definir (6.2.2) em função de (6.2.1), obtendo-se:

$$
S(t)=S(0) \times \exp \{\mu t+\sigma * W(t)\}, t \geq 0 .
$$

O último passo antes de construirmos o algoritmo para precificar uma opção é estimar o valor do parâmetro de volatilidade $\sigma^{*}$ do movimento browniano $B(t)$. Note que não estamos preocupados com a inferência de $\mu$ uma vez que, conforme apresentado no segundo capítulo, o preço justo de uma opção não depende do retorno esperado de seu ativo base, dependendo apenas da volatilidade do mesmo. Vale lembrar que, da definição de $R(t)$ e da padronização efetuada no eixo de tempo, $\sigma^{* 2}=\operatorname{Var}(R(1))$, o que é interpretado por dizer que $\sigma^{*}$ é o desvio padrão do retorno acumulado do ativo base até a data de exercício da opção. Assim, para um intervalo de tempo de comprimento $h$, temos que

$$
\sigma^{* 2}=\frac{\operatorname{Var}(R(t+h)-R(t))}{h}=\frac{\operatorname{Var}\left(\ln \frac{S(t+h)}{S(t)}\right)}{h} .
$$

Normalmente este parâmetro de volatilidade é expresso em termos anuais. A relação entre a volatilidade expressa em termos anuais e a volatilidade utilizada nos nossos cálculos e dada por $\sigma=\sigma^{*} \sqrt{252 / n d u}$, onde $\sigma$ adquire o sentido do desvio padrão do retorno acumulado do ativo base em um ano. O nome tradicional para $\sigma$ é volatilidade anual ou volatilidade per annum. Algumas pessoas cometem um pequeno abuso de notação expressando este número em termos percentuais, provavelmente com a intenção de expressá-lo em percentual do preço do ativo base (já que, para valores bem comportados de 
$\sigma$, o desvio padrão do retorno acumulado do ativo base em um ano é um número próximo do desvio padrão da variação percentual do preço do ativo base em um ano). Assim, fica-se subentendido sem maiores delongas que $\sigma=3 \%$ é a mesma coisa que dizer que $\sigma=0,03$.

Para evitar confusões com a notação no decorrer do texto, estaremos assumindo que desejamos precificar uma opção de compra cujo prazo de exercício é exatamente igual a um ano. O leitor todavia deve ter em mente que a única diferença entre o parâmetro que denominamos de $\sigma$ e o parâmetro que denominamos de $\sigma^{*}$ está na forma de divulgação. $\mathrm{Na}$ vida real, os prazos de exercício serão distintos e raramente exatamente iguais a um ano, assim devem ser feitos os devidos ajustes nos parâmetros para torná-los condizentes com o problema de interesse.

A estimativa de $\sigma$ pode ser feita de diversas maneiras. Vamos trabalhar, por enquanto, com a estimativa conhecida como volatilidade histórica, ou volatilidade estatística. Intuitivamente, para a obtenção desta bastaria pegarmos um conjunto de observações do preço do ativo base nos $M$ anos imediatamente anteriores à data de cálculo - incluindo o preço deste na data de cálculo visto que na data de cálculo ele é conhecido, calcularmos os retornos acumulados ocorridos entre cada ano e, por fim, calcular o desvio padrão destes retornos observados. Em termos mais precisos, para a seguinte série de preços (denotados em letra minúscula por se tratarem de valores observados de uma variável aleatória):

$$
s_{0}, s_{1}, s_{2}, \ldots, s_{M}
$$

podemos construir a série de retornos acumulados

$$
r_{1}=\ln \frac{s_{1}}{s_{0}}, r_{2}=\ln \frac{s_{2}}{s_{0}}, \ldots, r_{M}=\ln \frac{s_{M}}{s_{0}}
$$

e portanto segue naturalmente que

$$
\frac{\left(r_{1}-\frac{r_{M}}{M}\right)^{2}+\left(\left(r_{2}-r_{1}\right)-\frac{r_{M}}{M}\right)^{2}+\ldots+\left(\left(r_{M}-r_{1}\right)-\frac{r_{M}}{M}\right)^{2}}{M}
$$

é uma estimativa para $\sigma^{2}$. Segundo a notação tradicional da estatística, o valor de (6.2.7) será denotado por $\hat{\sigma}^{2}$.

De fato, na realidade não temos observações de muitos anos ( $M$ não é grande), e mesmo que tivéssemos, não é razoável acreditar que este parâmetro tenha se mantido constante por muitos anos. Por exemplo, não é razoável acreditar que o parâmetro de volatilidade foi no ano de 1997, onde tivemos a crise dos Tigres Asiáticos, ou mesmo no ano 
de 2003, onde não observou nenhum choque econômico (pelo contrário, observou-se forte otimismo nos mercados de renda variável).

Assim, normalmente tem-se uma série de observações de preços de freqüência superior à anual (por exemplo, freqüência diária), contendo observações em um intervalo de tempo até mesmo inferior a um ano, podendo este ser, por exemplo, um mês. Neste caso, a estimativa de $\sigma$ seguirá procedimento análogo ao descrito anteriormente, apenas devendo ser ajustada para levar em conta a freqüência das observações. Como, da definição de $R(t)$, o retorno acumulado em um ano é igual à soma dos incrementos nos retornos acumulados de cada dia do ano, e, da mesma definição, o processo $R(t)$ possui incrementos Oindependentes, tem-se que:

$$
\frac{\text { número de dias em um ano }}{\text { número de dias em um mês }} \times\left(\begin{array}{c}
\text { variância amostral dos } \\
\text { retornos diários em um mês }
\end{array}\right)=\begin{gathered}
\text { estimativa do quadrado } \\
\text { da volatilidade anual }
\end{gathered}
$$

\subsection{Um algoritmo para precificação de opções padrão}

Após uma considerável interrupção, podemos agora voltar ao problema exposto no final do segundo capítulo. Nosso objetivo agora é determinar um algoritmo para encontrar o preço justo em que deve ser negociada uma opção de exercício do tipo europeu, a qual gerará um fluxo de caixa futuro conforme descrito na seção 6.1 , tendo seu ativo base regido pelo modelo matemático descrito na seção 6.2. Para esta seção do texto, estaremos trabalhando apenas com opções padrão (plain vanilla) com strike igual a $K$. Apenas para efeito de ilustração, assumiremos que a opção a ser precificada é uma opção de venda. O modelo descrito pode facilmente ser adaptado para comportar uma opção de compra.

De (2.3.3) e (6.1.2), temos que o preço buscado é dado por

$$
P_{O P C \bar{A} O}=e^{-r T} E^{Q}[\max (0 ; K-S(1))] \text {, }
$$

onde $r$ denota a taxa livre de risco expressa em percentual ao ano sob o conceito de capitalização contínua, $T$ denota o tempo em anos até o exercício, e $E^{Q}$ significa que a esperança deve ser tomada em relação a uma medida de probabilidade específica, chamada 
medida neutra ao risco. Esta é definida como a medida em relação a qual o preço do ativo base descontado pela taxa livre de risco é um martingal ${ }^{6}$.

A construção da medida $Q$ envolve o conhecido Teorema de Girsanov, sobre o qual não pretendemos entrar em detalhes neste texto, deixando como referência Shreve [17]. Neste texto, é mostrado que o processo utilizado para modelar a dinâmica do preço do ativo base, dado por

$$
S(t)=S(0) \times \exp \{\mu t+\sigma W(t)\}, t \geq 0,
$$

quando regido pela medida $Q$ tem as mesmas características que o processo

$$
S^{Q}(t)=S(0) \times \exp \left\{\left(r-\frac{1}{2} \sigma^{2}\right) t+\sigma W(t)\right\}, t \geq 0 .
$$

Ou seja, se os retornos do ativo base seguem um movimento browniano com parâmetro de deslocamento $\mu$ e parâmetro de volatilidade $\sigma$, as probabilidades neutras ao risco necessárias para a precificação deste ativo são obtidas considerando que estes retornos seguissem um outro movimento browniano com parâmetro de deslocamento $r-\frac{1}{2} \sigma^{2}$ e mesmo parâmetro de volatilidade.

Observamos que o rigor matemático não nos permite afirmar que (6.3.2) regido por $Q$ e (6.3.3) são o mesmo processo. Eles são processos diferentes, mas suas distribuições de dimensões finitas coincidem. Assim, o Teorema 5.2 nos permite substituir um pelo outro em nossos cálculos. A vantagem desta transformação está no fato de que, apesar de necessitarmos trabalhar com uma medida de probabilidade diferente, sob a qual não conhecemos as propriedades dos processos envolvidos (por exemplo, sob essa medida o processo $W(t)$ não será um movimento browniano padrão e os incrementos do processo $S(t)$ terão médias diferentes), por meio dela podemos encontrar um processo substituto de mesmo parâmetro de volatilidade e que também é uma função do movimento browniano padrão.

De (6.3.1) e (6.3.3), temos que

$$
P_{\text {OPC. } \mathrm{AO}}=e^{-r T} E\left[\max \left\{0 ; K-S(0) \times \exp \left\{\left(r-\frac{1}{2} \sigma^{2}\right) T+\sigma W(1)\right\}\right\}\right],
$$

\footnotetext{
${ }^{6}$ Uma seqüência aleatória $\left\{X_{n}\right\}$ com $E\left[\left|X_{n}\right|\right]<\infty$ é um martingal se $E\left[X_{n}\left|X_{0}, X_{1}, \ldots . X_{n-1}\right|=X_{n-1}\right.$ para todo $n \geq 1$. A demonstração do fato de que qualquer medida tal que, em relação a esta, o preço do ativo base descontado pela taxa livre de risco é um martingal faz o papel das probabilidades neutras ao risco apresentadas no segundo capítulo é dada no Anexo 2.
} 
que podemos rescrever como:

$$
P_{\text {OPÇÃO }}=e^{-r T} \int_{C} \max \left\{0 ; K-S(0) \times \exp \left\{\left(r-\frac{1}{2} \sigma^{2}\right) T+\sigma x(1)\right\}\right\} d W,
$$

onde $x$ designa um elemento genérico do espaço $C$ (ou seja, uma função contínua qualquer definida em [0;1]; portanto, $x(1)$ corresponde ao valor desta função para a abcissa 1) e $W$ é a medida de Wiener apresentada no capítulo anterior.

Conforme visto no final do capítulo anterior, o Teorema de Donsker nos assegura que (6.3.5) é o limite de

$$
e^{-r T} \int_{C} \max \left\{0 ; K-S(0) \times \exp \left\{\left(r-\frac{1}{2} \sigma^{2}\right) T+\sigma x(1)\right\}\right\} d P_{n},
$$

onde $P_{n}$ são medidas de probabilidade em $(C, \mathcal{C})$ associadas às funções aleatórias $x_{n}(t)$ definidas em (5.3.3). Desta forma, para termos todos os subsídios necessários para efetuar os cálculos, resta-nos escolher um valor suficientemente grande para $n$ e construir as variáveis aleatórias i.i.d. $\xi_{1}, \xi_{2}, \ldots$ de média zero e variância finita. Assim, o algoritmo para achar o preço de uma opção padrão é constituído dos seguintes passos:

(i) Escolha $n$.

(ii) Defina $n$ variáveis aleatórias independentes $\xi_{1}, \xi_{2}, \ldots, \xi_{n}$ com a seguinte distribuição:

$$
P\left[\xi_{k}=\sigma\right]=P\left[\xi_{k}=-\sigma\right]=\frac{1}{2}, \quad 1 \leq k \leq n .
$$

(iii) Construa o processo $Z^{(n)}(t)$ igual à função aleatória definida em (5.3.3) tomando como as parcelas do somatório as variáveis aleatórias $\xi_{1}, \xi_{2}, \ldots, \xi_{n}$ construídas no passo (ii).

(iv) Defina a seguinte medida de probabilidade em $(C, \varrho)$ :

$$
P_{n}[x]=P\left[Z^{(n)}(t)=x(t) \text { para todo } t \in[0 ; 1]\right] .
$$

(v) Calcule a integral definida em (6.3.6) tomando como $P_{n}$ a medida de probabilidade definida no passo (iv).

Algumas observações sobre este algoritmo devem ser feitas, iniciando-se o processo $Z^{(\prime \prime)}(t)$. A Figura 29 ilustra as trajetórias possiveis para este processo. Cada trajetória é composta pelas flechas do desenho colocadas em seqüência de modo que o começo da próxima flecha coincida com o fim da anterior. Os valores em círculos correspondem à 
probabilidade de que ocorra uma flecha dado que a sua anterior ocorreu. Note que este processo possui a forma de uma árvore de cenários, o que facilita o cálculo das medidas envolvidas no passo (iv) do algoritmo. A medida de probabilidade de uma trajetória qualquer até um determinado ponto do tempo (até o final de uma flecha) é obtida multiplicando-se as probabilidades de cada uma das flechas do caminho entre o instante zero e o instante em que se deseja efetuar o cálculo.

Vale observar que a árvore em questão é recombinante, o que é uma excelente propriedade computacional dado que o número de trajetórias possíveis nos instantes de tempo, onde há uma ramificação do processo, cresce linearmente com o tempo - caso a árvore não o fosse, este número cresceria exponencialmente com o tempo, o que prejudicaria qualquer implementação computacional não só do passo (iv) do algoritmo proposto, como também do passo ( $v$ ) visto que, para o nosso caso, a integral a ser calculada no passo (v) assume a seguinte forma:

$$
e^{-r T} \sum_{Z} \max \left\{0 ; K-S(0) \times \exp \left\{\left(r-\frac{1}{2} \sigma^{2}\right) T+\sigma x(1)\right\}\right\} \times P_{n}(x),
$$

onde $Z$ é o conjunto formado por todas as trajetórias $x$ do processo $Z^{(n)}(t)$.

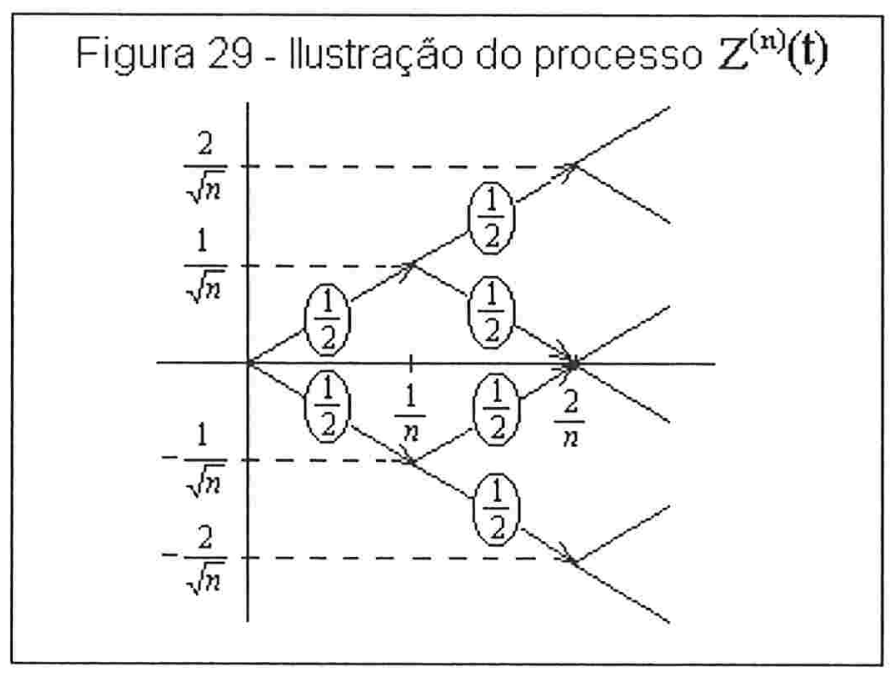

Para auxiliar na compreensão do processo $Z^{(n)}(t)$, apresentamos na Figura 30 uma ilustração de todo o processo $Z^{(t)}(t)$. O número no final de cada flecha indica o valor da medida de probabilidade $P_{n}$ de todas as trajetórias que passam pelo ponto ao qual esta 
flecha se refere (ou, em outras palavras, a probabilidade de que alguma trajetória passe pelo ponto ao qual a flecha se refere).

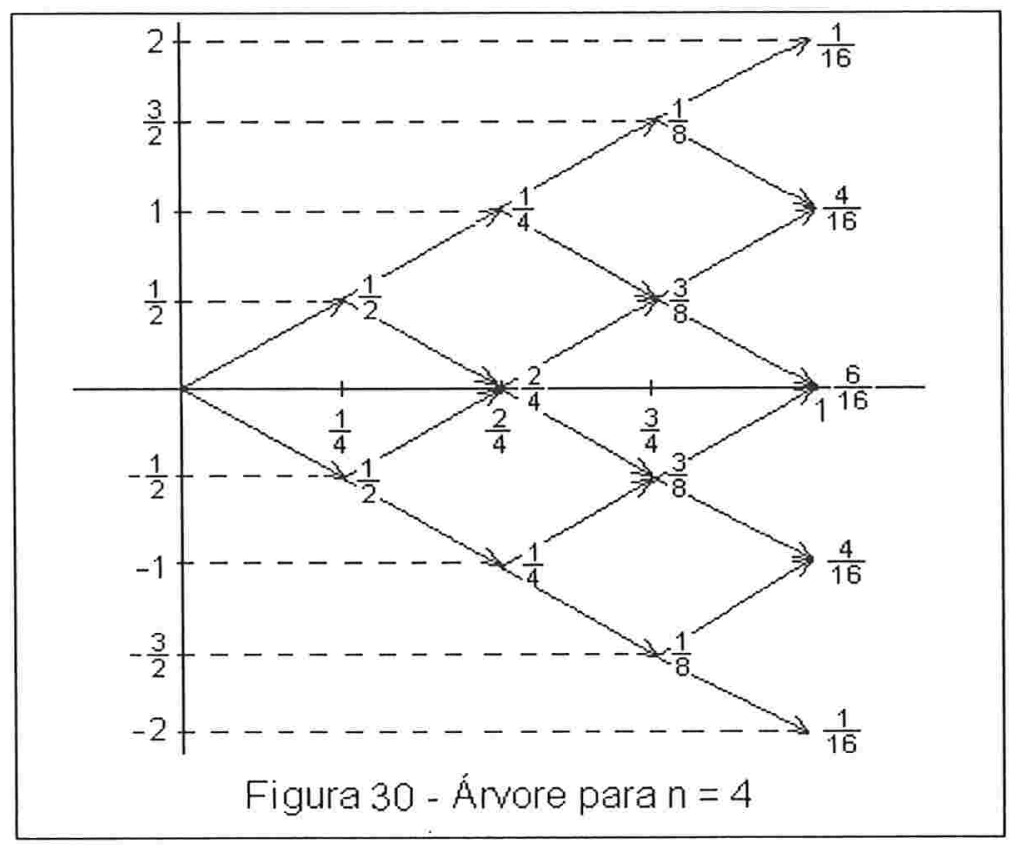

\subsection{Estudando o algoritmo proposto}

Vamos nesta seção estudar a construção do processo em tempo discreto $Z^{(n)}(t)$ (lembramos que o índice superior " $(n)$ " denota que este processo foi feito na grade de tempo com espaçamento igual $\frac{1}{n}$ ). Como visto na seção anterior, a evolução desse processo entre intervalos de tempos consecutivos foi obtida com o uso de $n$ variáveis aleatórias $\xi_{1}, \xi_{2}, \ldots, \xi_{n}$, as quais eram independentes e identicamente distribuídas. Exatamente por causa deste fato, não é necessário citarmos índice inferior destas variáveis. Desta forma, introduziremos agora a variável aleatória $\xi^{(n)}$, que tem a mesma distribuição como qualquer uma variável desta série, sendo assim utilizada para fazer referência às $n$ variáveis aleatórias $\xi_{1}, \xi_{2}, \ldots, \xi_{n}$.

Assim, a distribuição de $\xi^{(n)}$ é dada por:

$$
P\left[\xi^{(n)}=\sigma\right]=P\left[\xi^{(n)}=-\sigma\right]=\frac{1}{2} .
$$


Esta distribuição surgiu em função da necessidade de que, para que o Teorema de Donsker possa ser aplicado neste caso, assegurando que o processo em tempo discreto $Z^{(n)}(t)$ seja um bom aproximador do processo de tempo contínuo $W(t)$, duas condições sejam válidas, a saber:

> O valor esperado do acréscimo do processo aproximador num período da grade discreta é igual ao valor esperado do acréscimo do processo que está sendo aproximado no intervalo de tempo igual ao comprimento do período da grade discreta; e

> A variância do acréscimo do processo aproximador num período da grade discreta é igual à variância do acréscimo do processo que está sendo aproximado, no intervalo de tempo igual ao comprimento do período da grade discreta.

Estas condições podem ser sintetizadas no seguinte sistema de equações:

$$
\left\{\begin{array}{c}
\mathrm{E}\left[\xi^{(n)}\right]=\mathrm{E}\left[W\left(\frac{1}{n}\right)\right]=0 \\
\operatorname{Var}\left[\xi^{(n)}\right]=\operatorname{Var}\left[W\left(\frac{1}{n}\right)\right]=\frac{1}{n}
\end{array} .\right.
$$

A variável aleatória definida em (6.4.1) foi escolhida de forma a satisfazer as condições impostas pelo sistema (6.4.2). No entanto, notamos que esta variável não é a única escolha que satisfaz as condições necessárias.

A primeira razão para que a definição de $\xi^{(n)}$ dada em (6.4.1) não seja a única escolha correta é que podemos defini-la de forma que ela assuma mais que dois valores (neste caso, as árvores das Figuras 29 e 30 seriam multinomiais, ao invés de binomiais). Contudo, mesmo se nos restringirmos à consideração de variáveis que possam assumir apenas dois valores, ainda veremos que a definição de $\xi^{(n)}$ dada em (6.4.1) não é a única correta.

Vamos redefinir a variável aleatória $\xi^{(n)}$ de forma mais genérica. Para isso, designe como $a$ e $b$ os valores que $\xi^{(n)}$ pode assumir e $p$ a probabilidade de que ela assuma o valor $a$ (consequentemente, a probabilidade de que ela assuma o valor $b$ é igual a $1-p$ ). Podemos sintetizar esta redefinição como

$$
P\left[\xi^{(n)}=a\right]=p=1-P\left[\xi^{(n)}=b\right] .
$$


É fácil calcular que:

$$
\begin{aligned}
\mathrm{E}\left[\xi^{(n)}\right] & =a p+b(1-p) \\
\operatorname{Var}\left[\xi^{(n)}\right] & =p(1-p)(a-b)^{2}
\end{aligned}
$$

Portanto, aplicando (6.4.2), temos que as condições que garantem a validade do Teorema de Donsker para a variável definida em (6.4.3) são:

$$
\left\{\begin{array}{c}
a p+b(1-p)=0 \\
p(1-p)(a-b)^{2}=\frac{1}{n}
\end{array}\right.
$$

É fácil ver que estas duas equações com três incógnitas $(a, b, p)$ possuem um número infinito de soluções. Com cada tripla $(a, b, p)$ que satisfaça o sistema (6.4.5) podemos gerar o processo $Z^{(n)}(t)$ de maneira análoga à utilizada na definição da função em (5.3.3), e este processo aproximará o movimento browniano padrão $W(t)$ no sentido do Teorema de Donsker. A Figura 31 ilustra o processo $Z^{(n)}(t)$ construído com base na variável $\xi^{(n)}$ definida em (6.4.3). Doravante o processo $Z^{(n)}(t)$ será chamado de Modelo Binomial do Movimento Browniano Padrão e sua árvore será chamada de Árvore Binomial para o Movimento Browniano Padrão.

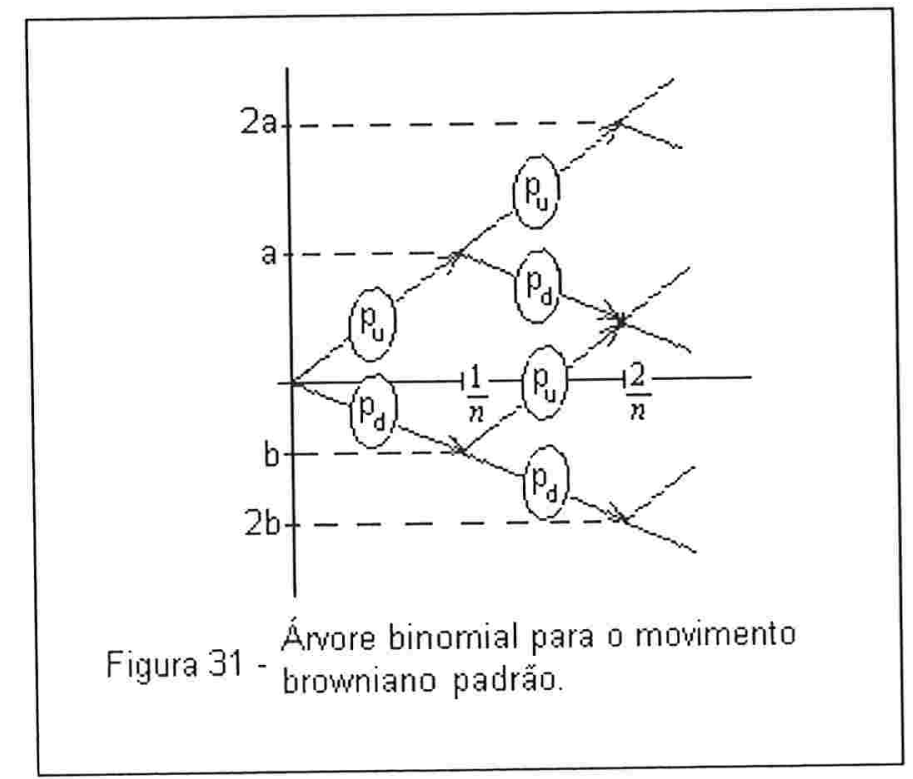

Chamamos a atenção para a forma da apresentação da árvore binomial. No eixo de tempo estão marcados os períodos do processo $Z^{(n)}(t)$. Note que o comprimento destes 
períodos $^{7}$ é $\frac{1}{n}$. Em cada nó da árvore há o valor que o processo $Z^{(n)}(t)$ assume quando passa por este nó. Por cima de cada flecha há o valor que corresponde a probabilidade do processo passar por esta flecha, dado que ele está no nó, de onde esta flecha parte. Na ilustração, $p_{u}$ é a probabilidade do processo "subir", que é igual a $p$ e $p_{d}$ é a probabilidade do mesmo "cair", sendo igual a $1-p$.

Agora lembre que, se $B(t)$ é um movimento browniano com parâmetro de deslocamento $\mu$ e parâmetro de volatilidade $\sigma$, ele também pode ser escrito como:

$$
B(t)=\mu t+\sigma W(t), t \geq 0 .
$$

A equação (6.4.6) deixa claro que $B(t)$ pode ser visto como o processo obtido do processo $W(t)$ via uma transformação linear que multiplica $B(t)$ por $\sigma$ e acrescenta ao resultado o valor $\mu t$. Faremos agora a mesma transformação com o processo $Z^{(n)}(t)$. A árvore binomial para o processo resultante, doravante denominado como $Y^{(n)}(t)$ tem a seguinte forma:

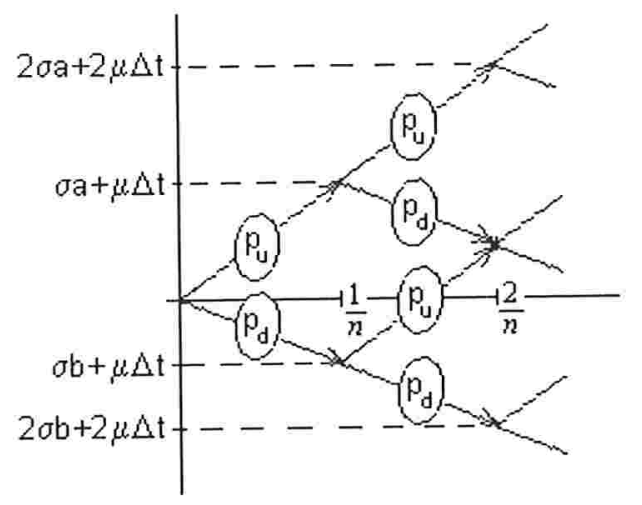

Figura 32 -

llustração da árvore binomial para o movimento browniano com parâmetro de deslocamento igual a $\mu$ e parâmetro de volatilidade igual a $\sigma$. Nesta árvore. temos que $\Delta \mathrm{t}=\frac{1}{n}$

É claro da própria construção do processo $Y^{(n)}(t)$, que as probabilidades das flechas são preservadas: as flechas "para baixo" têm probabilidade $1-p$, e as "para cima" têm probabilidade $p$, enquanto que os valores nos nós têm relação com os valores nos nós da

\footnotetext{
${ }^{7} \mathrm{Na}$ Literatura há uma outra interpretação do comprimento de período (period length), atribuindo a este o valor de $T / n$, onde $n$ é o número de passos da árvore binomial construída para aproximar o movimento browniano no intervalo $[0 ; T]$. Claro que se $T$ for 1 , então este conceito concorda com o nosso.
} 
Árvore do Movimento Browniano Padrão via a relação:

$$
\text { nó em } \left.Y^{(n)}(t)=\sigma \times \text { (valor do nó em } W(t)\right)+\mu \times \text { (abcissa do nó). }
$$

Às vezes há interesse em expressar estes valores por uma relação direta com o Movimento Browniano definido em (6.4.6). Chamando então de $U$ o valor da "subida" e $D$ o valor da "descida", ou seja, para $U=\sigma a+\mu \Delta t$ e $D=\sigma b+\mu \Delta t$, e levando em conta que:

$$
\begin{array}{r}
E[B(\Delta t)]=E[W(\Delta t)+\mu \Delta t]=\mu \Delta t \quad \mathrm{e} \\
\operatorname{Var}[B(\Delta t)]=\operatorname{Var}[\sigma W(\Delta t)+\mu \Delta t]=\sigma^{2} \Delta t,
\end{array}
$$

temos de (6.4.5) que:

$$
\left\{\begin{array}{c}
U p+D(1-p)=E[B(\Delta t)] \\
p(1-p)(U-D)^{2}=\operatorname{Var}[B(\Delta t)]
\end{array} .\right.
$$

Vamos agora construir uma árvore binomial para o processo $S(t)$ definido em (6.3.2) ${ }^{8}$ utilizado para modelar a dinâmica do preço do ativo base. Lembremos que a fórmula dada em (6.3.2) deixa claro que o processo $S(t)$ é obtido do processo $B(t)$ via uma transformação (elevar $e$ à potência $B(t)$ e multiplicar o resultado por $S(0)$ ).

Faremos esta mesma transformação com o processo $Y^{(n)}(t)$, aproximador do processo $B(t)$ e chamaremos o processo resultante de $X^{(n)}(t)$, que é dado por:

$$
X^{(n)}(t)=S(0) \times \exp \left\{Y^{(n)}(t)\right\} .
$$

A árvore binomial correspondente ao processo $X^{(n)}(t)$ tem a seguinte forma:

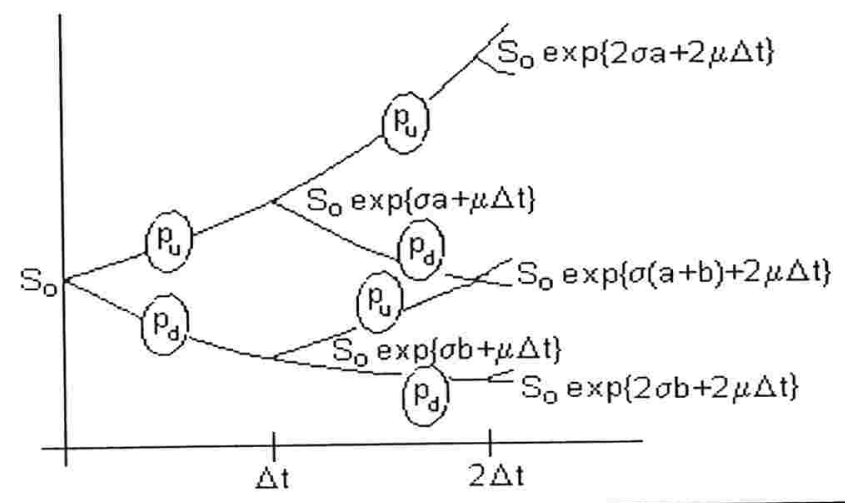

Figura 33 - Árvore binomial para o processo da dinâmica do preço do ativo base.

$$
\Delta \mathrm{t}=\frac{1}{n}
$$

\footnotetext{
${ }^{8} \mathrm{Em}$ (6.3.2) o parâmetro de volatilidade foi expresso como $\sigma^{*}$ e posteriormente introduziu-se um novo parâmetro, $\sigma$, que é o parâmetro $\sigma^{*}$ ajustado para o conceito de volatilidade anualizada. A partir deste momento, apenas para manter a conformidade com a nomenclatura comum da literatura financeira, citaremos sempre como $\sigma$ o parâmetro de volatilidade do processo gerador dos retornos do ativo base, enfatizando que a diferença entre os parâmetros $\sigma$ e $\sigma^{*}$ está apenas na interpretação do significado de um intervalo de tempo de comprimento unitário no modelo.
} 
Assim como no caso da árvore para o processo $B(t)$, neste caso também há interesse em expressar os valores de subidas e descidas da árvore diretamente dos parâmetros do processo $S(t)$, o qual a árvore aproxima. A natureza multiplicativa do processo $S(t)$, ou seja, o fato de que $S(t+\Delta t)$ pode ser expresso pelo produto de $S(t)$ por um determinado fator, faz com que as subidas e as descidas da árvore sejam expressas em termos desses fatores, os quais denominam-se por razão de subida e razão de descida, ilustrados na Figura 34 , na qual $u$ é a razão de subida e $d$ é a razão de descida.

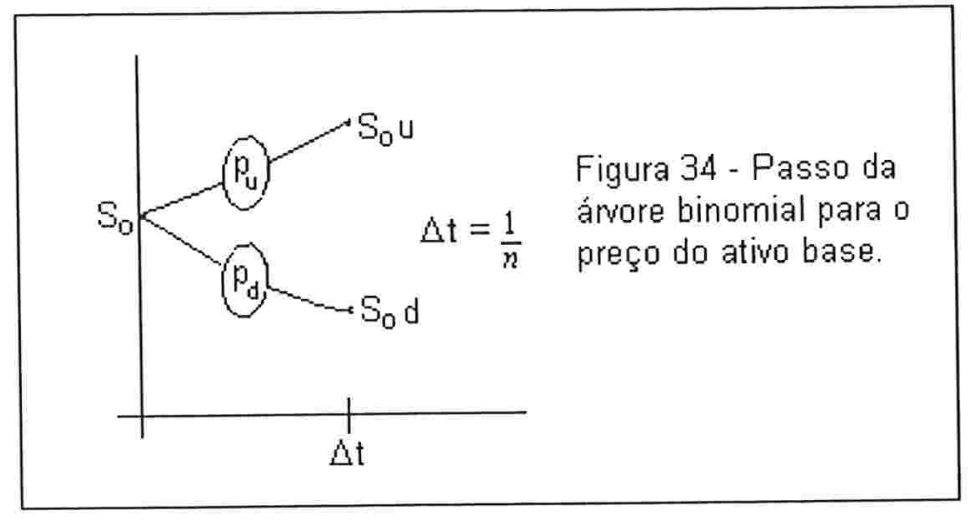

Vamos então construir as equações que relacionam as razões $u$ e $d$ com 0 comportamento do processo $S(t)$. Note que $u$ e $d$ são apenas reparametrizações do modelo dado em (6.3.2) (isto é, $u=\exp \{\mu \Delta t+\sigma a\}$ e $d=\exp \{\mu \Delta t+\sigma b\}$ onde $a$ e $b$ satisfazem as equações condições impostas em (6.4.5)). Assim, temos que

$$
\operatorname{Var}[\ln (S(\Delta t))]=\operatorname{Var}[\sigma W(\Delta t)]=\sigma^{2} \Delta t
$$

e portanto

$$
\ln \left(\frac{u}{d}\right)=\sigma(a-b) .
$$

Juntas, (6.4.12), (6.4.13) e a segunda equação do sistema (6.4.5) implicam que

$$
p(1-p)\left[\ln \left(\frac{u}{d}\right)\right]^{2}=\operatorname{Var}[\ln (S(\Delta t))]=\sigma^{2} \Delta t,
$$

que é o resultado da "transformação" da segunda equação do sistema (6.4.5).

A transformação da primeira equação do sistema (6.4.5) é um pouco mais complicada. Para esclarecê-la notamos primeiramente que 


$$
E[S(\Delta t)]=E[S(0) \times \exp \{\mu \Delta t+\sigma W(\Delta t)\}]=S(0) \times \exp \left\{\left(\mu+\frac{\sigma^{2}}{2}\right) \Delta t\right\},
$$

e expandindo-se este resultado em série de Taylor tem-se que:

$$
S(0) \times \exp \left\{\left(\mu+\frac{\sigma^{2}}{2}\right) \Delta t\right\}=S(0) \times \exp \{\mu \Delta t\} \times\left(1+\frac{\sigma^{2}}{2} \Delta t+\frac{\sigma^{+}}{2}(\Delta t)^{2}+\ldots\right)
$$

Lembremos que a primeira equação do sistema (6.4.5) gera a condição:

$$
p a+(1-p) b=0 \text {. }
$$

Além disso, das duas equações do sistema (6.4.5) obtemos a condição:

$$
a^{2} p+b^{2}(1-p)=\sigma^{2} \Delta t .
$$

Observe que

$$
\begin{aligned}
E\left[X^{(n)}(\Delta t)\right] & =S(0) \times \exp \{\mu \Delta t+\sigma a\} p+S(0) \times \exp \{\mu \Delta t+\sigma b\}(1-p)= \\
= & S(0) \times \exp \{\mu \Delta t\}(p \times \exp \{\sigma a\}+(1-p) \times \exp \{\sigma b\})
\end{aligned}
$$

Expandindo o resultado da última conta em séries de Taylor, obtemos que:

$$
E\left[X^{(n)}(\Delta t)\right]=S(0) \times \exp \{\mu \Delta t\}\left(\begin{array}{l}
p\left\{1+\sigma a+\frac{\sigma^{2} a^{2}}{2}+\frac{\sigma^{3} a^{3}}{3}+\ldots\right\}+ \\
(1-p)\left\{1+\sigma b+\frac{\sigma^{2} b^{2}}{2}+\frac{\sigma^{3} b^{3}}{3}+\ldots\right\}
\end{array}\right) \Rightarrow
$$

$$
E\left[X^{(n)}(\Delta t)\right]=S(0) \times \exp \{\mu \Delta t\}\left(1+\sigma(p a+(1-p) b)+\frac{\sigma^{2}}{2}\left(a^{2} p+b^{2}(1-p)\right)+\ldots\right) .
$$

Portanto,

$$
E\left[X^{(n)}(\Delta t)\right]=E[S(\Delta t)]+o(\Delta t)
$$

e, por conseqüência das equações do sistema (6.4.5), obtemos que $u$ e $d$ devem ser tais que

$$
p u+(1-p) d=\exp \left\{\left(\mu+\frac{\sigma^{2}}{2}\right) \Delta t\right\}
$$

Assim, concluímos que para o processo $X^{(n)}(t)$ obtido com base nas razões $u$ e $d$ ser um aproximador do processo da dinâmica do preço em tempo contínuo $S(t)$ no sentido do Teorema de Donsker, é suficiente que ele satisfaça ao mesmo tempo as equações (6.4.14) e (6.4.23). Assim como nos casos anteriores de aproximação, neste caso podemos dar a seguinte interpretação verbal estas equações: 
> Para a equação (6.4.23): o valor esperado do acréscimo do processo aproximador num período da grade discreta é aproximadamente igual ao valor esperado do acréscimo do processo que está sendo aproximado no intervalo de tempo igual ao comprimento do período da grade discreta, com um erro proporcional a este comprimento; e

> Para a equação (6.4.14): a variância do logaritmo do acréscimo do processo aproximador num período da grade discreta é igual à variância do logaritmo do acréscimo do processo que está sendo aproximado no intervalo de tempo igual ao comprimento do período da grade discreta.

Os resultados obtidos também podem ser sintetizados na seguinte proposição:

PROPOSIÇÃO 6.1. Se o processo $Z^{(n)}(t)$, é a aproximação discreta do movimento browniano padrão $W(t)$, então:

(a) o processo $Y^{(n)}(t)$, dado por $Y^{(n)}(t)=\mu t+\sigma Z^{(n)}(t)$, é a aproximação discreta do movimento browniano com parâmetro de deslocamento $\mu$ e de volatilidade $\sigma$, isto é, do processo $B(t)$ dado por $B(t)=\mu t+\sigma W(t)$; e

(b) o processo $X^{(n)}(t)$, dado por $X^{(n)}(t)=S(0) \times \exp \left\{\mu t+\sigma Z^{(n)}(t)\right\}$, é a aproximação discreta do processo $S(t)$ dado por $S(t)=S(0) \times \exp \{\mu t+\sigma W(t)\}$.

Esta proposição, em palavras simples, mas não muito precisas, afirma que a transformação linear e exponencial preservam a propriedade de aproximação. Portanto, é possível aproximar o processo do preço do ativo base com base em qualquer aproximação do movimento browniano padrão.

Agora chegou o momento para esclarecer o que significa afirmar que $Y^{(n)}(t)$ aproxima $B(t)$, e o que significa afirmar que $X^{(n)}(t)$ aproxima $S(t)$. O leitor deve lembrar que aproximamos o processo $W(t)$ por um processo $Z^{(n)}(t)$. O sentido desta aproximação está na afirmação do Teorema de Donsker de que, para toda função real e limitada $f$, é válido que:

$$
E\left\lfloor f\left(Z^{(n)}(t), t \in[0 ; 1]\right)\right\rfloor \stackrel{n \rightarrow \infty}{\longrightarrow} \mathrm{E}[f(W(t), t \in[0 ; 1])] .
$$

Suponhamos que a função $f$ possa ser escrita como uma função composta $f=F \circ G$, onde a função $G$ transforma $W(t)$ em $S(t)$. Então o Teorema de Donsker implica que: 


$$
E\left[F\left(X^{(n)}(t), t \in[0 ; 1]\right)\right] \stackrel{n \rightarrow \infty}{\longrightarrow} E[F(S(t), t \in[0 ; 1])] .
$$

Um dos exemplos de função composta como a definida no parágrafo anterior é a função de payoff de uma opção padrão de venda com exercício europeu:

$$
f(x)=\max (0 ; K-S(0) \times \exp \{\mu t+\sigma x\}) .
$$

Lembrando que o preço de mercado desta opção é dado por:

$$
\begin{gathered}
\exp \{-r T\} \times E^{Q}[\max (0 ; K-S(0) \times \exp \{\mu t+\sigma W(t)\})]= \\
=\exp \{-r T\} \times E^{Q}[\max (0 ; K-S(1))]
\end{gathered}
$$

temos, pelo Teorema de Donsker, que este preço pode ser aproximado por:

$$
\exp \{-r T\} \times E^{Q}\left[\max \left(0 ; K-X^{(n)}(t)\right)\right] .
$$

O valor numérico da expressão (6.4.28) pode ser calculado com o auxílio da árvore do processo $X^{(n)}(t)$. Esta árvore pode ser construída diretamente com os valores de $p, u$ e $d$ que satisfaçam ao mesmo tempo as equações (6.4.14) e (6.4.23), ou pode ser construída a partir da árvore de $Z^{(n)}(t)$, como proposto no algoritmo da Seção 6.3 , sendo soluções equivalentes para o mesmo problema. Por ser mais intuitiva, a primeira solução é a preferida dos engenheiros financeiros que decidem implementar um método de árvore binomial.

Já que sabemos sobre a relação das equações (6.4.14) e (6.4.23) com o sistema (6.4.5), e sabemos também que o sistema (6.4.5) possui uma infinidade de soluções, então concluímos que o sistema composto por estas equações também possui uma infinidade de soluções $(p, u, d)$. Uma delas, equivalente à implementação do algoritmo da Seção 6.3, gera o que é conhecido no mercado como modelo de Jarrow Rudd (Jarrow \& Rudd, 1983), ou também "árvore de probabilidades iguais", sendo igual a:

$$
\left\{\begin{array}{l}
p=1-p=\frac{1}{2} \\
d=2 \frac{\exp \{\mu \Delta t\}}{\exp \{2 \sigma \sqrt{\Delta t}\}+1} \\
u=2 \frac{\exp \{\mu \Delta t+2 \sigma \sqrt{\Delta t}\}}{\exp \{2 \sigma \sqrt{\Delta t}\}+1}
\end{array} .\right.
$$

Uma outra solução gera a conhecida árvore de Cox-Ross-Rubinstein (Cox, Ross \& Rubinstein, 1979), sendo igual a: 


$$
\left\{\begin{array}{l}
p=\frac{\exp \left\{\left(\mu+\frac{\sigma^{2}}{2}\right) \Delta t-d\right\}}{u-d} \\
u=\exp \{\sigma \sqrt{t}\} \\
d=\frac{1}{u}=\exp \{-\sigma \sqrt{t}\}
\end{array} .\right.
$$

A árvore de Cox-Ross-Rubinstein tem uma pequena deficiência e uma enorme vantagem. É sobre isso que versaremos no resto do texto da presente seção.

Em primeiro lugar, falaremos sobre a vantagem da árvore de Cox-Ross-Rubinstein. Para compreender isso, é necessário lembrar, que a precificação da opção usa a medida de probabilidade neutra ao risco e não a medida real. Isso significa que as trajetórias do processo devem ser preservadas, mas a medida (ou seja, a probabilidade) delas deve ser transformada (de sorte tal que o processo resultante seja um martingal depois de descontada a taxa livre de risco, conforme discutido no Anexo 2).

Apresentamos em (6.3.3) que esta mudança de medida é equivalente a substituir o parâmetro de deslocamento original $\mu$ por $\left(r-\sigma^{2} / 2\right)$. Até o momento, as árvores apresentadas nesta seção foram construídas considerando a medida de probabilidade real. É claro que é possível construí-las considerando a nova medida de probabilidade, já que basta construir a árvore resolvendo o sistema composto pelas as equações (6.4.14) e (6.4.23) fazendo as devidas substituições no parâmetro de volatilidade.

O leitor deve observar que a solução da árvore de probabilidades iguais dada em (6.4.29) depende do parâmetro de deslocamento, e portanto não estamos preservando as trajetórias ao fazer a mudança de medida adotando esta solução. No entanto a mudança da medida não afeta a volatilidade $\sigma$ (e nem pode afetar $^{9}$ ), o que garante que, assintoticamente, as mudanças feitas nas trajetórias não são muito significativas.

\footnotetext{
${ }^{9}$ Vamos lembrar, do Capítulo 2, que as probabilidades neutras ao risco são definidas nos cenários futuros para o preço do ativo base, os quais são conhecidos por todos os agentes do mercado. Assim, passando para a construção de medidas de probabilidade para processos estocásticos, isto é equivalente a dizer que a medida neutra ao risco é definida no mesmo conjunto de trajetórias possiveis para o preço do ativo objeto. Ocorre que, no caso do movimento browniano, dois processos com parâmetros de volatilidade diferentes possuem diferentes conjuntos de trajetórias possíveis (Resnick, 1992). Este fato nos permite chegar à duas conclusões: 1) Se definíssemos uma medida neutra ao risco sob a qual o processo de retornos muda a sua variância, estaríamos cometendo uma
} 
No entanto, suponha que o leitor está em uma situação onde é necessário trabalhar não apenas com o modelo discreto para o processo da dinâmica do preço do ativo base na medida neutra ao risco como também com o modelo para o verdadeiro processo. Neste caso, o leitor deveria implementar uma solução para o parâmetro de deslocamento $\mu$ e outra para o parâmetro $\left(r-\sigma^{2} / 2\right)$. Intuitivamente, parece que estes diferentes valores para este parâmetro obrigariam o leitor a construir duas árvores, gastando maior tempo de processamento, memória para armazenamento do dobro da quantidade de valores e também o tempo humano. Além disso, o leitor estaria alterando as trajetórias do preço do ativo base ao fazer a mudança de medida, o que não é uma das melhores coisas a serem feitas.

Este problema não existirá caso o leitor utilize para os valores de $(p, u, d)$ a solução proposta por Cox-Ross-Rubinstein. Isto porque os valores dos nós na árvore de Cox-RossRubinstein não depende do parâmetro de deslocamento, sendo que apenas as probabilidades dependem deste parâmetro. Note que, no processo original, elas são geradas por:

$$
p=\frac{\exp \left\{\left(\mu+\sigma^{2} / 2\right) \Delta t\right\}-d}{u-d},
$$

enquanto que, na medida neutra ao risco, as probabilidades são geradas por:

$$
p=\frac{\left.\exp \left\{\left(r-\sigma^{2} / 2\right)+\sigma^{2} / 2\right\rfloor t\right\}-d}{u-d}=\frac{\exp \{r \Delta t\}-d}{u-d} .
$$

O leitor ainda pode notar que a expressão de $p$ para a medida neutra ao risco da árvore de Cox-Ross-Rubinstein é extremamente simples.

Agora falamos da pequena deficiência do modelo de Cox-Ross-Rubinstein. A deficiência não está muito escondida. Se o leitor substituir os valores de $u=\exp \{\sigma \sqrt{\Delta t}\} \mathrm{e}$

incorreção semelhante a, no mundo dos cenários, definir probabilidades neutras ao risco para cenários diferentes dos que se vislumbra para o futuro, logo a mudança de medida não pode afetar o parâmetro de volatilidade; 2) A hipótese de que todos os agentes do mercado conhecem o conjunto de cenários possíveis para o futuro pode ser reformulada, no mundo dos processos estocásticos, para uma hipótese de que todos os agentes do mercado conhecem a variância dos retornos para cada instante de tempo até o instante final. Claramente o nosso modelo não viola esta hipótese, já que a variância dos retornos foi assumida conhecida e constante igual a $\sigma$. 
$d=\exp \{-\sqrt{\Delta t}\}$ na expressão $p(1-p)\left[\ln \left(\frac{u}{d}\right)\right]^{2}$, ele irá descobrir que esta será igual a $4 p(1-p) \sigma^{2} \Delta t$ e não $\sigma^{2} \Delta t$ como dever ser, conforme a equação (6.4.14).

Para mostrar que isso não é um obstáculo, expandiremos a expressão para $p \mathrm{em}$ série de Taylor. Note que, embora na expansão de Taylor que pretendemos construir o "parâmetro pequeno" seja $\Delta t, \sqrt{\Delta t}$ também está presente. Quando $\Delta t$ tende ao 0 , o valor de $\sqrt{\Delta t}$ tende ao 0 também, porém mais devagar de que $\Delta t$. Desta forma, a expansão de Taylor seria por $\sqrt{\Delta t}$, a qual nos dirá que:

$$
\begin{gathered}
p=\frac{\exp \left\{\left(\mu+\sigma^{2} / 2\right) \Delta t\right\}-\exp \{\sigma \Delta t\}}{\exp \{\sigma \Delta t\}-\exp \{-\sigma \Delta t\}}= \\
=\frac{\left(1+\left(\mu+\sigma^{2} / 2\right) \Delta t+\frac{\left(\mu+\sigma^{2} / 2\right)^{2}(\Delta t)^{2}}{2 !}+\ldots\right)-\left(1-\sigma \sqrt{\Delta t}+\frac{\sigma^{2} \Delta t}{2 !}-\frac{\sigma^{3}(\Delta t)^{3 / 2}}{3 !}+\ldots\right)}{\left(1+\sigma \sqrt{\Delta t}+\frac{\sigma^{2} \Delta t}{2 !}+\frac{\sigma^{3}(\Delta t)^{3 / 2}}{3 !}+\ldots\right)-\left(1-\sigma \sqrt{\Delta t}+\frac{\sigma^{2} \Delta t}{2 !}-\frac{\sigma^{3}(\Delta t)^{3 / 2}}{3 !}+\ldots\right)}= \\
=\frac{\sigma \sqrt{\Delta t}+\mu \Delta t-\frac{\sigma^{3}(\Delta t)^{3 / 2}}{3 !}+\ldots}{2 \sigma \sqrt{\Delta t}+2 \frac{\sigma^{3}(\Delta t)^{3 / 2}}{3 !}+\ldots}=\frac{1}{2}+o(\sqrt{\Delta t}) .
\end{gathered}
$$

Logo, conforme $t$ tender a zero, o valor de $p$ tende a $1 / 2$. Isso faz com que $p(1-p)$ tenda a $1 / 4$. Portanto temos que $p(1-p)\left[\ln \left(\frac{u}{d}\right)\right]^{2} \stackrel{\Delta t \rightarrow 0}{\longrightarrow} \sigma^{2} \Delta t$. Em outras palavras, a equação (6.4.14) é satisfeita assintoticamente, o que é suficiente para a validade do Teorema de Donsker.

Em termos práticos, a deficiência agora discutida apenas atrapalhará caso o valor de $\Delta t$ seja grande. Na prática, isso não acontece. Se o intervalo de tempo for de um ano e for dividido em 200 partes, então $\Delta t=\frac{1}{200}$, e para este valor, com $\sigma=0,15$ e $\mu=0,1$, por exemplo (dados anualizados), teremos que $u=1,010663051, d=0,9894494$, e portanto 
$p=0,523578177 \quad$ e $\quad \operatorname{assim} \quad p(1-p)\left[\ln \left(\frac{u}{d}\right)\right]^{2}=1,122461 \times 10^{-4}, \quad$ diferindo-se de $\sigma^{2} \Delta t=1,125 \times 10^{-4}$ somente após a sétima casa decimal.

\subsection{Resultados da implementação do algoritmo da Seção 6.3}

Implementamos o algoritmo descrito na Seção 6.3, cujo código em linguagem C++ é apresentado no Anexo 3, com o intuito de apresentar ao leitor a sua convergência. Efetuamos os cálculos com uma fictícia opção européia de venda de IBOVESPA a 25.000 pontos com data de exercício no dia 16 de fevereiro de 2005. A base dos cálculos foi 0 fechamento do dia 14 de janeiro de 2005, situação em que o preço do ativo base era de 24.924 pontos e a taxa livre de risco expressa em termos anuais sob o conceito de capitalização contínua era igual a 0,16629. A volatilidade anual dos retornos do ativo base foi estimada conforme descrito na Seção $6.2 \mathrm{com}$ base nas observações diárias das pontuações de fechamento do IBOVESPA entre os dias 15 de setembro de 2004 e 14 de janeiro de 2005, base do cálculo, sendo igual a 0,19267.

Os cálculos do preço da opção foram efetuados variando-se o número de partes em que o intervalo de tempo entre a data de cálculo e a data de exercício foi dividido. Observase que algoritmo converge de forma oscilatória. A Figura 35 apresenta os resultados obtidos segmentando-se o intervalo de tempo em até 100 partes.

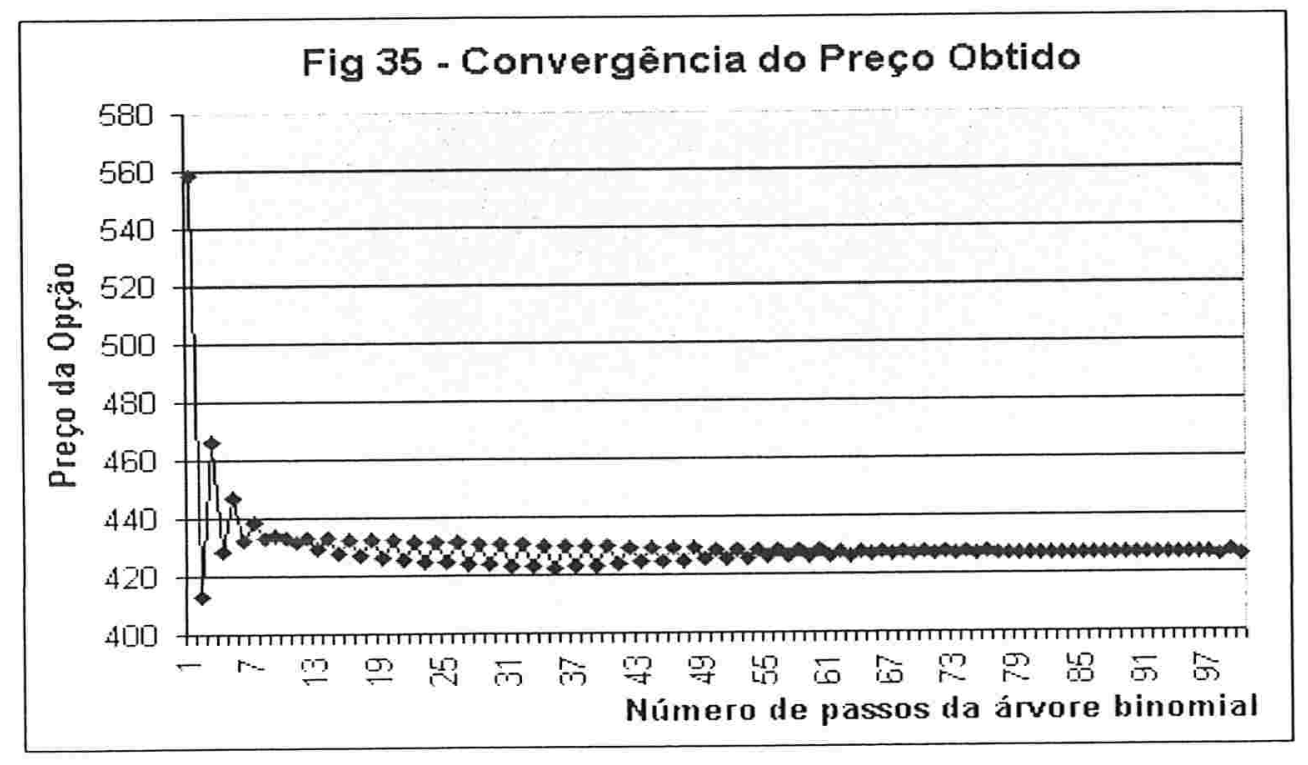


Apesar de nos garantir que a convergência irá ocorrer, o Teorema de Donsker não nos dá uma medida da qualidade da aproximação, ou seja, ao se estabelecer um nível de precisão $\varepsilon$ com a qual queremos calcular o preço aproximado da opção, não sabemos de antemão o valor de $n$ tal que o preço aproximado não se distancie do preço verdadeiro por mais de $\varepsilon$. Esta deficiência é suprida repetindo a execução do algoritmo para valores crescentes de $n$ até que, por um certo número de vezes seguidas, o preço obtido entre a $n$ ésima repetição não se distancie do preço obtido na (n-1)-ésima repetição por mais do que o nível de precisão desejado.

Por exemplo, para $n$ igual a 199 o preço da opção obtido foi igual a 426,806 enquanto que para $n$ igual a 200 este preço foi igual a 426,417, uma diferença absoluta de 0,389 ou aproximadamente $0,09 \%$ do preço da opção. Portanto, o valor de 426,417 pode ser tomado como a aproximação do verdadeiro valor com uma margem de erro na casa dos centavos.

O leitor ainda pode comparar os resultados obtidos com os valores que seriam obtidos com o modelo a tempo contínuo de Black \& Scholes (1973), que dá a solução analítica para o preço de mercado de uma opção européia de venda padrão. De acordo com este modelo, o preço é dado pela seguinte fórmula:

$$
P_{O P C \bar{A} O}=K \times \exp \{-r T\} N\left(-d_{2}\right)-S(0) N\left(-d_{2}\right),
$$

onde $K$ é o preço de exercício da opção, $r$ denota a taxa livre de risco expressa em percentual ao ano sob o conceito de capitalização contínua, $T$ denota o tempo em anos até o exercício, $S(0)$ é o preço do ativo base no momento do cálculo,

$$
\begin{gathered}
d_{1}=\frac{\ln (S(0) / K)+\left(r+\sigma^{2} / 2\right) T}{\sigma \sqrt{T}} \mathrm{e} \\
d_{2}=d_{1}-\sigma \sqrt{T},
\end{gathered}
$$

com $\sigma$ denotando a volatilidade anualizada dos retornos do ativo base.

Substituindo os dados do nosso problema na equação (6.5.1) obtemos que o preço da opção é 426,313, um valor bem próximo do obtido com o uso do algoritmo descrito na Seção 6.3. 


\subsection{Um algoritmo para precificação de opções exóticas}

O algoritmo proposto na Seção 6.3, apesar de possuir simples implementação e de funcionar muito bem no caso das opções padrão, não é viável computacionalmente para a maioria das opções exóticas. O problema no caso das opções exóticas está no fato de que ao menos um dos valores de $g(S)$ e de $h(S)$ da função de payoff da opção depende de toda a trajetória do preço do ativo base até o momento do exercício, e não apenas do ponto final da mesma, como no caso de uma opção padrão. Desta forma, se fossemos montar uma árvore binomial para a precificação de uma opção exótica, esta não seria mais recombinante uma vez que, embora o número de pontos finais crescem linearmente com o tempo, o número de trajetórias cresce exponencialmente com o tempo.

Por exemplo, considere novamente a árvore da Figura 30. No primeiro instante de tempo, o número de pontos finais e trajetórias é o mesmo, igual a dois. No entanto, para o segundo instante de tempo, possuímos apenas três pontos finais, mas o número de trajetórias já é igual a quatro, visto que cada uma das duas trajetórias do estágio anterior se ramificou em outras duas. Para o terceiro instante de tempo, o número de pontos finais aumentou para quatro, mas agora já possuímos oito trajetórias diferentes pois cada uma das quatro do estágio anterior se ramificou em outras duas. Prosseguindo com raciocínio análogo, poderemos ver que após somente quinze passos, apesar de termos dezesseis pontos finais, teremos 32.768 trajetórias diferentes, gerando um custo computacional elevado com uma alta chance de ainda nem termos nos aproximado da solução correta.

A maneira mais utilizada pelos engenheiros financeiros para lidar com este problema é trabalhar com o conceito de simulação de Monte Carlo. Trata-se de um procedimento simples mas com o poder de ser aplicado a uma vasta gama de situações.

Um exemplo bastante intuitivo do procedimento de Monte Carlo é a simulação de Monte Carlo para o cálculo da probabilidade de que, após o lançamento de dois dados, a soma dos números obtidos seja igual a um determinado valor (por exemplo, 8). Neste caso, pedimos ao computador que simule muitas vezes o lançamento de dois dados, anotando o resultado destes lançamentos. Depois ele irá contar em quantas vezes este resultado foi igual a 8 e dar como uma estimativa da probabilidade de interesse o valor do quociente entre o número de simulações tais que o resultado da soma foi igual a 8 e o número total de simulações. 
Claramente não há vantagens em se efetuar uma simulação de Monte Carlo para situações simples, onde o cálculo pode ser feito analiticamente (como no caso do lançamento dos dois dados). No entanto isto é muito útil quando queremos calcular algo que não possui solução analítica, como por exemplo, a esperança da expressão (6.3.1). Neste caso estaríamos gerando aleatoriamente um grande número de trajetórias para o preço do ativo base que possuam a distribuição de probabilidades neutra ao risco desejada e calculando o valor da função de payoff da opção em cada uma destas simulações. A esperança desejada seria a simples média amostral dos valores obtidos.

Desta forma, o algoritmo para achar o preço de uma opção exótica é constituído dos seguintes passos:

(i) Escolha $n$ (número de subintervalos em que o intervalo de tempo entre a data de cálculo e o exercício será particionado) e escolha nsim (número de simulações a serem efetuadas).

(ii) Defina $n \operatorname{sim} \times n$ variáveis aleatórias independentes $\xi_{j}^{i}$, para $1 \leq i \leq n \operatorname{sim}$ e $1 \leq j \leq n$ tais que:

$$
\xi_{j}^{i} \sim N\left(\left(r-\frac{1}{2} \sigma^{2}\right) \frac{1}{n}, \frac{\sigma^{2}}{n}\right) .
$$

(iii) Construa nsim trajetórias $S^{\prime}$, para $1 \leq i \leq n \operatorname{sim}$ e $1 \leq j \leq n$, tais que, para $t=\frac{j}{n}, S^{i}(t)=S(0) \times \exp \left\{\sum_{k=1}^{j} \xi_{j}^{i}\right\}$, para $t=0, S^{i}(t)=S(0)$ e, para os demais valores de $t, S^{i}(t)$ seja definida por interpolação linear entre seus pontos.

(iv) Calcule, para cada trajetória $S^{\prime}$, os valores de $g\left(S^{i}\right)$ e de $h\left(S^{i}\right)$ e a sua função de payoff.

(v) Obtenha o preço da opção calculando

$$
P_{\text {OPC.AO }}=\frac{e^{-r T} \sum_{i=1}^{n \cdot \operatorname{sim}} f^{i}}{n \operatorname{sim}} .
$$

onde $r$ denota a taxa livre de risco expressa em percentual ao ano sob o conceito de capitalização contínua, $f^{i}$ denota o valor da função de payoff da opção para a simulação $i$ e $T$ denota o tempo em anos até o exercício. 
Lembramos que o Teorema de Donsker continua garantindo a convergência deste algoritmo para o preço correto que seria obtido em um modelo a tempo contínuo já que as variáveis $\xi_{1}, \xi_{2}, \ldots$ só precisam ter a mesma média e variância do processo que desejamos aproximar para que a convergência continuem sendo garantida. Isto continua sendo válido no algoritmo dado anteriormente.

\subsection{Implementando o algoritmo da Seção $6.6 \mathrm{com}$ dados do mercado brasileiro}

Implementamos o algoritmo dado na seção anterior para algumas fictícias opções exóticas de compra de IBOVESPA com exercício europeu, strike fixo igual a 25.000 pontos e exercício no dia 16 de fevereiro de 2005, tomando como base dos cálculos o fechamento do dia 14 de janeiro de 2005. A taxa livre de risco e o valor do ativo base no instante do cálculo são os mesmos que os utilizados na Seção 6.5. Apenas a volatilidade foi estimada de maneira diferente, a ser descrita no último capítulo, com o intuito de podermos comparar os preços destas opções exóticas fictícias com os preços das opções padrão que foram negociadas no mercado nesta data e constatarmos assim que características deixam uma opção exótica mais cara ou mais barata. Assim, a volatilidade utilizada foi a volatilidade implícita no preço de uma opção de compra padrão de IBOVESPA (o tipo de exercício não faz diferença para este tipo de opção, como veremos no próximo capítulo) negociada na mesma data, sendo igual a 0,26785.

Como todas opções a serem precificadas possuem strike fixo, a escolha de $g(S)$ da função de payoff da opção irá determinar que tipo de opção exótica estaremos precificando. Nesta seção trabalharemos com dois tipos de opções exóticas, as asiáticas e as lookback.

Em uma opção asiática de strike fixo igual a $K$, o valor de $g(S)$ é obtido calculando-se a média dos valores assumidos pelo preço do ativo base em alguns pontos de sua trajetória. Esta opção também é conhecida como opção asiática com média discreta (discrete averaging). Normalmente a média a ser utilizada na função de payoff da opção corresponde à média dos valores assumidos pelo preço do ativo base no fechamento do pregão. Também é possível definir uma opção asiática $\operatorname{com} g(S)$ sendo igual a média dos valores assumidos pelos preços do ativo base durante toda a sua trajetória, e no caso teríamos uma opção asiática com média contínua (continuous averaging). Este tipo de opção asiática é menos comum que o primeiro. 
A média a ser calculada pode ser definida como a média aritmética ou a média geométrica. A principal dificuldade na precificação de uma opção asiática ocorre quando seu payoff é baseado em uma média aritmética, e se deve ao fato do processo que definimos para modelar a dinâmica do preço do ativo base possuir incrementos multiplicativos, e assim a distribuição de probabilidades da soma destes valores se torna intratável em um modelo a tempo contínuo. Como conseqüência, não existe uma solução analítica para a obtenção do preço de mercado de uma opção asiática com média aritmética, sendo fundamental o uso de um processo de aproximação.

Com base nos dados de entrada do problema e assumindo que o horizonte para o cálculo da média dos preços do ativo base na função de payoff iniciasse na data de cálculo, encontramos o preço de mercado de uma fictícia opção de compra asiática com exercício do tipo europeu (média aritmética discreta pelos preços de fechamento) aplicando o algoritmo da seção anterior para alguns valores de $n$ e de nsim. Constatamos que o principal determinante da convergência deste algoritmo foi o número de simulações. A tabela da página a seguir apresenta os resultados obtidos. Note que os resultados foram um tanto instáveis efetuando-se 1.000 simulações, no entanto mesmo trabalhando-se apenas com 5.000 simulações já obtivemos resultados mais estáveis, sugerindo uma convergência adequada.

Observamos que, neste mesmo dia, uma opção de compra padrão de mesmo ativo base, preço e data de exercício foi negociada na Bolsa de Valores de São Paulo por $\mathrm{R} \$ 905,00$. A tabela com os resultados da aplicação do algoritmo sugere que o preço de mercado da opção asiática em estudo esteja em torno de $\mathrm{R} \$ 495,00$. Isto indica que uma opção asiática é muito mais barata do que uma opção padrão de mesmas características.

\begin{tabular}{|c|c|c|}
\hline & \multicolumn{2}{|c|}{ PRECYO OBTIDO } \\
\hline & $n \operatorname{sim}=1000$ & $n \mathrm{sim}=5000$ \\
\hline & 506,164 & 490,697 \\
\hline$\frac{84}{168}$ & 483,935 & 479,676 \\
\hline $\begin{array}{l}\frac{168}{3336} \\
\end{array}$ & 477,536 & 485,603 \\
\hline 336 & 520,357 & 495,500 \\
\hline 672 & 435,688 & 494,115 \\
\hline 1344 & 467,367 & 496,507 \\
\hline
\end{tabular}


O motivo deste fato reside na característica menos agressiva de uma opção asiática. Intuitivamente, como o fluxo de caixa gerado por esta opção depende da média aritmética dos preços do ativo base durante um determinado período, a chance de que a opção esteja fora do dinheiro na data do exercício (ou seja, tenha valor igual a zero) é menor do que se ela dependesse apenas do ponto final da trajetória, que possui uma distribuição de probabilidades muito mais dispersa que a da média dos valores assumidos durante a trajetória. No entanto, isto também diminui o valor deste fluxo de caixa nas situações em que ele é positivo, e é exatamente este valor que dita o preço justo de uma opção, já que esta nunca irá gerar fluxo de caixa negativo para seu titular. Quando a opção está vinculada a algo mais volátil, ela se torna mais valiosa já que, apesar de um acréscimo na volatilidade aumentar tanto a chance de que ela pague menos como a chance de que ela pague mais, há uma assimetria oriunda do fato de que esta permite ao titular não exercê-la se der prejuízo, mas exercê-la sempre que ela der lucro. A assimetria existe exatamente pelo fato de uma opção ser um direito, e não um dever.

Deste modo, verifica-se que uma opção asiática está mais recomendada para investidores menos agressivos e menos dispostos a correr todos os riscos inerentes ao mercado financeiro. Além de garantir uma diminuição nos riscos ela é mais barata do que uma opção padrão. É claro que estes benefícios não vêm de graça - ela não irá garantir ao seu titular tanto retorno quanto uma opção padrão garante.

Finalizamos este capítulo precificando uma opção lookback com exercício europeu. Em uma opção lookback de strike fixo igual a $K$, o valor de $g(S)$ é obtido calculando-se o menor valor assumido pelo preço do ativo base durante toda a sua trajetória caso se trate de uma opção de compra, ou então o maior valor assumido pelo preço deste ativo caso se trate de uma opção de venda.

Na precificação deste tipo de opção, a passagem do mundo em tempo contínuo para o mundo em tempo discreto exige que se tome muito cuidado na hora de se dimensionar o comprimento do período. Se o comprimento do período não for pequeno o suficiente, corremos o risco de estar subprecificando demasiadamente a opção lookback. Para verificar este fato, considere o gráfico da trajetória do IBOVESPA entre os dias 01 de abril de 2004 e 01 de julho de 2004, apresentado na Figura 36 e considere que desejamos obter a tempo discreto o mínimo desta trajetória, necessário para o cálculo da função de payoff de uma opção de venda lookback. 


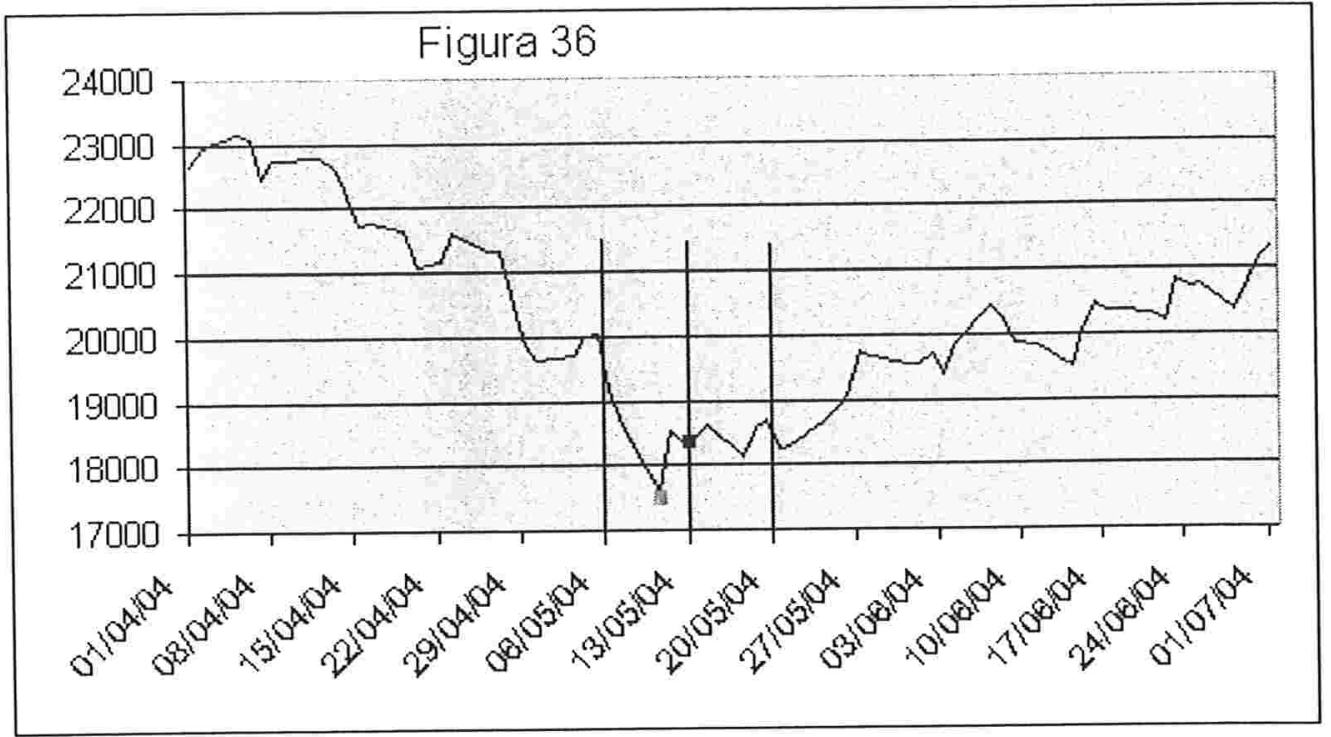

O leitor pode perceber que o mínimo ocorreu em um ponto entre os dias 06 e 13 de maio, igual a 17.610 pontos. No entanto, caso o comprimento do período em nosso tempo discreto fosse de uma semana, estaríamos obtendo um outro valor para o mínimo, igual a 18.409 pontos (o ponto do dia 13 de maio), cometendo assim na nossa aproximação um erro de quase $5 \%$ do valor real e obtendo um valor muito menor do que o devido para o payoff de uma opção lookback de venda.

Implementamos o cálculo do preço de uma opção lookback fictícia de compra com strike fixo e mesmos parâmetros que os da opção asiática precificada anteriormente. A tabela a seguir apresenta os resultados obtidos para alguns valores de $n$ e de $n \operatorname{sim}$. Note que o algoritmo aplicado a esta opção não convergiu rapidamente, precisando de mais de mil passos para que o preço obtido a tempo discreto convergisse para o preço que seria obtido a tempo contínuo, o qual possui fórmula fechada para o caso de uma opção européia, encontrada em Conze \& Vizwanathan (1991), e é apresentado na última linha da tabela. Apesar da maior necessidade de passos, o algoritmo de precificação, se bem implementado, não consome muito tempo de processamento. Foi necessário aproximadamente um minuto para que o código apresentado no Anexo 3 calculasse o preço da opção de interesse com $n \operatorname{sim}=5.000$ e $n=1.344$ em um Pentium III 500 Mhz com sistema operacional Windows $98 \mathrm{e}$ 196 MB de memória RAM. 


\begin{tabular}{|c|c|c|}
\hline & \multicolumn{2}{|c|}{ PREÇO OBTIDO } \\
\hline & $n \operatorname{sim}=1000$ & $n \operatorname{sim}=5000$ \\
\hline $\begin{array}{l}42 \\
84\end{array}$ & $1.525,61$ & $1.537,59$ \\
\hline $\begin{array}{c}84 \\
168\end{array}$ & 1.568 & 599,20 \\
\hline$\frac{168}{336}$ & $1.583,07$ & $.593,61$ \\
\hline 336 & $1.644,32$ & $1.620,37$ \\
\hline 672 & $1.654,62$ & $1.609,94$ \\
\hline 1344 & $1.673,49$ & $1.668,05$ \\
\hline CONTINUO & & $1.670,13$ \\
\hline
\end{tabular}

Diversas técnicas podem ser aplicadas para melhorar o algoritmo da seção anterior e apressar a convergência. Uma das sugestões para diminuir o número de simulações necessárias é simular as variáveis aleatórias definidas em (6.6.1) com o uso de variáveis antitéticas. Neste procedimento, para cada valor simulado constrói-se uma simulação adicional de valor igual ao valor obtido menos duas vezes o quanto ele se desviou da média da distribuição teórica. Para o caso em que a distribuição teórica possui média zero, a idéia se resume a, para cada valor simulado, construir outra simulação adicional de mesmo valor absoluto e sinal invertido. Este procedimento é descrito em Kouwenberg (2001).

Para diminuir o tamanho de $n$, uma das sugestões é se utilizar da extrapolação de Richardson, descrita em Jeffreys \& Jeffreys (1988). A idéia da extrapolação de Richardson reside em tentar explicar o preço da opção obtido a tempo discreto como uma função de $n$. Se a função for bem escolhida, o valor da mesma para $n \rightarrow \infty$ irá aproximar com boa precisão o preço da opção a tempo contínuo.

A convergência do algoritmo de precificação de uma opção lookback é um grande exemplo da necessidade da condição que as medidas de probabilidade associadas ao processo aproximador sejam apertadas para que haja convergência fraca (vide a Definição 5.2), não bastando que haja convergência pontual entre as medidas associadas ao processo aproximador e as associadas ao processo aproximado. Lembramos que, pelo Teorema 5.9, uma seqüência de medidas de probabilidade em $(C, \mathcal{C})$ é apertada se ela somente atribui peso às trajetórias cujo ponto inicial é limitado (que é o caso das nossas trajetórias pois elas sempre começam com $S(0))$ e se for válido que

$$
\lim _{\delta \rightarrow 0} \sup _{n}\left\{P_{n}\left(x: w_{r}(\delta)>\varepsilon\right)\right\}=0, \forall \varepsilon>0,
$$


$\operatorname{com} w_{x}(\delta)=\sup _{|s-t|<\delta}|x(s)-x(t)|, 0<\delta<1$.

A condição dada em (6.7.1) pode ser interpretada como a afirmação de que, para um comprimento de período suficientemente pequeno (ou seja, um valor de $n$ suficientemente grande), a medida de probabilidade atribuída às trajetórias onde há uma oscilação muito forte entre dois instantes de tempo discretos tende a zero. Em outras palavras, como as medidas de probabilidade associadas ao processo aproximador são apertadas, a partir de um certo valor de $n$ a probabilidade de que o nosso algoritmo calcule erroneamente o valor do mínimo (ou máximo) da trajetória a tempo contínuo como aconteceu no exemplo da Figura 36 se reduz a zero, garantindo assim a convergência do mesmo.

O leitor deve ter percebido que uma opção lookback de strike fixo é muito mais cara que uma opção padrão de mesmas características (enquanto a opção padrão foi negociada a $R \$ 905,00$, o preço de mercado da opção lookback foi de $R \$ 1.670,13)$. Isto se deve ao fato da opção lookback garantir preços muito melhores ao seu titular, podendo ser utilizada por este como um veículo para se atingir o sonho de se comprar na baixa e se vender na alta. Heynen \& Kat (1994) ilustram como pode ser feito para se atingir este sonho com o uso de uma opção lookback, apresentando o caso de um investidor que acredita em uma forte alta do mercado durante os próximos três meses.

Se este investidor hipotético tivesse comprado uma opção de compra padrão com preço de exercício igual ao preço a vista do ativo base no momento e, de fato, o preço do ativo base subisse fortemente durante dois meses, mas depois caísse tudo o que subiu no terceiro mês, este investidor não teria nenhum lucro com compra de sua opção, embora tenha acertado em cheio que o mercado iria subir. No entanto, se o mesmo investidor tivesse comprado uma opção de compra lookback naquele momento, não haveria problemas em que o mercado caísse no terceiro mês até mais do que ele subiu nos dois primeiros meses, já que o valor a ser recebido pelo titular no ato do exercício da opção continuaria sendo calculado com base no máximo atingido pelo preço do ativo base durante os três meses, não sendo impactado pela queda do último mês.

Toda esta comodidade gerada ao titular não vem gratuitamente, de modo que as opções lookback são muito caras comparadas com os demais tipos de opções. Este é um dos principais empecilhos para que este tipo de opção se torne mais popular no mercado mundial. 


\section{USANDO A TEORIA PARA PRECIFICAR OPÇÕES AMERICANAS}

\subsection{Uma equação para o preço de uma opção com exercício do tipo americano}

Como visto nos capítulos anteriores, a diferença entre uma opção com exercício do tipo americano e uma com exercício do tipo europeu, mantidas iguais as demais características destas opções, está no fato de que a primeira permite ao seu titular que este exerça o seu direito de compra ou venda antecipadamente, a qualquer momento. Desta forma, por se tratar de um direito adicional que é dado ao titular, esta opção possui valor maior ou igual que a sua similar com exercício europeu.

A dificuldade em precificar uma opção com exercício do tipo americano está no fato de que o fluxo de caixa gerado por esta é menos previsível que o de uma similar com exercício do tipo europeu, visto que este fluxo de caixa não irá mais acontecer em uma data predeterminada, e sim a qualquer momento, dependendo de se é mais vantajoso para o titular exercer o seu direito naquele momento ou não. No entanto, a resposta à questão de se é mais vantajoso ou não exercer antecipadamente uma opção americana depende, entre outros fatores, dos valores futuros que o preço do ativo base pode assumir. Portanto, o valor de uma opção com este tipo de exercício depende, além da trajetória passada do preço do ativo base, da trajetória futura esperada para este mesmo preço.

Note que a forma da função de payoff de uma opção americana é a mesma que a de uma opção européia, a diferença estará no instante em que esta opção é exercida. Assim, se o titular souber o instante de tempo $t \in[0 ; 1]$ exato em que ele deve exercer a sua opção, a função de payoff de uma opção americana de compra será

$$
f(S, t)=\max \left(0 ; g\left(S_{t}\right)-h\left(S_{t}\right)\right) \text {, }
$$

onde $S$ é a trajetória do preço do ativo base entre a data do início da opção (que pode, sem perda de generalidade, ser assumida como a data de cálculo) e a última data do exercício, sendo assim um elemento de $C$, e $S$, denota esta trajetória apenas entre a data de início da opção e o instante de tempo $t$. A função de payoff de uma opção americana de venda é definida de forma análoga.

Assim, a questão chave em achar o preço de mercado de uma opção americana está em determinar o instante de tempo $t$ tal que é ótimo exercer antecipadamente esta opção. 
Claramente, para cada trajetória do preço do ativo base haverá um instante ótimo $t$. Por exemplo, só compensará exercer antecipadamente uma opção de venda americana se o preço do ativo base cair o suficiente. Nas trajetórias onde isto acontece no começo das mesmas, o exercício antecipado será ótimo já no começo destas, ou seja, para valores de $t$ próximos de zero. Nas trajetórias onde isto só acontece em um instante de tempo mais próximo do final da trajetória, o exercício antecipado será ótimo somente nos últimos instantes de tempo, ou seja, para valores de $t$ próximos de um.

Vamos agora observar que, se no momento imediatamente anterior ao do exercício regular da opção, um investidor que não a exerceu até este momento, não a exercesse antecipadamente novamente, ele estaria neste momento dando a ela o mesmo valor que o de uma opção européia (pois ele não terá outra chance de exercê-la antecipadamente). Este valor já sabemos que, para uma opção de compra, é igual a

$$
I\left(S_{1-}\right)=e^{-r d t} E^{Q}\left[\max \left(0 ; g\left(S_{1}\right)-h\left(S_{1}\right)\right)\right],
$$

onde $r$ denota a taxa livre de risco expressa em percentual ao ano sob o conceito de capitalização contínua, $d t$ denota o tempo em anos decorrido entre os dois instantes, e $E^{Q}$ significa que a esperança deve ser tomada em relação a medida neutra ao risco. Esse valor também é conhecido como valor de continuação da opção ou valor intrínseco.

Como o nosso mercado é composto por investidores racionais que, para o mesmo nível de risco, desejam maximizar o seu retorno esperado, é razoável assumir que eles sempre irão exercer a sua opção quando isto Ihes proporcionar um fluxo de caixa superior ao valor intrínseco da opção, portanto o valor de uma opção americana no momento imediatamente anterior ao do exercício regular da mesma é igual a

$$
\operatorname{Pr}_{1-}=\max \left(g\left(S_{1_{-}}\right)-h\left(S_{1_{-}}\right) ; I\left(S_{1-}\right)\right) \text {, }
$$

Já no instante imediatamente anterior ao instante imediatamente anterior ao do exercício (o qual denotaremos por 1--), o valor intrínseco de uma opção americana pode ser definido em função do valor da opção no instante imediatamente seguinte já que, se não exercê-la até aquele instante, o titular teria a chance de exercê-la no instante imediatamente seguinte. Neste caso poderemos aplicar o mesmo conceito de precificação neutra ao risco, e o valor intrínseco da opção seria igual ao preço esperado da mesma sob a medida neutra ao risco no instante imediatamente posterior trazido a valor presente pela taxa de juros livre de risco, ou seja:

$$
I\left(S_{1--}\right)=e^{-r \cdot t h} E^{Q}\left[\max \left(0 ; \operatorname{Pr}_{1-}\right) \mid S_{1--}\right]
$$


Note que a esperança está condicionada à trajetória do ativo base no instante 1-- pois esta é conhecida e terá influência direta na trajetória do preço ativo base no instante posterior.

O leitor agora já deve ter percebido que podemos recursivamente calcular o preço da opção, já que o preço da mesma em 1-- pode ser calculado uma vez que seu valor intrínseco é conhecido neste momento. Portanto, trabalhando com tempo discreto e particionando o intervalo de tempo em $n$ subintervalos, temos que o preço de uma opção americana de compra pode ser dado a qualquer instante $i$ por

$$
\operatorname{Pr}_{i}=\max \left(g\left(S_{i}\right)-h\left(S_{i}\right) ; e^{-r d t} E^{Q}\left[\max \left(0 ; \operatorname{Pr}_{i+1}\right) \mid S_{i}\right]\right)
$$

com

$$
\operatorname{Pr}_{n}=\max \left(0 ; g\left(S_{n}\right)-h\left(S_{n}\right)\right)
$$

\subsection{Modificando o algoritmo da Seção 6.3 para o caso das opções americanas}

O algoritmo da Seção 6.3 pode ser facilmente adaptado para que ele considere a precificação de uma opção com exercício do tipo americano, bastando que o passo (v) - o cálculo da esperança sob a medida neutra ao risco - seja adaptado para trabalhar de forma recursiva, utilizando uma técnica conhecida como programação dinâmica. Apresentamos a seguir o algoritmo para achar o preço de uma opção padrão:

(i) Escolha $n$.

(ii) Defina $n$ variáveis aleatórias independentes $\xi_{1}, \xi_{2}, \ldots, \xi_{n}$ com a seguinte distribuição:

$$
P\left[\xi_{k}=\frac{1}{\sqrt{n}}\right]=P\left[\xi_{k}=-\frac{1}{\sqrt{n}}\right]=\frac{1}{2}, \quad 1 \leq k \leq n .
$$

(iii) Construa o processo $Z^{(n)}(t)$ igual à função aleatória definida em (5.3.3) tomando como as parcelas do somatório as variáveis aleatórias $\xi_{1}, \xi_{2}, \ldots, \xi_{n}$ construídas no passo (ii).

(iv) Defina a seguinte medida de probabilidade em $(C, C)$ :

$$
P_{n}[x]=P\left[Z^{(n)}(t)=x(t) \text { para todo } t \in[0 ; 1]\right] .
$$

(v) Defina $\operatorname{Pr}_{\mathrm{n}}$ como em (7.1.6) tomando

$$
S(1)=S(0) \times \exp \left\{\left(r-\frac{1}{2} \sigma^{2}\right) T+\sigma Z^{(n)}(1) \sqrt{T}\right\}
$$


(vi) Calcule, para $i$ variando de $n-1$ até 0 , o valor de $\operatorname{Pr}_{i}$ conforme a equação (7.1.5) utilizando a seguinte equação para o processo do preço:

$$
S(i / n)=S(0) \times \exp \left\{i\left(r-\frac{1}{2} \sigma^{2}\right) d t+\sigma Z^{(n)}(i / n) \sqrt{(i / n) d t}\right\} .
$$

No algoritmo apresentado, $T$ é o tempo em anos entre a data de cálculo e a última data de exercício. $O$ valor de $d t$ é obtido dividindo $T$ pelo número de partições efetuadas no intervalo de tempo.

\subsection{Resultados da implementação do algoritmo da Seção 7.2}

Implementamos o algoritmo descrito na seção anterior, cujo código em linguagem C++ é apresentado no Anexo 3, com o intuito de apresentar ao leitor as diferenças entre os preços de opções européias (calculados com o algoritmo da Seção 6.3) e americanas de características similares. Efetuamos os cálculos para quatro tipos de opções padrão de mesmo ativo base, strike e data de exercício:

> Venda com exercício europeu;

$>$ Venda com exercício americano;

$>$ Compra com exercício europeu; e

$>$ Compra com exercício americano.

As opções tiveram como ativo base o IBOVESPA, com strike a 25.000 pontos e data de exercício no dia 16 de fevereiro de 2005. A base dos cálculos foi o fechamento do dia 14 de janeiro de 2005, situação em que o preço do ativo base era de 24.924 pontos e a taxa livre de risco expressa em termos anuais sob o conceito de capitalização contínua era igual a 0,16629 (mesmos parâmetros utilizados na Seção 6.5). A volatilidade anual dos retornos do ativo base foi estimada conforme descrito na Seção 6.2 com base nas observações diárias das pontuações de fechamento do IBOVESPA entre os dias 15 de setembro de 2004 e 14 de janeiro de 2005, base do cálculo, sendo igual a 0,19267.

Os preços foram calculados tomando $n$ igual a 210. A tabela a seguir apresenta os resultados obtidos: 


\begin{tabular}{|c|c|c|}
\hline \multicolumn{3}{|c|}{$\begin{array}{c}\text { VALORES OBTIDOS PARA AS OPÇÖES } \\
\text { PADRÄO SOBRE IBOVESPA }\end{array}$} \\
\hline & EUROPÉ|A & AMERICANA \\
\hline COMPRA & 694,64 & 694,64 \\
\hline VENDA & 426,47 & 462,21 \\
\hline
\end{tabular}

O leitor pode notar que a opção européia de venda é de fato um tanto mais barata que a sua similar com exercício americano, no entanto as opções de compra apresentam o mesmo valor independente do tipo de exercício. Os resultados obtidos não são mera coincidência, sendo de fato possivel formular o seguinte teorema, atribuído a Merton (1973):

TEOREMA 7.1. Suponha que o mercado é composto por investidores racionais, os quais nunca comprarão um ativo $B$ em detrimento de um ativo $A$ se eles souberem que, em alguma uma data futura, o retorno de $A$ será estritamente maior que $O$ de $B$ para alguns cenários desta data e também será sempre pelo menos igual ao de $B$ para todos os cenários. Então nunca será ótimo exercer antecipadamente uma opção de compra padrão com exercício americano, e portanto uma opção de compra padrão com exercício americano tem o mesmo valor que uma opção de compra padrão com exercício europeu de mesmas características.

Para provar este teorema, precisamos antes do seguinte lema:

LEMA 7.1. Seja $c_{t}$ o preço de uma opção de compra padrão européia no instante $t$ e seja $T$ o tempo entre a data de início desta opção e a data de exercício. Em um mercado onde todos os investidores são racionais no sentido do Teorema 7.1, sempre teremos que:

$$
c_{t}>S(t)-K e^{-r(T-t)} \text {. }
$$

Prova. Considere o ativo $A$ equivalente a uma carteira composta por um investimento de $c_{l}$ na opção de compra padrão européia e mais $K e^{-r(T-t)}$ em títulos de renda fixa livres de risco e o ativo $B$ equivalente a um investimento de $S(t)$ no ativo base. No instante de exercício $T$, o ativo base (e portanto o investimento $B$ ) irá valer $S(T)$. Considere agora os seguintes cenários:

- $S(T) \leq K$. Neste caso a opção não terá valor e portanto o ativo $A$ terá valor igual a $0+K=K$, sendo mais caro que o ativo $B$. 
> $S(T)>K$. Neste caso o valor da opção será igual a $S(T)-K$ e portanto o valor do ativo $A$ será igual a $(S(T)-K)+K=S(T)$, possuindo assim o mesmo valor que o ativo $B$.

Portanto, na data $T$, o ativo $A$ terá valor estritamente maior que o de $B$ para alguns cenários e também será sempre pelo menos igual ao de $B$ para todos os cenários. Assim, como o mercado é composto por investidores racionais, o preço do ativo $A$ tem que ser estritamente maior que o preço do ativo $B$, do contrário o seu retorno superará o retorno do ativo $B$ em alguns cenários e será pelo menos igual ao de $A$ em todos os cenários, o que será uma contradição à hipótese de que os investidores deste mercado são racionais.

Logo, teremos que $c_{t}+K e^{-r(T-t)}>S(t) \Rightarrow c_{t}>S(t)-K e^{-r(T-t)}$

Prova do Teorema 7.1. O investidor que estiver exercendo no instante $t$ uma opção de compra padrão com exercício do tipo americano estará, na prática, vendendo-a por $S(t)-K$. Ele, portanto, nunca o fará dado que o preço de uma opção americana é sempre maior ou igual ao de uma européia de mesmas características e o preço desta opção européia é, de acordo com o Lema 7.1, maior que $S(t)-K e^{-r(T-t)}>S(t)-K$.

\subsection{A fronteira ótima de exercício ou "curva de gatilho"}

Como visto no capítulo anterior, o algoritmo da árvore binomial pode até gerar excelentes resultados para as opções padrão, no entanto seu desempenho computacional não é bom quando desejamos precificar uma opção exótica. Para as opções exóticas, novamente sugerimos o uso da simulação de Monte Carlo.

A vantagem do algoritmo baseado em uma árvore binomial é que a decisão de exercer ou não uma opção é obtida de forma instantânea, visto que os cálculos já são feitos com as trajetórias já construídas e a partir do ponto final por recursão reversa. Em uma simulação de Monte Carlo o procedimento não é tão simples porque a simulação é feita do início para o fim da trajetória, e portanto, a não ser que o nosso algoritmo possua uma "bola de cristal" afirmando que a melhor oportunidade para exercer é naquele momento, e não em momentos futuros, não conseguiremos implementar a precificação de uma opção americana exótica. 
Caso esta "bola de cristal" seja conhecida, a precificação se torna um tanto simples, bastando alterar o algoritmo da simulação de Monte Carlo para considerar, durante a simulação de cada trajetória, que o exercício foi efetuado quando era ótimo. Depois bastará calcular o valor presente esperado sob a medida neutra ao risco do payoff da opção em cada uma das trajetórias simuladas, que terão diferentes pontos finais.

Felizmente a hipotética "bola de cristal" existe e seu funcionamento é um tanto intuitivo. Inicialmente exemplificaremos o funcionamento e a construção desta ferramenta tomando como base uma opção de venda padrão com exercício do tipo americano.

É intuitivo para o leitor que o exercício antecipado de uma opção de venda padrão seja efetuado somente se o preço do ativo base estiver baixo ao ponto de não compensar mais o risco de se manter esta opção em carteira e se perder todo o lucro acumulado com a queda do ativo. Se o preço do ativo base estiver em qualquer patamar inferior ao deste preço hipotético, então a opção sempre deve ser exercida.

Se o procedimento descrito no parágrafo anterior for verdadeiro, então a nossa "bola de cristal" na verdade será uma função no espaço $S(t) \times t$ determinando o valor de $S(t)$ a partir do qual sempre será ótimo exercer a nossa opção. Neste caso, a nossa ferramenta seria da seguinte forma:

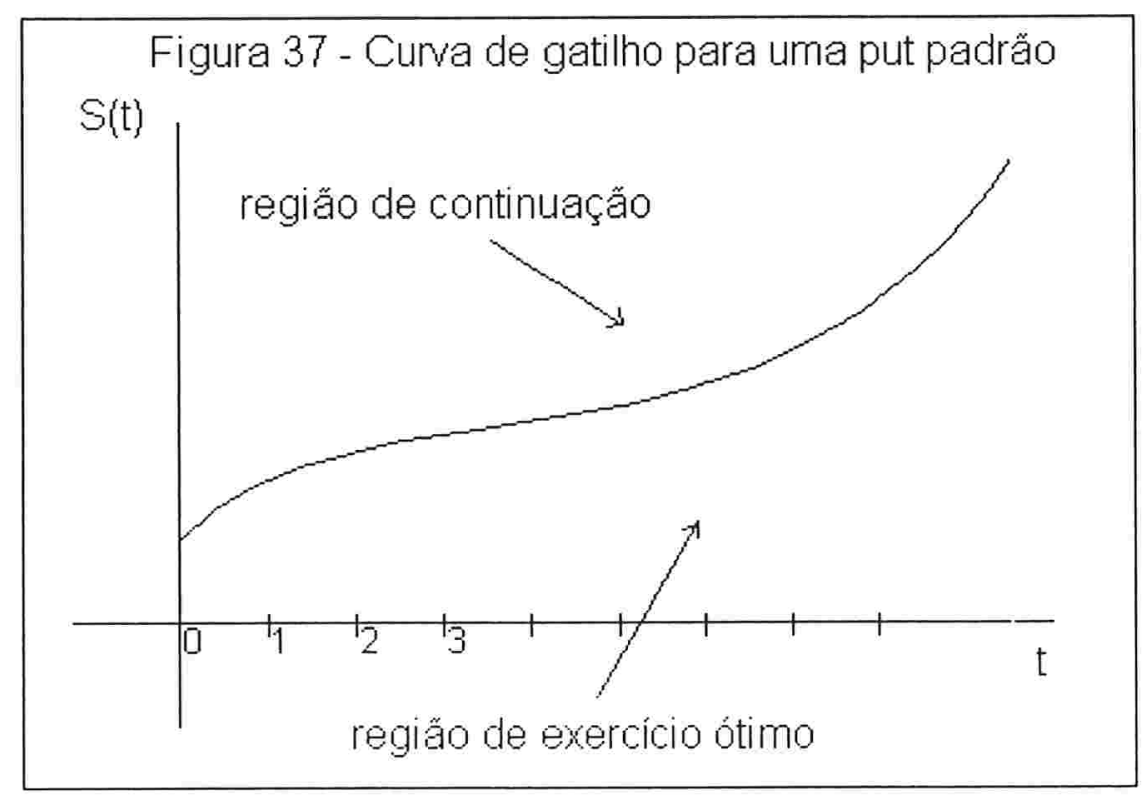


Felizmente a ferramenta ilustrada na Figura 37 existe e é conhecida na literatura como fronteira ótima de exercício ou curva de gatilho. A prova da existência desta fronteira pode ser econtrada em Wu \& Fu (2003), onde os autores também provam a existência da mesma para uma opção asiática.

\subsection{Modificando o algoritmo da Seção 6.6 para o caso das opções americanas}

Desta forma, para precificarmos opções asiáticas exóticas o algoritmo da Seção 6.6 deve ser alterado de forma a incluir dois passos:

$>$ Obter a curva de gatilho; e

- Verificar durante todos os instantes da trajetória simulada se o exercício antecipado é ótimo naquele momento e efetuar o exercício caso este seja ótimo.

A curva de gatilho é obtida com métodos numéricos, normalmente baseados em simulações reversa no tempo. Um dos modelos de simulação bastante utilizados devido à sua flexibilidade é o de Grant, Vora \& Weeks (1997), o qual trabalha a tempo discreto.

Exemplificamos este modelo considerando uma opção de venda padrão. Neste caso, o algoritmo seria como segue:

(i) Faça $t=T-1$.

(ii) Escolha um ponto $(S(t), t)$ e simule nsim trajetórias para o preço do ativo base a partir deste ponto até $O$ instante $T$ verificando durante os instantes intermediários $t+1, \ldots, T$ se a opção deve ser exercida em algum destes instantes ou não.

(iii) Calcule o valor intrínseco desta opção para o ponto $(S(t), t)$ escolhido. Caso o exercício antecipado seja ótimo para este ponto, busque o menor valor de $\varepsilon$ tal que em $(S(t)+\varepsilon, t)$ o exercício antecipado não seja mais ótimo (por exemplo, repita o passo (ii) com o ponto $(S(t)+\varepsilon, t)$ aumentando gradualmente os valores de $\varepsilon$ até não seja mais ótimo o exercício antecipado). Caso o exercício antecipado não seja ótimo para este ponto, busque o maior valor de $\varepsilon$ tal que em $(S(t)-\varepsilon, t)$ o exercício antecipado passe a ser ótimo.

(iv) Faça $t=t-1$ e repita os passos (ii) e (iii) até $t=0$. 
A escolha do ponto $(S(t) \pm \varepsilon, t)$ que deve ser feita no passo (iii) pode ser feita também utilizando um algoritmo de bisseção conforme descrito no Seção 7.3.2 de Frota (2003). Este procedimento necessitará de menos iterações para encontrar o verdadeiro ponto da curva de gatilho. Concluído o cálculo da curva de gatilho, deve-se prosseguir com os seguintes passos:

(i) Escolha $n$ (número de subintervalos em que o intervalo de tempo entre a data de cálculo e o exercício será particionado) e escolha nsim (número de simulações a serem efetuadas).

(ii) Defina $n \operatorname{sim} \times n$ variáveis aleatórias independentes $\xi_{j}^{i}$, para $1 \leq i \leq n \operatorname{sim}$ e $1 \leq j \leq n$ tais que:

$$
\xi_{j}^{i} \sim N\left(\left(r-\frac{1}{2} \sigma^{2}\right) \frac{1}{n}, \frac{\sigma^{2}}{n}\right) .
$$

(iii) Construa nsim trajetórias $S^{\prime}$, para $1 \leq i \leq n \operatorname{sim}$ e $1 \leq j \leq n$, tais que, para $t=\frac{j}{n}, S^{i}(t)=S(0) \times \exp \left\{\sum_{k=1}^{j} \xi_{i}^{i}\right\}$, para $t=0, S^{i}(t)=S(0)$ e, para os demais valores de $t, S^{i}(t)$ seja definida por interpolação linear entre seus pontos.

(iv) Para cada trajetória $S$, encontre com base na curva de gatilho o primeiro ponto tal que o exercício seja ótimo. Calcule os valores de $g\left(S^{i}\right)$ e de $h\left(S^{i}\right)$ e a sua função de payoff.

(v) Obtenha o preço da opção calculando

$$
P_{O P C \overline{\mathrm{A} O} O}=\frac{\sum_{i=1}^{n \operatorname{sim}} e^{-r t,} f^{i}}{n \operatorname{sim}} .
$$

onde $r$ denota a taxa livre de risco expressa em percentual ao ano sob o conceito de capitalização contínua, $f^{\prime}$ denota o valor da função de payoff da opção para a simulação $i$ e $t_{i}$ denota o tempo em anos até o primeiro ponto em que o exercício é ótimo na simulação $i$ (caso o exercício nunca tenha sido ótimo para esta simulação $t_{i}$ será igual ao tempo até a última data de exercício). 


\subsection{Implementando o algoritmo da Seção $7.5 \mathrm{com}$ dados do mercado brasileiro}

Implementamos o algoritmo da seção anterior (o código é apresentado no Anexo 3) para a precificação de uma fictícia opção de venda asiática com exercício americano cujo ativo base foi o IBOVESPA, com strike a 25.000 pontos e data de exercício no dia 16 de fevereiro de 2005. Todos os demais dados foram os mesmos que os utilizados na Seção 6.5.

Os resultados obtidos são apresentados na tabela abaixo. Apresentamos também os valores de uma opção asiática de venda com exercício europeu e demais características iguais para efeito de comparação dos preços. O leitor pode notar que a opção asiática americana possui maior valor que a européia.

\begin{tabular}{|c|c|c|}
\hline \multicolumn{3}{|c|}{$\begin{array}{l}\text { Valores obtidos aplicando o algoritmo } \\
\text { proposto para a precificação das opçöes } \\
\text { de compra asiática ficticias ( } n=63 \text { ) }\end{array}$} \\
\hline \multirow{2}{*}{ TIPO } & \multicolumn{2}{|c|}{ PRECO OBTIDO } \\
\hline & $n \operatorname{sim}=1000$ & $n \operatorname{sim}=5000$ \\
\hline EUROPÉIA & 260,413 & 264,682 \\
\hline AMERICANA & 293,989 & 290,275 \\
\hline
\end{tabular}




\section{TÓPICOS ADICIONAIS NA TEORIA DE PRECIFICAÇÃO DE OPÇÕES}

Concluímos o trabalho apresentando alguns tópicos importantes para os leitores que desejarem prosseguir com o estudo de modelos avançados. Para isso, retornamos à nossa discussão sobre as hipóteses assumidas e o princípio de precificação por neutralidade ao risco.

\subsection{A questão da volatilidade}

Uma das principais hipóteses assumidas em nossos cálculos foi a de que os retornos do ativo base definidos pelo processo $R(t)=\ln (S(t) / S(0))$ (apresentado no início da Seção 6.2) seguiam um movimento browniano com parâmetro de deslocamento $\mu$ e volatilidade $\sigma$. Todavia há muitos estudos, inclusive com observações do mercado brasileiro, mostrando que, na prática, os incrementos neste processo não aparentam ter distribuição Normal, possuindo uma distribuição empírica de caudas mais pesadas (ou seja, com uma maior probabilidade de ocorrência de eventos extremos).

O leitor no entanto deve lembrar da nossa discussão na Seção 3.3, na qual afirmamos que o próprio Teorema de Donsker já nos garantiria, sob certas condições, que a hipótese assumida sobre o processo $R(t)$ não estaria de todo incorreta. De fato, o teorema afirma que qualquer processo de incrementos aditivos, independentes e identicamente distribuídos irá assintoticamente se comportar como um movimento browniano com incrementos de mesma média e variância que os do processo qualquer. Desta forma, principalmente no caso da precificação de opções de compra padrão (independente do tipo de exercício), que são as mais negociadas em todo o mercado mundial, o fato da distribuição dos incrementos do processo $R(t)$ possuir caudas mais pesadas que as da Normal não geraria problemas, pois para precificar este tipo de opção só estaríamos interessados no valor final da trajetória, que assintoticamente seria igual ao de um movimento browniano.

O problema está um pouco mais em baixo: a hipótese de que os incrementos do processo $R(t)$ são independentes e identicamente distribuídos não parece ser válida. Caso o leitor se recorde da nossa discussão sobre a hipótese do mercado eficiente, ele lembrará que, apesar de eficiência de mercado claramente implicar que a variação no retorno 


\section{2 - Tópicos Adicionais na Teoria de Precificação de Opções}

acumulado de um determinado ativo no mercado se mova segundo um processo estocástico, o conceito de eficiência de mercado não necessariamente implicará que esta variação seja assintoticamente regida por um movimento browniano.

As evidências contra a hipótese de que os incrementos no processo de retorno acumulado de um ativo sejam independentes e identicamente distribuídos explicam alguns vieses sistemáticos observados nos modelos que assumem que este processo seja explicado por um movimento browniano, sendo o principal deles o excessivo erro de precificação em opções muito fora do dinheiro e muito dentro do dinheiro. Uma das formas utilizadas pela comunidade de engenheiros financeiros para tentar contornar este problema é utilizar o conceito de volatilidade implícita, introduzido por Black (1976).

Como o próprio nome diz, a volatilidade implícita de uma opção é o valor de $\sigma$ tal que o preço justo teórico desta opção calculado assumindo que o processo $R(t)$ siga um movimento browniano com volatilidade $\sigma$ seja igual ao preço que efetivamente está sendo negociado no mercado. Este conceito já foi utilizado no decorrer deste trabalho (mais precisamente na Seção 6.7), exatamente com a mesma finalidade que os engenheiros financeiros normalmente o utilizam: comparar preços de diferentes opções.

O valor de volatilidade implícita normalmente é diferente de uma opção para outra, indicando exatamente qual opção está mais "cara" ou "barata". Além disso, a volatilidade implícita da mesma opção pode variar com o tempo; a comparação da volatilidade implícita de uma mesma opção hoje com a de ontem pode nos indicar quão forte está a demanda por esta opção hoje comparada com a demanda verificada ontem. Alguns exemplos reais:

> No dia 14 de janeiro de 2005, uma opção de compra americana de IBOVESPA com strike a 25.000 pontos esteve negociada a $\mathrm{R} \$ 905,00$, a uma volatilidade implícita igual a 0,26785. Ao mesmo tempo, uma opção de venda americana de IBOVESPA de mesmo strike e data de vencimento esteve negociada a $\mathrm{R} \$ 957,00$, a uma volatilidade implícita igual 0,36885. A maior volatilidade implícita na put indicava uma maior demanda pela mesma, significando que os investidores estavam mais cautelosos com o rumo do mercado e pagando mais caro para ter o direito de vender o ativo a um preço determinado do que para ter o direito de compra-lo pelo mesmo preço. De fato, na semana seguinte o preço do ativo base caiu de 24.924 para 23.818, confirmando a informação de que os investidores precificavam como mais provável uma queda no preço deste ativo. 
> No dia 21 de janeiro de 2005, na semana seguinte à fatídica queda, uma opção de compra americana de IBOVESPA com strike a 24.000 pontos (ou seja, a de valor strike mais próximo do preço do ativo base no momento) esteve negociada a $\mathrm{R} \$ 809,00$, a uma volatilidade implícita 0,32621 - note o aumento na volatilidade implícita em uma semana, já que este número é razoavelmente comparável com os 0,26785 da opção de strike de 25.000 da semana anterior, que era a mais próxima de estar no dinheiro. Isto foi um indicativo de que os investidores estavam precificando um aumento na probabilidade de uma alta no preço deste ativo. De fato, após duas semanas (no dia 04 de fevereiro de 2005) este ativo já estava sendo negociado a 25.731 pontos $^{10}$.

Outro fator que pode ser notado é que a volatilidade implícita de uma opção padrão normalmente é superior à volatilidade histórica do ativo base calculada com base em séries de freqüência menor, conforme descrito na Seção 6.2. Isto se deve ao fato dos retornos dos ativos no mercado normalmente serem autocorrelacionados positivamente. Para compreender isto, considere as três séries apresentadas na Figura 38.

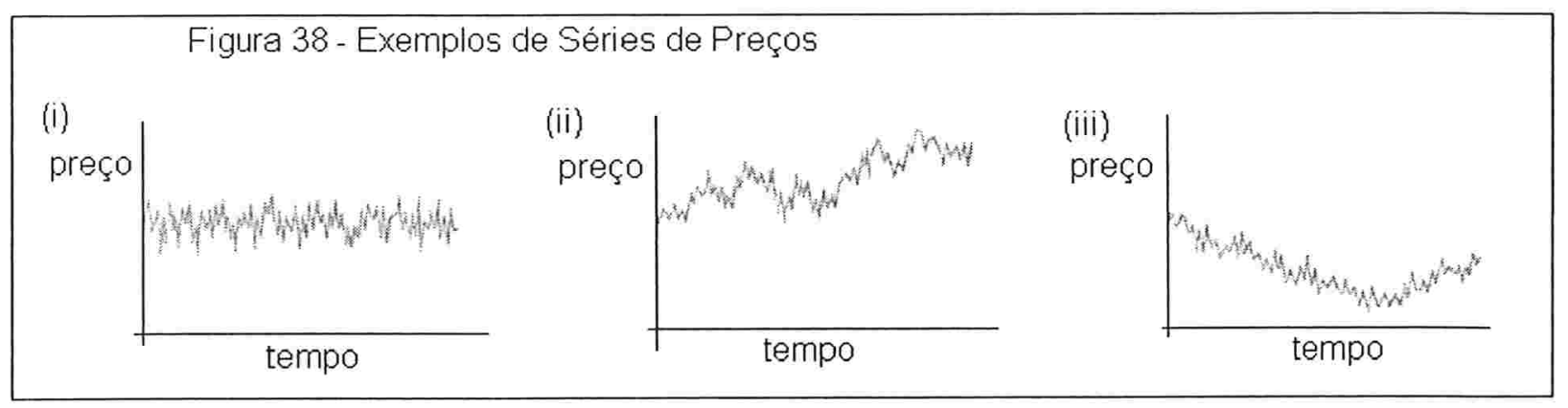

A série ilustrada em (i) possui incrementos autocorrelacionados negativamente, sendo um exemplo de série com reversão à média. A variância do ponto final da trajetória é razoavelmente pequena nesta série, sendo inferior à variância do ponto final da trajetória de

\footnotetext{
${ }^{10}$ Os exemplos dados apenas ilustram um dos usos comuns da volatilidade implícita para se inferir sobre o retorno esperado de um ativo, não constituindo recomendação de estratégia de investimentos. De fato, estes resultados devem ser vistos com ressalvas já que as opções sobre IBOVESPA possuem poucos negócios diários, embora estes sejam feitos em volumes financeiros altos dado que as opções sobre IBOVESPA são um dos veículos preferidos dos investidores institucionais e corporativos mais arrojados. Acrescentamos que volatilidade implícita de uma opção também pode ser influenciada por demandas unilaterais oriundas de distorções do mercado. Por exemplo, em 1995, no auge de sua carreira especulativa, Nick Leeson vendeu tantas opções de Nikkei que deixou a volatilidade implícita destas opções bem abaixo dos níveis históricos.
} 
um movimento browniano, ilustrada na série (ii), na qual estes incrementos são independentes. A terceira série possui incrementos autocorrelacionados positivamente, movendo-se em tendências. No caso da terceira série, a variância do ponto final da trajetória é superior à do movimento browniano.

Se o leitor voltar ao capítulo anterior e observar a Figura 36, que é uma série de preços observados no mercado, irá perceber que esta série é muito mais parecida com a série (iii) do que a série (ii), que é a assumida no cálculo dos modelos de precificação de opções apresentados até o momento. Assim, o ajuste de freqüência proposto em (6.2.8) tende a subestimar a verdadeira variância do ponto final da trajetória, cujo valor é muito importante na precificação das opções.

Os engenheiros financeiros estão cientes deste fato. A maneira mais simplista de lidar com este inconveniente é ajustar o modelo de precificação para trabalhar com uma volatilidade em patamares superiores ao da volatilidade histórica obtida com dados de freqüência menor. Mas a série de retornos obtida com o ajuste ainda não se comportará como a série (iii), continuando a se comportar como a série (ii), só que mais dispersa.

É claro que é muito mais confiável ao invés de trabalharmos com adaptações, utilizarmos modelos que expliquem os deslocamentos do processo $R(t)$ como não independentes, com memória longa ou tendência de reversão à média, de forma a lidarmos melhor com as observações históricas. Um destes modelos, o $\mathrm{GARCH}$, foi inicialmente proposto por Bollerslev (1986). A adaptação deste modelo para o problema de precificação de opções foi proposta por Duan (1995), com um modelo que será exposto na próxima seção deste trabalho.

\subsection{O modelo GARCH para precificação de opções}

O modelo de Duan (1995) pertence à classe dos modelos de precificação de opções com volatilidade estocástica. A criação desta classe de modelos se baseia nas evidências empíricas de que os incrementos do processo $R(t)$ não sejam identicamente distribuídos, possuindo diferentes variâncias, as quais também aparentam ser oriundas de um processo aleatório. Desta forma, assume-se que estes incrementos possuam mesma média, porém constrói-se um modelo para a previsão da variância.

Um dos modelos para previsão da variância em um processo a tempo discreto é o conhecido GARCH (Generalized Auto Regressive Conditional Heteroskedasticity). Um 
processo de variância regida pelo modelo $\operatorname{GARCH}(p, q)$ é um processo $\varepsilon_{t} \sim N\left(0, h_{t}\right)$, cuja variância $h_{t}$ em um determinado instante de tempo $t$ é da forma

$$
h_{t}=\omega+\sum_{i=1}^{q} \alpha_{i} \varepsilon_{t-i}^{2}+\sum_{i=1}^{p} \beta_{i} h_{t-j} .
$$

Figura 39 - Ilustração de um processo GARCH $(1,1)$

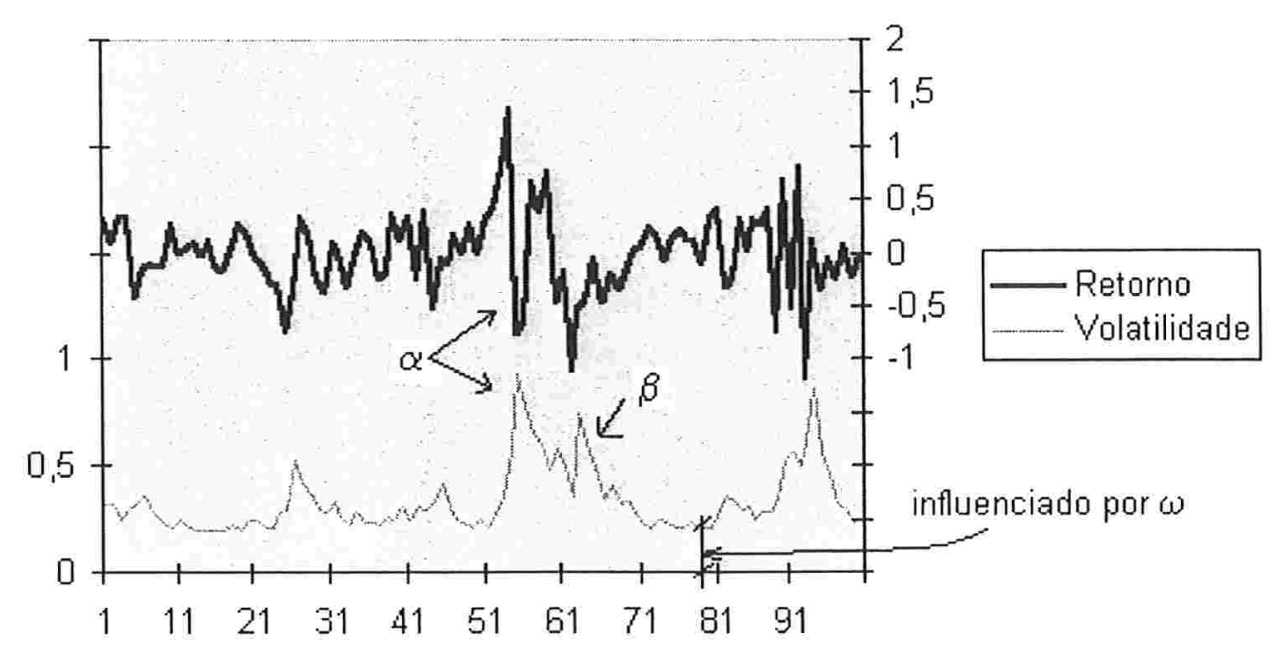

A Figura 39 ilustra uma série de incrementos no processo de retorno cuja variância seja regida pelo modelo $\mathrm{GARCH}(1,1)$. Por meio da figura é possível interpretarmos o significado de cada parâmetro deste modelo. O leitor pode notar que um processo GARCH $(1,1)$ possui três fatores explicativos para a sua variabilidade:

- O leitor deve perceber que no processo ilustrado na Figura 39, após um primeiro momento de choque (alta variância) que surge aleatoriamente, o processo tende a apresentar um acréscimo na sua variância no instante seguinte, dando prosseguimento ao choque. O leitor deve perceber que algo semelhante ocorre muito freqüentemente nos mercados de capitais: de repente uma notícia muito drástica e imprevista impacta a volatilidade do mercado em um determinado dia gerando uma forte alta ou queda, e logo após a notícia temos ainda um aumento na volatilidade, com um novo movimento forte na mesma direção ou até mesmo na direção oposta do movimento anterior. A principal função do parâmetro $\alpha$ é dimensionar o tamanho do impacto destas inovações aleatórias na variância do período seguinte. 
> O leitor também deve perceber que a variância do processo ilustrado na Figura 39, uma vez jogada para cima, tem memória longa, decaindo aos poucos com o tempo, sendo assim um processo autocorrelacionado. Esta auto correlação é ditada principalmente pelo parâmetro $\beta$.

$>\mathrm{Na}$ ausência de momentos de choque, a variância tende a cair e ficar constante em um determinado nível. A principal função do parâmetro $\omega$ é dimensionar este nível. O leitor deve notar que este nível não é o próprio valor de $\omega$, pois valores assumidos pela variância do processo no passado também influenciam o seu nível em um determinado instante, e portanto o parâmetro $\beta$ também o influencia. No exemplo da figura tivemos $\omega=0,02$ enquanto que o nível mínimo a que nos referimos foi de aproximadamente 0,036 . No entanto, mantidos os valores de $\alpha$ e de $\beta$ e criando um processo com $\omega=0,03$ (um aumento de $50 \%$ ), o nível mínimo assumido pela variância passou a ser de 0,055 (um aumento também próximo de $50 \%$ ), corroborando com a nossa afirmação de que este nível mínimo é diretamente influenciado pelo valor de $\omega$.

O primeiro passo do modelo proposto por Duan é assumir que a variância deste processo seja regida por um modelo GARCH. Desta forma, no caso de um modelo $\mathrm{GARCH}(1,1)$, o processo de preço do ativo base $S(t)$ será dado por

$$
S(t)=S(t-1) \times \exp \left\{\mu d t+\varepsilon_{r}\right\}
$$

onde $d t$ é o comprimento em anos do período de tempo discreto e $\varepsilon_{t} \sim N\left(0, h_{t}\right)$, com

$$
h_{t}=\omega+\alpha_{i} \varepsilon_{t-1}^{2}+\beta_{i} h_{t-1} .
$$

Uma grande vantagem deste modelo é que ele não está vinculado somente a uma especificação de variância que siga o processo $\operatorname{GARCH}(1,1)$. Havendo evidências empíricas, quaisquer especificações para a variância podem ser utilizadas, tais como ○ EGARCH (Nelson, 1991) ou o NGARCH (Engle \& Ng, 1993), que são modelos que capturam uma propriedade empírica conhecida como efeito alavancagem: oscilações fortemente negativas nos retornos são acompanhadas de maior volatilidade do que oscilações positivas de mesmo valor absoluto.

Assim como nos algoritmos propostos anteriormente, no modelo de Duan temos apenas uma fonte de aleatoriedade, $\varepsilon_{i}$, a qual está embutida no modelo para a dinâmica do preço do ativo base, como pode ser visto em (8.2.3). Com isto, o modelo é de mais simples 
compreensão e estimação que outros modelos de volatilidade estocástica. No entanto, ao assumir que a variância do processo siga um modelo $\mathrm{GARCH}$, uma complicação é introduzida na precificação por neutralidade ao risco.

Como a variância do processo dos retornos é influenciada por choques não antecipados nos mesmos, no cálculo das probabilidades neutras ao risco em um modelo $\mathrm{GARCH}$ de acordo com a hipótese de um mercado livre de oportunidades de arbitragem (discutida no segundo capítulo e no Anexo 2) sempre será necessário considerar o retorno esperado do ativo base (ou então fazer hipóteses sobre o prêmio por risco exigido pelos agentes de mercado para investir neste ativo), e assim as probabilidades que deveriam ser neutras ao risco não o serão. Em palavras mais simples mas menos precisas, neste modelo 0 processo da dinâmica do preço do ativo base tem muita variabilidade para que o preço de mercado da opção seja calculado somente com a hipótese de ausência de oportunidades de arbitragem.

Poderia ser argumentado que a necessidade da inclusão do prêmio por risco nos cálculos vem do fato que o modelo GARCH a tempo discreto gera uma especificação de mercado incompleto (Kallsen \& Taqqu, 1995). No entanto Duan (2001) prova a afirmação do parágrafo anterior, mostrando um exemplo de mercado completo onde a variância dos retornos é influenciada por choques não antecipados nos mesmos e provando que, neste mercado, para que se precifique uma opção com base na hipótese de ausência de oportunidades de arbitragem também será necessário incluir uma hipótese sobre o prêmio por risco exigido pelos agentes do mercado.

Assim, baseado em argumentos sobre a forma da função de utilidade dos agentes do mercado, Duan propõe assumir que o retorno esperado de um ativo com risco seja explicado como a seguinte função de sua volatilidade e do prêmio por unidade de risco, denotado por $\lambda$ :

$$
\exp \left\{\mu+\frac{h_{t}}{2}\right\}=\exp \left\{r+\lambda \sqrt{h_{t}}\right\} \Rightarrow \mu=r+\lambda \sqrt{h_{t}}-\frac{h_{t}}{2} .
$$

E então o processo da dinâmica do preço do ativo será dado por:

$$
S(t)=S(t-1) \times \exp \left\{\left(r-\lambda \sqrt{h_{t}}-\frac{h_{t}}{2}\right) d t+\varepsilon_{t}\right\} .
$$

Neste ambiente, o preço de mercado de uma opção continua sendo dado pelo valor esperado do payoff da mesma calculado sob uma certa medida $Q$ e descontado pela taxa livre de risco, isto é: 


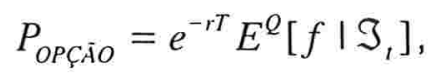

onde $r$ é a taxa de juros livre de risco expressa em termos anuais sob o conceito de capitalização contínua, $T$ é o tempo em anos entre o momento do cálculo e a data do exercício, $f$ é a função de payoff da opção a ser precificada, $\mathfrak{I}$, é a $\sigma$-álgebra gerada pelo conjunto de todas as informações disponíveis no instante $t$ (necessária por se tratar de um modelo de variância condicional à história do processo) e $E^{Q}$ denota que a esperança deve ser tomada com relação à outra medida de probabilidade, chamada de medida de preço em equilíbrio.

O leitor deve observar que dada $\mathfrak{I}_{t}$, a volatilidade do retorno para um período à frente é conhecida, sendo assim válido o princípio da precificação por neutralidade ao risco para o período de tempo imediatamente posterior, mesmo com a hipótese de que a variância dos retornos do ativo base siga um processo $\mathrm{GARCH}$. Assim, a medida de preço em equilíbrio $Q$ é obtida por meio de um princípio similar ao da precificação por neutralidade ao risco, o qual foi intitulado de princípio da precificação por neutralidade local ao risco (LRNVR). Assim, com argumentos similares aos utilizados na construção de uma medida de probabilidade neutra ao risco para o caso em que os retornos do ativo seguem um movimento browniano, conclui-se que para que uma medida de preço em equilíbrio $Q$ satisfaça o LRNVR é necessário que ela satisfaça as seguintes condições:

> é absolutamente contínua com respeito à medida de probabilidade real $P$;

$>\operatorname{Sob} Q, \frac{S_{t+1}}{S_{t}}$ possui distribuição lognormal;

- Sob $Q$, o processo de preço descontado pela taxa livre de risco é um martingal; e

$\operatorname{Var}^{Q}\left[\ln \left(\frac{S_{t+1}}{S_{t}}\right) \mathfrak{S}_{t}\right]=\operatorname{Var}^{P}\left[\ln \left(\frac{S_{t+1}}{S_{t}}\right) \mathfrak{I}_{t}\right]$.

O leitor deve notar que, se a variância dos incrementos no retorno acumulado do ativo base for constante, o LRNVR se reduz ao convencional princípio de precificação por neutralidade ao risco. Desta forma, pode-se dizer que o LRNVR é uma versão generalizada deste princípio.

Adicionalmente, Duan mostra que se a especificação da variância for um $\operatorname{GARCH}(1,1)$, ou seja, se (8.2.3) e (8.2.5) forem válidas, então teremos que o processo 
utilizado para modelar a dinâmica do preço do ativo base, quando regido pela medida $Q$, tem as mesmas características que o processo

$$
S(t)=S(t-1) \times \exp \left\{\left(r-\frac{\sigma^{2}}{2}\right) d t+\xi_{t}\right\},
$$

onde $\xi_{t} \mid I_{t} \sim N\left(0, \sigma_{t}^{2}\right)$, com $\sigma_{t}^{2}=\omega+\alpha\left(\xi_{t-1}-\lambda \sigma_{t-1}\right)^{2}+\beta \sigma_{t-1}^{2}$.

Em outras palavras, se (8.2.3) e (8.2.5) forem válidas, então a precificação das opções deste ativo base pode ser efetuada considerando que os retornos deste seguem um processo $\mathrm{NGARCH}$ (o GARCH assimétrico não linear de Engle e $\mathrm{Ng}$, 1993) com parâmetro de alavancagem igual ao prêmio por unidade de risco $(\lambda)$. Note que, apesar de não estar mais influenciando o retorno esperado do ativo base sob a medida $Q$, o prêmio por unidade risco não é eliminado com o LRNVR. Sob $Q$, este prêmio passa a afetar a inovação na variância condicional, a qual, por sua vez, afeta o preço do ativo base.

O modelo de Duan não possui solução analítica para o cálculo da esperança definida em (8.2.6), sendo desta forma necessário um algoritmo para a aproximação deste preço. Neste caso, para se precificar uma opção com exercício do tipo europeu pode-se utilizar um procedimento de simulação de Monte Carlo semelhante ao descrito na Seção 6.6, ou então um procedimento semelhante ao descrito na Seção 7.5 se a opção em questão possuir exercício do tipo americano, devendo-se apenas efetuar as devidas alterações na especificação da variância condicional. No Anexo 3 encontra-se uma implementação em linguagem $\mathrm{C}++$ de um procedimento de precificação assumindo um $\operatorname{GARCH}(1,1)$ para a especificação da variância.

\subsection{Implementando o modelo GARCH com dados do mercado brasileiro}

O código implementado no Anexo 3 foi utilizado para obter o preço de mercado das opções de compra padrão de ações preferenciais da Telemar, as mais negociadas no mercado de opções brasileiro, com exercício no dia 21 de fevereiro de 2005. A base dos cálculos foi fechamento do dia 14 de janeiro de 2005, no qual o ativo base encerrou o dia negociado a $\mathrm{R} \$ 40,20$. A taxa de juros livre de risco foi a mesma utilizada durante todo o decorrer deste texto, igual a 0,16629 .

Efetuamos os cálculos para todas as séries de opções de mesma data de exercício e ativo base cujos preços de exercício estivessem entre $R \$ 34,00$ e $R \$ 46,00$, ou seja, 
aproximadamente $15 \%$ abaixo e $15 \%$ acima do preço do ativo base. Para avaliar o desempenho do modelo GARCH, comparamos os preços obtidos por este com os preços que seriam obtidos aplicando-se o algoritmo descrito na Seção 6.3, o qual pressupõem que os incrementos no processo de retorno acumulado do ativo base são independentes e identicamente distribuídos.

$\mathrm{Na}$ implementação do modelo $\mathrm{GARCH}$, assumiu-se que a variância dos retornos diários do ativo base seguiam um processo $\operatorname{GARCH}(1,1)$. Os parâmetros $\omega, \alpha$ e $\beta$ deste modelo foram estimados com base na série de retornos diários das ações preferenciais da Telemar no período entre 18 de dezembro de 1998 e 14 de janeiro de 2005. Para esta estimação utilizamos a técnica da máxima verossimilhança ${ }^{11}$ com maximização utilizando o gradiente analítico, cujo código foi implementado por Trapletti (2004) e está disponível em http://www.r-project.org. O parâmetro $\lambda$ foi obtido de modo que a relação (8.2.4) fosse satisfeita para $\mu$ igual à média amostral da taxa logarítmica de retorno do ativo base no mesmo período de tempo. Os valores obtidos foram

\begin{tabular}{c|c|c|c|}
$\omega$ & $a$ & $\not A$ & $A$ \\
\hline 0,0000288 & 0,1278865 & 0,8482024 & 0,0229790 \\
\hline
\end{tabular}

Testamos a hipótese $H_{0}: \alpha=\beta=0$ contra a hipótese alternativa $H_{a}: \alpha \neq 0, \beta \neq 0$. Neste caso, sob $H_{0}$, a estatística do teste da razão de verossimilhanças é distribuída como uma Qui-Quadrado com 2 graus de liberdade. Seu valor assumido para o nosso teste $(54,14)$ gerou um $p$-valor praticamente igual a zero. Assim, rejeitamos a hipótese nula, confirmando que um processo $\mathrm{GARCH}(1,1)$ é mais adequado para modelar a variância dos retornos diários do ativo base.

Com o intuito de evitar discrepâncias na estimação do parâmetro volatilidade necessário para o algoritmo descrito na Seção 6.3 , não nos utilizamos do ajuste de

\footnotetext{
${ }^{11}$ Os estimadores de máxima verossimilhança para os parâmetros de uma determinada distribuição de probabilidades são aqueles que, dada uma amostra de uma população cuja característica de interesse segue, por hipótese, a distribuição assumida, especificam aquela distribuição de modo a maximizar a probabilidade de que esta amostra seja observada em um procedimento de amostragem simples. Este procedimento parte da hipótese de que, se uma amostra foi observada, então é muito mais provável que a população seja parecida com esta amostra do que com qualquer outra amostra não observada. Detalhes gerais deste procedimento e do teste de hipóteses baseado na estatística da razão de verossimilhanças podem ser encontrados em Mood, Graybill \& Boes (1974). Detalhes específicos deste procedimento para o modelo GARCH podem ser encontrados em Bollerslev (1986).
} 
freqüência proposto em (6.2.8). Ao invés disso, estimamos este parâmetro com base em janelas de tempo de comprimento de 24 dias úteis, que foi o mesmo tempo entre a data do nosso cálculo e a data do exercício da opção (lembrando que, no caso da precificação de uma opção de compra padrão a única volatilidade que nos interessa é a volatilidade do ponto final da trajetória do preço do ativo base). O valor obtido para a volatilidade em um período de 24 dias úteis foi de 0,12624 .

A tabela abaixo mostra os preços de mercado obtidos pelo modelo da Árvore Binomial com $n=192$, pelo modelo $\operatorname{GARCH}(1,1)$ e o preço pelo qual a opção foi efetivamente negociada no mercado, para cada preço de exercício. Observa-se que os preços obtidos pelo modelo $\mathrm{GARCH}(1,1)$ estão sempre mais próximos dos negociados pelo mercado do que os preços obtidos com a árvore. Observa-se também que os preços do modelo $\operatorname{GARCH}(1,1)$ se diferenciam muito mais dos preços obtidos pela árvore quando a opção está mais fora do dinheiro. Estas duas observações estão consistentes com o encontrado por Chaudhury, M. \& Wei, J. (1996) em seus testes teóricos assumindo que a variância dos retornos do ativo objeto sigam um processo GARCH(1,1).

\begin{tabular}{r|r|r|r|} 
PR EXERC. & PR. ARV. & PR. GARCH & PR. VERIF. \\
\hline 34,00 & 6,89 & 6,85 & 6,85 \\
\hline 36,00 & 5,16 & 5,09 & 5,10 \\
\hline 38,00 & 3,66 & 3,54 & 3,49 \\
\hline 40,00 & 2,45 & 2,29 & 2,06 \\
\hline 42,00 & 1,53 & 1,38 & 1,03 \\
\hline 44,00 & 0,90 & 0,78 & 0,44 \\
\hline 46,00 & 0,51 & 0,43 & 0,17 \\
\hline
\end{tabular}

Para facilitar a visualização dos resultados, apresentamos também a diferença em valor absoluto dos preços obtidos por cada modelo em relação aos preços efetivamente negociados. O leitor pode observar que os erros de precificação para as opções fora do dinheiro persistem, mas são bem menores no modelo $\operatorname{GARCH}(1,1)$. 


\begin{tabular}{r|r|r|} 
PR EXERC. & ERRO ARV. & ER. GARCH \\
\hline 34,00 & 0,04 & 0,00 \\
\hline 36,00 & 0,06 & 0,01 \\
\hline 38,00 & 0,17 & 0,05 \\
\hline 40,00 & 0,39 & 0,23 \\
\hline 42,00 & 0,50 & 0,35 \\
\hline 44,00 & 0,46 & 0,34 \\
\hline 46,00 & 0,34 & 0,26 \\
\hline
\end{tabular}

Acrescentamos que, embora foi necessário inferir sobre o prêmio por risco do ativo base, esta variável não teve grande impacto nos preços obtidos. Efetuamos os cálculos distorcendo fortemente os valores deste parâmetro e não verificamos diferenças significativas. Por exemplo, tomando este parâmetro igual a 0,22979 (multiplicamos o parâmetro por dez), o preço de mercado da opção com strike igual a $R \$ 40,00$ calculado pelo modelo $\operatorname{GARCH}(1,1)$ alterou-se apenas em 6 centavos (aproximadamente $3 \%$ do preço efetivamente negociado), passando de $R \$ 2,29$ para $R \$ 2,35$. Tomando este parâmetro igual a 0,0022979 (dividimos o mesmo por dez), o preço calculado não se alterou.

Por fim, acrescentamos que os resultados obtidos ainda podem ser melhorados com o uso de modelos que captem o efeito alavancagem. Estudos com dados do mercado brasileiro sugerem que o modelo $\operatorname{EGARCH}(1,1)$ possua desempenho superior ao do $\operatorname{GARCH}(1,1)$ (Araújo, Barbedo, Figueiredo \& Lemgruber, 2003). A construção da medida de preço em equilíbrio que satisfaz o LRNVR quando a especificação da variância é um $\operatorname{EGARCH}(1,1)$ é dada em Schmitt (1996).

\subsection{Concluindo o trabalho}

Neste trabalho apresentamos de maneira didática e intuitiva como a aproximação de processos estocásticos em tempo contínuo por processos em tempo discreto pode ser utilizada para a precificação de opções tradicionais e exóticas. Para isso, apresentamos o problema da precificação de opções e posteriormente a teoria econômica necessária para solucioná-lo e as ferramentas estatísticas disponíveis para tal, estando sempre focados no uso de métodos de aproximação visto que poucos são os casos práticos onde há uma solução analítica satisfatória.

Assumidas algumas hipóteses sobre a distribuição de probabilidades dos retornos diários do ativo base da opção a ser precificada, provamos com todo o rigor matemático 
necessário que os métodos de aproximação propostos são efetivos. Por fim, aproveitamos toda a teoria discutida nos sete primeiros capítulos e apresentamos um modelo promissor, também baseado em aproximações a tempo discreto, que relaxa a necessidade de algumas hipóteses dentre as assumidas anteriormente.

Lembramos que, apesar muito bem aplicável à necessidade prática dos engenheiros financeiros, a teoria apresentada ainda possui restrições. Afinal, não estamos assumindo nada mais do que um mercado eficiente, completo, livre de oportunidades de arbitragem e composto por agentes racionais e aversos ao risco que conhecem todo o conjunto de cenários futuros possíveis.

A hipótese de um mercado livre de oportunidades de arbitragem parece ser muito razoável de ser assumida, e de fato o é. No entanto as demais hipóteses sempre geram questionamentos acadêmicos sobre a sua validade.

O leitor pode considerar que este modelo não é válido para a precificação de um bilhete de loteria. Neste caso, definitivamente os agentes não se encaixam na definição de investidor racional. Para constatar isto, basta observar que um bilhete da Mega-Sena com prêmio de $\mathrm{R} \$ 35$ milhões para $\mathrm{R} \$ 1,50$ apostado tem uma probabilidade de apenas 1/50.063.860 de gerar este fluxo de caixa, tendo 50.063.859/50.063.860 de probabilidade de gerar uma perda total do capital investido. Desta forma, o valor futuro esperado de cada unidade de dinheiro aplicada neste ativo é de aproximadamente $R \$ 0,466$, o que dá ao agente um retorno esperado de $-53,4 \%$ em um curtíssimo período de tempo com um imenso risco. No entanto, o sucesso desta aplicação mesmo entre muitos engenheiros financeiros nos leva a crer que ela é preferida por muitos.

O exemplo do parágrafo anterior, apesar de exagerado, pode nos levar a uma analogia com as opções extremamente fora do dinheiro e de relativamente curto prazo de maturação. O fluxo de caixa esperado destas opções é semelhante ao de uma loteria, com uma alta probabilidade de perda total e uma baixa probabilidade de um ganho imenso ao seu titular. Se os agentes do mercado se comportarem para estes ativos da mesma forma que se comportam para uma loteria, a hipótese de agentes racionais e aversos ao risco pode ser muito restritiva para a precificação dos mesmos.

A hipótese de que os agentes conhecem todo o conjunto de cenários futuros possíveis já é relaxada com o uso do modelo GARCH para a precificação de opções, já na Seção 6.4 apresentamos que o parâmetro de volatilidade do modelo para a dinâmica do preço do ativo base é quem determina este conjunto de cenários. Como no modelo $\mathrm{GARCH}$ este parâmetro 
é assumido como desconhecido para os instantes de tempo que vêm depois do imediatamente posterior, estamos assumindo que os agentes só conhecem todo o conjunto de cenários possíveis para o instante imediatamente posterior.

É claro que o leitor mais céptico poderia afirmar que o modelo ótimo não deveria considerar a variância conhecida nem mesmo para o instante imediatamente posterior. Afinal, qual agente de mercado sabia no dia 10 de setembro de 2001 que no dia seguinte haveria um ataque terrorista nos Estados Unidos e o IBOVESPA iria fechar com uma queda de $9,17 \%$, a mais forte em uma janela de tempo considerando os dois anos e meio anteriores?

Por mais incrível que pareça, a hipótese de que o processo do preço do ativo base não seja previsível dadas as informações atualmente disponíveis, a que formulamos como a hipótese de que o mercado é eficiente, também tem questionamentos acadêmicos, a despeito de uma grande quantidade de evidências a favor desta hipótese. O leitor mais curioso é encorajado a consultar alguns exemplos de anomalias fornecidas em Brock, Lakonishok. \& LeBaron (1992) e em Dennis et al (1995). Claramente, se os tópicos levantados por estes autores forem assumidos como válidos, o modelo para a dinâmica do preço do ativo base deve ser completamente reformulado

Talvez a hipótese considerada como a mais restritiva seja a que o mercado é completo. Neste caso, não seria sempre possível eliminar o risco considerando os ativos $B$ e $R$ do segundo capítulo, visto que um deles não existiria, e a hipótese de ausência de oportunidades de arbitragem sozinha não seria suficiente. Assim, em palavras mais simples, deve-se assumir hipótese sobre o perfil de aversão a riscos dos agentes, de forma semelhante ao feito por Duan (1995), para tentar efetuar a precificação assumindo que alguns dos riscos não eliminados podem ser tolerados pelos agentes. Uma explicação mais detalhada deste procedimento é dada em Xu (2004).

Desta forma, esperando ter contribuído para o conhecimento do leitor sobre modelos de precificação de opções, concluímos o trabalho afirmando que ainda não se pode dizer que o modelo ótimo é conhecido, embora a comunidade acadêmica esteja muito evoluída em seu percurso. De fato, ainda há muito trabalho a ser feito. 


\section{ANEXO 1 TEOREMAS IMPORTANTES PARA O CASO $S=C$}

\section{A.1. O Teorema de Prohorov (Teorema 5.7)}

Nós provaremos o resultado sucessivamente para $R^{k}$, para $R^{\infty}$, para $S \sigma$-compacto (uma união enumerável de conjuntos compactos), e, finalmente, para um $S$ geral. Cada um dos últimos três casos é lidado reduzindo-o ao caso precedente.

O caso $R^{k}$. Se $\left\{P_{n}\right\}$ é uma seqüência em $I I$, o teorema de Helly implica que a seqüência $\left\{F_{n}\right\}$ das correspondentes funções de distribuição contém uma subseqüência $\left\{F_{n^{\prime}}\right\}$ tal que

$$
F_{n}(x) \rightarrow F(x)
$$

nos pontos de continuidade de $F$, onde $F$ é uma função contínua à direita. Há em $\left(R^{k}, \Re^{k}\right)$ uma medida $\mu$ tal que $\mu(a, b]$ seja $F$ diferenciada em torno dos vértices do retângulo $k$-dimensional $(a, b]$. Então seguirá que $P_{n^{\prime}} \Rightarrow \mu$ se provarmos que $\mu\left(R^{k}\right)=1$.

Dado $\varepsilon$, escolha um conjunto compacto $K$ em $R^{k}$ tal que $P_{n^{\prime}}(K)>1-\varepsilon$ para todo $n^{\prime}$, o que é possível porque $I I$ é apertado. Agora escolha $a$ e $b$ tais que $K \subset(a, b]$ e tais que todos os vértices $2^{k}$ de $(a, b]$ são pontos de continuidade de $F$ (isso é possível porque somente uma quantidade enumerável de hiperplanos paralelos $(k-1)$ dimensionais pode ter uma medida $\mu$ positiva). Uma vez que $P_{n}(a, b]$ é $F_{n^{\prime}}$ diferenciada em torno dos vértices de $(a, b], \quad(\mathrm{A} .1 .1)$ implica $P_{n^{\prime}}(a, b] \rightarrow \mu(a, b]$. De $P_{n} \cdot(a, b] \geq P_{n}(K)>1-\varepsilon$, segue que $\mu(a, b] \geq 1-\varepsilon$. Como $\varepsilon$ foi escolhido arbitrariamente, $\mu\left(R^{k}\right)=1$. Portanto $I I$ é relativamente compacto.

Para o caso $R^{\infty}$ precisaremos do seguinte lema.

LEMA A.1. Se I/ é uma família apertada em $(S, \Sigma)$ e se $h$ é um mapeamento contínuo de $S$ até $S^{\prime}$ então $\left\{P h^{-1}: P \in I I\right\}$ é uma família apertada em $\left(S^{\prime}, \Sigma^{\prime}\right)$. 
Prova. Dado $\varepsilon$, escolha em $S$ um conjunto compacto $K$ tal que $P(K)>1-\varepsilon$ para todo $P$ em $I I$. Se $K^{\prime}=h K$, então $K^{\prime}$ é compacto e $h^{-1} K^{\prime} \supset K$, de forma que $P h^{-1}\left(K^{\prime}\right)>1-\varepsilon$ para todo $P$ em $I I$.

O caso $R^{\infty}$. Se II é uma família apertada em $\left(R^{\infty}, \Re^{\infty}\right)$, então pelo Lema A.1, $\left\{P \pi_{k}^{-1}: P \in I I\right\}$ é, para cada $k$, uma família apertada em $\left(R^{k}, \mathfrak{R}^{k}\right)$. Pelo Teorema de Prohorov para $R^{k}$, provado via o Teorema de Helly, nós podemos selecionar uma subseqüência $\left\{P_{n^{\prime}}\right\}$ de uma dada seqüência $\left\{P_{n}\right\}$ em $I I$, tal que $P_{n} \pi_{k}^{-1}$ convirja fracamente para uma medida de probabilidade $\mu_{k}$ em $\left(R^{k}, \Re^{k}\right)$. Pelo método da diagonal, podemos escolher a seqüência $\left\{P_{n^{\prime}}\right\}$ de forma que $P_{n} \pi_{k}^{-1} \Rightarrow \mu_{k}$ é válida para todo $k$ simultaneamente.

Uma vez que as medidas $\mu_{k}$ obviamente satisfazem as condições de consistência do Teorema de existência de Kolmogorov, há uma medida de probabilidade $Q$ em $\left(R^{\infty}, \Re^{\infty}\right)$ tal que $Q \pi_{k}^{-1}=\mu_{k}$ para todo $k$. No entanto, $P_{n} \pi_{k}^{-1} \Rightarrow Q \pi_{k}^{-1}=\mu_{k}$ para cada $k$, de forma que as distribuições de dimensões finitas de $P_{n}$. convergem para aqueles de $Q$, o que implica $P_{n^{\prime}} \Rightarrow Q$. Portanto, em $R^{\infty}$ uma família apertada também é relativamente compacta.

Para o caso $\sigma$-compacto e os casos gerais, nós precisaremos de mais dois lemas. Suponha que $S_{0}$ seja um subconjunto de Borel de $S$ :
(A.1.2)
$S_{0} \in \sum$.

Agora é um $S_{0}$ espaço métrico em sua própria e relativa topologia; seja $\sum_{0}$ o símbolo da classe de conjuntos de Borel para $S_{0}$. De $(A .1 .2)$ segue que

$$
\Sigma_{0}=\left\{A: A \subset S_{0}, A \in \Sigma\right\}
$$

em particular,

$$
S_{0} \subset \Sigma
$$

Se $P$ é uma medida de probabilidade em $(S, \Sigma)$ com, $P\left(S_{0}\right)=1$, seja $P^{r}(r$ de "restrita") a medida de probabilidade em $\left(S_{0}, \sum_{0}\right)$ aceita pela restrição de $S$ até $S_{0}$ (veja (A.1.4)). Se $P$ é a medida de probabilidade em $\left(S_{0}, \sum_{0}\right)$, seja $P^{c}$ ( $e$ de "estendida") a 
medida de probabilidade em $(S, \Sigma)$ com $P^{e}(A)=P\left(A \cap S_{0}\right)$ para $A \in \sum$ (veja (A.1.3)). Note que $P^{e}\left(S_{0}\right)=1$.

Se $P$ é uma medida de probabilidade em $(S, \Sigma) \operatorname{com} P\left(S_{0}\right)=1$, então

$$
\left(P^{r}\right)^{r}=P
$$

se $P$ é uma medida de probabilidade em $\left(S_{0}, \Sigma_{0}\right)$, então

$$
\left(P^{e}\right)^{\cdot}=P \text {. }
$$

Se, no Lema A.1 e no Teorema 2.5, nós tomarmos $h$ como sendo o mapeamento identidade de $S$ até $S_{0}$, obteremos o lema a seguir.

LEMA A.2. Se II é uma família apertada em $\left(S_{0}, \Sigma_{0}\right)$, então $I I^{e}=\left\{P^{e}: P \in I I\right\}$ é uma família apertada em $(S, \Sigma)$. Se $P_{n} \Rightarrow P$ em $\left(S_{0}, \Sigma_{0}\right)$,então $P_{n}^{e} \Rightarrow P^{e}$ em $(S, \Sigma)$.

Além disso, também é possível provar o seguinte lema:

LEMA A.3. Se $P_{n} \Rightarrow P$ em $\left(S, \sum\right)$ e $P_{n}\left(S_{0}\right)=P\left(S_{o}\right)=1$, então $P_{n}^{r} \Rightarrow P^{r}$ em $\left(S_{0}, \Sigma_{0}\right)$.

Prova. O conjunto aberto geral em $S_{0}$ é $G_{0}=G \cap S_{0} \operatorname{com} G$ aberto em $S$. Uma vez que $P_{n}^{r}\left(G_{0}\right)=P_{n}(G)$ e $P^{r}\left(G_{0}\right)=P(G), \lim _{\inf } P_{n}(G) \geq P(G)$ implica

$$
\lim \inf _{\mathrm{n}} P_{n}^{r}\left(G_{0}\right) \geq P^{r}\left(G_{0}\right) .
$$

$O$ caso $\sigma$-compacto. Se $S$ é $\sigma$-compacto, então $S$ é separável e por essa razão pode ser embutido homeomorficamente em $R^{\infty}$. Como $S$ é $\sigma$-compacto, logo também o é sua imagem sob o homeomorfismo; em particular, esta imagem é um subconjunto Borel de $R^{\infty}$. Logo, S é homeomórfico para um subconjunto Borel de $R^{\infty}$. Pelo Teorema 2.5, uma convergência fraca persiste sob o homeomorfismo, e portanto a relativa compactação de II também. Uma vez que a relativa compactação de conjuntos persiste sob homeomorfismo, também persiste a propriedade de apertado de II. Por essa razão podemos trocar $S$ pela sua imagem homeomórfica.

Podemos portanto assumir que $S$ é um subconjunto de Borel de $R^{\infty}$. Se $I I$ é apertado em $(S, \Sigma)$, então, pelo Lema A.2 aplicado a $R^{*}$ e seu subconjunto $S, I I^{*}$ é 
apertado em $\left(R^{\infty}, \Re^{\infty}\right)$. Como já foi provado, o Teorema de Prohorov é válido em seu maior espaço, $I I^{e}$ é relativamente compacto, tanto que, para cada seqüência $\left\{P_{n}\right\}$ em $I$, a seqüência correspondente $\left\{P_{n}^{e}\right\}$ contém uma subseqüência $\left\{P_{n}^{e}\right\}$, convergindo fracamente no sentido de $\left(R^{\infty}, \Re^{\infty}\right)$ para algum $Q$.

Por II ser uma família apertada, há, para cada $\varepsilon$, um subconjunto compacto $K$ de $S$ tal que $P_{n^{e}}^{e}(K)=P_{n^{\prime}}(K)>1-\varepsilon$ para todo $n^{\prime}$, de forma que $Q(S) \geq(K) \geq \lim \sup _{n} P_{n}^{e}(K) \geq 1-\varepsilon$. Deste modo $S$ suporta $Q$ tão bem quanto todo o $P_{n}^{e}$, e logo, pelo Lema A.3 e por (A.1.5), $P_{n^{\prime}}$ converge fracamente no sentido de $(S, \Sigma)$ para $Q^{r}$. Assim, se $S$ é $\sigma$-compacto uma família apertada também é relativamente compacta.

O caso geral. Para $S$ qualquer e para $S_{o}=\bigcup_{i} K_{i}$, onde $K_{i}$ é um conjunto compacto em $S$ tal que $P\left(K_{i}\right)>1-1 / i$ para todo $P$ em II, $S_{0}$ suporta cada elemento de II e II $=\left\{\mathrm{P}^{\mathrm{r}}: \mathrm{P} \in \mathrm{II}\right\}$ é uma família apertada em $\left(S_{0,}, \Sigma_{0}\right)$. Pelo caso considerado, $\mathrm{II}^{\mathrm{r}}$ é relativamente compacto. Para cada seqüência $\left\{P_{n}\right\}$ em II, portanto, a seqüência correspondente $\left\{P_{n}^{r}\right\}$ contem uma subseqüência $\left\{P_{n}^{r}\right\}$ convergindo fracamente no sentido de $(S, \Sigma)$ para $Q^{e}$. Logo, II é relativamente compacto, o que prova o Teorema de Prohorov em sua completa generalidade.

\section{A.2. A Existência da Medida de Wiener}

Sejam $\xi_{1}, \xi_{2}, \ldots$, variáveis aleatórias em algum espaço de probabilidade $(\Omega, \beta, P)$. Definimos $S_{n}=\xi_{1}+\ldots+\xi_{n}$, com $S_{0}=0$, e construímos $X_{n}$ da soma parcial $S_{0}, S_{1}, \ldots, S_{n}$. Para os pontos $i / n$ em $[0,1]$ definimos

$$
X_{n}\left(\frac{i}{n}, \omega\right)=\frac{1}{\sigma \sqrt{n}} S_{l}(\omega)
$$

Para os pontos remanescentes $t$ de $[0,1]$, nós definimos $X_{n}(t, \omega)$ pela interpolação linear, ou seja, se $t \in[(i-1) / n: i / n]$, então 
(A.2.2)

$$
\begin{aligned}
& X_{n}(t, \omega)=\frac{(i / n)-t}{1 / n} X_{n} \\
& \left(\frac{i-1}{n}\right)+\frac{t-(i-1) / n}{1 / n} X_{n}\left(\frac{i}{n}\right)=\frac{1}{\sigma \sqrt{n}} S_{i-1}(\omega)+n\left(t-\frac{i-1}{n}\right) \frac{1}{\sigma \sqrt{n}} \xi_{i}(w)
\end{aligned}
$$

Como $i-1=[n t]$ se $t \in[(i-1) / n ; \mathrm{i} / n)$, podemos juntar (A.2.1) e (A.2.2) para obter:

$$
X_{n}(t, \omega)=\frac{1}{\sigma \sqrt{n}} S_{[n t]}(\omega)+(n t-[n t]) \frac{1}{\sigma \sqrt{n}} \xi_{[n t]+1}(\omega) .
$$

Sendo válido o seguinte teorema:

TEOREMA A.1. Suponha que $\left\{X_{n}\right\}$ seja definido por (A.2.3). A seqüência $\left\{X_{n}\right\}$ é apertada se para cada $\varepsilon$ positivo existe um $\lambda$, com $\lambda>1$, e um número inteiro $n_{0}$ tal que, se $n \geq n_{0}$, então

$$
P\left\{\max _{i \leq n}\left|S_{k+i}-S_{k}\right| \geq \lambda \sigma \sqrt{n}\right\} \leq \frac{\varepsilon}{\lambda^{2}}
$$

vale para todo $k$.

O teorema acima é importante dado que na seção 2.5 vimos de maneira menos formal que a soma definida por (A.2.3) é apertada se seu módulo de continuidade converge em probabilidade para zero, condição que foi reduzida a

$$
\frac{1}{\delta} P\left\{\max _{i \leq \delta} \frac{1}{\sigma \sqrt{n}}\left|S_{k+i}-S_{k}\right| \geq \varepsilon\right\} \leq \eta \text {. }
$$

Prova do Teorema A.1. Dado $\varepsilon$ e $\eta$, produziremos um $\delta(0<\delta<1)$ e um no para os quais (A.2.5) é válido para todo $k$ se $n \geq n_{0}$. Uma vez que (A.2.5) se torna mais restritivo conforme $\varepsilon$ e $\eta$ diminuem, podemos assumir $0<\varepsilon, \eta<1$.

Pela hipótese, com $\eta \varepsilon^{2}$ no lugar de $\varepsilon$, existem $\lambda>1$ e $n_{1}$ tais que

$$
P\left\{\max _{i \leq n}\left|S_{k+1}-S_{k}\right| \geq \lambda \sigma \sqrt{n}\right\} \leq \frac{\eta \varepsilon^{2}}{\lambda^{2}}
$$

para $n \geq n_{1}$ e $k \geq 1$. Fazendo $\delta=\varepsilon^{2} / \lambda^{2}$, uma vez que $\lambda>1>\varepsilon$, nós temos $0<\delta<1$.

Seja $n_{0}$ um número inteiro excedendo $n_{1} / \delta$. Se $n \geq n_{0}$, então $[n \delta] \geq n_{1}$, então segue por (A.2.6) que 


$$
P\left\{\max _{i \leq[n \delta]}\left|S_{k+i}-S_{k}\right| \geq \lambda \sigma \sqrt{[n \delta]\} \leq \frac{\eta \varepsilon^{2}}{\lambda^{2}} .}\right.
$$

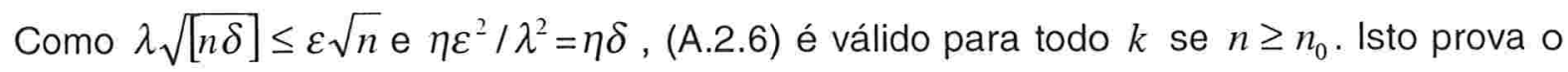
Teorema A.1.

Não é difícil perceber que é suficiente que (A.2.4) seja válido para $k \leq n \lambda^{2} / \varepsilon$, mas nós precisaremos disso. No entanto, se $\left\{\xi_{n}\right\}$ é estacionário, então (A.2.4) é reduzido para

$$
P\left\{\max _{i \leq n}\left[S_{i}\right] \geq \lambda \sigma \sqrt{n}\right\} \leq \frac{\varepsilon}{\lambda^{2}} .
$$

Absorvendo $\sigma$ em $\lambda$, o requerimento pode ser alterado para

$$
P\left\{\max _{i \leq n}\left[S_{i}\right] \geq \lambda \sqrt{n}\right\} \leq \frac{\varepsilon}{\lambda^{2}}, \lambda>\sigma .
$$

TEOREMA A.2. Existe em $(C, \varrho)$ uma medida de probabilidade $W$ tal como a da Definição 2.19.

Prova. Sejam $\xi_{1}, \xi_{2}, \ldots$ independentes e normalmente distribuídos (em algum $(\Omega, \beta, P)$ com média 0 e variância 1. Seja $X_{n}$ a função aleatória definida por (A.2.3) com $\sigma=1$ :

$$
X_{n}(t, \omega)=\frac{1}{\sqrt{n}} S_{[n t]}(\omega)+(n t-[n t]) \frac{1}{\sqrt{n}} \xi_{[n t++1}(\omega) \text {. }
$$

Seja $P_{n}$ a distribuição de $X_{n}$ em $C$. Esta medida é bem definida porque $X_{n}$ é mensurável $\left(X_{n}^{-1} \Gamma \subset \beta\right)$.

Nós primeiro mostraremos que as distribuições de dimensões finitas de $P_{n}$ convergem fracamente para aquilo que queremos que as distribuições de dimensões finitas de $W$ sejam. Depois disso, nós provaremos que a seqüência $\left\{P_{n}\right\}$ é apertada. Está claro que o limite de qualquer subseqüência fracamente convergente $\left\{P_{n}\right\}$ irá satisfazer os requerimentos colocados em $W$. A idéia desta prova, portanto, é que a seqüência de medidas $P_{n}$ aproxima a suposta medida $W$.

Como já visto, a distribuição de dimensões finitas $P_{n} \pi_{t_{1} \ldots}^{-1}$ é apenas a distribuição do vetor aleatório $\left(X_{n}\left(t_{1}\right), \ldots, X_{n}\left(t_{k}\right)\right)$. Considere um determinado ponto $t$. Por (A.2.9) e pela normalidade assumida de $\xi_{n}, X_{n}(t)$ é normal com média 0 and variância 


$$
\frac{[n t]}{n}+\frac{(n t-[n t])^{2}}{n}
$$

essa variância difere de $t$ por no máximo $2 / n$. Portanto $X_{n}(t) \stackrel{\wp}{\longrightarrow} N(0, t)$.

Claramente, nós podemos tratar dois ou mais pontos da mesma maneira; as distribuições de dimensões finitas portanto convergem fracamente para aquelas prescritas por $W$. Para provar que $\left\{P_{n}\right\}$ é apertado, aplica-se o Teorema A.1. Para provar que (A.2.8) é válido, escrevemos

$$
E_{i}=\left\{\max _{i<i}\left|S_{j}\right|<2 \lambda \sqrt{n \leq\left|S_{i}\right|}\right\}
$$

Pela estacionariedade e independência de $\xi_{n}$, nós temos que

$$
\begin{aligned}
& \text { (A.2.12) } \quad P\left\{\max _{i \leq n}\left|S_{i}\right| \geq 2 \lambda \sqrt{n}\right\} \leq \mathrm{P}\left\{S_{n} \mid \geq \lambda \sqrt{n}\right\}+\sum_{i=1}^{n-1} P\left(E_{i} \cap\left\{S_{n}-S_{i} \mid \geq \lambda \sqrt{n}\right\}\right) \\
& =P\left\{S_{n} \mid \geq \lambda \sqrt{n}\right\}+\sum_{i=1}^{n-1} P\left(E_{i}\right) P\left\{S_{n-1} \mid \geq \lambda \sqrt{n}\right\} \leq P\left\{S_{n} \mid \geq \lambda \sqrt{n}\right\}+\sum_{i=1}^{n-1} P\left(E_{i}\right) P\left\{S_{n-1} \mid \geq \lambda \sqrt{n-i}\right\} .
\end{aligned}
$$

Uma vez que $S_{j} / \sqrt{j}$ é normalmente distribuído com média 0 e variância 1 e portanto tem terceiro momento finito $a$ independente de $j(a=2 \sqrt{2 / \pi})$ segue, por (A.2.12) e pela Desigualdade de Chebyshev que

$$
P\left\{\max _{i \leq n}\left|S_{i}\right| \geq 2 \lambda \sqrt{n}\right\} \leq \frac{a}{\lambda^{3}}+\sum_{i=1}^{n-1} P\left(E_{i}\right) \frac{a}{\lambda^{3}} .
$$

Como os conjuntos $E_{i}$ são disjuntos, nós podemos concluir que

$$
P\left\{\max _{i \leq n}\left|S_{i}\right| \geq 2 \lambda \sqrt{n}\right\} \leq \frac{2 a}{\lambda^{3}}, \quad n=1,2, \ldots
$$

Dado $\varepsilon$, escolha $\lambda$ tal que $2 a / \lambda<\varepsilon$ e $\lambda>1$. Então (A.2.14) implica que

$$
P\left\{\max _{i \leq n}\left|S_{i}\right| \geq 2 \lambda \sqrt{n}\right\} \leq \frac{\varepsilon}{\lambda^{2}},
$$

que é (A.2.8), exceto pela constante igual a 2 na esquerda, o que é irrelevante. Portanto, pelo Teorema A.1 temos que $\left\{P_{n}\right\}$ é apertado, o que completa a prova. - 


\section{ANEXO 2}

\section{O USO DE MARTINGAIS NA PRECIFICAÇÃO NEUTRA AO RISCO}

Nosso objetivo é mostrar como o princípio da precificação pela neutralidade ao risco pode ser generalizado para a precificação de derivativos financeiros utilizando conceitos da Teoria de Martingais. Nossos argumentos serão exibidos no âmbito de um modelo de mercado. Apesar de ser um modelo, ele é suficientemente fiel aos comportamentos essenciais do mercado real e, por isso, as conclusões derivadas neste modelo são aceitas no mercado verdadeiro. Assumiremos neste anexo que o tempo corre de 0 até um finito inteiro $T$.

Definimos no intervalo contínuo de tempo $[0 ; T]$ um processo estocástico de tempo discreto, o qual será chamado de $S_{n}, n=0,1, \ldots, T$. Este processo será tomado no nosso modelo como o processo de evolução do preço de um ativo.

Para simplificar nossas explicações, assumiremos uma estrutura específica nas trajetórias deste processo. Esta estrutura está apresentada na Figura 40. A estrutura assumida quer dizer que as trajetórias do processo $S_{n}, n=0,1, \ldots, T$ formam uma árvore recombinante com dois galhos a partir de cada nó. Cada um dos nós foi rotulado, e seus "nomes" são apresentados em parênteses na figura. Notamos que a estrutura assumida não é a Árvore Binomial do sexto capítulo. Ela seria tal, se existisse $P \in(0 ; 1)$ tal que

$$
P\left[S_{n=1}=s+1 \mid S_{n}=s\right]=1-P\left[S_{n+1}=s-1 \mid S_{n}=s\right]=P
$$

para todo $n<T$ e todo $s$.

Figura 40 - Árvore Recombinante

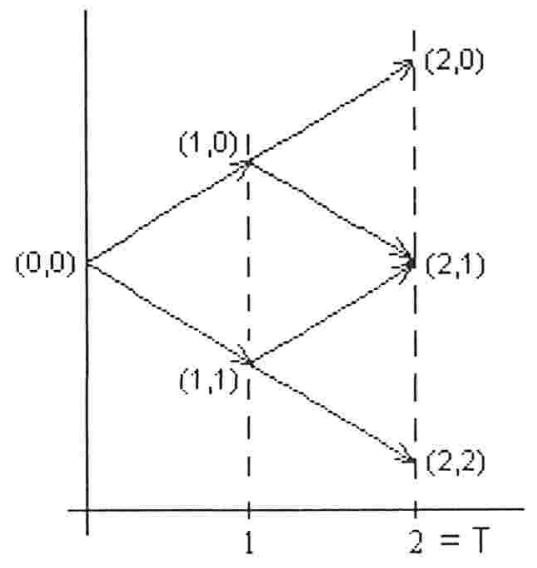


Nós não assumimos a condição (B.1), apesar de que esta aparecerá em certos casos específicos a serem estudados.

Designamos por $p((i, j) \rightarrow(n, m))$ a probabilidade do processo seguir do nó $(i, j)$ para o nó $(n, m)$. Com isso a probabilidade de qualquer caminho da árvore é o produto das probabilidades em seqüência de nós do caminho. Designamos por $s_{(i, j)}$ o valor do ativo base no nó $(i, j)$. Com isso temos a seguinte relação com o que chamamos de "processo do preço" $S_{n}, n=0,1, \ldots, T$ :

$$
\begin{aligned}
& S_{0}=s_{(0,0)} ; S_{1}=s_{(1,0)} \text { com probabilidade } p((0,0) \rightarrow(1,0)) \\
& \qquad ; S_{1}=s_{(1,1)} \text { com probabilidade } p((0,0) \rightarrow(1,1)) \\
& \text { e assim por diante para } S_{2}, S_{3}, \ldots, S_{t} .
\end{aligned}
$$

Vamos assumir a existência de um banco com um capital infinito e um número infinito de agentes de mercado. As situações que consideraremos assumem que nenhum dos agentes se utilizará de capital próprio para financiamento de suas estratégias, sendo possibilitado a qualquer agente tomar emprestado ou investir neste banco qualquer quantia de dinheiro. Para simplicidade de notação, a taxa de juros para empréstimos e investimentos, denotada pela letra $r$, não será utilizada - trabalharemos com os valores apresentados em preço descontado por esta, estando em capital equivalente a dinheiro do tempo $t=0$.

Além de emprestar e investir dinheiro no banco, os agentes do nosso modelo podem comprar e vender uma quantidade arbitrária de ativos. Tais compras e vendas deverão ser feitas somente nos instantes $0,1 \ldots, T-1$. O preço unitário de um ativo será determinado pelo processo $S_{n}, n=0, \ldots, T$.

Assumiremos que, no nosso modelo, o mercado está em uma condição de equilibrio tal que sempre haverá alguém que queira vender seus ativos quando um agente qualquer estiver interessado em comprar. Da mesma forma, sempre haverá alguém que queira comprar ativos quando um agente qualquer estiver interessado em vendê-las. Assumimos a possibilidade de que um agente efetue uma venda a descoberto ("short sale"), operação na qual o agente efeturá uma venda de uma determinada quantidade de 


\section{4 - O Uso de Martingais na Precificação Neutra ao Risco}

ativos sem tê-la previamente, ficando com a obrigação de encerrar a sua posição em aberto até o instante $T$. O capital recebido na venda é aplicado no banco, recebendo como rentabilidade a taxa de juros. Para encerrar a sua posição, o agente resgatará o capital do banco e comprando o ativo a preço de mercado no instante do encerramento. Apesar da obrigação de que a posição seja encerrada até o instante $T$, o agente pode encerrar a sua posição a qualquer momento do nosso tempo discreto.

Para efeito da nossa teoria não será necessário postular sobre as probabilidades dos galhos da árvore do preço do ativo base, sendo no entanto assumido que todos os agentes e o banco conhecem os dos valores que ativo pode assumir em todos os nós da árvore. O que eles não sabem é qual dos galhos será seguido. Por exemplo, no instante 0 , todos sabem do valor do ativo base neste instante e sabem que no próximo instante 10 preço pode subir para o valor $S_{(1,0)}$ ou pode descer para $S_{(1,1)}$. Porém no instante 0 não se sabe qual destas duas alternativas irá acontecer.

Já que nosso modelo do preço do ativo base é um processo em tempo discreto, então seria cômodo considerar o desenvolvimento do modelo todo somente por tempos $0,1 \ldots, T$, que será exatamente o procedimento que adotaremos. Para que a aceitação desta conveniência gere um problema semântico com relação ao preço em que é realizado um negócio ${ }^{12}$, no nosso modelo postulamos que a cada instante primeiramente o ativo base assumirá seu preço $S_{n}$ e depois ocorrerão as transações envolvendo este ativo pelo preço assumido.

Apresentamos agora um exemplo em que a árvore de preço do ativo é a mostrada na Figura 41. Considere agora a seguinte estratégia:

- Se o preço chegar ao nó $(1,1)$, no qual o preço do ativo é igual a 80 , ir ao banco e tomar emprestado 80 para comprar uma unidade do ativo. No instante de tempo seguinte, vender o ativo comprado e devolver os 80 para o banco (o leitor deve se lembrar que estamos trabalhando com os preços trazidos a valor presente pois o valor da taxa de juros não fará diferença no nosso modelo).

- Se acontecer o contrário e o preço chegar ao nó $(1,0)$, então não fazer nada.

\footnotetext{
${ }^{12}$ O problema seria: quando se diz que um agente compra um determinado ativo no tempo $n$, deve ser entendido que o valor do ativo base no tempo n $\left(S_{n}\right)$, já é conhecido, ou ainda não? Ou seja, no instante $n$ opera-se com o valor de $S_{n}$ ou de $S_{n-1}$ ?
} 


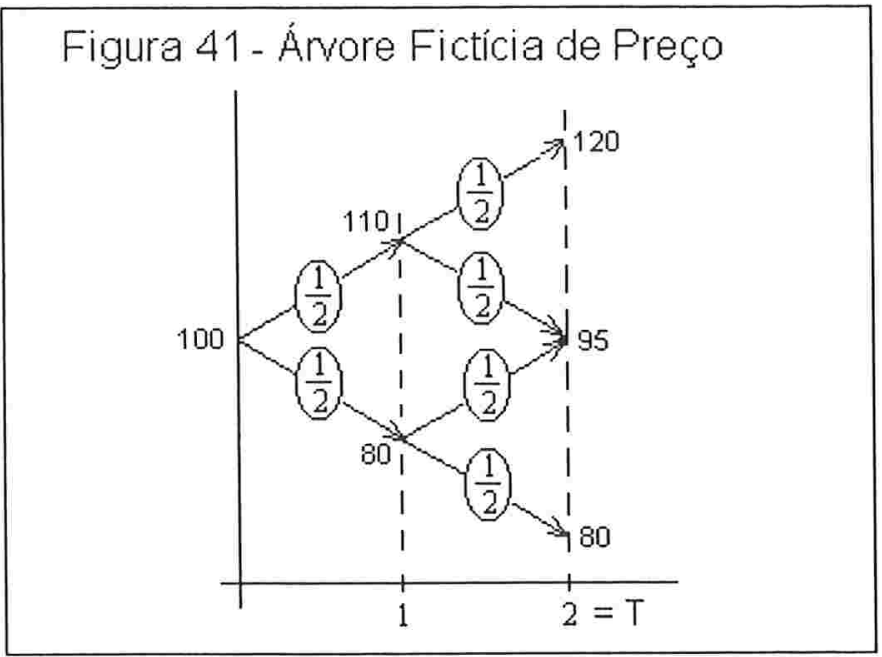

Observe que essa estratégia não exige nenhum investimento inicial de capital próprio (todo o capital necessário para a compra do ativo base é tomado emprestado no banco). Vamos analisar o valor que pode ficar no bolso do agente no instante final $T=2$ se ele seguir esta estratégia. Como esta estratégia não exige investimento inicial, então qualquer valor remanescente será lucro.

Note que o valor final não depende somente dos últimos nós da árvore, mas também de todo o caminho que o preço do ativo percorre. Portanto, para que esta análise seja correta, ela deve ser feita trajetória por trajetória. A análise é apresentada na tabela abaixo.

\begin{tabular}{l|r} 
TRAJETÓRIA & VALOR FINAL ESTRATÉGIA \\
\hline$(0,0)>>(1,0)>>(2,0)$ & 0,00 \\
\hline$(0,0)>>(1,0)>(2,1)$ & 0,00 \\
\hline$(0,0)>>(1,1)>>(2,1)$ & 15,00 \\
\hline$(0,0)>>(1,1)>(2,2)$ & 0,00 \\
\hline
\end{tabular}

A tabela deixa claro que a estratégia investigada pode não dar nem lucro nem perda, mas enquanto há a chance de que ela dê lucro de 15,00 dependendo da trajetória seguida pelo preço do ativo, em nenhum caso a estratégia gera prejuízo. Quando tal estratégia existe em um mercado, dizemos que ele possui uma oportunidade de arbitragem (note que esta definição está em linha com a Definição 2.3).

Claro que um mercado com oportunidades de arbitragem é irreal, pois no mundo real todos os agentes irão seguir tal estratégia, uma vez que ela oferece lucro sem risco. No mundo real, o excesso de demanda por ativos no nó $(1,1)$ fará com que o preço 


\section{6 - O Uso de Martingais na Precificação Neutra ao Risco}

desses ativos aumente; é fácil ver que com um ligeiro aumento no preço neste nó a estratégia proposta perde o seu atrativo, que é assegurar que perdas não ocorram.

Os argumentos acima apresentados justificam que ao precificarmos uma opção num modelo de mercado, é necessário:

(a) construir um modelo de mercado em que não existam oportunidades de arbitragem com o ativo base;

(b) precificar a opção de maneira tal que o mercado não ofereça uma oportunidade de arbitragem com o ativo base e mesma.

Esclarecemos que no item (a) é tratado o mercado em que os agentes podem montar as estratégias deles por meio de compras e vendas com ativos e com empréstimos e investimentos envolvendo o banco. Já no item (b) é tratado o mercado em que os agentes podem fazer tudo que podiam no item (a) e, além disso, podem comprar e vender quantidades arbitrárias de opções nos instantes $0,1 \ldots, T-1$.

Agora vale a pena notar que nossa definição de mercado com arbitragem implica que caso se queira provar que um certo modelo de mercado não possui arbitragem, então se deve mostrar que nenhuma estratégia pode oferecer lucro sem risco. Então surge a questão crucial para tudo que estamos discutindo: seria possível percorrer por todas as estratégias possíveis e imagináveis e mostrar que nenhuma delas oferece lucro sem risco?

Por mais incrivel que possa parecer esta pergunta possui uma solução. Esta se compõe de três considerações, as quais apresentamos a seguir uma por uma. A primeira consideração é dada pela proposição abaixo:

PROPOSIÇÃO B.1. Suponha ser possível atribuir uma probabilidade estritamente positiva a cada trajetória do processo do preço de maneira tal que:

(B.3) $\sum$ (probabilidade da trajetória $) \times($ valor final de estratégia nesta trajetória $)=0$

sobre todas

as trajetórias

Então a estratégia envolvida na fórmula (B.3) não oferece lucro sem risco. 
Prova. Suponha que a estratégia envolvida ofereça lucro sem risco. Então o valor final dela em cada trajetória seria nulo ou positivo. Logo, a média ponderada desses valores por pesos estritamente positivos seria um numero estritamente positivo, o que contradiz a condição (B.3), a qual alega que essa média ponderada é zero. Por absurdo conclui-se que a estratégia não pode dar lucro sem risco.

Notamos que as probabilidades das trajetórias envolvidas em (B.3) não são obrigadas a serem verdadeiras probabilidades, ou seja, aquelas probabilidades que regem a evolução do processo do preço. Este fato segue diretamente do argumento que provou a afirmação, colocada logo após (B.3). Chamaremos esta probabilidade hipotética por $Q$. Com esta notação a relação (B.3) pode ser rescrita como:

$E^{Q}$ [valor final da estratégia] $=0$

Acima e no restante do texto, $E^{Q}$ significa a esperança matemática em relação à medida de probabilidade $Q$.

Para enunciarmos a segunda consideração necessária para nossos argumentos precisamos definir o conceito de martingal.

DEFINIÇÃO B.1. - Um processo em tempo discreto $X_{n}, n=0,1,2, \ldots, T$ é um martingal em relação à medida $Q$, se

$$
E^{Q}\left[X_{m+k} \mid X_{0}=x_{0}, X_{1}=x_{1}, \ldots, X_{m}=x_{m}\right]=x_{m}
$$

para todo $m, k$ e todos $x_{0}, x_{1}, \ldots, x_{m}$.

Existe um teorema denominado Teorema sobre a transformação de martingais, cujo conteúdo, sendo expresso no âmbito do nosso modelo, afirma que:

TEOREMA B.1. Se o processo do preço de um ativo é um martingal em relação a uma medida $Q$, então os valores de qualquer estratégia montada com este ativo formam um martingal em relação à mesma medida.

Prova. Vide Bingham \& Kiesel (2004).

A terceira e última consideração necessária para respondermos por completo à pergunta elaborada na página anterior se baseia em uma simples conta que mostra que se os valores de uma estratégia formam um martingal em relação a uma medida $Q$, então 
$E^{Q}$ [valor final da estratégia]= valor inicial da estratégia

Lembramos agora que as oportunidades de arbitragem são aproveitadas por meio estratégias que não exigem capital inicial, ou seja, as estratégias cujo valor inicial é zero. Portanto, concluímos que, se o processo do preço de um ativo é um martingal em relação a $Q$, então para todas as oportunidades de arbitragem, é válido que

$E^{Q}$ [valor final da estratégia] $=0$.

Agora, juntando as três considerações, concluímos que a solução do item (a) nosso problema principal (construir um modelo de mercado que não permite arbitragem) se resume construir o modelo e a achar uma medida $Q$ nas trajetórias do processo de preço dos ativos neste modelo, tal que este processo descontado pela taxa livre de risco se torne um martingal em relação à medida $Q$ (lembre-se de que estamos trabalhando com os preços descontados pela taxa livre de risco).

Com base na solução para o item (a) do nosso problema central poderemos tratar do item (b) do mesmo. A sua solução é simples. Basta construir o processo do preço da opção de forma que ele também seja um martingal em relação à medida $Q$, a qual foi encontrada para resolver o item (a) do problema.

A justificativa de por que o método proposto no parágrafo anterior para a construção do processo do preço da opção atende as exigências da precificação correta baseia-se nas mesmas três considerações efetuadas para resolver o item (a) do nosso problema central. Para se certificar disso lembramos, em primeiro lugar, que a precificação correta é aquela que não introduz arbitragem no mercado. Isso quer dizer que não pode existir estratégia que envolva compras e vendas da opção e que ofereça lucro sem risco. Mas se o preço da opção é um martingal em relação à medida $Q$, então o Teorema B.1 (precisamente falando, a versão vetorial desse teorema, apresentado em Bingham \& Kiesel (2004)) garante que o processo de valores de qualquer estratégia envolvendo o ativo base (que já é um martingal em relação à medida $Q$ ), a opção e a taxa de juros livre de risco (que é constante), também irá ser um martingal em relação à medida $Q$. Assim, se considerarmos todas as estratégias com valor inicial igual a zero, obteremos por (B.7) que elas possuirão valor esperado sob a medida $Q$ igual a zero. Daí segue-se que a estratégia não pode dar lucro sem risco. Logo, justificamos a construção.

Notamos que é possível saber o preço da opção no último instante de tempo do nosso modelo $T$. Mesmo quando o exercício é antecipado, podemos tomar seu valor e leva-lo a valor futuro para o instante final $T$. 
Uma das formas de se construir processo do preço de uma opção assegurando que este seja martingal em relação à medida de $Q$ é o procedimento chamado recursão reversa. Este procedimento constrói os valores de preço no instante $n$ com base nos valores do instante $n+1$. O mesmo foi descrito com maiores detalhes no sétimo capítulo ${ }^{13}$, sendo implementado no Anexo 3. Ao se começar dos valores no instante $T$, os quais são conhecidos, conforme alegamos no parágrafo anterior, em cada passo da recursão reversa este procedimento assegura a propriedade de que o preço da opção é um martingal em relação à medida $Q$.

Notamos, finalmente, que durante o nosso trabalho não estivemos interessados em encontrar todos os valores do processo de preço de opção, mas somente o seu valor no nó inicial. Este valor é obtido por meio de uma conta semelhante àquela da qual falamos na terceira consideração, de modo que, para $r$ igual à taxa livre de risco expressa em percentual ao ano sob o conceito de capitalização contínua e $T$ igual o tempo em anos até o exercício, valor inicial da opção $=e^{-r T} E^{Q}$ [valor final da opção], que foi a fórmula utilizada durante todo o nosso trabalho.

${ }^{13}$ Embora o procedimento descrito no sétimo capítulo seja direcionado para a precificação de opções com exercício do tipo americano, é importante salientar que ele é igualmente válido para as opções com exercício do tipo europeu, bastando para isso aplicar o mesmo procedimento considerando que o exercício antecipado nunca é ótimo (ele não é nem mesmo permitido para uma opção européia). 


\section{ANEXO 3 \\ IMPLEMENTAÇÕES EM C++ DOS ALGORITMOS PROPOSTOS}

Nas páginas a seguir apresentamos o código fonte de todos os algoritmos implementados

e citados no decorrer do texto. Tais algoritmos foram implementados em $\mathrm{C}++\mathrm{e}$ compilados com a versão 5.5.1 do Borland $\mathrm{C}++$.

O editor de texto utilizado para a criação do código foi a versão 1.62 do SciTE, disponível em http://www.scintilla.org. 
// código em C++ para precificação de op̣öes pachräo, asiáticas e lokback

i/ de strike fixo, de com pra ou de venda com exercicio europeu ou am ericano.

// B il liotecas pactrăo.

Hindude smaths

Hinclube sistream

thalude atedibo

I/ B hliotecas necessárias para o func inam ento da boloteca utitiada para a / genacăo de núm eros a katortos de distribuicäo nom al.

tinilude stime?

thelude "storhastatrantomo h"

Hinchuae "stochasticherseme opp"

fat

If B Dloteca utilizada para a geracäo de num eros a leatorios de distributaco

I/ nom al Esta bobloceca esta disponírel sob a licerca GNU em

Thetp : iww agner org/random:

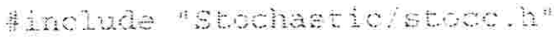

\#nclude "stownation stosl ope"

Stochasticlib1 Norm(time(j));

using namespace std;

I Durante todo o codigo, os seguintes nom es de variáveis serăo sempre para:

$\because$ ht $n$-Am azenax o rúm ero de particoses efetuadas no tizo tem poral.

If fhat sm a - A mazenar a volatiliade amalizada do ativo base.

If Lats - Amazenar o preco intialdo atwo base.

$\therefore$ Hoat $\mathrm{x}$ - Amazenar o preco de exercíco da opcâo.

$\because$ Hbat $r$ - Amazenar a taxa de juros en percentualao ano.

i) fhat t-Amazenar comprim ento em anos do perído entre smulaçōes.

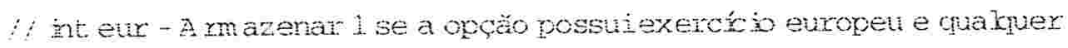

if outro vabr se a opça possuiezercio am ericano.

$/ /$ int $\mathrm{pp}$ - A mazenar 1 se a opção a ser precif cada for um a op̧äo de com pra

if equaquer outro valor se a mesn a for urn a opcăo de venda.

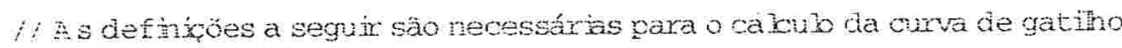

I das opças asiaticas de venda con exercicio do tpo an excano. Este cálub

If e feto particinancio-se o eixo tem poralem n subinteryabs e o intervab

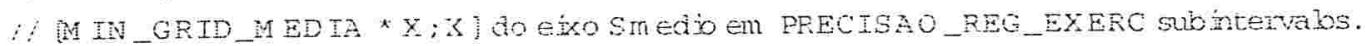

IA cutra coordenada da curva de gatiho foue na vertade ú um plano no espaco

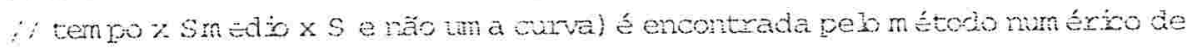

A bsseccăo. A bissecçó feita dentro do intervalo M IN GRID_PRECo * $s$;

$\because \mathrm{TOEO}$ ORD_PREO * $\mathrm{S}$.

I Se a curva de gatino estiver acin a de TOD GRD _RECO - S, thatos

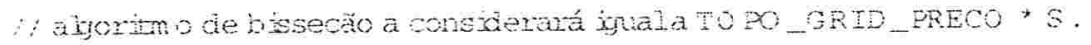

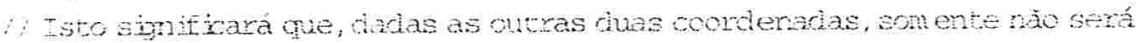

ond exercer antecindam ente a opcáo se en estiver no dine iro e opreco

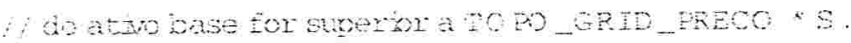

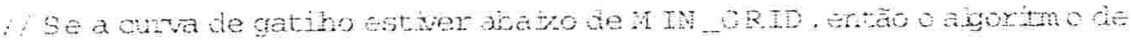

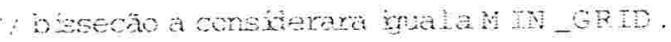

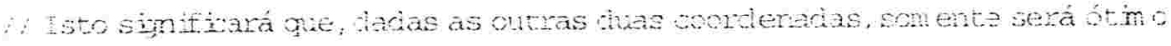

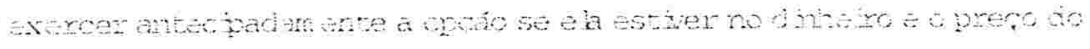

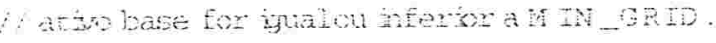

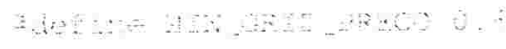

A 
Hotine TOPC GRID PECO 1.1

HAEthe PRECTAO RES EXERO 50

I/ Este nún ero deve ser sem pre par e m a.or ou iguala 2 , do contrário a

$1 /$ bisecção năo ficará bem definida.

fdefine PASBOS_eTsEccaO 20

I/ Ma acro para arredondar núm eros decin ais paxa hteiros.

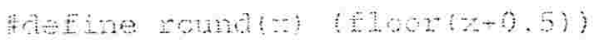

float Plain_Vanilla_option (float sgma, float $S$, float X, float r, float $t$, float *arvore, float *payoff, int $\mathrm{n}$, int eur, int $\mathrm{cp})($

if Recebe param etros conform e descrito nas linas de comentárì 23 a 33 e If retorna preç justo um a opcăo padrăo (Pla in vanila) calculado pelo

II método da árvore biron jalos parán etros da árvore são obtidos ton ando

$\because$ as projabilidades neutras ao risco ignass a $1 / 2$. E possfielateraro

I: código de forma a ssco iner os param etros confom e proposto no

$/$ modelo de Cox-Ross-Rubinstein.

i: 0 fbat ${ }^{*}$ arvore $e$ un vetor de tam anho $n+1$ contendo iniciam ente os

II cenários para os vabres possíveis do preço do ativo base no último

T passo dáárvore.

i) Ebat* payoff é um vetor de tam anho n+1 contendo intiam ente os

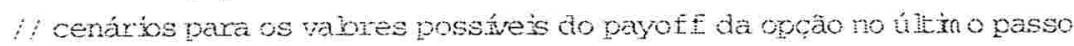

$\because$ da arvore.

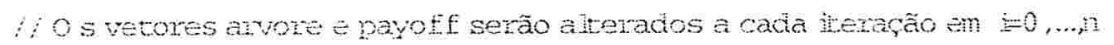

$\therefore$ de form a a conter em anorelo ..ij os vabres possteis para o preco

If do atiro base na iremą̧a i basso ida árorele de forma a conter

i em payoff[0 ...21] os vabres possivets pata o preco justo da opcăo na

it iterạăo $i-1$ passo $i-1$ da árvore)

int $i, j$;

float $u_{i} /$ Loganitno da taxa de retomo no cenáro de ata.

float pu; i/ Probabiliade neutra a risco para o cenário de aita.

float $d_{;} /$Logaritu o da taxa de retomo no cenário de baixa.

float pd; / Probabiliade neutra a risco para o cenáro de baixa.

float aux;

$\mathrm{u}=\exp ((r-0.5 * \operatorname{pow}(\operatorname{sgma}, 2)) * t+\operatorname{sgma} * \operatorname{sqr} t(t)) ;$

$\mathrm{d}=\exp ((r-0.5 * \operatorname{pow}(\operatorname{sgma}, 2)) * t-\operatorname{sgma} * \operatorname{sqr} t(t))$;

$\mathrm{pu}=0.5 ; \mathrm{pd}=0.5 ;$

i) Para esco her os parâm etros confom e proposto por Cox-Ross-Rubinsten,

If retire os caractens hditatios de com entarto das duas linhas abaxo.

$\therefore u=$ exp (sgna $\left.{ }^{*} \operatorname{sent}(t)\right) ; d=1 ; u$;

$\therefore \mathrm{pu}=(\exp (\mathrm{r} * \mathrm{i}-\mathrm{d}): \mathrm{u}-\mathrm{d}) ; \mathrm{pd}=1-\mathrm{pu}$

for $(i=n ; i>) ; i--)\{$

2. Obtém de vabres posétes para o preco do atto base no passo ie

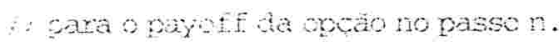

for $(j=i j<=i ; j++)($

arvore $[j]=s * \operatorname{pow}(d, j) * \operatorname{pow}(u, i-j)$;

if $(i==n) \quad($

if $(\mathrm{cp}==-1) \quad\{$

payoff $[j]=(\operatorname{arvore}[j]>X)$ ? (arvore $[j]-X): i_{i}$

\} else \{

payoff $[j]=(X>\operatorname{arvore}[j]) ?(X$-arvore $[j]): \lambda_{i}$

\}

C:Borland'Sounoebptins qpp - Fie date: 05/02/2005 - Fie tine:12 0554 PM 


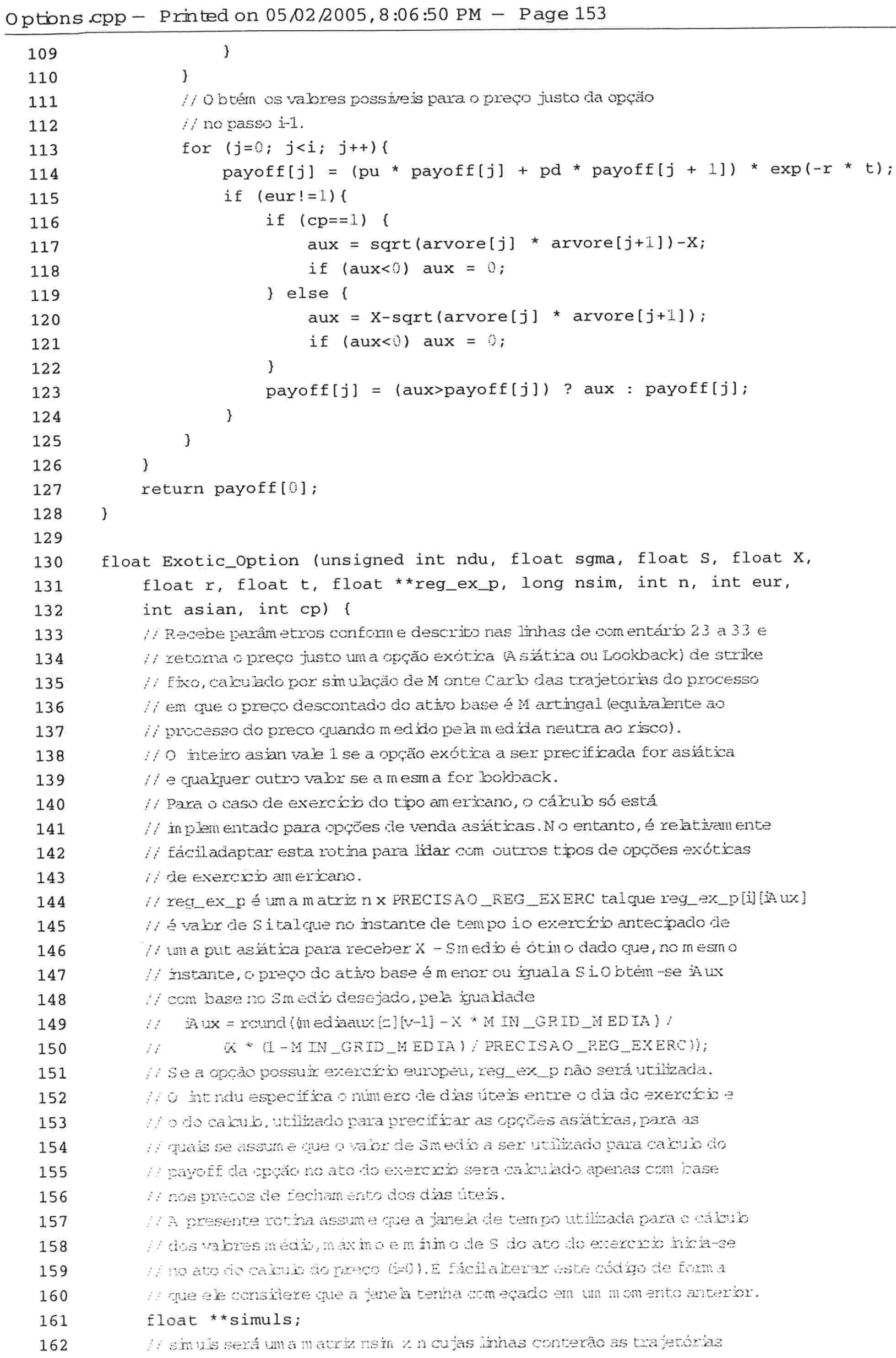

float Exotic_option (unsigned int ndu, float sgma, float S, float X, float $r$, float $t$, float **reg_ex_p, long $n s i m$, int $n$, int eur, int asian, int $\mathrm{cp})($

/ Recebe parâm etros conform e descrito nas linhas de com entár 23 a 336 i/ retona o preço justo uma opcra exotica A siática ou Lookbacki de strike

If fro, cabuado por sm uacaáo de M onte Carb das trajetorias do processo

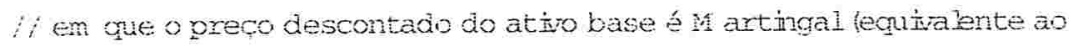
if processo do preco quando medido pela m edida neutra ao riscol.

if inteiro asian vale 1 se a opça exótica a ser precificada for asiática // e crualner outro vabr se a m esm a for bokback.

// para o caso de exercício do tipo am ercano, o cálub só está

/f in pim entado para opcöes de venda astaticas. No entanto, é relatiam ente

If fáciladaptar esta rotina para lidar com outros tipos de opçōes exóticas

if de exercicio an exicano.

// reg_ex_p é uma matriz $n x$ PRECISAO_REG_EXERC tal que reg_ex_p[i][A ux]

If é vabr de sitalque no instante de tempo io exercíio antecipado de

I/ tha a put asática para receber $\mathrm{x}-\mathrm{sm}$ edi é ótino dado que, no m esmo

I ristante, o preço do atio base é menor ou ruala siobtén -se ia ux

Y com base no smedio desejado, pela guakade

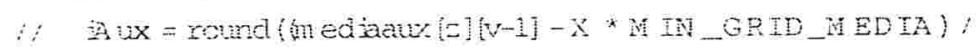

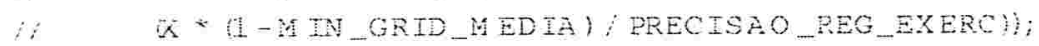

S Se a opa possuir exench buropen, reg_ex p na será utilizada.

So htrdu especifica nim ero de das utes entre o dia do exercíci

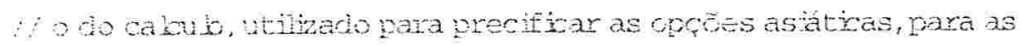

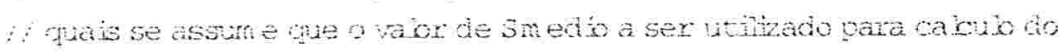

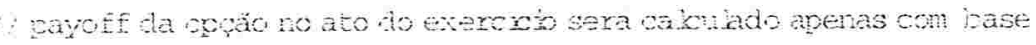

$\therefore$ cop preos de techam ento dos das uteis.

I A presente rotha assme gue a janeh de tempo wtiliada para o cábub

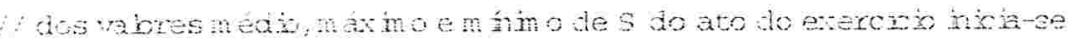

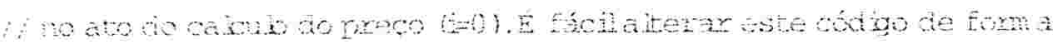

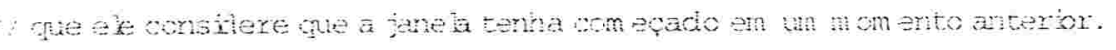

float **simuls;

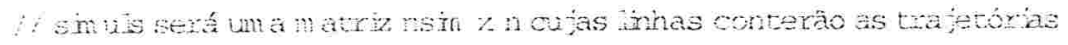


if simuladas para o processo de interesse a tempo discreto.

float **aux;

I/ Em aux estarão ann azenadas as trajetórias sim uladas para $\mathrm{S}$ m edo no I/ caso da opçäo ser asiatica, 5 maxmo no caso da opcäo ser bokback de I/ compra es m inimo no caso da upçáo ser bokback de venda.

float precoaux, resultado $=0$;

long $i, j, k=n / n d u$;

simuls $=$ new float* [nsim]; aux $=$ new float* [nsim];

float* trajet; trajet $=$ new float $[n+1] ;$ trajet $[0]=0$;

I sim ua as trajetónias para o processo de interesse e quarda os vabres

If da trajetória necessarios para a detem inacão do payoff da opçâ.

il o bs: esta in plem entaçäo ficará um tanto devagar se o núm ero de simulaçoses

if for muito alto porgue ela armazena na m en oria todas as trajetoras

i) sinuladas. Isto pode ser contomado facim ente, adaptando-se este código

i/ para que el am azene na memóna avenas o va br do payof da opça em

If cacla simulacăo, ao invés de toda a trajetóría do preço do ativo base.

for $(i=0 ; i<n s i m ; i++)\{$ simuls $[i]=$ new float $[n] ; \operatorname{aux}[i]=$ new float $[n] ;$

for $(j=1 ; j<=n ; j++)\{$ trajet $[j]=($ float $)(r-$ pow $($ sgma, 2$) / 2) * t$; trajet $[j]+=$ Norm. Normal $(0,($ float $) \operatorname{sqrt}(t)$ * sgma) ; trajet $[j]+=\operatorname{trajet}[j-1]$; simuls[i][j-1] = exp $(\operatorname{trajet}[j])$; simuls[i][j-i] * $s^{*}$

C :Borland'Souncebptions app - Fie date: 05,02/2005 - Fie tine:12 0554 PM 
if (eur==1) \{

for $(i=0 ; i<$ nsim; $i++) \quad\{$

if $(\mathrm{cp}==1)$ ( precoaux $=(\operatorname{aux}[i][n-1]>x)$ ? $\operatorname{aux}[i][n-1]-x: 0 ;$

\} else \{ precoaux $=(\operatorname{aux}[i][n-1]>x)$ ? $0: x-\operatorname{aux}[i][n-1] ;$

C :BordandiSouroelOptions spp - Fie date: 05,02/2005 - Fib tine:12 05 54 PM 


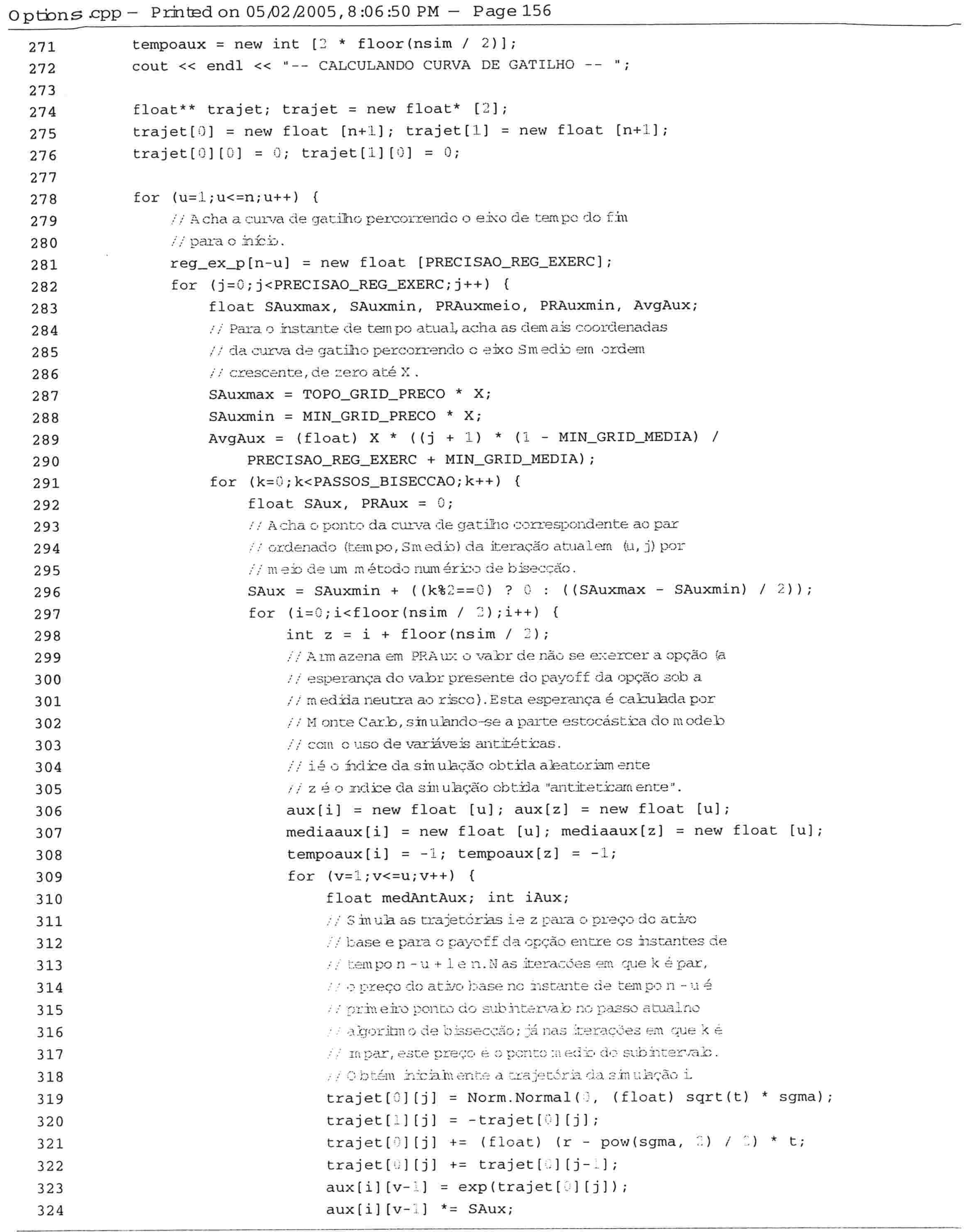

C :Bortand'Samoebptins cqp - Fie date: 05,02/2005 - Fib tine:12 05 54 PM 


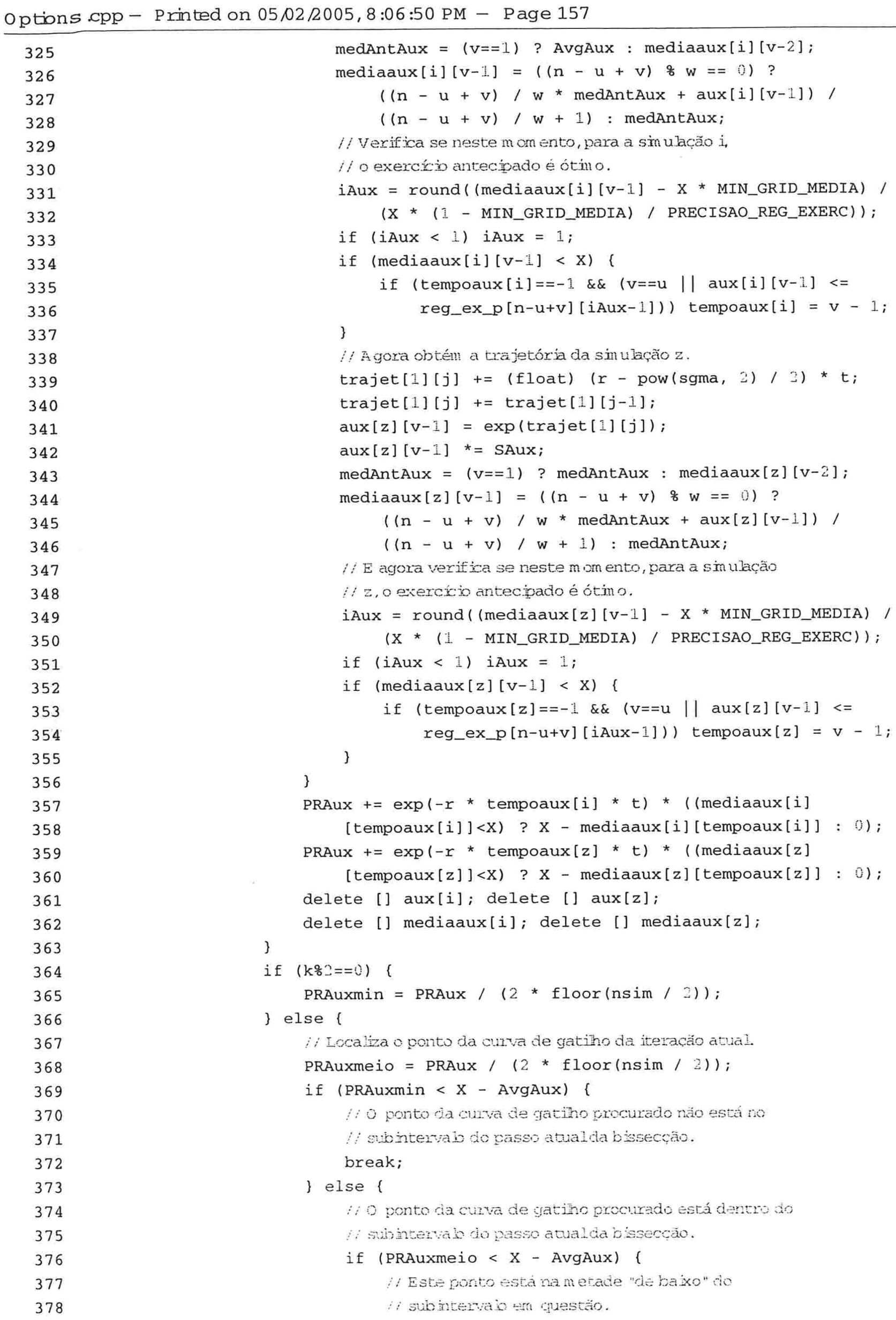

medAntAux $=(\mathrm{v}==1)$ ? AvgAux : mediaaux $[i][\mathrm{v}-2]$;

$\operatorname{mediaaux}[i][v-1]=((n-u+v) \& w==0)$ ?

$((\mathrm{n}-\mathrm{u}+\mathrm{v}) / \mathrm{w}$ * medAntAux $+\operatorname{aux}[\mathrm{i}][\mathrm{v}-\mathrm{l}]) /$

$((n-u+v) / w+1)$ : medAntAux;

// Verifica se neste $m$ on ento, para a smulaçăo $i$,

// o exercício antecipado é ótimo.

iAux $=\operatorname{round}($ (mediaaux $[i][\mathrm{v}-1]-\mathrm{X}$ * MIN_GRID_MEDIA) /

$(X$ * (I - MIN_GRID_MEDIA) / PRECISAO_REG_EXERC)) ;

if $($ iAux $<1)$ iAux $=1$;

if (mediaaux[i] [v-I] $<\mathrm{X})($

if (tempoaux[i]==-1. \&\& $(v==u \quad||$ aux [i] [v-l.] $<=$ reg_ex_p $[n-u+v][i A u x-1]))$ tempoaux $[i]=v-1$; \}

IAgora obtén a trajetóría da sinulação $z$.

trajet $[1][j]+=($ float $)(r-\operatorname{pow}(\operatorname{sgma}, 2) / 2) * t$;

trajet $[1][j]+=\operatorname{trajet}[1][j-1]$;

$\operatorname{aux}[z][v-1]=\exp (\operatorname{trajet}[1][j])$;

$\operatorname{aux}[\mathrm{z}][\mathrm{v}-1] *$ * SAux;

medAntAux $=(\mathrm{v}==1)$ ? medAntAux : $\operatorname{mediaaux}[\mathrm{z}][\mathrm{v}-2]$;

$\operatorname{mediaaux}[\mathrm{z}][\mathrm{v}-1]=((\mathrm{n}-\mathrm{u}+\mathrm{v}) \& \mathrm{w}==0)$ ?

$((\mathrm{n}-\mathrm{u}+\mathrm{v}) / \mathrm{w} * \operatorname{medAntAux}+\operatorname{aux}[\mathrm{z}][\mathrm{v}-1]) /$

$((n-u+v) / w+1)$ : medAntAux;

// E agora verifica se neste mom ento, para a sin ulaçào

if z, o exerckio antecipado é ótino.

iAux $=\operatorname{round}((\operatorname{mediaaux}[\mathrm{z}][\mathrm{v}-1]-\mathrm{X}$ * MIN_GRID_MEDIA $) /$

$(X$ * (I - MIN_GRID_MEDIA ) / PRECISAO_REG_EXERC $))$;

if (iAux $<1)$ iAux $=1$;

if (mediaaux $[\mathrm{z}][\mathrm{v}-1]<\mathrm{X}$ ) \{

if (tempoaux $[z]==-1 \& \& \quad(v==u \quad|| \operatorname{aux}[z][v-1]<=$ reg_ex_p $[n-u+v][i A u x-1]))$ tempoaux $[z]=v-1$; \}

\}

PRAux $+=\exp (-r *$ tempoaux $[i] * t) *((\operatorname{mediaaux}[i]$

[tempoaux[i]]<X) ? $\mathrm{X}$ - mediaaux[i][tempoaux[i]] : 0); PRAux $+=\exp (-r *$ tempoaux $[z] * t) *((\operatorname{mediaaux}[z]$

[tempoaux $[z]]<X)$ ? $X$ - mediaaux $[z][t e m p o a u x[z]]: 0)$; delete [] aux[i]; delete [] aux[z];

delete [] mediaaux[i]; delete [] mediaaux[z];

\}

if $(k \% 2==0) \quad\{$

PRAuxmin $=\operatorname{PRAux} /(2 *$ floor $($ nsim $/ 2))$;

\} else \{

i) Iocaliza o ponto da cuva de gatiho da iteraçăo aual.

PRAuxmeio $=$ PRAux $/(2 *$ floor $(n \operatorname{sim} / 2)) ;$

if (PRAuxmin < X - AvgAux) \{

I) ponto da curva de gatiho procurado nato está no

If mintervab do passo atualda bissecca.

break;

\} else \{

:O ponto da curva de catino procurado está dentro do

If suintenab do passo atualcabieseccáo.

if (PRAuxmeio < X - AvgAux) (

" Este ponto esta na metace "de baxo" do

$\therefore$ subinterab um cuestä́. 


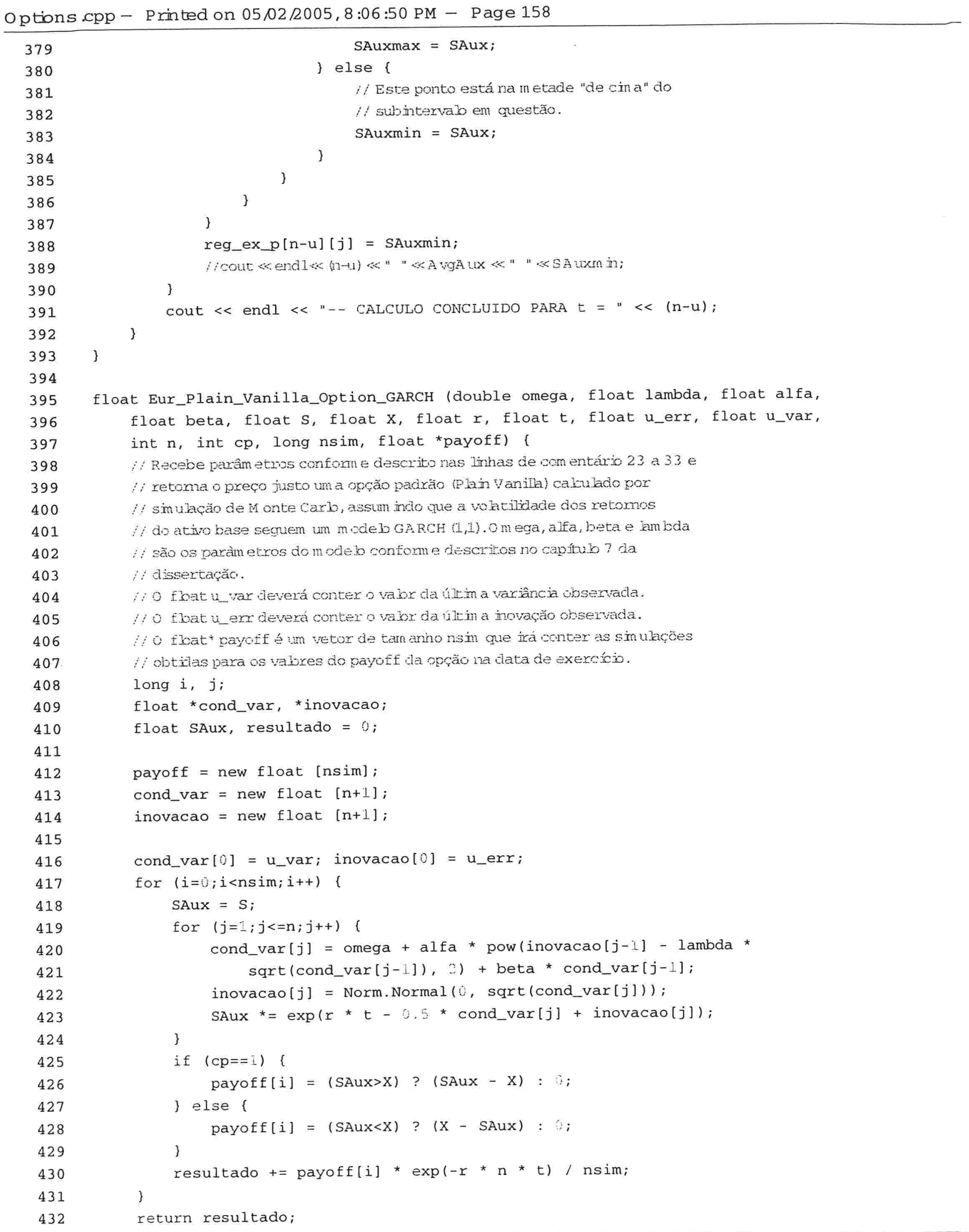




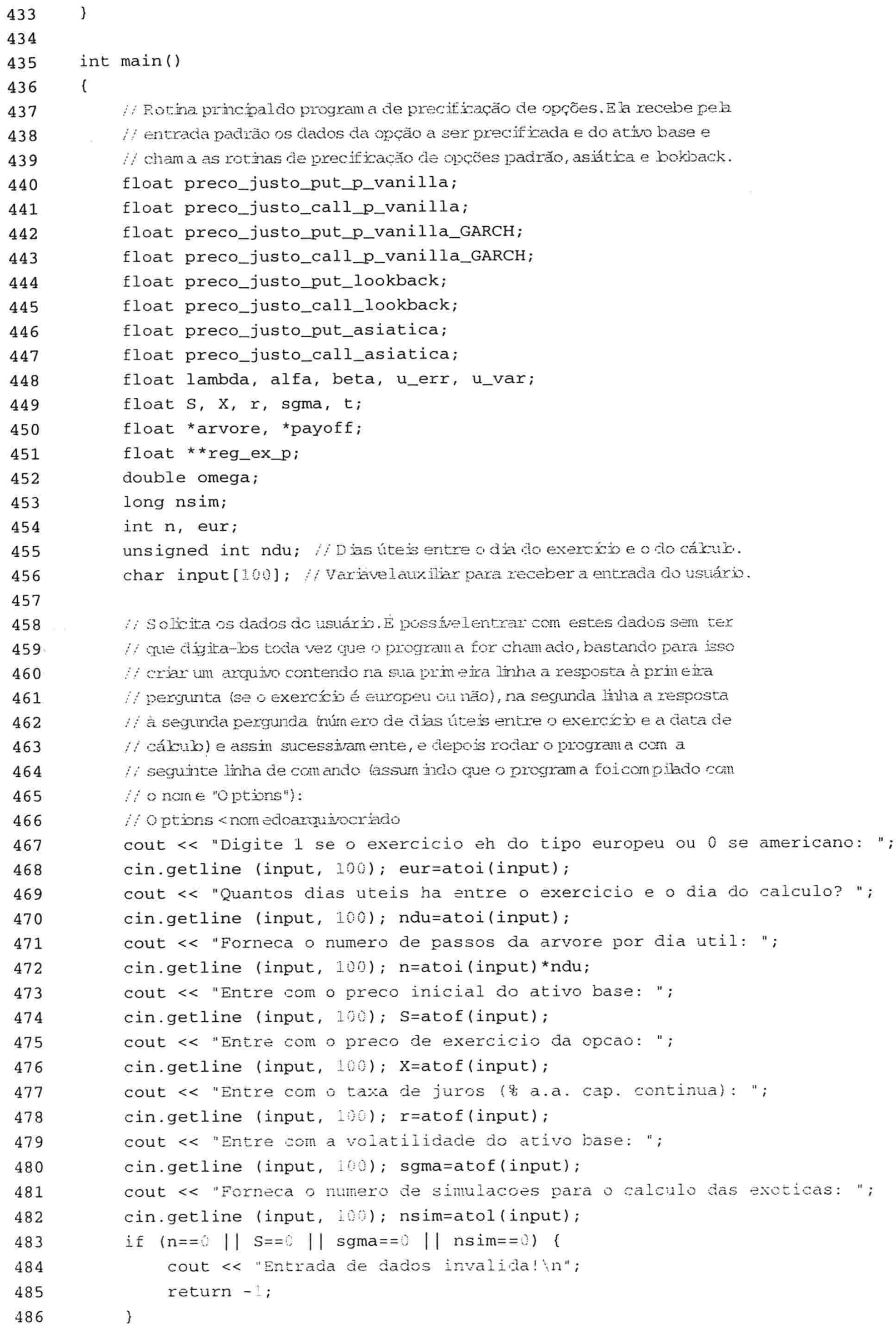

C :Bortand Souroeloptions cqp - Fie date:05,02/2005 - Fie time:12 0554 PM 


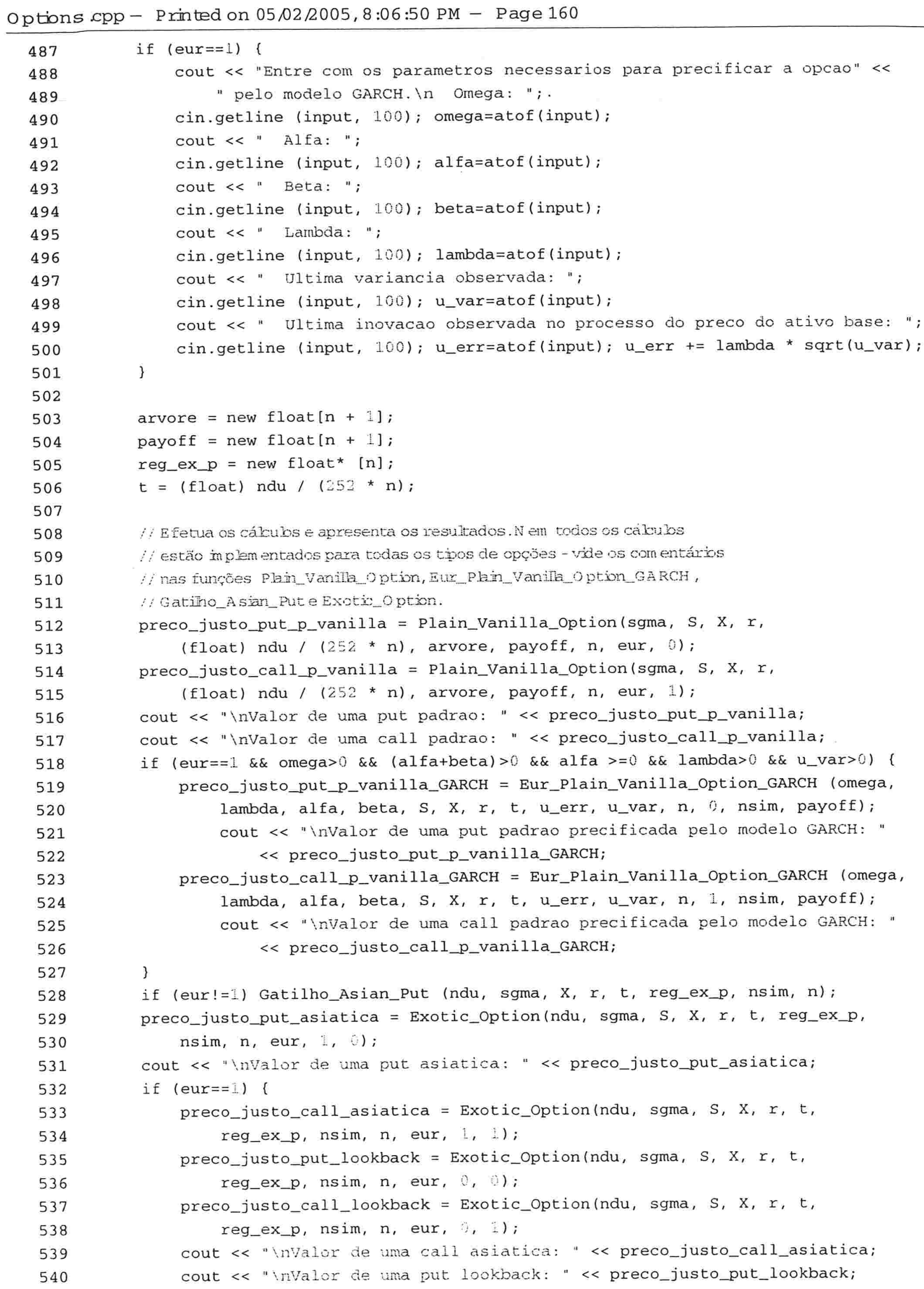

if $($ eur $==1)$ \{

cout \&< "Entre com os parametros necessarios para precificar a opcao" < "pelo modelo GARCH. In Omega: "; . cin.getline (input, 100); omega=atof(input); cout $<$ "Alfa: ";

cin.getline (input, 100); alfa=atof (input); cout $\ll$ " Beta: "; cin.getline (input, 100); beta=atof (input); cout $\ll$ "Lambda: "; cin.getline (input, 100); lambda=atof (input); cout $<"$ Ultima variancia observada: "; cin.getline (input, 100); u_var=atof (input); cout < " Ultima inovacao observada no processo do preco do ativo base: "; cin.getline (input, 100); u_err=atof(input); u_err += lambda * sqrt (u_var); \}

C :Borland'Sounce Optins cqp - Fie date: 05/02/2005 - Fie tine:12 05 54 PM 
Options .cpp - Printed on 05/02/2005, 8:06:50 PM - Page 161

541 cout $\ll$ " \nValor de uma call lookback: " « preco_justo_call_lookback;

542

543

544

.

\}

C :Borland Sounce bptions cpp - Fie date: 05/02/2005 - Fip tine:12 0554 PM 


\section{REFERÊNCIAS BIBLIOGRÁFICAS}

[1] Araújo, G. S., Barbedo, C. H. S., Figueiredo \& A. C., Lemgruber, E. F., "Contornando os Pressupostos de Black \& Scholes: Aplicação do Modelo de Precificação de Opções de Duan no Mercado Brasileiro". Trabalhos Para Discussão, Banco Central do Brasil, 78, Out 2003.

[2] Baidya, T. K. N. \& Castro, A. L., "Convergência dos Modelos de Árvores Binomiais para Avaliação de Opções", Pesquisa Operacional, 21, 2001, 17-30.

[3] Belitsky, V., Kimura, H., Tommasini, P., Precificação de Derivativos, Preprint, 2004.

[4] Billingsley, P., Convergence of Probability Measures, 1st ed. John Wiley \& Sons, 1968.

[5] Billingsley, P., Convergence of Probability Measures, 2nd ed. John Wiley \& Sons, 1999.

[6] Bingham, N. H. \& Kiesel, R., Risk-Neutral Valuation: Pricing and Hedging of Financial Derivatives, 2nd ed. Springer Series in Finance, 2004.

[7] Black, F., "The Pricing of Commodity Contracts", Journal of Financial Economics, 3, 1976, 167-179.

[8] Black, F., Scholes, M., "The pricing of options and corporate liabilities", J. Political Econ., 81, 1973, 637-659.

[9] Bollerslev, T., "Generalized Autoregressive Conditional Heteroskedasticity", Journal of Econometrics, 31, 1986, 307-327.

[10] Brock, W., Lakonishok, J. \& LeBaron, B., "Simple technical trading rules and the stochastic properties of stock returns", Journal of Finance, 47, 1992, 1731-1764.

[11] Chaudhury, M. \& Wei, J., "A Comparative Study of $\operatorname{GARCH}(1,1)$ and Black-Scholes Option Prices”. Working Paper, McGill Finance Research Centre, 1996.

[12] Chourdakis, K., Financial Derivatives. Queen Mary - University of London, Lecture Notes Summer 2003.

[13] Conze, A., \& Viswanathan, R., "Path Dependent Options: The Case of Lookback Options", Journal of Finance, 1991, 1893-1907.

[14] Cox, J., Ross, S., Rubinstein M., "Option Pricing: A Simplified Approach." Journal of Financial Economics, 7, September 1979. 
[15] Dennis, P., Perfect, Steven B., Snow, Karl N. \& Wiles, Kenneth W., "The Effects of Rebalancing on Size and Book-to-Market Ratio Portfolio Returns", Financial Analysts Journal, May-Jun 1995.

[16] Duan, J.-C., "The GARCH option pricing model", Mathematical Finance, 5, 1995, 1332.

[17] Egloff, D., Min-Oo, M., Convergence of Monte Carlo Algorithms for Pricing American Options, Preprint, 2002.

[18] Engle, R. \& Ng, V., "Measuring and Testing The Impact Of News On Volatility". Journal of Finance, 48, 1993, 1749-1778.

[19] Fama, Eugene F., The Distribution Of The Daily Differences Of The Logarithms Of Stock Prices. University Of Chicago, Ph.D Thesis, 1964.

[20] Frota, A., Avaliação de Opções Americanas Tradicionais e Complexas. PUC-RJ, Dissertação de Mestrado, 2003.

[21] Heynen, R. \& Kat, H., "Lookback Options with Discrete and Partial Monitoring of the Underlying Price". Applied Mathematical Finance, Vol 2, 1995, 273-283.

[22] Hofmann, K. H., Introduction to General Topology. Darmstadt University of Technology, Lecture Notes Summer 2004.

[23] Hull, J. C. Options, Futures, and Other Derivatives, 4th ed. Prentice Hall, 2000.

[24] Jarrow, R. \& Rudd, A., Option Pricing, Dow Jones - Irwin, 1983.

[25] Jeffreys, H. \& Jeffreys, B. S., "L. F. Richardson's Method." \$9.091 in Methods of Mathematical Physics, 3rd ed. Cambridge, England: Cambridge University Press, 1988, p. 288.

[26] Jorion, P., Value at Risk, McGrawHill, New York, 1997.

[27] Kallsen, J. \& Taqqu, M., "Option Pricing in ARCH-type Models: with Detailed Proofs". Technical Report No. 10, Freiburger Zentrum für Datenanalyse und Modellbildung, Universität Freiburg i. Br., 1995.

[28] Kouwenberg, R., "Scenario Generation and Stochastic Programming Models for Asset/Liability Management", European Journal of Operational Research, 134, 2001, $51-64$.

[29] Merton, R., "Theory of Rational Option Pricing". The Bell Journal of Economics and Management Science, Vol 4, 1973, 141-183.

[30] Mood, A. M., Graybill, F. A. \& Boes, D. C., Introduction to the Theory of Statistics. Mcgraw-Hill, New York, 3rd ed., 1974.

[31] Munkres, J. R., Topology, 2nd ed. Prentice-Hall, 2000. 
[32] Nelson, D., "Conditional Heteroskedasticity In Asset Returns: A New Approach". Econometrica, 59, 1991, 347-370.

[33] Rao, M. M. Measure Theory And Integration. Wiley, 1987.

[34] Resnick, S., Adventures in Stochastic Processes. Birkhäuser, 1992.

[35] Schmitt, C., "Option Pricing Using EGARCH Models". AFIR Colloquium Proceedings, Oct 1996, 1311-1336.

[36] Stroustrup, B., The C++ Programming Language, 3rd ed. Addison-Wesley, 2000.

[37] Shreve, S., "Girsanov's Theorem and Risk Neutral Measure", Lectures on Stochastic Calculus and Finance, Carnegie Mellon University, 1996.

[38] Tham, J., Risk-neutral Valuation: A Gentle Introduction http://ssrn.com/abstract=290044, Nov 2001.

[39] Trapletti, A., "tseries: Time series analysis and computational finance". $R$ package version 0.9-24., 2004.

[40] Wheeden, R. L., Zygmund, A., Measure and Integral: An Introduction to Real Analysis. New York, Dekker, 1977.

[41] Wu, R. \& Fu, M., "Optimal Exercise Policies and Simulation Based Valuation for American Asian Options" Operations Research, Jan-Feb 2003.

[42] Xu, M., "Risk Measure Pricing and Hedging in Incomplete Markets", Working Paper, 2004. 